\title{
Stable isotope investigations on speleothems from different cave systems in Germany.
}

\author{
Dissertation \\ zur Erlangung des Doktorgrades \\ der Mathematisch - Naturwissenschaftlichen Fakultäten \\ der Georg - August - Universität
}

vorgelegt von

Peter Nordhoff

aus Wolfenbüttel

Göttingen 2005 


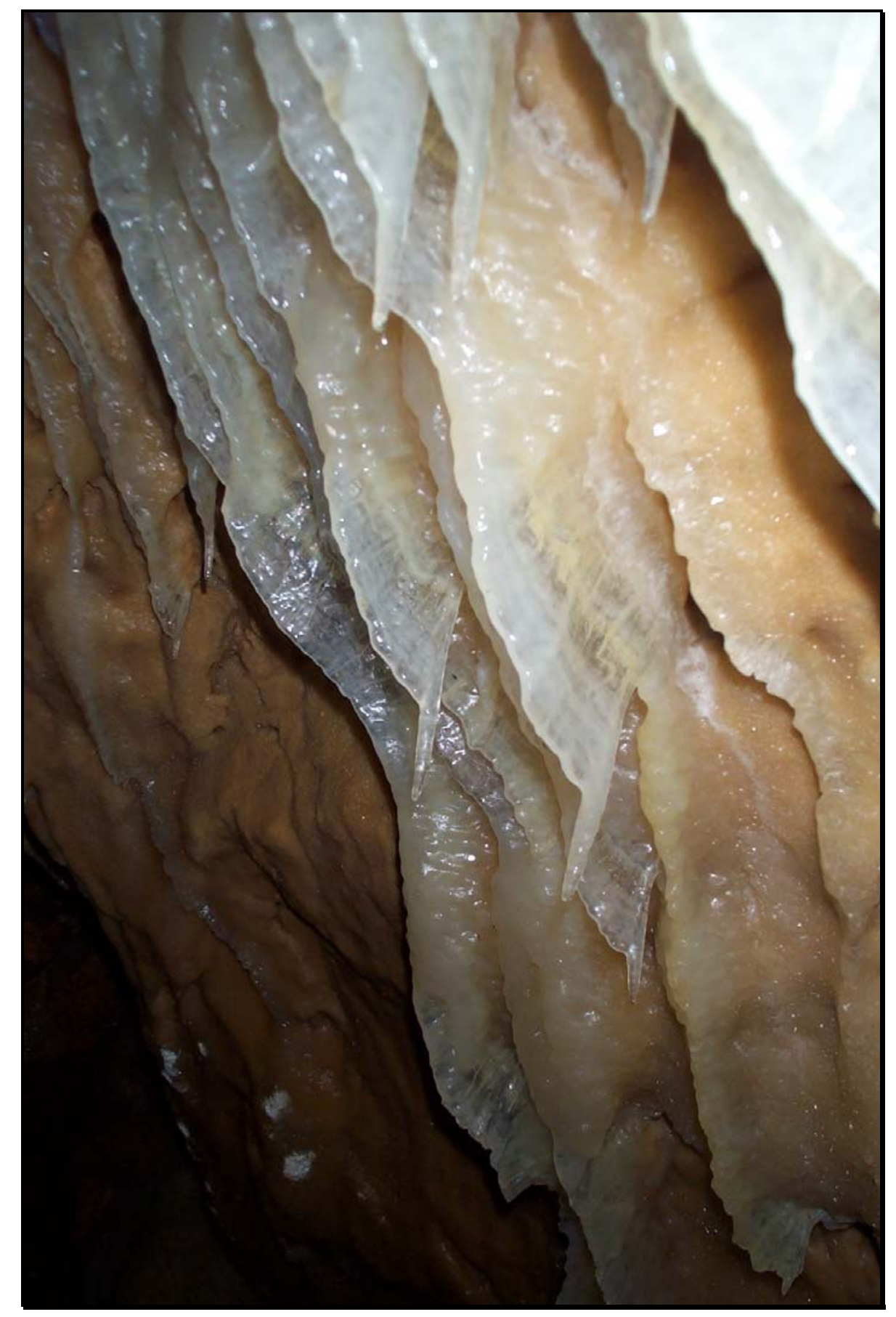

D7

Referent:

Prof. Dr. B.T. Hansen

Koreferentin:

Dr. B. Wiegand

Tag der mündlichen Prüfung:

13.06.2005 


\section{Summary}

Seven speleothems from six independent cave systems in Germany were investigated on their suitability as paleoclimatic archives. The caves are located in the Jurassic Limestones of the Swabian/Franconian Alb (southern Germany) and in a small-scale Devonian (reef) complex of the Harz Mountains (northern Germany). Based on the chronological control using ${ }^{234} \mathrm{U} /{ }^{230}$ Th (TIMS) ages, $\delta^{18} \mathrm{O} / \delta^{13} \mathrm{C}$ timeseries of the speleothems were established and related to known paleoclimatic events. Results of the present-day assessment of the cave systems demonstrated that the cave temperature responses; the stable isotopic abundances of the dripwater, and present-day cave calcites reflect mean annual surface air temperatures as well as established isotopic equilibrium conditions during cave calcite precipitation. However, existing biases have been monitored but most of them may be deduced to anthropogenic influences like mining operations (Zaininger-Cave, Swabian Alb) or showcave business (Hermann's- and Baumann's-Cave, Harz Mountains). Although the scenarios leave partially an imprint on present-day spelean calcites, like the indicated non-equilibrium conditions at the Zaininger-Cave, their temporal imprint is restricted very much to the last couple of decennial years and thus assumed not to influence the paleorecords at all. Since the $\delta^{18} \mathrm{O}$ compositions of present-day calcite precipitates are primarily controlled by temperature, the sites may thus be suitable for paleoclimatic investigations from a today perspective.

Since the paleorecords of the Hermann's- and Baumann's-Cave stalagmites (Harz Mountains) display ages, which are not in chronological order, a construction of timeseries was not possible.

Past stable isotopic equilibrium conditions of the remaining paleorecords were verified using the single layer "Hendy-Test" as well as $\delta^{18} \mathrm{O} / \delta^{13} \mathrm{C}$ regression analyzes of the subsample profiles. Late Pleistocene growth periods were found in the Paleocave Hunas Stalagmite (79373 \pm 8237 to $76872 \pm$ 9686 a. B.P.; Franconian Alb) and the Cave Hintere Kohlhalde Stalagmite (44158 \pm 3329 to $2709 \pm$ 303 a B.P.; Swabian Alb). Unexpectedly, the latter displays no macroscopic visible growth hiatuses and was deposited continuously during the "cold" OIS 2 and the LGM. This has been interpreted owing to the special conditions and mode of vadose water circulation of a discontinuous permafrost zone which may have prevailed on the Swabian Alb during that time. Here, just like for the subsequent periods, principal changes in mean $\delta^{18} \mathrm{O} / \delta^{13} \mathrm{C}$ and linear extension rates of the timeseries echoed the Boelling/Alleroed Interstadial and Younger Dryas cold phase. The comparison of coeval timeseries between the Cave Hintere Kohlhalde stalagmite, the Zaininger-Cave stalactite (both Swabian Alb) and the Mühlbach-Cave stalagmite (Franconian Alb) reveal some analogy such as the transitions from the Late Glacial to the Early Holocene between 10513 and 10587 cal. a B.P. for the Swabian Alb and 10227 cal. a B.P. for the Franconian Alb; the anomaly around $8.2 \mathrm{ka} \mathrm{B.P.} \mathrm{recorded} \mathrm{in}$ the Zaininger- and Mühlbach-Cave; and a climatic deterioration which leads to an almost simultaneous cessation of speleothem growth on the Swabian/Franconian Alb between 2.5 and 2.8 ka B.P. Important changes of the stable isotopic composition occur together with changes in growth rate and in the macroscopic aspect of the investigated speleothems. This confirms that general climatic and environmental parameters control the recorded variations and that they are not owing to very local factors. 


\section{Zusammenfassung}

In dieser Arbeit wurden sieben Speläotheme aus sechs verschiedenen Höhlensystemen in Deutschland auf ihre Eignung als kontinentale, paläoklimatische Archive hin untersucht. Die Höhlen sind in den Jurakalken der Schwäbischen/Fränkischen Alb (S-Deutschland) und den devonischen Riffkalken des Harzes ( $N$-Deutschland) lokalisiert. Auf der Grundlage von ${ }^{234} \mathrm{U} /{ }^{230} \mathrm{Th}$ (TIMS) Altersdatierungen wurden $\delta^{18} \mathrm{O} / \delta^{13} \mathrm{C}$ Zeitreihen konstruiert und deren potentielle paläoklimatische Signale im globalen Kontext diskutiert.

Zusätzliche $\delta^{18} \mathrm{O} / \delta^{13} \mathrm{C}$ Messungen von Höhlentropfwässern, rezenten Höhlenkalken und des Hintergrundgesteins sowie das Monitoring von Parametern der Höhlenatmosphäre (T, rel.F.) ergaben einerseits eine grundsätzliche Übereinstimmung mit den durchschnittlichen Jahreswerten der meteorischen Niederschläge und der Oberflächentemperatur. Sie bestätigten andererseits die während der Höhlenkalzitausfällung (und damit Fraktionierung) vorherrschenden isotopischen Equilibriumsbedingungen. Damit sind vorgefundene $\delta^{18} \mathrm{O}$ Variationen der rezenten Höhlensinter ein Indikator für ausschließlich temperaturgesteuerte, zeitlich längerfristige (Klima-) Veränderungen der Erdoberfläche. Einige, diesbezüglich ermittelte Inkonsistenzen ließen sich auf anthropogene Einflüsse wie aktiven Steinbruchbetrieb (Zaininger Höhle, Schwäbische Alb) oder den Betrieb als Schauhöhlen (Baumanns- und Hermannshöhle, Harz) zurückführen. Diese Szenarien führten zwar wie im Fall der Zaininger Höhle teils zu kinetischen Fraktionierungsbedingungen während der rezenten Höhlensinterablagerung, konnten aber aufgrund ihres begrenzten temporären Einflusses für die verbleibende holozäne Rekonstruktion der Paläo-Zeitreihen vernachlässigt werden. Die ${ }^{234} \mathrm{U} /{ }^{230} \mathrm{Th}$ (TIMS) Altersdatierungen der Harzer Stalagmiten aus der Baumanns- und Hermannshöhle ergaben Alter in nicht chronologischer Abfolge und sind damit für die weitere Konstruktion von Zeitreihen nicht geeignet.

Die Verifikation der isotopischen Equilibriumsbedingungen für die Paläo-Zeitreihen erfolgte mittels Hendy-Tests entlang einiger, prominenter Anwachsringe und anhand von $\delta^{18} \mathrm{O} / \delta^{13} \mathrm{C}$ Regressionsanalysen entlang des vertikalen Probenprofils. Spätpleistozäne Sinterwachstumsphasen wurden für den Stalagmiten aus der Höhlenruine Hunas ( $79373 \pm 8237$ bis $76872 \pm 9686$ a. B.P.; Fränkische Alb) und dem Stalagmiten aus der Hinteren Kohlhaldenhöhle (44158 \pm 3329 bis $2709 \pm 303$ a B.P.; Schwäbische Alb) nachgewiesen. Überraschenderweise scheint der Hintere Kohlhaldenstalagmit kontinuierlich über das relativ „kalte“ OIS 2 und LGM abgelagert worden zu sein, da makroskopisch kein Wachstumshiatus zu beobachten ist. Als begünstigende Faktoren wurden dabei die paläogeographische Position der Schwäbischen Alb im Periglazial und die topographische Lage der Höhle diskutiert. In Verbindung mit vermutlich diskontinuierlichen Permafrostbedingungen und (unregelmäßigen) Auftauphasen könnte so eine kleinräumige Wasserzirkulation im vadosen Bereich initiiert worden sein um so die Tropfwasserversorgung zu gewährleisten. Dies wird, wie auch für das Boelling/Alleroed Interstadial und die J üngere Dryas Kaltphase, gestützt durch prinzipielle Variationen $\operatorname{der} \delta^{18} \mathrm{O} / \delta^{13} \mathrm{C}_{\text {(Speläothem) }}$-Gehalte und Veränderungen der linearen Sinterwachstumsrate. Weiterhin legt ein Vergleich der Zeitreihen der Speläotheme aus der Hintere Kohlhalden- und der Zaininger Höhle (beide Schwäbische Alb), sowie der Mühlbachquellhöhle (Fränkische Alb) den Übergang vom 
Spätglazial zum jungen Holozän zwischen 10513 and 10587 cal. a B.P. für die Schwäbische Alb und 10227 cal. a B.P. für die Fränkische Alb nahe. Neben dem kurzzeitigen Kälteeinbruch um ca. 8.2 ka B.P., der sich in den $\delta^{18} \mathrm{O} / \delta^{13} \mathrm{C}$ - Archiven der Zaininger und der Mühlbachquellhöhle widerspiegelt, führt die klimatische Verschlechterung um 2.5 - 2.8 ka B.P. nahezu zum simultanen Wachstumsstop aller hier untersuchten Speläotheme der Schwäbischen/Fränkischen Alb.

Zusammenfassend finden in den hier untersuchten Speläothemen auffällige Variationen im stabilen $\delta^{18} \mathrm{O} / \delta^{13} \mathrm{C}$ I sotopenbestand in Übereinstimmung mit Veränderungen der Wachstumsraten und der makroskopischen Höhlensintermorphologie statt. Deren chronologische Verifikation konnte auf Basis der absoluten ${ }^{234} \mathrm{U} /{ }^{230} \mathrm{Th}$ (TIMS) Altersdatierungen und in Abhängigkeit externer, paläoklimatischer Faktoren erfolgreich vorgenommen werden. 
Contents

Prologue

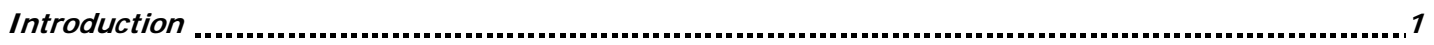

i)

Speleogenesis.

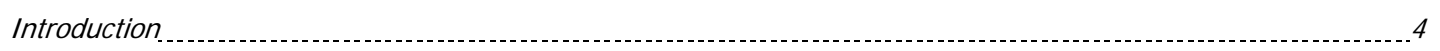

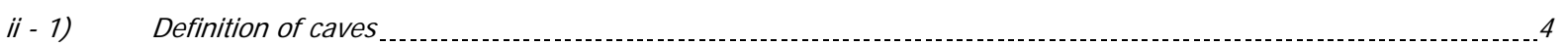

ii - 2) Classification schemes of caves

ii - 3) Principle speleogenesis in limestones _.

ii - 3.1) The initial phase and setup of a "proto-cave"

ii - 3.1.1) Cave development along a single bedding plane.......................................................................

ii - 3.2) The vertical development (and establishment of a cave level)

ii - 3.3) Dissolution of limestones

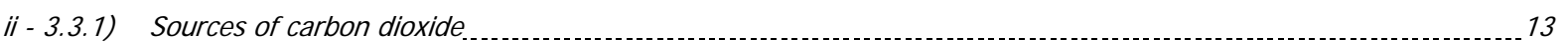

Quintessence

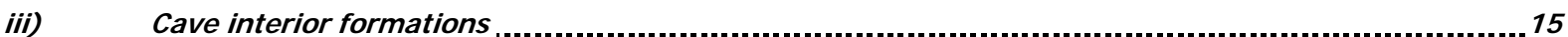

Introduction

iii - 1) Carbonate Deposition (and speleothem fabric control) .................................................................

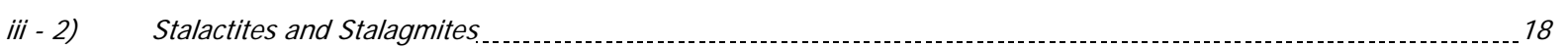

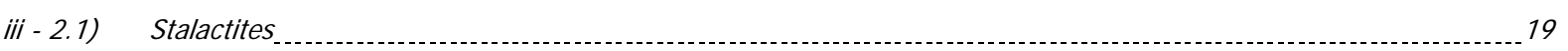

iii - 2.2) Stalagmites

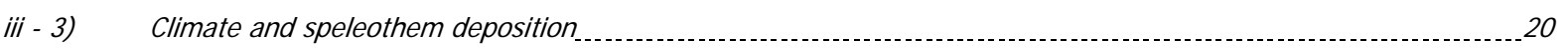

Quintessence

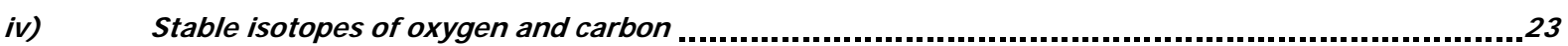

iv - 1) Basics

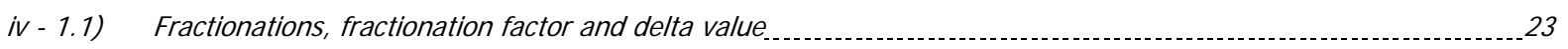

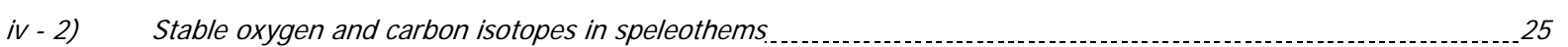

iv - 2.1) Oxygen

iv - 2.2) The cave temperature effect

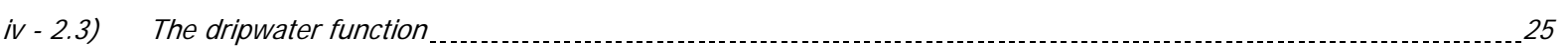

iv - 2.3.1) Time

iv - 2.4) Problems and points of discussion

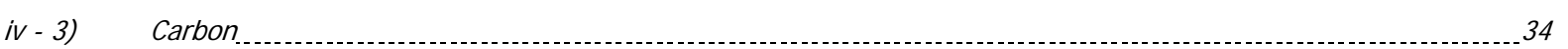

iv - 3.1) Problems and points of discussion $\ldots$

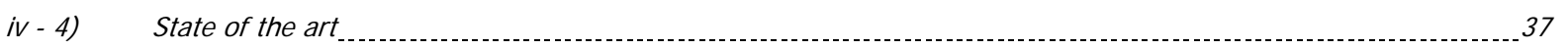

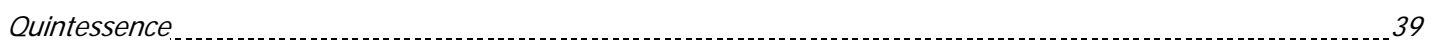




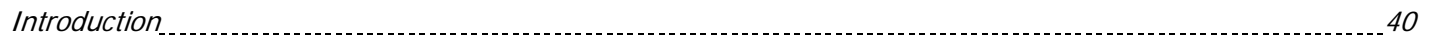

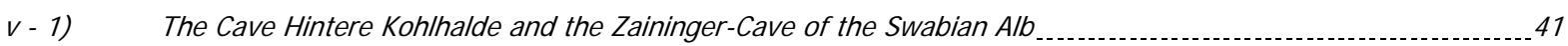

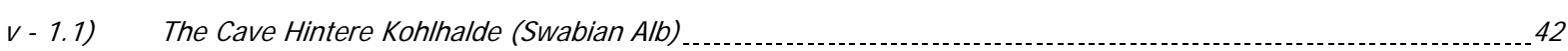

$v$ - 1.2) The Zaininger-Cave (Swabian Alb) _

$v$ - 1.3) Some assumptions on the speleogenesis of the Cave Hintere Kohlhalde and the Zaininger-Cave ..................47

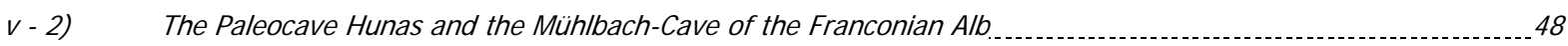

$v$ - 2.1) The Paleocave Hunas (Franconian Alb)

$v$ - 2.2) The Mühlbach-Cave (Franconian Alb)

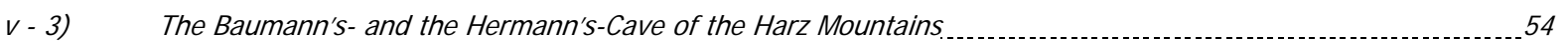

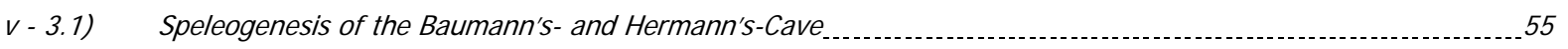

Quintessence

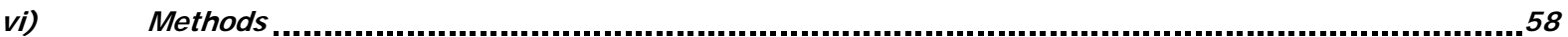

Introduction _.

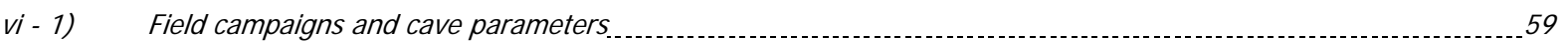

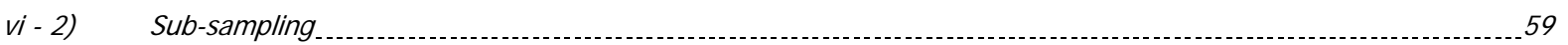

$v i-3) \quad$ Stable isotope analyses.

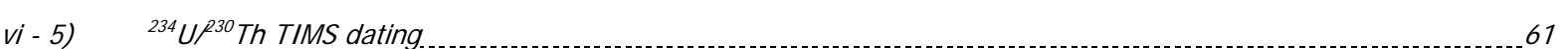

vii - 1) Results and discussion: Present-day calibration ....................................................62

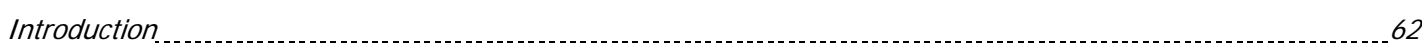

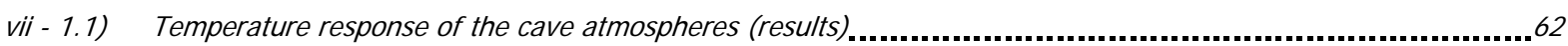

vii - 1.1.1) Temperature response of the cave atmospheres (discussion)

vii - 1.2) Stable oxygen/carbon isotopic distributions of cave contents (results)

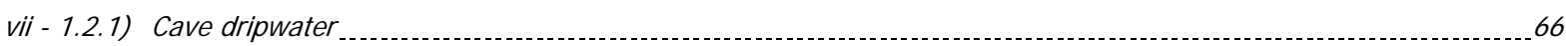

vii - 1.2.2) Host rock

vii - 1.2.3) Recent cave calcite depositions 69

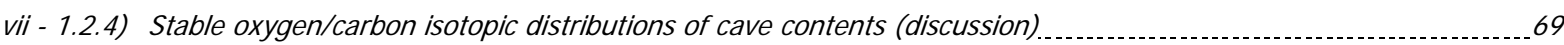

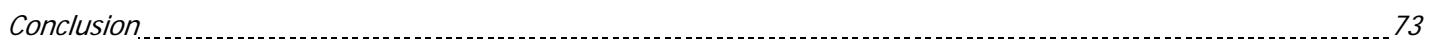

vii - 2) Results and discussion: Speleothem paleorecords..................................................74

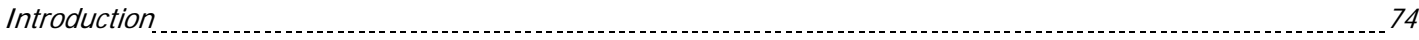

vii - 2.1) The stalagmites HKH-1, ZH-1 and the ZH-STK stalactite of the Cave

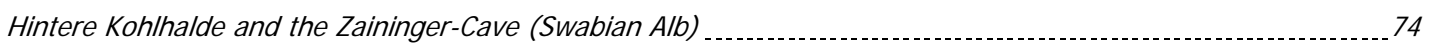

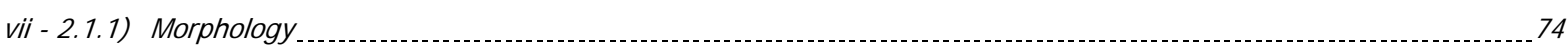

vii - 2.1.2) Chronological control and extension rate

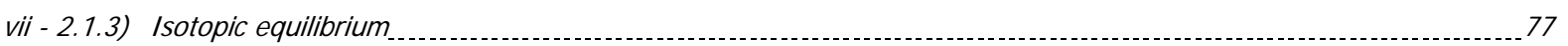

vii - 2.1.4) Isotopic composition timeseries

The stalagmite HKH-1 of the Cave Hintere Kohlhalde (Swabian Alb) _. 79

vii - 2.1.5) Isotopic composition timeseries

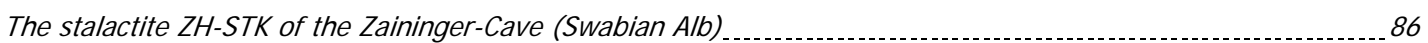

vii - 2.1.6) Isotopic compositions timeseries

The stalagmite ZH-1 STM from the Zaininger-Cave (Swabian Alb) 
vii - 2.2) The HU-stalagmite of the Paleocave Hunas and the MH-stalagmite of the

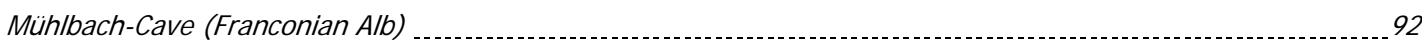

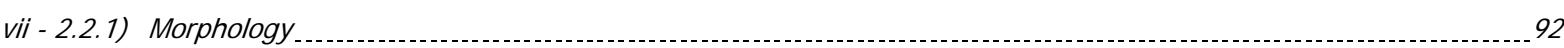

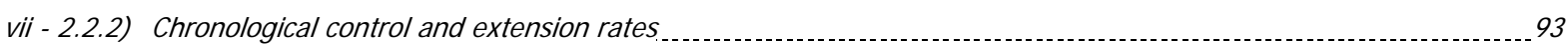

vii - 2.2.3) Isotopic equilibrium _...

vii - 2.2.4) Isotopic composition timeseries

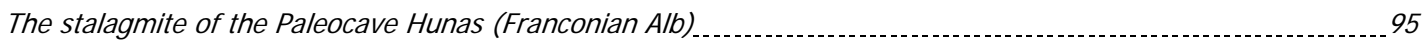

vii - 2.2.5) Isotopic composition timeseries

The Mühlbach-Cave stalagmite (Franconian Alb) _...

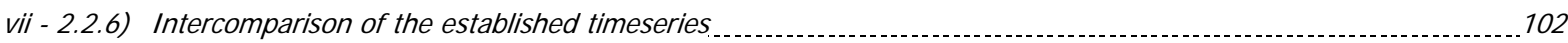

Conclusion Swabian and Franconian Alb speleothems .......................................................... 107

vii - 2.3) The stalagmites of the Baumann's- and Hermann's-Cave (Harz Mtns.)

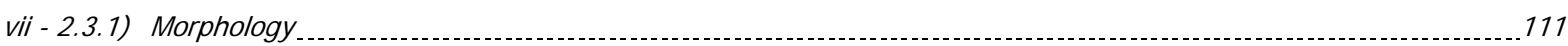

vii - 2.3.2) Chronological control _._.

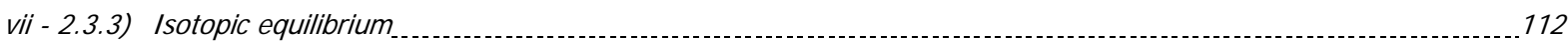

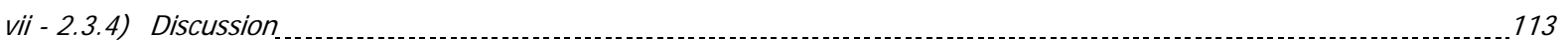

Conclusion $\ldots \ldots \ldots$

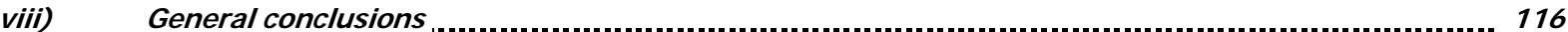

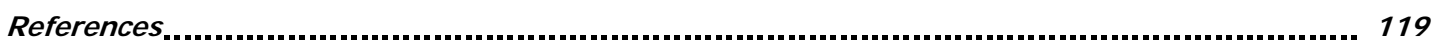




\section{$F_{\text {gyures and }} T_{\text {ables }}$}

Prologue

Figure $P$ - 1:

The main branches of speleology

i) Introduction

1

Figure $i-1$ :

Modeled global mean temperature development for the year 2070.

ii) Speleogenesis

Table ii - 1:

Classification categories according to cave length.

Table ii - 2:

Some classification schemes for karst solution caves.

Figure ii - 1:

Development of water conduits.

Figure ii - 2:

The initiation of cave systems with multiple inputs.

Figure ii - 3:

The four stage cave model.

Figure ii - 4:

Geometry of successive caves in multiphase systems and fissure frequency.

Figure ii - 5:

Process equation and kinetics, dissolution of calcium carbonate.

Figure ii - 6:

The principle of mixing corrosion.

Figure ii - 7:

Carbon dioxide pathways to the underground.

ii) Cave interior formations

Figure iii - 1:

Evolution of supersaturated solutions. Closed- vs. open-system conditions.

Figure iii - 2: Variations of $\mathrm{pCO}_{2}$ of the parent feeding water on the equilibrium solubility of cave calcite vs. aragonite precipitates.

Figure iii - 3: Different patterns of the growth of columnar crystal calcites in speleothems and the development of inclusions.

Table iii - 1:

The compromise listing of speleothem forms.

Figure iii - 4: $\quad$ The growth of soda straw stalactites.

Figure iii - 5: $\quad$ Cumulative growth frequency distribution of 520 speleothem uranium series analyses from Northwest Europe.

iv) Stable isotopes of oxygen and carbon

$\begin{array}{ll}\text { Figure iv - 1: } & \begin{array}{l}\text { Regional/local meteoric waterlines from various weather stations and } \\ \text { the GMLW. } \\ \text { Figure iv - 2: }\end{array} \\ \text { Figure iv - 3: } & \text { Schematic oxygen isotope fractionation of water in the atmosphere. } \\ \text { Figure iv - 4: } & \text { Model for the stable oxygen evolution in German speleothems for the } \\ \text { Table iv - 1: } & \text { Estimates for the stable oxygen isotope evolution in German speleothems } \\ \text { Figure iv - 5: } & \text { for the Holocene and the Pleistocene. } \\ \text { Figure iv - 6: } & \text { Speleothem carbon sources. } \\ & \text { Stable carbon isotopes in speleothems. }\end{array}$

v) Regional Geology and Sites

Figure $v$ - 1:

Figure $v-2$ :

Figure $v$ - 3:

Figure $v$ - 4:
Location of the studied sites and the main karst areas of Germany.

Candle stalagmites of the Cave Hintere Kohlhalde.

Cave map Hintere Kohlhalde with sample positions.

Locations of the Cave Hintere Kohlhalde and the Zaininger-Cave (Swabian Alb). 
Figure v - 5 and - 6: $\quad$ Limestone quarry of the company "Rösch" near the village of Zainingen.

Figure $v$ - 7: Zaininger-Cave: Convex riverbanks.

Figure v - 8: $\quad$ Groundoutline and cross-section of the Zaininger-Cave with sample positions.

Table $v-1$ :

Cave refill of the Paleocave Hunas: Paleoclimatological interpretation after Brunnacker.

Figure $v$ - 9:

Cave refill of the Paleocave Hunas: Profile.

Figure $v$ - 10:

Paleocave Hunas and lower 10 m exploration dig.

Figure $v$ - 11:

Locations of the Paleocave Hunas and the Mühlbach-Cave (Franconian Alb).

Figure $v-12$ :

Cave Map of the Mühlbach-Cave.

Figure $v$ - 13:

Cave passages of the Mühlbach-Cave.

Figure $v$ - 14:

Locations of the Baumann's- and Hermann's-Cave (Harz Mountains).

Figure $v$ - 15:

Ground outline of the Baumann's-Cave (top) and cross-section of the Hermann's-Cave.

Table $v$ - 2:

Framedata for the investigated cave systems and cave environments.

vi) Methods

Figure vi - 1, 2:

Field sampling of cave sediments.

Table $v$ - 1:

The field sessions and sample types.

Table $v$ - 2:

Instrumental techniques used for stable isotope analyses of calcite and water.

vii - 1) Results and discussion: Present-day calibration

Figure vii - 1.1:

Table vii - 1.1:

Table vii - 1.2:

Figure vii - 1.2:

Figure vii - 1.3:

Figure vii - 1.4:

Figure vii - 1.5:

Table vii - 1.3:

Table vii - 1.4:

Figure vii - 1.6:
Monthly mean $\delta^{18} \mathrm{O}$ rain of IAEA/WMO stations closest to investigated sites.

Annual mean $\delta^{18} \mathrm{O}$ rain of IAEA/WMO stations closest to investigated sites.

Cave temperatures vs. regional MAAT and mean annual meteoric precipitation.

Icicles Zaininger-Cave.

Stable isotopic composition of the dripwater samples in regard to the GMWL.

$\delta^{18} \mathrm{O}$ of cave dripwater and meteoric precipitation of the nearest

IAEA/WMO stations.

Stable oxygen vs. stable carbon isotopic composition of recent cave

calcite precipitates.

Stable oxygen vs. stable carbon isotopic composition host rocks.

Summary of $\delta^{18} \mathrm{O}$ and $\delta^{13} \mathrm{C}$ values for the recent cave calcite precipitates,

associated dripwater and calculated calcite $\delta^{18} \mathrm{O}_{\mathrm{C}}$.

Analyzed vs. calculated $\delta^{18} O_{C}$ equilibrium values of cave calcite precipitates

from the Baumann's and Hermann's-Cave.

vii - 2) Results and discussion: Speleothem paleorecords

Figure vii - 2.1:

Figure vii - 2.2:

Figure vii - 2.3:

Figure vii - 2.4:

Table vii - 2.1:

Figure vii - 2.5:

Figure vii - 2.6:

Figures vii - 2.7/2.8:

Table vii - 2.2:

Table vii - 2.3:

Figure vii - 2.9:

Table vii - 2.4:
The $\mathrm{HKH}-1$ stalagmite and its internal longitudinal section.

$\mathrm{ZH}-1$ stalagmite of the Zaininger-Cave (cross-section).

The longitudinal cross-section of ZH-STK stalactite (Zaininger-Cave).

The linear extension rates of the HKH-1 STM.

HKH-1 stalagmite: $\delta^{18} \mathrm{O} / \delta^{13} \mathrm{C}$ correlations Hendy layers.

$\mathrm{HKH}-1$ stalagmite: $\delta^{18} \mathrm{O}$ single layer variations.

ZH-1 stalagmite: Scatterplot $\delta^{13} \mathrm{C}$ versus $\delta^{18} \mathrm{O}$.

$\delta^{18} \mathrm{O}, \delta^{13} \mathrm{C}$ timeseries and linear regression analysis Cave Hintere Kohlhalde.

Summary of measurements of $\delta^{18} \mathrm{O}$ and $\delta^{13} \mathrm{C}$ timeseries from the $\mathrm{HKH}-\mathrm{I}$

stalagmite.

$\delta^{18} \mathrm{O}$ mean of the $\mathrm{HKH}-1$ stalagmite tuned to the OIS chronostratigraphy.

$\delta^{18} \mathrm{O}, \delta^{13} \mathrm{C}$ timeseries of the stalactite $\mathrm{ZH}$-STK.

Summary of measurements of $\delta^{18} \mathrm{O}$ and $\delta^{13} \mathrm{C}$ timeseries from the $\mathrm{ZH}$-STK

stalactite. 
Figure vii - 2.10:

Table vii - 2.5:

Figure vii - 2.11:

Figure vii - 2.12:

Figure vii - 2.13:

Figure vii - 2.14:

Figure vii - 2.15:

Figure vii - 2.16:

Table vii - 2.6:

Figure vii - 2.17:

Table vii - 2.7:

Figure vii - 2.18:

Table vii - 2.8:

Figure vii - 2.19:

Figures vii - 2.20:

Figures vii - 2.21:

Figures vii - 2.22: $\delta^{18} \mathrm{O}, \delta^{13} \mathrm{C}$ timeseries of the stalagmite $\mathrm{ZH}-1$ STM from the Zaininger Cave. Summary of measurements of $\delta^{18} \mathrm{O}$ and $\delta^{13} \mathrm{C}$ timeseries from the $\mathrm{ZH}-1$ stalagmite. Longitudinal cut of the Mühlbach-Cave stalagmite (Franconian Alb) and subsample locations.

Close-up of the internal longitudinal structure of the HU-stalagmite. $\delta^{18} \mathrm{O}$ variations along the tested Hendy layers (HU-stalagmite).

Hunas stalagmite: $\delta^{18} \mathrm{O}$ versus $\delta^{13} \mathrm{C}$ of the layers checked for isotopic equilibrium conditions.

$\delta^{18} \mathrm{O}$ single layer variations $\mathrm{MH}$-stalagmite.

MH-stalagmite: $\delta^{18} \mathrm{O}$ vs. $\delta^{13} \mathrm{C}$ linear regression analysis.

Summary of measurements of $\delta^{18} \mathrm{O}$ and $\delta^{13} \mathrm{C}$ timeseries from the Hunas-Cave stalagmite.

$\delta^{18} \mathrm{O}, \delta^{13} \mathrm{C}$ timeseries from the stalagmite of the Paleocave Hunas. Summary of measurements of $\delta^{18} \mathrm{O}$ and $\delta^{13} \mathrm{C}$ timeseries from the Mühlbach-Cave stalagmite.

$\delta^{18} \mathrm{O}, \delta^{13} \mathrm{C}$ timeseries of the Mühlbach-Cave stalagmite. Summary of discussed speleothem parameters. HKH-1 STM, ZH-STK and MH-STM $\delta^{18} O$ timeseries between 22 to 2 cal. ka B.P.

The longitudinal section and established ${ }^{234} \mathrm{U}^{230} \mathrm{Th}$ TIMS ages of the stalagmites from the Baumann's- and Hermann's-Cave.

Check for isotopic equilibrium of the Baumann's-Cave Stalagmite BH-2a. Check for isotopic equilibrium of the Hermann's-Cave Stalagmite HH-STM. 


\section{Prologue}

Natural sciences have long been interested in past climates since the change of global/regional environmental conditions provide a potential explanation for the spatial and chronological distribution of differing vegetational communities and/or animal habitats. Caves are open-systems connected to the surface via fissures, pits, or sinkholes. Thus, their contents may reflect environmental changes of the landscape above the cave. Due to the subterranean position, cave contents such as bones, teeth, speleothems or human artefacts may be preserved within the cavities and escape the often radical changes of the surface. This becomes especially crucial in geological times characterized by relatively fast changes in environmental conditions like the glacial-interglacial cycles of the Quaternary period. Any records bearing potential paleoinformation were mostly lost on the landsurface due to erosional forces. Yet, the interest in exploring caves has been driven in earlier times by mystical transfigurations, by fashion like in the Period of Romanticism and only later by the awakening exploring desires of the young Natural Philosophy.

Thus, the first written report of a cave visit in Germany is dated 1488 (GoLDAST 1605; in: ROSENDAHL and KRAUSE 1996). The monk Felix Fabri from the Dominican Order visited the Sirgenstein-Cave (Sirgensteinhöhle), which is located in the vicinity of Blaubeuren (Swabian Alb, southern Germany). Within the 15th century and the uprising Period of the Renaissance, evidences about cave visits increased. A remarkable publication of this era is the "De ortu et causis subterraneorum" about the nature of caves, which was published in 1546 by GEROG ACRICOLA. Von Alvensleben established the first cave map in 1656 (STOLBERG 1958) from the Baumann's-Cave (Baumannshöhle), Harz Mountains (northern Germany). During the Period of the Baroque, cave tourism in the Harz region was already well established and the Baumann's-Cave was protected by state law. The first cave map of the Swabian Alb in southern Germany was published between 1716 and 1726 for the Sontheimer-Cave (Sontheimer Höhle; WeISSENSEE 1753).

With the Period of the Renaissance, the upcoming of the Natural Philosophy and triggered by technological improvements of the following Industrial Revolution, the scientific approach in speleology started to develop. The increased findings of fossil bones led to greater acknowledgement and social impact of the idea of natural evolution. Thus, one of the earliest expressions for "speleology" is the German word "Höhlenkunde". It first appeared in a paper read to the academic society in Vienna on 5th December 1850 (T.R. SHAw 1992). Finally, the establishment of Palaeontology as an independent science in Germany was marked by the publication of J. F. ESPER about animal fossil bones in caves of the Franconian Alb ("Ausführliche Nachricht von Neuentdeckten Zoolithen unbekannter vierfüssiger Thiere"). The "Schwäbische Höhlenverein" (Swabian Cave Club) was founded in 1889 as one of the world's first speleological clubs. Besides the exploration of caves, increasing emphasis has been placed on paleontological and archeological research. Following World War I, the focus even broadened to more multidisciplinary aspects of research which resulted for instance in the publications of StOLBERG (1926) about caves in the Harz Mtns. 
The speleological research underwent a sharp drawback during the Third Reich, leading to a coerced merge of all speleological clubs under the "Reichsbund für Karst- und Höhlenforschung" (this encompasses Germany and Austria). One of the main targets was to extract the huge cave register of the speleological clubs, which could be used by Nazi geologists as a handy database. From 1943 on the Nazis' intention was to protect the German defense industry against increasing air strikes of the allies. Hitler and Göring (10.10.1943) gave orders to transfer war technology into caves, cellars, and mining sites (SPEER 1984). Since the Nazis provided these locations with codenames, the reconstruction of the original sites has not been completed yet. Some examples are the cave Heimkehle (Harz Mountains.) with the codename "Heller" or "A5" (squeezers of the company "J unkers", Schönebeck) or the cave J ettenhöhle (codename "Ör") with fine-mechanical war equipment of the company "R. Rinkel GmbH" (city of Göttingen). The Hermann's- and Baumann's-Cave at Rübeland were combined under the code "Gulden" (ENGELBRECHT 1997).

The German Speleological Federation (Verband der deutschen Höhlen- und Karstforscher, VdHK) was founded 1955 as a precursor of the first umbrella organization for speleologists in Germany, the "Hauptverband deutscher Höhlenforscher" (1922-45) and the "Deutsche Gesellschaft für Karstforschung" (1945-50). The objectives are "to survey and protect the caves and karst-phenomena in Germany as well as the protection of the environment and the natural monuments in the karst regions of Germany" (http://hfc-hersfeld.de/vdhk.html). Today, "speleology" comprises all aspects of cave science as shown in figure $P-1$. Consequently, the term is defined in the Oxford Dictionary as the "scientific study of caves".

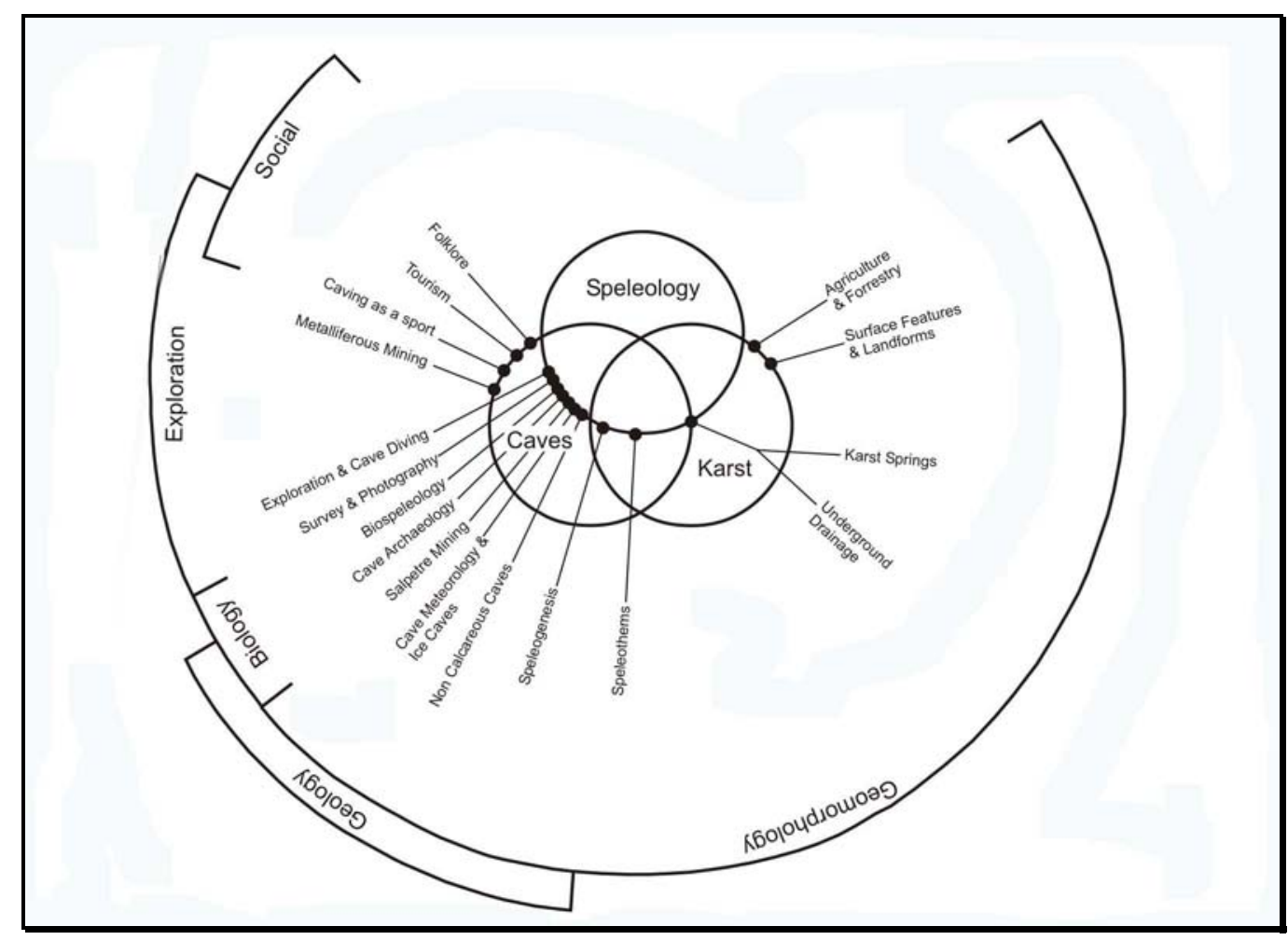

Figure $P$ - 1: The main branches of speleology (after SHAW 1992). 


\section{Introduction}

The cause of global warming over the last century remains a controversial issue with significant ecological and socio-economic implications. Many scientists attribute the current global warming to the greenhouse effect, the hole in the ozone layer and related changes in the Earth's climate system. These are enhanced by anthropogenic activities like the massive, and (considering the geological timescale) very rapid release of carbon dioxide, methane and exceeding usage of fossil fuels like coal and petroleum (e.g. PETIT 1999). Other scientists claim that other, rather natural factors are responsible for this, such as the increase of the sun's output or the increasing number and strength of volcanic eruptions. Regardless of the potential causes for the rapid temperature increase today, this warming will have important implications for the human well-being and health (see scenarios in figure i - 1).

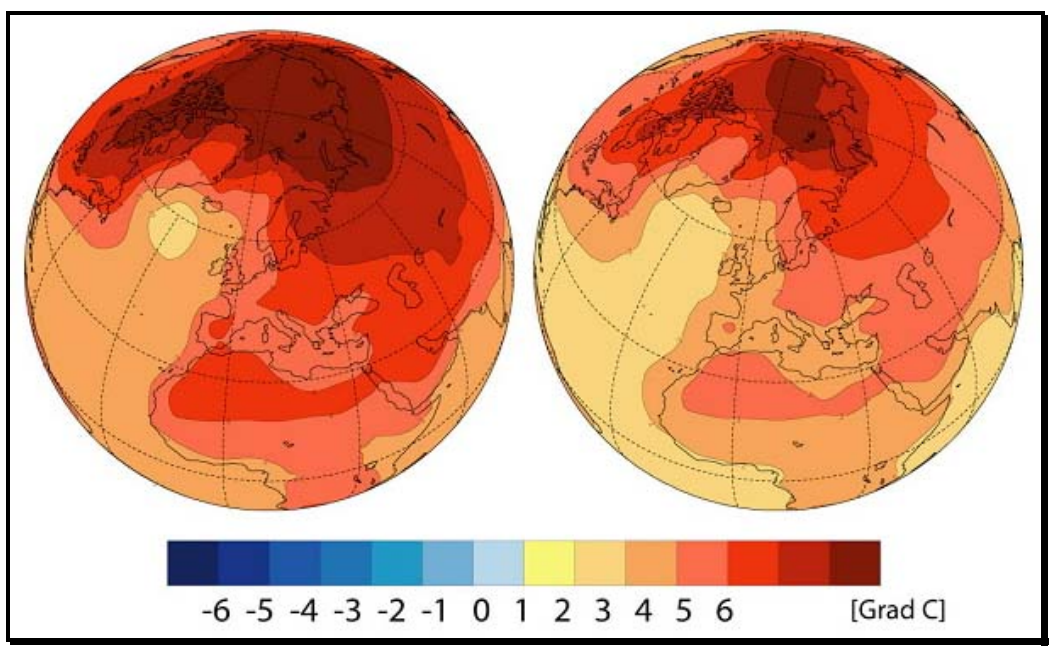

Figure i - 1: Modeled global mean temperature development for the year 2070. The left scenario describes a very heterogeneous world. The underlying theme of the model is self-reliance and preservation of local identities. Fertility patterns across regions converge very slowly, which results in high population growth. Economic development is primarily regionally oriented and per capita economic growth and technological change are more fragmented and slower than in other storylines. The right scenario describes a world in which the emphasis is on local solutions to economic, social, and environmental sustainability. It is a world with moderate population growth, intermediate levels of economic development, and less rapid and more diverse technological change than other storylines. While the scenario is also oriented toward environmental protection and social equity, it focuses on local and regional levels (after Intergovernmental Panel on Climate Change - Special Report on Emissions Scenarios / IPCC SRES 2000 and 2001). 
This is already indicated by a number of scenarios like migrations driven by e.g. sea-level rises in mainly low-level coastal plains bordering the oceans; by the spreading of deserts which triggers an increased need and concurrence on water-resources; or by the gaining influence on mosquito-related diseases like malaria or dengue fever, and water-borne diseases like cholera (e.g. ISSAR 2003, EPSTEIN et al. 1998).

The Earth has warmed significantly over the last 140 years and the development within the 20th century seemed to be unprecedented in the last 1200 years (e.g. Houghton 2004, BRADLEY 1999). This highlights the need for paleoclimatic investigations since these data provide a base for testing hypotheses about potential causes of climatic change. Therefore, the knowledge about the natural scatter of past climates provides the necessary background information from which the present-day anthropogenic impacts on climate change can be extracted unambiguously. The increasing possibility to forecast and model climatic variations in the future is the basis to develop effective countermeasurements, to take political action for socio-economically responsible and sustainable developments on behalf of Planet Earth.

The propagation and retreat of ice masses, peat bog growth, lake level variations, beetle populations, vegetation distribution, tree ring growth and speleothem depositions are some of the paleoclimatic archives which usually contain proxy information on the continent influenced by the climatic fluctuations of the Quaternary. The climatic informations of the proxy records are usually embedded in a number of extraneous "noise" or natural scatter of non-climatic forcings owing e.g. to very local factors. Thus, the proxies act as a filter from which the climatic signal has to be extracted. In order to do so, it is crucial to know which particular climatic factors, like mean annual air temperature, meteoric and effective precipitation, relative humidity, or seasonality control the proxy and how the proxy data respond to the change, being e.g. linear, continual, time-lag.

Due to mainly dating uncertainties on Quaternary deposits (AlLEY et al. 1997, WoLfARTH et al. 1996) there is still a chronological bias between the different sites and locations recording major paleoclimatic events. Nevertheless, numerous Quaternary continental climatic investigations on icecores (J OHNSEN et al. 1972, OESCHGER et al. 1984, GRIP members 1993), on lake sediments (Siegenthaler et al. 1984, OVerpeck 1996, von Grafenstein et al. 1996, 1998, LotTer et al. 1992), or on pollen records (WEGMÜLLER and LOTTER 1990, COHMAP members 1988, LITT et al. 2001) contributed to a better knowledge on the chronology of the rapid environmental changes during this period. The chronological resolution as a result of spatial sampling, subsampling and dating uncertainties limit the potential correlations since higher resolute events will not be detected. On the other hand, detected correlations may represent a single widespread event, a time-transgressive event, or even just a number of local uncorrelated events. Thus, it is still important to compare different proxies at a variety of locations to increase the statistical basis.

During the last three decades there has been an increasing interest in using cave deposits or speleothems as paleoclimatic archives. The specific cave environments favors the preservation of paleoclimate records covering several glacial-interglacial cycles of the Quaternary, whereas other 
terrestrial deposits usually loose their recorded informations owing to erosion. A further advantage is the possibility of direct dating, e.g. via the ${ }^{14} \mathrm{C}$ method (GeYh and Franke 1970, HenNIG et al. 1979) or with U/Th decay series (e.g. AtKInSON et al. 1978, SMART et al. 1988, LI et al. 1989). Since the mechanisms of speleothem deposition are sensitive to external, often climatically driven processes, they respond to decadal-annual short-term changes as well as to long-term changes (e.g. QuINIF et al. 1990, Shopov et al. 1994, MCDermott et al. 1999, QIn et al. 1999, PeretTe et al. 1999, Linge et al. 2001, Frappier et al. 2002, Plagnes et al. 2002, J ImÉnez de Cisneros et al. 2003, MCDermott 2004). In very exceptional cases some stalagmites seem to show seasonally growth of laminae and even offer high resolutional timeseries (BAKER et al. 1993). Being continental deposits, speleothems are therefore an important complement to the deep-sea and ice-core records.

Many of the variables that can be analyzed in speleothems may serve as (paleo-) climatic proxies. Measurable parameters are stable isotope ratios, inter-annual thickness variations of growth laminae, growth rate changes, variations in trace element abundances, organic acid contents and trapped pollen grains. Of particular interest are the stable oxygen and carbon isotopic compositions of the speleothems and systematic studies commenced more than three decades ago by HENDY and WILSON (1968), HENDY (1971) or THOMPSON et al. (1976). Oxygen and carbon isotope studies have been discovered as a valuable tool to quantify the temperature and vegetational changes respectively (Emiliani 1971, Hendy 1971, Schwarcz 1986, Harmon et al 1978, Gascoyne et al. 1980, Goede et al. 1990, Fricke and O'Neil 1999, Frumkin et al. 1999, LaURitZen and Lundberg 1999, Fleitmann et al. 2003). The overall closed crystalline fabric of the speleothems usually avoids post-depositional contaminations or exchanges, which is a crucial criteria e.g. for the reliability of U-series disequilibrium datings.

However, until now the knowledge about the specific climatic and environmental controls leaving an imprint on the stable isotopic composition of the speleothems are scarce, not fully understood and is probably the cause for the lack of convincing paleoclimatic reconstructions from these proxies.

o This study contributes to a better understanding of the speleothem responses on potential climatic and environmental forcings in dependency of the associated cave environments.

o It is the first strategic paleoclimatic research conducted on several speleothems from independent German cave systems and bears the opportunity of comparing coeval paleorecords since comparable analytical methods and proxies were used.

o Owing to the low detection limits of the used TIMS (Thermal Ionization Mass Spectrometry) it is possible to ${ }^{234} \mathrm{U} /{ }^{230} \mathrm{Th}$ date speleothems from the Swabian/Franconian Alb in southern Germany despite their known very low uranium content. 


\section{Speleogenesis}

\section{Introduction}

The evolution of cave deposits can only be understood in context with the origin of the corresponding cave and surrounding geo-hydrological setting (e.g. karst area). In this section necessary definitions and models for cave classification and speleogenesis are provided whereas cave calcite deposits are treated in the following section iii. Since the cave locations of this study are situated in the Devonian and J urassic limestones of northern and southern Germany, the focus is narrowed down to the karstic environments.

\section{ii - 1) Definition of caves}

The International Speleological Union defines cave as a "natural underground cavity, large enough to be entered by man" which can partly or entirely be filled with sediments, water, or ice (FINK 1973, TRIMMEL 1968). Thus, this rather anthropocentric definition makes the accessibility for humans the crucial criterion of all caves. WREDE (1996) postulates a minimum size/extension of $5 \mathrm{~m}$, surrounded by the corresponding host rock. Other authors like FORD and WILLIAMS (1989) lay more emphasis on the genetic aspects of cave evolutions. They define karst cave as a solutional opening that is greater than $5-15 \mathrm{~mm}$ in diameter, as this is the effective minimum aperture for turbulent flow conditions. All these definitions exclude artificial underground cavities (e.g. mining shafts, rock-cellars), cleavages and porosity (usually too small), or any animal constructions since they are usually too small and not surrounded by hardrocks.

\section{ii - 2) Classification schemes of caves}

The most obvious ways to classify caves are geological-petrographical criteria depending on the type of rock in which they are created (chalk, limestone, gypsum, sandstone, granite etc.), and the classification according to the horizontal and vertical dimension within the mountain. Since the spatial extend of a cave largely depends on the stage of exploration, the disadvantage of the latter is that caves can slip from one category into the next higher, depending on exploration advances (e.g. BöGLI 1978).

\begin{tabular}{|l|c|}
\hline small caves & $<50 \mathrm{~m}$ \\
medium caves & $50-500 \mathrm{~m}$ \\
large caves & $500-5000 \mathrm{~m}$ \\
giant caves/caverns & $>5000 \mathrm{~m}$ \\
\hline
\end{tabular}

Table ii - 1: Classification categories according to cave length (BöGLI 1978). 
The longest caves of Germany are the caves "Salzgrabenhöhle" (9064 m, Bavaria), "Fuchslabyrinth" (8300 m, Baden-Württemberg) and the "Hölloch" (7085 m, Bavaria). These data are provided by T. Müller and A. Wolf of the cave club „Arge Grabenstetten e.V.“ and were last updated Nov. 2002 (http://www.arge-grabenstetten.de).

Taking speleo-genetical aspects into account primary or co-diagenetical caves may generally be distinguished from secondary or post-diagenetical caves. Primary caves often appear in igneous rocks as vesicles and lava tunnels (e.g. Hawaii, Lanzarote, I celand) or in sedimentary caves such as over covering-, reef-, and tufa-caves. A well-known tufa-cave are the Hell Grottoes ("Höllgrotten") at Bar/Zug in Switzerland where calcareous tufa deposits below the rock wall of Lorze Gorge build up the cavity (EIKENBERG et al. 2001).

Secondary caves are created after diagenesis and can be formed either by forces from the exterior ("exogenic caves") or by forces within the mountain itself ("endogenous caves"). Erosion and weathering processes from the exterior sometimes result in shelter-caves, wind-caves, river-bank caves or wave-cut caves. The driving forces creating endogenous caves are tectonic processes and corrosion. This lead to a rather broad classification in tectonic- or karst-caves although this has been criticized being too static/schematic since a strict separation between tectonic and dissolution processes is not possible (BöGLI 1978, Ford and WilLIAMS 1989, WREDE 1996, GILLIESON 1996). Usually, tectonically prescribed cracks/fissures/cleavages are used as initiative pathways for the solvent water (see below).-

Karst or corrosion caves occur much more frequently than any other type of cave and BöGLI (1978) suggests following classification:

- bedding caves - are created between two layers of similar, soluble rock.

- contact caves - run between two different kinds of rocks where the underlying one is insoluble.

- joint caves - are created along joints and faults.

As it is evident, there is no classification that encompasses all subterranean cavities owing to the mentioned variability and complexity of karst solutional cave characteristics. Thus, FORD and WILLIAMS (1989) present a somewhat limited and simple classification, but which is at least universally based. For the course of this thesis the generic classification scheme (table ii - 2, next page) is adopted. 


\begin{tabular}{|c|c|c|}
\hline \multicolumn{3}{|c|}{ Some classification of solution caves } \\
\hline \multicolumn{3}{|l|}{$\begin{array}{l}\text { A) By internal } \\
\text { characteristics }\end{array}$} \\
\hline 1) & By size: & aggregate length or depth or volume. \\
\hline 2) & $\begin{array}{l}\text { By measure of vertical or horizontal } \\
\text { dimensions }\end{array}$ & \\
\hline 3) & By plan form: & $\begin{array}{l}\text { entrance of niche (abri), chamber (room), linear } \\
\text { passage } \\
\text { branchwork, network, anastomosis, spongework } \\
\text { multiphase branchworks, rectilinear combinations. }\end{array}$ \\
\hline 4) & By passage cross-section form: & circular or elliptical, canyon, breakdown, compound. \\
\hline 5) & By relation to a regional water-table: & $\begin{array}{l}\text { vadose, water table cave, } \\
\text { phreatic, compound, relict. }\end{array}$ \\
\hline 6) & By categories of deposits: & $\begin{array}{l}\text { speleothem cave, gypsum (crystal) cave } \\
\text { sand cave, ice cave, archaeological site etc. }\end{array}$ \\
\hline \multicolumn{3}{|l|}{$\begin{array}{l}\text { B) In relation to } \\
\text { external factors }\end{array}$} \\
\hline 1) & Modes of geologic control: & $\begin{array}{l}\text { rock type (limestone, gypsum etc.), joint-guided, } \\
\text { fault-guided, etc; horizontal strata, steeply } \\
\text { dipping, folding etc. }\end{array}$ \\
\hline 2) & By topographic setting: & mountain caves, plateau caves etc. \\
\hline 3) & By relation to topography: & $\begin{array}{l}\text { underdrain valley or valley flank, meander } \\
\text { cut off, connect poljes, foot cave etc. }\end{array}$ \\
\hline 4) & By role in fluvial system: & $\begin{array}{l}\text { allogenic river caves, holokarst drains, } \\
\text { shortcut caves, combinations, } \\
\text { sea cave etc. }\end{array}$ \\
\hline 5) & By aquifer type: & $\begin{array}{l}\text { ideal pipe cave }=>\text { continuum }=>\text { perfect } \\
\text { spongework cave. }\end{array}$ \\
\hline 6) & $\begin{array}{l}\text { By role in geomorphic and } \\
\text { hydrologic cycles: }\end{array}$ & $\begin{array}{l}\text { active cave }=>\text { episodic }=>\text { relict cave } \\
\text { (preserved, intercepted, truncated, destroyed) }\end{array}$ \\
\hline 7) & By climatic setting: & $\begin{array}{l}\text { humid tropical, semi-arid, mediterranen, temperate, } \\
\text { alpine, arctic, etc. }\end{array}$ \\
\hline
\end{tabular}

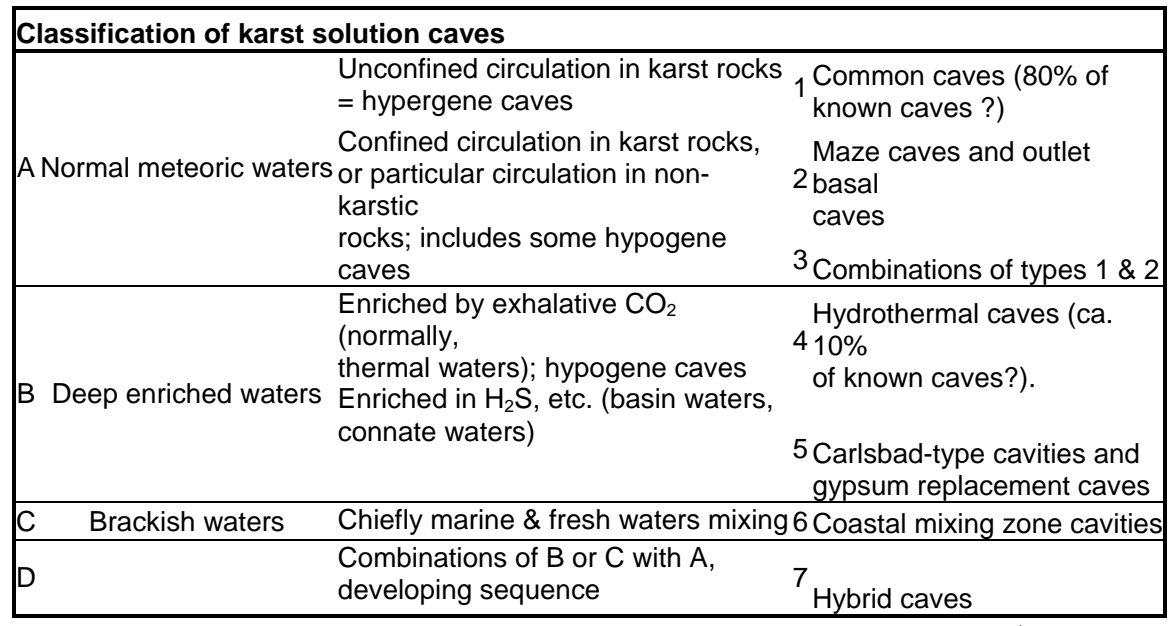

Table ii- 2: Some classification schemes for karst solution caves (FoRD and WILLIAMS 1989).

\section{ii - 3) Principle speleogenesis in limestones}

Subterranean solution cave systems are a result of highly variable parameters like hydrochemical factors depending on "internal" (petrologic, tectonic, climatic, biotic, and pedogenic) conditions and by external base level conditions (point of outflow, pressure gradient). Given this variation there is until now no single theory of speleogenesis or even classification (see also above) which would encompass all of them. 
Nevertheless the principal mechanisms and driving factors for the origin of caves in limestones are outlined.

\section{ii - 3.1) The initial phase and setup of a "proto-cave"}

Once water is circulating in the limestone, the process of limestone solution, of rock architecture and of morphological processes like incasion in the evolution of a cave become dominant.

The initial phase of the subterranean cavity evolution is, driven by the hydraulic gradient, usually characterized by slow moving water in the phreatic zone with dominating limestone solution processes (Figure ii - 5 below). J oints, bedding interstices and faults will serve as precursors for the penetrating water. This is an important reason why lots of cave passages in Germany are orientated NNE or SE, following the Rhinish or Hercynian orogeny (e.g. Cave Kluterthöhle or Erdmannshöhle, Germany). But before karst solution begins, minimum apertures of connected voids in the fissures are small, usually less than $1 \mathrm{~mm}$ and their aggregate volume is also small. Thus, available runoff is quickly able to fill them with a resulting watertable near the ground surface.

\section{ii - 3.1.1) Cave development along a single bedding plane}

The development and widening from interstice to cave passage (under phreatic conditions) has been investigated under laboratory conditions by several authors (BöGLI 1964b and 1969d, EWERS 1972 and 1982). BöGL proved the permeability of even sub-capillary and capillary interstices in dependency of the pressure gradient whereas EWERS $(1972,1982)$ investigations focused more on the development and widening of water conduits in water soluble-rocks. A block of salt was pressed on a water-filled (transparent) plastic cushion, enclosing in between a capillary interstice and an even pressure gradient was applied between the inflow and the drainage. As expected, the initial mode of flow was laminar within the plane and a conduit or tube began to form at the point of the inflow which developed along the hydraulical gradient in the direction of the outflow. Simultaneously thinner side branches spread out. As the plane maintained a high resistance, the flow was slow and very small in amount. Thus, any variations in cross-sections and other properties of the interstices were insignificant as long as this high resistant element persisted. As seen in figure ii - 1 the leading conduit deformed the equipotential field and therefore reduced the pressure gradients at the solution fronts of its competing side-branches. When the outflow was reached, the high resistance to flow was destroyed and the laminar flow conditions switched to turbulent patterns because the connected tube was an inhomogeneity. As a consequence, the equipotential field was reoriented onto it (because of its high hydraulic conductivity/permeability), which enforced its growth and enlarged the crosssection, while the side branches completely ceased to grow (see figure ii. - 1 below). FORD and WILLIAMS (1989) refer to this stage as "proto-tube" which contains after EWERS (1982) experiments diameters of $>1 \mathrm{~mm}$. With turbulent flow conditions the proto-tube may expand comparatively fast to minimum cave dimensions. 


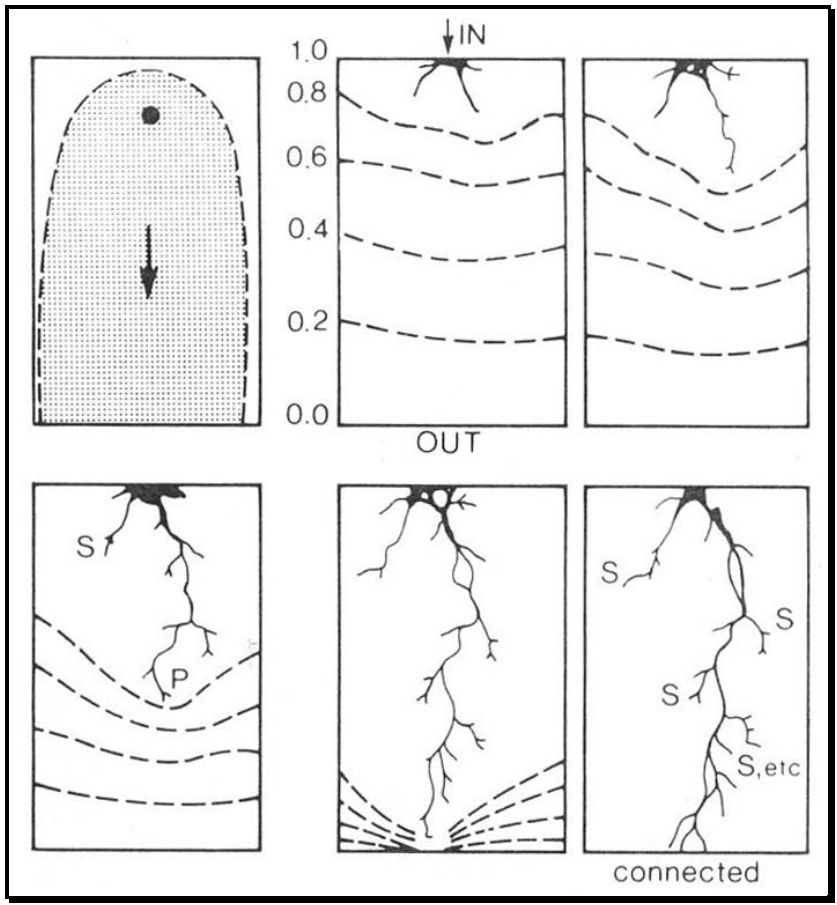

Figure ii - 1: Development of water conduits according to EWERS (1978 and 1982). The conduit propagates from sink to spring by preferential development of one proto-conduit. Grey shades in the upper left is the flow field/envelope at the start of dissolution.

Dashed lines $=$ equipotentials, $P=$ principal, leading conduit, $S=$ subsidiary tubes and branches

Where the limestone massif is fractured, the proto-tubes will preferably expand along fractures or bedding planes to minimize the flow resistance. The resulting communicating network of pathways creates not only favorable conditions for drainage but also promotes additional water inputs at joints (or joint-bedding intersections) which will enhance the development of the cave conduits through the process of mixing corrosion (BöGLI 1978; Mixing corrosion see below).

The duration until the setup of the proto-tube in the initial phase is long, due to the slow laminar waterflow and high resistance of the plane. Referring to his laboratory investigations BöGLI (1964b and $1969 \mathrm{~d}$ ) calculated for the first active interstice ( $40 \mathrm{~m}$ water column) a velocity of ( $\left.\mathrm{v}_{\text {seepage }}\right) 0.003$ $\mathrm{m} / \mathrm{h}$ if the distance of seepage was $30 \mathrm{~m}$. The timeperiod for this stage would amount to $41,7 \mathrm{~d}$. This is also supported by DREYBRODT (1988) who estimated that it would take $500 \mathrm{ka}$ for the widening of a pathway to $1 \mathrm{~m}$ under diffusive laminar flow conditions.

A couple of proceeding experiments tried to narrow down the origin of a proto-tube in applying more and more complex setups in attempt to simulate natural karst environments (Figure ii - 2). Since the above mentioned settings represent one point inflow sources, investigations were performed for multiple inputs in a single rank, and in simulating different altitudes in multiple ranks and as a restricted input model:

Multiple inputs in a single rank display a competitive development of solution conduits, following the same logic concerning high-low resistance rules like in the single input simulation. The same is valid for multiple input ranks, but additionally the flow envelops of further inputs "rank 2" are obstructed by those closest to the outflow boundary ("rank 1") (see Figure ii - 2). The proceeding "rank 2" can only connect to the outflow boundary after "rank 1" inputs have established an outflow connection, leading to reduced resistance of the plane and a steepening of the hydraulic gradient in their rear. The cave system links laterally and headwards together until either the available karst rock area is incorporated, or the minimum hydraulic gradient is reached. The restricted input case differs from the multiple rank 
input model because its inputs are restricted to a narrow zone or line, e.g. a valley floor where the karst is exposed. Again, the input point nearest to the outflow is developed first and constrains the far inputs.

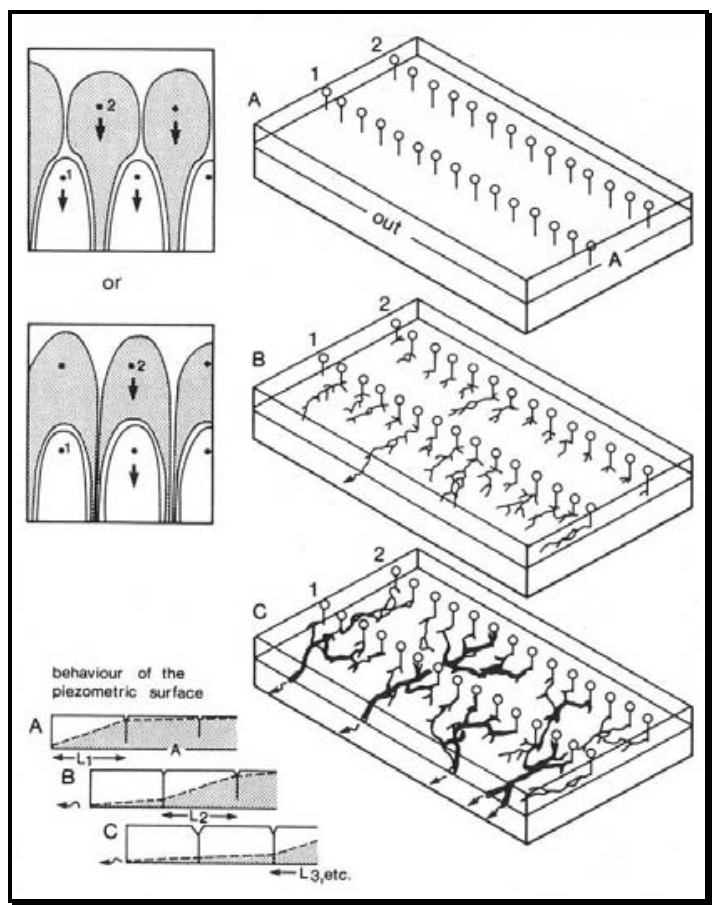

Figure ii - 2: The initiation of cave systems with multiple inputs (here: two ranks). Flow field configurations limit rear rank (2) access to an output boundary. The cave network is connected up in a headward sequence, with recession of the zone of steep hydraulic gradient (lower left) (FORD and WILLIAMS 1989).

\section{ii - 3.2) The vertical cave development}

Above, the case of cave evolution along a single bedding plane has been emphasized. Since under normal environmental conditions the water enters along multiple entry points/bedding planes the possibility of more complex developments in depth and length is given. FORD and WILLIAMS (1989) proposed a four-stage model for the further propagation from a deep phreatic cave to watertable caves. The dominant process is the fissure control, meaning an increasing fissure density, and decreasing hydraulic resistance (non-proportional, idealized) between the first and fourth stage. In each case all proto-tubes from the input have already connected to the output and the spring position is stable. 
Figure ii - 3: The four stage model differentiating the basic types of phreatic and water table caves (FORD and WILLIAMS 1989).

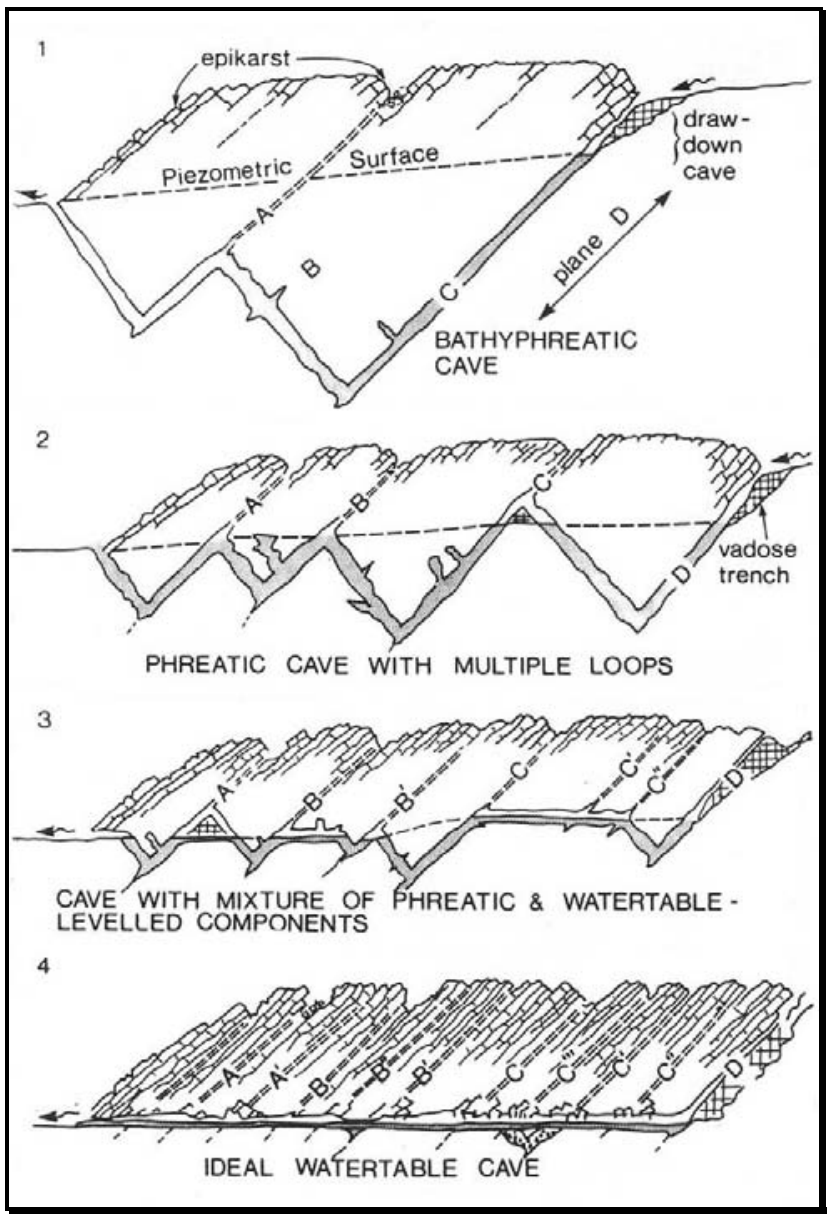

1. Bathyphreatic cave/deep phreatic cave In a bathyphreatic cave there is a single downward loop below the water table as the frequency of fissures is too low for any alternative and due to a very high hydraulic resistance. All displayed tubes $(A, B, C)$ propagate and connect as indicated in the multi-rank case. " $\mathrm{C}$ " captures most of the available runoff as it has the headward advantage and will therefore be expanded.

\section{Phreatic cave with multiple loops}

Given a higher fissure frequency a multipleloop phreatic cave system evolves. In this situation the piezometric surface is initially higher in the rock mass. Due to the propagation and enlargement of the network it lowers until it approximates with the top of the loops.

\section{Cave with mixture of phreatic and watertable-leveled components}

Highly fissured rocks and consequently diminished hydraulic pressure (low resistance) may create a cave with a mixture of phreatic loops and water table-leveled elements. Such systems are observed often along the strike or along major joints, display shallow loops along bedding planes and are linked by short horizontal sections.

\section{Ideal watertable cave}

The first cave stage is developed along horizontal passages and the fissure frequency is high. As a consequence direct routes may be excavated between the different inputs down the dip. The flow becomes absorbed due to further enlargement of these passages and the piezometric surface lowers down to the watertable.

The four stage scheme of speleogenesis represents an approximation and continuum, which means that individual caves often display more than one state at a given time. Also the fissure density evolves through time by the solutional enlargement of joints, which may lead to further changes in passage morphology.

Fissure frequency decreases remarkably as a function of depth in most limestone massifs, which allows for the development of a bathyphreatic cave system (initial low-frequency and increased 
density; stage 1) with deep loops. Along enlarged joints and fissures these may develop into multiple loops and connections of lesser amplitude, resulting into a transition of type 2 and 3 as the spring lowers by allogenic processes and the upper passages are abandoned. In the "end" a highly fissured massif, a cave with a mixture of watertable-leveled and phreatic passages may evolve (Figure ii - 4).

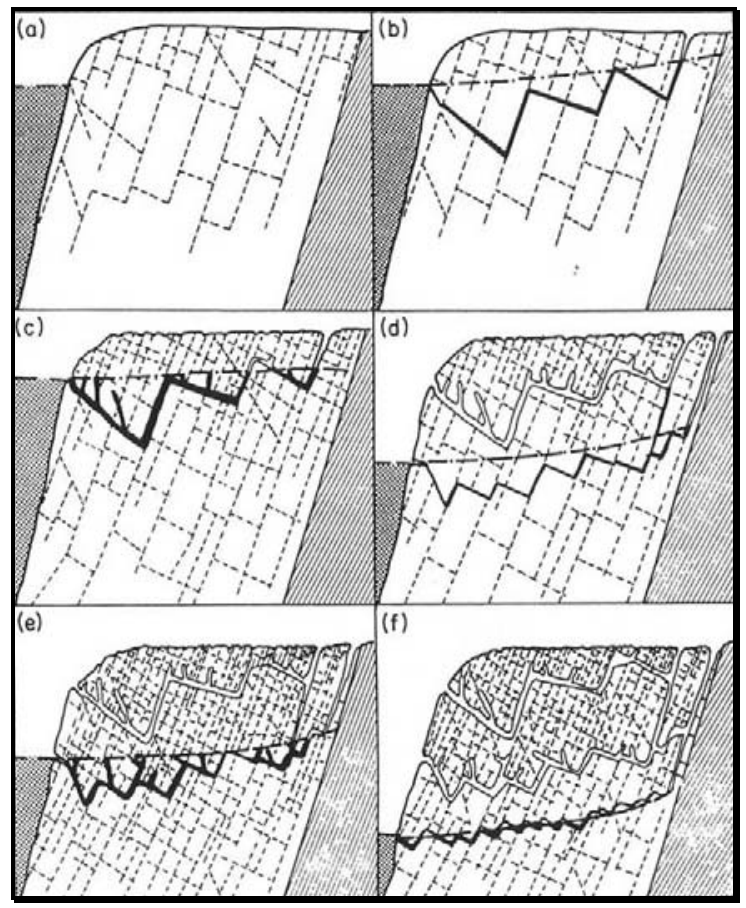

Figure ii - 4: The geometry of successive caves in a multiphase system is affected by the increase of fissure frequency over time (FORD and WILLIAMS 1989).

Until here the cave development under phreatic conditions has been summarized. The process of vadose cave origin may start when principal-tubes extend, connect, and enlarge. The reservoir capacity of the rock increases and the piezometric surface lowers until it becomes stabilized at some minimum gradient to the spring.

\section{ii - 3.3) Dissolution of limestones}

The principal process for the development of subterranean cavities is the well-known slow dissolution of calcite and/or dolomite in acidified water. Although organic and mineral acids may be very important in certain circumstances the main driving process is the carbonic acid, which is formed from dissolved carbon dioxide. The sequence of reactions is given below in Figure ii - 5. PICKNETT et al. (1976) demonstrated the effect of a continuous (open-system) and discontinuous (closed-system) delivery of carbon dioxide on limestone dissolution. With open-system conditions the $\mathrm{CO}_{2}(\mathrm{~g})$, the seepage water, and the limestone are in continuous contact. The closed-system conditions are characterized by a cut-off of $\mathrm{CO}_{2}(\mathrm{~g})$, hence leading to a non-replacement of $\mathrm{CO}_{2}$ (dissol.). In this case the amount of dissolved limestone is therefore diminished (see also next section iii). 

i. $\underline{\mathrm{CO}}_{2} \Leftrightarrow \mathrm{CO}_{2}$
(slow); diffusion of carbonic acid into water
(air) (dissol.)

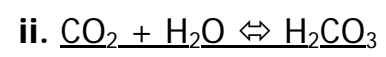 (dissol.)
iii. $\underline{\mathrm{H}}_{2} \underline{\mathrm{CO}}_{3} \Leftrightarrow \mathrm{H}^{ \pm}+\underline{\mathrm{HCO}}_{3}^{-} \quad$ (fast); dissociation of carbonic acid into hydrogen and hydrogen carbonate ions.
iv. $\underline{\mathrm{CaCO}}_{3} \Leftrightarrow \mathrm{Ca}^{2+}+\underline{\mathrm{CO}}_{3}^{2-} \quad$ (slow); dissociation of calcite crystal lattice to ions.
v. $\underline{\mathrm{H}}^{ \pm}+\mathrm{CO}_{3}{ }^{2-} \Leftrightarrow \mathrm{HCO}_{3}$
(fast); association of carbonate ions with hydrogen ions to form a hydrogen carbonate.

Figure ii - 5: Process equation and kinetics, dissolution of calcium carbonate (simplified, GILLIESON 1996).

Thus, seeping water contacting the limestone will finally reach saturation beyond which no more dissolution of the host rock will occur unless conditions change. Due to this, many processes in speleogenesis were inexplicable like the described widening of primary conduits at the onset of subterranean karstification under deep phreatic conditions, the timing and/or the extend of proto-tube propagation. BöGLI (e.g. 1964a and b, 1978) discovered and postulated the concept of "mixingcorrosion" based on the theoretical work of ERNST (1964). Mixing corrosion occurs when two bodies of saturated water in respect to calcite but different $\mathrm{pCO}_{2}$ (partial pressures of $\mathrm{CO}_{2}$ ) mix at e.g. tributary junctions in a cave or below the watertable in the phreatic zone. The new solution is undersaturated which leads to further dissolution of the limestone until equilibrium is achieved. As the origin of water from various inflow points (single or different rank) is the normal case in a limestone massif, the different $\mathrm{pCO}_{2}$ loads in the seeping waters is easily imaginable, especially where the water originates partly from bare Karst and respectively from areas covered by vegetation (Figure ii - 6).

Another process which might lead to dissociation even under deep phreatic and/or initial cave origin conditions was investigated by SVENSSON (1992): Solutions with saturation levels above $90 \%$ in respect to calcite display a very slow dissolution rate until its equilibrium is achieved. Therefore, the solution is able to cover longer distances in a limestone massif. The presence of ions like phosphate potentially contaminating the surface of calcite lattices seem to exert a major forcing on the slowing down of the dissolution since this effect was not monitored with "clean" artificial calcites under laboratory conditions. 


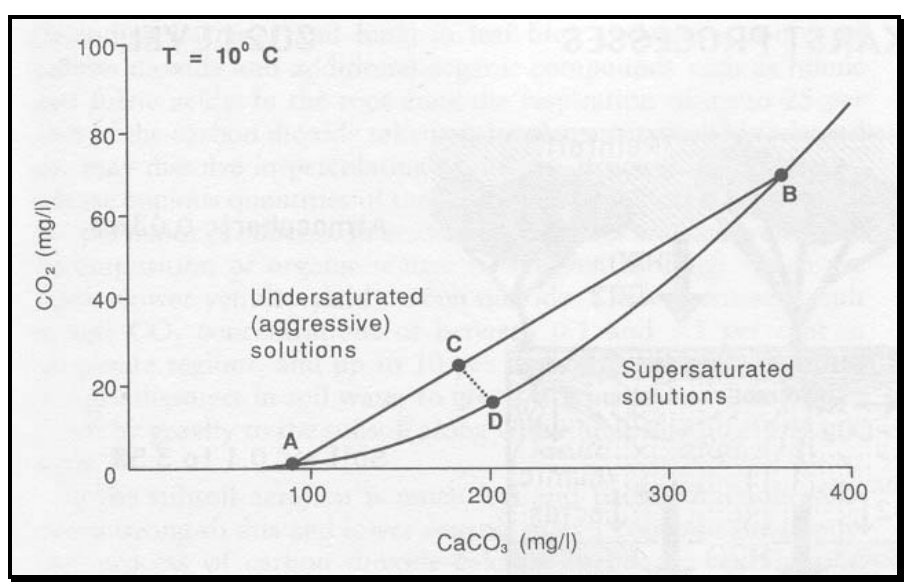

Figure ii - 6: The principle of mixing corrosion: The curve ADB shows the solubility of calcium carbonate with respect to dissolved $\mathrm{CO}_{2}$. Mixing of two saturated solutions $A$ and $B$ produces a solution $C$ that is undersaturated. Solution C will evolve to saturation along the line CD (GILLIESON 1996 and references herein).

\section{ii - 3.3.1) Sources of carbon dioxide}

The dominating force for the dissolution of most limestones is the carbonic acid, which is derived from dissolved carbon dioxide. The most important source for $\mathrm{CO}_{2}$ is the air of the atmosphere and of the pedogenic zone, with contents generally between 0.0034 and $0.1 \%$ of the total volume. This amount drops down with increasing altitude, in forests due to assimilation or in close contact with melting snow, limestone, and air (e.g. EK et al. 1969). The $\mathrm{CO}_{2}$ content in the air of the soil-zone exceeds that of the atmosphere with values between 10 and 100 times. This leads to soil-zone values of 0.1 and $3.5 \%$ in temperate regions and up to $10 \%$ in the tropics. The $\mathrm{CO}_{2}$ of the soil's air stems from bacterial decomposition of organic material in the soil and by root respiration (e.g. MIOTKE 1974).

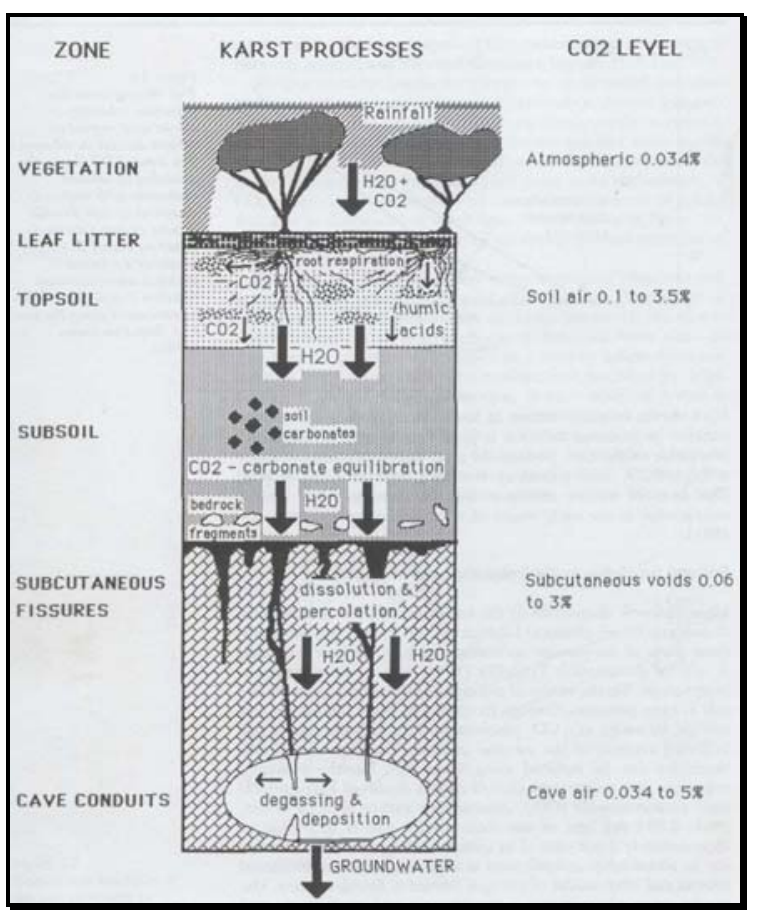

Figure ii - 7: Carbon dioxide pathways to the underground.

The way of $\mathrm{CO}_{2}$ through vegetation, soil and subcutaneous zones of the karst with provided range of $\mathrm{CO}_{2}$ concentrations in temperate ecosystems (GILLIESON 1996). 
Much of the gas dissolves in soil-water to give a weak acid that is carried down to the subsoil along with humic or fulvic acids. In this area the aeriation and the organic matter content decreases, leading to reduced bacterial action. In the subsoil and the lower subcutaneous/epikarst (below the soil zone, high porosity zone of weathered rocks) zones, high level erosional solution processes due to carbon dioxide-calcium carbonate equilibration take place (WILLIAMS 1983). From this point on the propagating dissolution is taking place by above mentioned processes and limitations (fissure control and hydraulic gradient, open- or closed-system, mixing corrosion, slow dissolution of nearly saturated solvents).

\section{Quintessence}

The main requirement for the genesis of huge cave systems is, apart from the existence of soluble host rocks, the abundance of interstices (fissures, joints, bedding planes, faults) along which seeping water can move according to the hydraulic gradient. The laminar waterflow in direction of the outlet is slow because of the high resistance of the plane(s). The growth and widening of conduits under (laminar) phreatic conditions is limited with the exception of joints due to mixing corrosion processes. It is here and/or after connection of the proto-pathways to the spring that a turbulent waterflow will take place which reinforces the growth of the proto-caves. This triggers the lowering of the piezometric surface and the higher loops of the foremost phreatic conduits, which might become vadose. This will later be enforced by a lowering of the spring. In normal meteoric water only $10 \mathrm{mg} / \mathrm{l}$ of a limestone is soluble, which is not enough for the development of huge cave systems. By processes of $\mathrm{CO}_{2}$ diffusion and hydration to $\mathrm{H}_{2} \mathrm{CO}_{3}$, a weak acid is provided which is the solvent in need to equilibrate to calcium carbonate while it got transported along the hydraulic gradient of a limestone massif.

Generally a cave system may have formed in a variety of ways at different times, and might best be regarded as a dynamic passing through a sequence of stages. 


\section{Cave I nterior Formations}

\section{Introduction}

Cave calcite-, spelean calcite-formations or speleothems comprise in addition to in situ breakdown materials and clastic cave sediments the group of cave interior formations. A speleothem ("spelaion"=cave, "thema"=deposit) is a "secondary mineral deposit formed in caves" (MOORE 1952) and is derived from cool water (or hot in geothermal settings) circulating the Karst. Generally speleothem-terms like "stalactite", "stalagmite" or "cave pearl" refer to the outer morphology and form whereas "cave mineral" is used for the mineral species of a deposit. Neither of the terms defines the growth mechanisms of speleothems or their genetic origin (HILL and FORTI 1986). Since in this thesis only calcite speleothem precipitates (and of these stalactites and stalagmites) are used as potentially archives for paleoclimate investigations, their origin is exclusively summarized here.

\section{iii - 1) Carbonate Deposition (and speleothem fabric control)}

The main processes by which carbonate formations are deposited are via $\mathrm{CO}_{2}$ degassing and by evaporation. The seeping water, characterized by a high pedogenically derived $\mathrm{pCO}_{2}$ (high dissolved $\mathrm{CO}_{2}$.load) enters the cave atmosphere with a relative low $\mathrm{pCO}_{2}$ almost reflecting surface atmosphere conditions (rarely more than the factor 10; EK et al. 1969).

Figure iii - 1: Evolution of supersaturated solutions. Closed-system vs. open-system conditions:

The chemical composition of the supersaturated solution feeding the speleothems depends on the $\mathrm{pCO}_{2}$ of the soil covering the cave and on the way the seeping water absorbs $\mathrm{CO}_{2}$. Whereas with closedsystem conditions (line " $A$ ") the pedosphere is essentially free of calcite the seeping rainwater attains equilibrium with $\mathrm{pCO}_{2}$ of the soil and starts dissolution of the bedrock until saturation. The dashed line gives the equilibrium concentration which will be approached by a solution in the cave atmosphere with $\mathrm{pCO}_{2}$ of $3 \times 10^{-4} \mathrm{~atm}$ and $\mathrm{T}=$ $10^{\circ} \mathrm{C}$. Below this line the feeding water " $A$ " remains aggressive towards calcite and might therefore be able to create dissolution features in the cave like karren or dissolution pockets at the rOof (DREYBRODT and FRANKE 1994).

Therefore the generation of supersaturated solutions and thus speleothem precipitation under closed-system conditions is only possible when the pedogenic $\mathrm{CO}_{2}$ exceeds $10^{-2} \mathrm{~atm}$. If calcite is abundant in the pedosphere, it will be dissolved up to saturation with respect to the soil- $\mathrm{CO}_{2}$ under open-system conditions (line " $\mathrm{C}$ "). The concentration of this solution is above the dashed line, supersaturations and speleothem forming conditions occurs, even for $\mathrm{pCO}_{2}$ as low as $5 \times 10^{-3} \mathrm{~atm}$ (DREYBRODT 1999). 


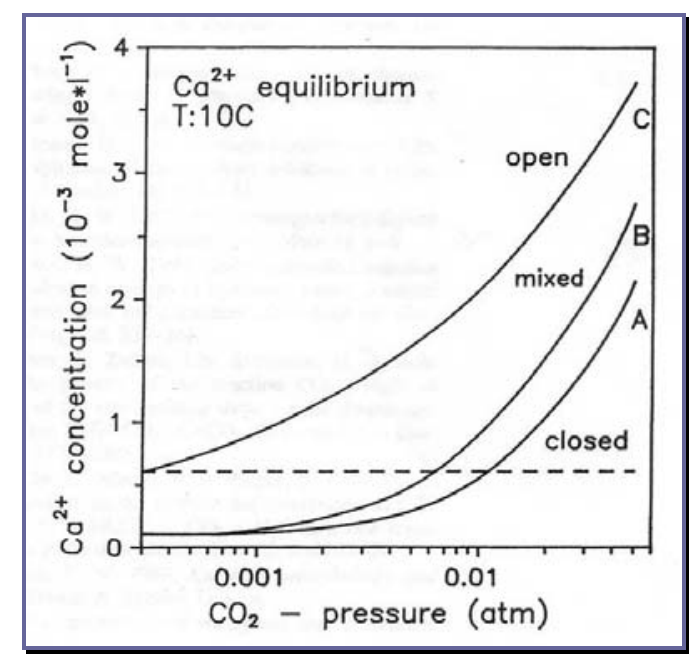

Being out of equilibrium with the cave environment, the $\mathrm{CO}_{2}$ of the seepage water will be lost from solution (Figure iii - 2). This raises saturation levels of the solution with respect to calcite/aragonite (or other minerals in solution) which will necessarily precipitate. The process of evaporation similarly may cause calcareous depositions by the subsequent enrichment of $\mathrm{CO}_{2}$ (and dissolved ions) of the seepage water thus promoting oversaturation and rapid precipitation of $\mathrm{CaCO}_{3}$. Since the most caves display in its deep interior a relative humidity above $95 \%$ and an annual constant temperature, degassing of $\mathrm{CO}_{2}$ without evaporative influences is considered to be the primary cause of cave carbonate deposition (WHITE 1976). Also given in comparatively limited situations, evaporative conditions are found in caves of arid regions and in central Europe usually near cave entrances or in seasonally dry caves (BögLI 1978, FORD and WILLIAMS 1989, LAURITZEN and LUNDBERG 1999). Those affected speleothems often seem to display microcrystalline, porous, and soft crystals. In contrast, a hard and comparatively "coarse" calcite is precipitated by slow degassing of $\mathrm{CO}_{2}$ from the parent solution and becomes predominant in humid cave interiors. Their c-axis is usually orientated in the direction of growth with columnar crystals, which are parallel or radiating slightly, often referred interchangeably to as "palisade patterns" (e.g. HILL and FORTI 1986). This is discussed in a series of publications and summarized by Railsback (http://www.gly.uga.edu.railsback/speleoatlas.html). They may coalesce laterally so that the entire speleothem forms a single crystal (Figure iii - 3). Usually, the start of most speleothem precipitations is as single aggregates of many individuals competing for space growing on common surfaces. The growth of crystals oriented perpendicular to the surface will then be favoured leading to a columnar fabric (ONAC 1997). Inclusions usually filled with fluids generate in spaces left between growing columns and are sealed by later depositions. 


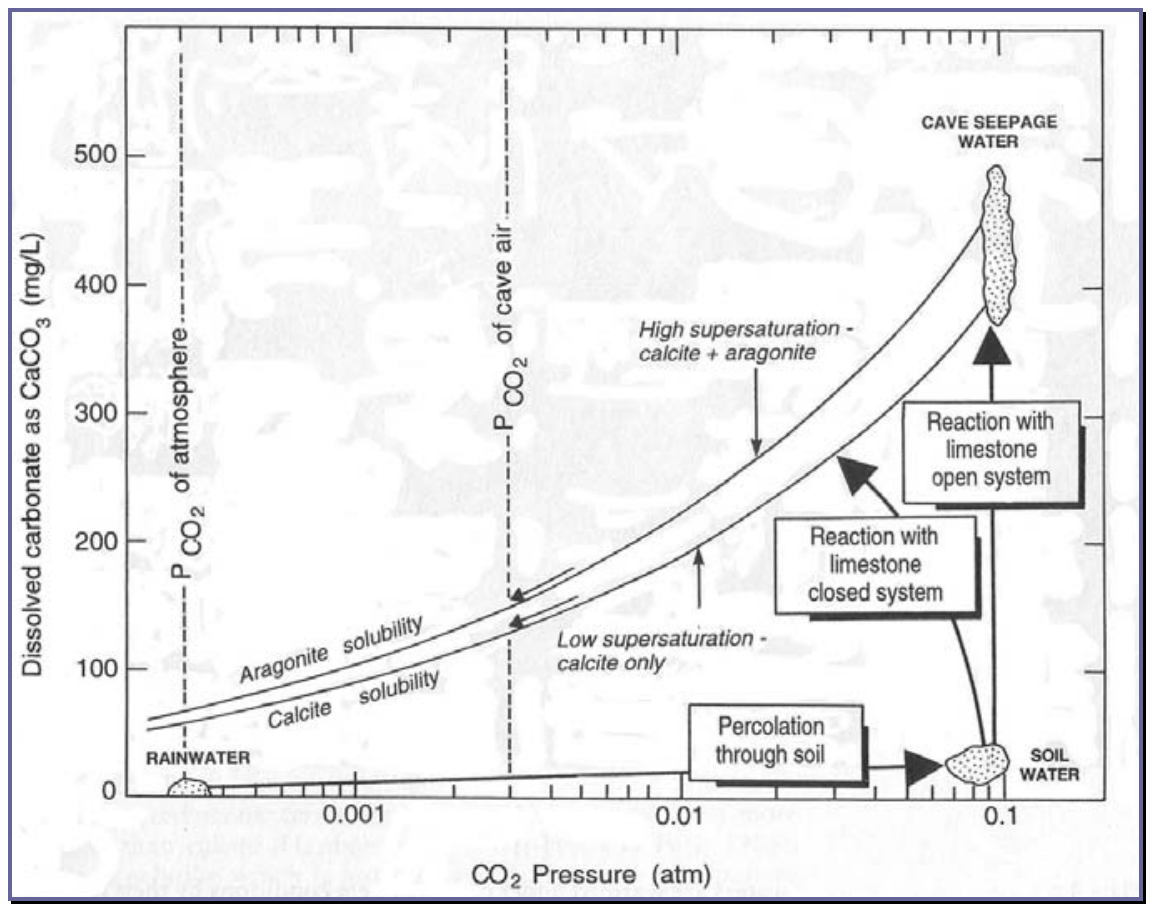

Figure iii - 2: Variations of $\mathrm{pCO}_{2}$ of the parent feeding water on the equilibrium solubility of cave calcite vs. aragonite precipitates. Supersaturated solutions deposited in conditions with a continuous $\mathrm{CO}_{2}$ supply (open-system) tend to produce calcite and aragonite depositions, while a limited $\mathrm{CO}_{2}$ uptake (closed-system) seem to promote calcite precipitations alone (WHITE 1988).

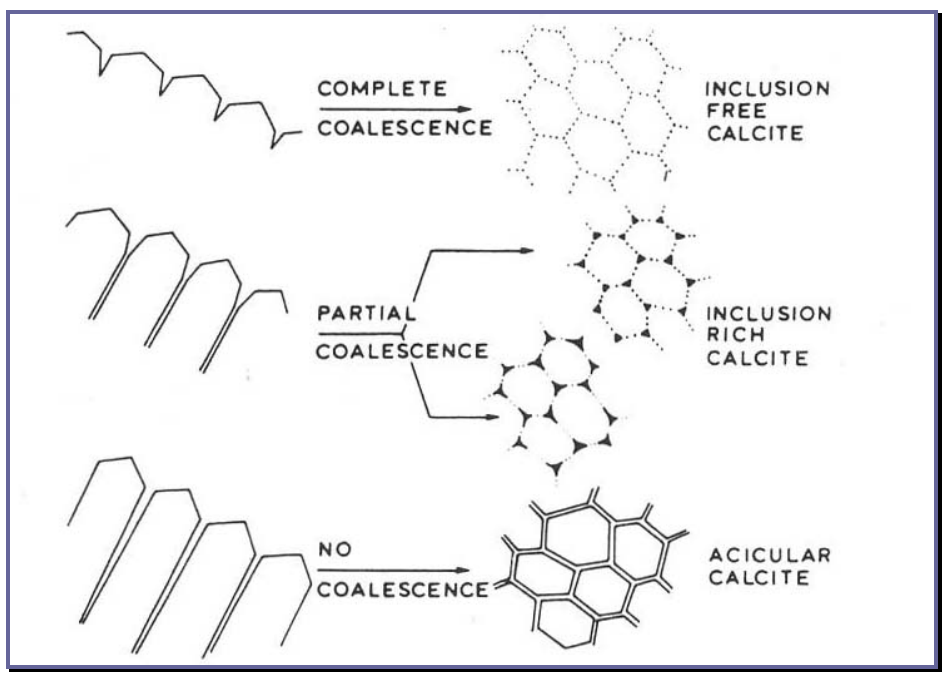

Figure iii - 3: Different patterns of the growth of columnar crystal calcites in speleothems and the development of inclusions (HILL and FORTI 1986).

Generally there seems to be no single dominant factor that controls the development of speleothem fabrics. In temperate Alpine and Irish caves FRISIA et al. (2000) mentioned different factors like driprate, level of supersaturation, impurity content, and possibly the $\mathrm{Mg} / \mathrm{Ca}$ ratio of the feeding water. These factors seemed to have a combining effect on the development of columnar, fibrous, 
microcrystalline, dendritic, and calcareous tufa fabrics in the investigated speleothems. In this study, the columnar and fibrous fabrics are associated with continuously wet environment, from fluids at near-equilibrium conditions (low supersaturation). Highly defective microcrystalline fabrics grow at the same level of supersaturation but under variable discharge of the feeders and the presence of growth inhibitors. The occurrence of dendritic fabrics with the highest density of crystal defects correlated with disequilibrium conditions (still high supersaturation) under periodic low-flow-regimes that may have resulted in prolonged outgassing.

Although more than 200 cave minerals are known (HILL and FORTI 1986), only calcite, aragonite, and gypsum are considered as common. Calcite is by far the most important cave mineral and is mostly composed of a low magnesium calcite containing < $4 \mathrm{~mol} \% \mathrm{MgCO}_{3}$ (WHITE 1976).

The occurrence of aragonite, calcites' orthorhombic polymorph was long underestimated for spelean minerals and is followed in the ranking by gypsum (GILLIESON 1996), whereas e.g. WHITE (1976) gave it an inverse estimation. As aragonite is more soluble than calcite (HILL and FORTI 1986, HARMON et al. 1983) a solution that is just saturated in respect to calcite is still aggressive to aragonite. With prevailing low temperature and pressure conditions of the cave's atmosphere, this solution will lead to calcite precipitation (PICKNETT et al. 1976). The existence of pre-existing calcite crystal surfaces promotes further calcite growth as it is best suited compared and in relation to "new" aragonite growth. The principal reasons given for aragonite growth include ion substitution or "poisoningeffects" by in sensu strictu foreign ions like $\mathrm{Sr}^{2+}, \mathrm{Mg}^{2+}, \mathrm{SO}_{4}{ }^{2-}$, organic and/or clay particles and/or rapid $\mathrm{CO}_{2}$ degassing/evaporation at high supersaturation levels (e.g. BISCHOFF and FYFE 1968, BISCHOFF 1968, Zeller and Wray 1956, Craig et al. 1984, White 1976, Hill and ForTI 1986, GonZalez and LOHMANN 1988). Open-system conditions seem to promote this, whereas maintained closed-system conditions seem to produce rather pure calcite precipitations (WHITE 1988).

Pure, impurity free calcite and aragonite speleothems have no intrinsic color at all and are usually translucent to colorless. Coloration occurs due to clastic intrusions, trace elements and organics like fulvic and humid substances (e.g. WhITE 1976, WhITE 1981, LAURITZEN et al. 1986). White to a milky tan and opaque colors are often referred to high density/frequency of fluid inclusions. In similitude to the potential fabric control on the evolution speleothems, the question on its color bears no single but often even contradictory answer: "Some of the contradiction in results may stem from the difficulty in distinguishing between color due to chromospheres (metal ions that are actually in solid solution in the lattices of minerals), that due to pigments (metals concentrated on grain boundaries of minerals), that due to organic stains" (HILL and FORTI 1986).

\section{iii - 2) Stalactites and Stalagmites}

The principal classifications of speleothem forms are given in table iii - 1 below. Out of a multitude of existing speleothem specimens, stalagmites and stalactites were subject of investigations in this study and thus their development and guiding constraints are summarized. 


\begin{tabular}{|l|l|l|}
\hline $\begin{array}{l}\text { 1. Dripstone and flowstone } \\
\text { forms: }\end{array}$ & 2. Erratic forms: & 3. Sub-aqueous forms \\
a) stalactites & a) shields & a) rimstone pools \\
b) stalagmites & b) helictites & b) concretions \\
c) draperies & c) botryoidally & c) pool deposits \\
d) flowstone sheets & forms & \\
& d) anthodites & d) crystal linings \\
\hline
\end{tabular}

Table iii - 1: The compromise listing of speleothem forms (WHITE 1976). Underlined forms are summarized below.

\section{iii - 2.1) Stalactites}

The fundamental forms for speleothems are soda straw stalactites (and draperies) and they are formed from drops before they fall from cave ceilings and walls. The degassing of single drops of seepage water produce a ring of calcite about $\sim 5 \mathrm{~mm}$ in diameter (CURL 1973) or 2-9 mm diameter following HILL and FORTI (1986). Curl's analysis shows that the diameter is related to the gravitational force on the pendant drop and the surface tension of the liquid through the dimensionless Bond number $\left(\mathrm{B}_{0}\right)$ by the relationship:

$$
\mathrm{B}_{0}=\frac{\rho \mathrm{gd}^{2}}{\sigma}
$$

Bond number $\left(\mathrm{B}_{0}\right) ; \rho=$ density of the solution; $\mathrm{g}=$ gravity; $\mathrm{d}=$ diameter of the straw; $\sigma=$ surface tension of the solution

The calcite ring grows downwards as a hollow tube (one ring below the other) made of a single crystal with its c-axis oriented down the straw (Figure iii - 4). Seepage of water occurs through grain boundaries and along cleavage cracks of the wall and leads to deposition on the outside and consequently to a gradual thickening of the soda straw. The central channel may become obstructed by crystal growth in the orifice or via introduction of foreign matter. This gradually forces the feeding water to percolate down the outer flanks of the soda straw. Thus, there will be a gradual transformation of the straw type to a more or less conical shaped style. A section cut perpendicular to the growth axis displays mostly a layering of alternating rings somewhat similar to growth rings on trees. C-axes orientation can be subparallel to the central channel, radiate from it, or being randomly distributed, depending on the driprate and constancy of deposition (Figure iii - 4, WHITE 1976). Maximum dimensions of stalactites are limited by the strength of attachment to the cave roof (and therefore on the strength of rock) and the dimension of the cavity itself. 


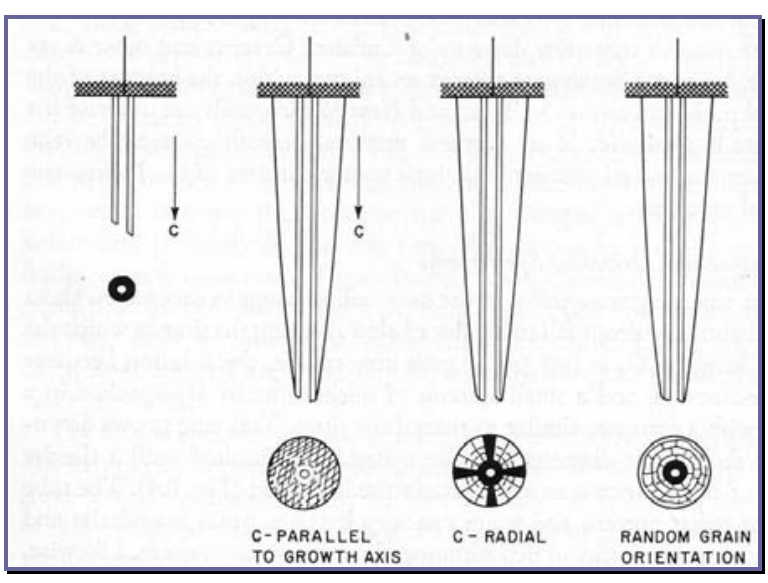

Figure iii - 4: The growth of soda straw stalactites depends on the rate and constancy of deposition. Without necessarily changing of the outer morphology a slow and constant calcite precipitation leads to an internally monocrystalline straw with the c-axis of calcite grains parallel to the axis orientation of the proto-straw, whereas faster and/or fluctuating growth conditions result in randomly orientated grains. (WHITE 1976).

\section{iii - 2.2) Stalagmites}

Drops that fall to the floor continue to deposit most of its calcite load and build up stalagmites (or flowstones) whose growth laminae thin away from the drop impact point. Much effort was carried out to correlate the outer stalagmite morphology to environmental conditions during calcite deposition: After WHITE (1976) constant driprates, water hardness and cave atmosphere promote uniform diameter stalagmites, while decreasing deposition rates result in conical forms. FRANKE (1961, 1963, $1965,1975)$ categorized the form of stalagmites and associated mode of origin into three groups. Uniform diameter stalagmites (1) with preferred new growth at the top (not down the outer flanks) are promoted by constant driprates, solute concentrations of the feedwater, and the cave atmosphere. The relation of the available amount of $\mathrm{CaCO}_{3}\left(\mathrm{C}_{0}\right)$, flow rate $(\mathrm{Q})$ and rate of vertical growth $(\dot{Z})$ may also be expressed as:

$$
\mathrm{D}=2 \frac{\mathrm{C}_{0} \mathrm{Q}}{\Pi \dot{Z}}
$$

The increase in diameter is proportional to the flow rate and drip fall height (CURL 1973, GAMS 1981). Periodic fluctuations in growth height and a greater fall distance leads to a greater splash at the drop impact point and are likely to produce stalagmites with terraced or corbelled thickening, forming e.g. palm tree trunks (2). The most common type is the conical or tapered form (3), attributed either to a decreasing growth rate (FRANKE 1961, 1965) or increasing fall height (GAMS 1981) which promotes increasing calcite precipitations from a waterfilm down the flanks with a smooth transition to the cave floor/flowstone sheets.

\section{iii - 3) Climate and speleothem deposition}

The elevated $\mathrm{CO}_{2}$ of the seepage is derived from high partial pressures of $\mathrm{CO}_{2}$ in the pedosphere (generated by microbial processes and root respiration, see above). This provides a climatic related signal because the soil- $\mathrm{CO}_{2}$ production is positive correlated to the prevailing surface temperature. Thus, $\mathrm{CO}_{2}$ concentrations and spelean calcite deposits (and travertine) are associated with warm periods. In cold climate regions like the arctic or in high alpine areas speleothem growth is seldom 
encountered since the lower pedogenic $\mathrm{CO}_{2}$ production (shorter growing season) either inhibits the speleothem growth completely or slows it down considerably (SOLOmon et al. 1987). In addition, growth may cease due to a lack in vadose recharge in times of permafrost or glacial advance (e.g. ATKINSON et al. 1986, GASCOYNE 1992, or GORDON et al. 1989). The very decreased speleothem deposition during glacial periods or colder stades is supported by some bulk growth frequency studies performed by e.g. HENNIG (1979), GASCOYNE (1992) BAKER et al. (1993).

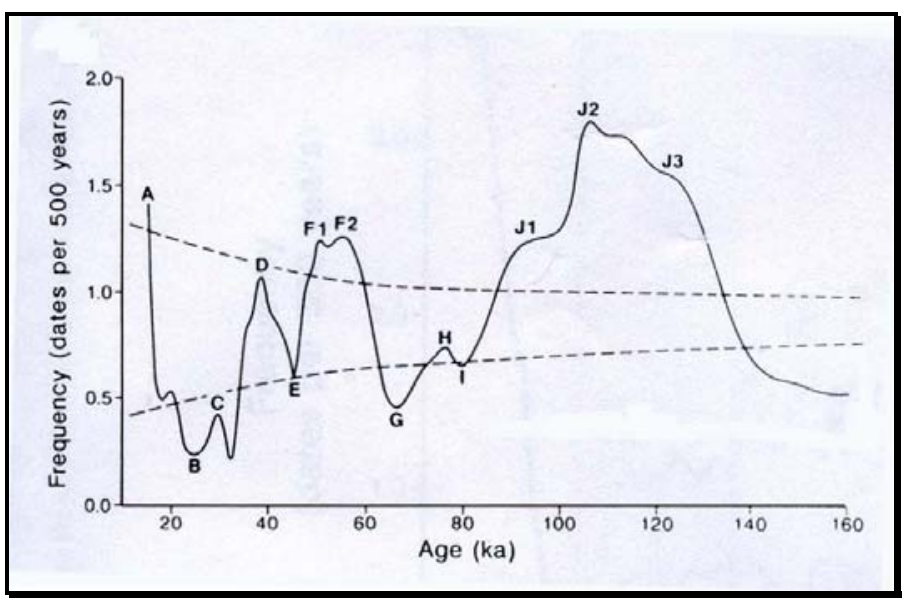

Figure iii - 5: Cumulative growth frequency distribution of 520 speleothem uranium series analyses from Northwest Europe (BAKER et al. 1993). $95 \%$ error bars generated from random data runs are represented by dashed lines. Above the lines high growth levels are indicated, thus below significantly low.

Thus, very high levels correlate in figure iii - 5 with the Holocene interglacial, the OIS (oxygen isotope stage, MaRTInson et al. 1987) events 3.13, 3.3 and 3.3.1 (peaks "D", "F1" and "F2") or with the OIS 5 ("J 12-"J 3") whereas the troughs indicate low growth frequencies occurring during colder isotope stages like the OIS 2.2 maxima (trough B). The significant low growth frequency " $E$ " does not correlate with any OIS event but does correlate with the cool and arid period in the Grand Pile pollen record (GUIOT et al. 1989).

\section{Quintessence}

Secondary spelean calcite depositions occur when seepage water with a high load of dissolved $\mathrm{CO}_{2}$, usually from the soil-zone enters the cave atmosphere with exceedingly low $\mathrm{pCO}_{2}$ environment. In need to equilibrate with the cave environment, $\mathrm{CO}_{2}$ will be lost from the solution by degassing, raises the saturation levels of the seepage water with respect to calcite or aragonite and consequently precipitates. Since the main criteria of this process is the $\mathrm{pCO}_{2}$ difference between the seepage solution and a given environment, other processes that promote supersaturations of the solution like occurring evaporation will have the same effect. The level of supersaturation may influence just like other factors e.g. being driprate, impurity content, the ratios of the typical calcite elements like $\mathrm{Mg}$, $\mathrm{Ba}, \mathrm{Sr}$, the presence of humic/fulvic acids of the dripwater the speleothem fabric and color. 
Nevertheless, geochemical criteria, mechanisms and/or interactions of the different factors are not fully understood at all and are widely discussed in the scientific community.

Since high $\mathrm{pCO}_{2}$ waters of soil-zone origin and vadose recharge are mandatory for the genesis of speleothems they are unlikely to form in regions overlain by, or peripheral to ice-sheets. In those regions, speleothem growth usually ceases due to one or more of the following reasons:

1. no soil-zone due to stripping away by glacial abrasion, 2 . there is no groundwater circulation and recharge because of the ice-sheet or permafrost, 3. soils may survive but vegetation is minimal, or 4 . the cave have been flooded due to obstructed/blockage of drainage by an ice-sheet or valley glacier. 


\section{W Stable isotopes of oxygen and carbon}

\section{iv - 1) Basics}

Stable isotopes (greek: iso=equal, topos=place) of a given element occupy the same position in the periodic table. They have the same number of protons $(Z)$ but a different number of neutrons $(N)$. Therefore, they are identical chemical elements but with different masses (mass number $A=Z+N$ ). The chemical element oxygen has three stable isotopes, ${ }^{16} \mathrm{O},{ }^{17} \mathrm{O}$ and ${ }^{18} \mathrm{O}$, with abundances of 99.76 , 0.035 and $0.2 \%$, respectively (NIER 1950). Carbon counts two stable isotopes, ${ }^{12} \mathrm{C}$ and ${ }^{13} \mathrm{C}$. Usually the two most naturally abundant isotopes are measured, that is for oxygen the ratio of ${ }^{18} \mathrm{O}$ (terrestrial abundance of $0.204 \%$ ) to common ${ }^{16} \mathrm{O}(99.796 \%)$ that is 0.00204 .

\section{iv - 1.1) Fractionations, fractionation factor and delta value}

Due to the varying masses of the isotopes, associated molecules will have different reaction rates, which leads to diverging physical/chemical behavior. These differences are called isotope effects and are the result of quantum mechanical effects (e.g. Hoefs 1997). Molecules with different isotopes of a given element in equivalent positions also have varying energies because of differences in the vibrational components that are again mass-dependent. The energy of a molecule decreases with decreasing temperature and at absolute zero a finite value called the "zero-point energy" is assumed, which is greater than the minimum value by $1 / 2 h v$, where " $h$ " is the Planck's constant and " $v$ " the vibrational frequency. The vibrational energy of a molecule is inversely proportional to the square root of its mass. Therefore, molecules containing light isotopes have a higher vibrational energy and hence a higher zero-point energy than similar molecules with heavy isotopes. A consequence is that bounds between light isotopes are weaker, which means that these molecules are more reactive than bounds between heavy isotopes. Light isotopes will preferably concentrate in the less condensed phase of a given system, like in the gaseous phase compared to the liquid phase or in the liquid phase compared to the solid phase.

Thus, each physical (e.g. evaporation) or chemical (e.g. calcite precipitation) process will change the isotopic ratios and is called partitioning or fractionation (UREY 1947).

\section{Equilibrium isotope fractionation or isotope exchange}

are comparable to chemical equilibrium reactions and occur in isotopic equilibrium, e.g. in equilibrium calcite crystallization in water:

$$
\frac{1}{2} \mathrm{C}^{16} \mathrm{O}_{2}+\mathrm{H}_{2}{ }^{18} \mathrm{O} \Leftrightarrow \frac{1}{2} \mathrm{C}^{18} \mathrm{O}_{2}+\mathrm{H}_{2}{ }^{16} \mathrm{O}
$$




\section{Fractionation by kinetic processes}

Kinetic fractionation depends primarily on differences in reaction rates of isotopic molecules and is associated with incomplete and unidirectional processes such as evaporation, dissociation, diffusion, and biologically mediated reactions like photosynthesis. Kinetic processes will influence all chemical reactions not occurring in isotopic equilibrium.

The fractionation factor a between the two chemical compounds $A$ and $B$ is defined as the ratio of the isotopic ratios of each compound:

$\alpha_{A-B}=R_{A} / R_{B} ; R_{A}=\left({ }^{18} O /{ }^{16} O\right)$ and $R_{B}=\left({ }^{18} \mathrm{O} /{ }^{16} \mathrm{O}\right)$

Since fractionation processes range in minor variations in isotope concentrations, $\delta$-values as a fractional change in the ${ }^{18} \mathrm{O} /{ }^{16} \mathrm{O}$ ratio are usually expressed as permil difference from some reference.

$\delta^{18} \mathrm{O}_{\text {sample }}(\% 0)=\left(\frac{\mathrm{R}_{\text {sample }}-\mathrm{R}_{\text {ref }}}{\mathrm{R}_{\text {ref }}}\right) * 10^{3}$

whereas $R_{\text {ref }}$ is the isotopic ratio of a used reference.

If the ${ }^{18} \mathrm{O}$ content of the sample is higher than in the reference, meaning the sample is isotopically "heavier", $R_{\text {sample }}=\left({ }^{18} \mathrm{O} /{ }^{16} \mathrm{O}\right)$ will be larger than $\mathrm{R}_{\text {ref }}$ resulting in a positive $\delta^{18} \mathrm{O}_{\text {sample. }}$. Whereas $\delta^{18} \mathrm{O}_{\text {sample }}$ will be negative, if the sample is isotopically "lighter" than the reference. Therefore, the less the sample contains ${ }^{18} \mathrm{O}$, the smaller its ${ }^{18} \mathrm{O} /{ }^{16} \mathrm{O}$ and the smaller its $\delta^{18} \mathrm{O}$.

For differences in delta-values of less than twenty there exists a relation between the fractionation factor and the delta values of the involved components (FRIEDMANN and O'NEIL 1977).

$\Delta_{A-B}=\delta_{A}-\delta_{B} \cong 1000 \ln \alpha_{A-B}$

Of practical use is the approximate rule $\Delta_{A-B}=\delta_{A}-\delta_{B} \cong 1000(\alpha-1)$

For measurements in water, the reference "Vienna Standard Mean Ocean Water" (VSMOW), and "Vienna Pee Dee Belemnite" (VPDB) for carbonates are reported to. A conversion might be necessary when deriving information about the $\delta^{18} \mathrm{O}$ content of the water in which a carbonate was precipitated:

$\delta^{18} \mathrm{O}_{\text {VSMOW }}=1.03091 * \delta^{18} \mathrm{O}_{\text {VPDB }}+30.91$

$\delta^{18} O_{\text {VPDB }}=0.97002 * \delta^{18} O_{\text {VSMOW }}-29.98$

(Coplen et al. 1983) 


\section{iv - 2) Stable oxygen and carbon isotopes in speleothems}

\section{iv - 2.1) Oxygen}

The oxygen isotope composition of an in equilibrium precipitated speleothem $\left(\delta^{18} \mathrm{O}_{c}\right)$ is controlled by (i) the (cave-) temperature dependant fractionation between the precipitated cave calcite and its feeding solution and the (ii) initial $\delta^{18} \mathrm{O}$ values of the dripping water.

Isotopic equilibrium conditions during speleothem deposition can be tested with the so-called "HendyTest" (HENDY 1971) that compares measurements of $\delta^{18} O_{C}$ and $\delta^{13} C_{c}$ along a single growth layer. If kinetic fractionation like non-isotopic equilibrium occurred during precipitation, stable oxygen and carbon isotopes would change simultaneously as the water film ran off the sides of the stalagmite. If calcite precipitation occurred under isotopic equilibrium conditions, $\delta^{18} \mathrm{O}_{\mathrm{c}}$ would largely remain constant, while $\delta^{13} \mathrm{C}_{\mathrm{c}}$ would change progressively due to reservoir effects. Therefore, characteristic features of equilibrium conditions are insignificant changes of $\delta^{18} \mathrm{O}_{\mathrm{c}}$ along the growth layer and no correlation with the $\delta^{13} C_{C}$ of the same layer (GASCOYNE 1992). If kinetic processes are indicated, the speleothem is not suitable for paleoclimatic studies.

\section{iv - 2.2) The cave temperature effect}

The expression "cave temperature effect" refers to the fact that the equilibrium oxygen isotope fractionation during calcite precipitation is a function of the reaction temperature, which is the ambient cave temperature. The temperature of the feeding dripwater from which the calcite is precipitated equals the cave air temperature (in natural caves). The latter ranges close to the mean annual temperature outside the cave. Variations are less than $1^{\circ} \mathrm{C}$ with the varying seasons (WIGLEY and Brown 1976), tying potential $\delta^{18} \mathrm{O}_{\mathrm{C}}$ shifts of a speleothem only to long-term changes of the overall global climate.

KIM and O'NEIL (1997) calculated the fractionation factor at the water-calcite interface being 1.02846 for a temperature range between $10-40^{\circ} \mathrm{C}$ which increases by $0.00022(0.22 \%)$ per $1^{\circ} \mathrm{C}$ temperature decrease between $10-25^{\circ} \mathrm{C}$. Further values obtained for the oxygen isotopic fractionation out of a precipitating solution are given in Appendix iv - 1.

Vice versa an increase of the cave air and water temperature of $(+) 1^{\circ} \mathrm{C}$ will decrease the fractionation factor and speleothem $\delta^{18} \mathrm{O}_{C}$ by approximately (-) $0.22 \%$, less ${ }^{18} \mathrm{O}$ will be incorporated in the calcite.

\section{iv - 2.3) The dripwater function}

The second basic principle on which the use of speleothem stable oxygen isotopes rely is the observation that the $\delta^{18} \mathrm{O}$ content of the cave dripwater is almost constant throughout the year and approximates the mean annual meteoric precipitation at the surface. Weak seasonal variations in cave 
dripwaters range around $1 \%$ and follow the meteoric waterline (SCHWARCZ et al. 1976, YONGE et al. 1985, CABALLERO et al. 1996).

The spatial and temporal $\delta^{18} \mathrm{O}$ variations of the present meteoric precipitation are the result of cumulative effects, affecting the stable oxygen isotope composition beginning from the oceanic source zones to the rain-out at the site. In a first step the course of the vapor masses and its potential fractionations along the global meteoric cycle are outlined. In a second step the master variable "time" is considered, meaning how long-term changes driven by glacial/interglacial fluctuations influence changes of the "initial" $\delta^{18} O$ ratio of the vapor source and its implications on the $\delta^{18} O$ values of a speleothem:

The evolution of the $\delta^{18} \mathrm{O}$ (and $\delta^{2} \mathrm{H}$ ) composition of meteoric waters begins with the evaporation from the oceans. As the saturation vapor pressure of $\mathrm{H}_{2}{ }^{16} \mathrm{O}$ is higher than that of the $\mathrm{H}_{2}{ }^{18} \mathrm{O}$-molecule, the latter tends to move more slowly and keeps to the more condensated phase. Therefore, molecules of the water with the lighter isotope $\left({ }^{16} \mathrm{O}\right)$ evaporate more quickly and leave more of the heavy isotope behind in the ocean (or lake), relatively enriching the remaining ocean water with ${ }^{18} \mathrm{O}$ (e.g. CRAIG and GORDON 1965). Condensation is assumed to take place under equilibrium conditions with the ambient water-vapor followed by immediate or progressive rain-out. The evaporation-condensation processes of the meteoric cycle may be modeled following a Rayleigh distillation approach (DANSGAARD 1964, GAT 1996). Actual ocean water has by definition a $\delta^{18} \mathrm{O}$ value of $0 \%$ VSMOW, therefore assigning the corresponding water vapor and associated rain a negative $\delta^{18} \mathrm{O}$ value (as a lack of ${ }^{18} \mathrm{O}$ ). Since a corresponding difference in vapor pressure exists between $\mathrm{H}_{2} \mathrm{O}$ and $\mathrm{HDO}$ on the one hand and between $\mathrm{H}_{2}{ }^{16} \mathrm{O}$ and $\mathrm{H}_{2}{ }^{18} \mathrm{O}$ on the other hand, hydrogen and oxygen isotopic distribution patterns are correlated in all processes concerning evaporation and condensation (DANSGAARD 1964). Their relationship expressed as $\delta^{2} \mathrm{H}=8{ }^{18} \mathrm{O}+10 \%$ (VSMOW) for freshwaters including meteoric precipitation is known as the Global Meteoric Waterline (GMWL) and was first introduced by CRAIG (1961b). The slope (s) $=8$ is the ratio between the equilibrium isotope fractionations of hydrogen and oxygen for the rain condensation process; $+10 \%$ (d) is referred to as the deuterium excess ( $d$ excess), the intercept with the $\delta^{2} \mathrm{H}$ axis. The concept of deuterium excess $\mathrm{d}$ may be defined as $\mathrm{d}=$ $\delta^{2} \mathrm{H}-8 \delta^{18} \mathrm{O}$ (GAT 1996). A more precise regressionline due to a higher resolution of weather stations ( $n=219$ ) was established by ROZANSKI et al. (1993) in the course of the Global Network of I sotopes in Precipitation (GNIP) program by the IAEA (International Atomic Energy Agency) and the WMO (World Meteorological Organization) yielding: $\delta^{2} H=8.17( \pm 0.07){ }^{18} \mathrm{O}+11.27( \pm 0.65) \%$ VSMOW. Any given locality will have a characteristic local meteoric waterline (LMWL) that will vary from the global numerical coefficient 8 and/or the deuterium excess (Figure iv - 1). For example the Vienna IAEA station monitored a LMWL which is $\delta^{2} \mathrm{H}=7.07 \delta^{18} \mathrm{O}-1.38 \%$ (RoZANSKI et al. 1993). However, because it is not always possible to monitor meteoric precipitation over a representative period of time (at least 3 years) meteoric waterlines are usually inferred from the closest available monitoring station. 


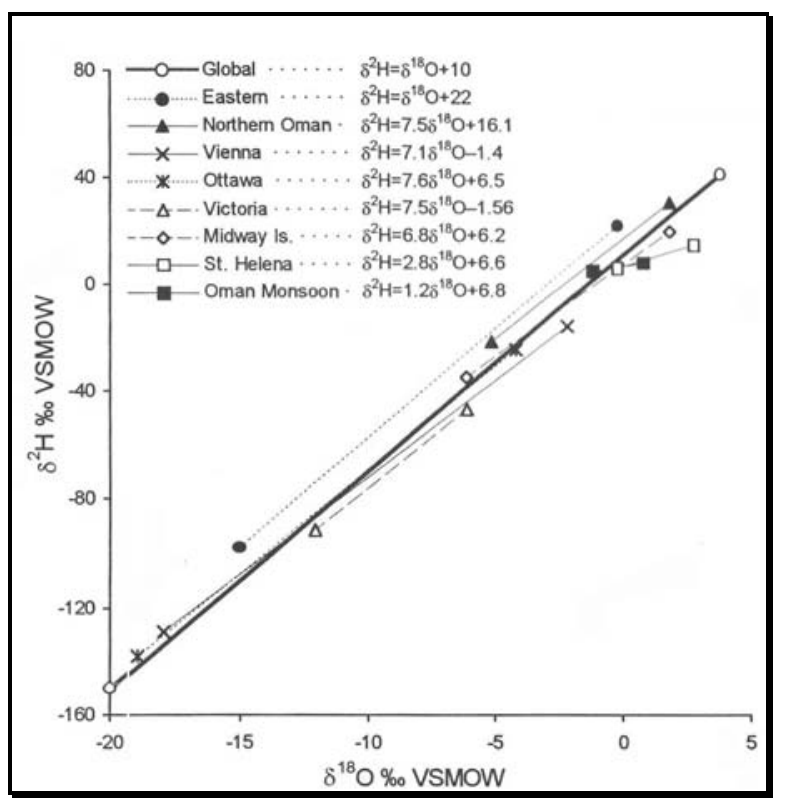

Figure iv - 1: Regional/local meteoric waterlines from various weather stations and the GMLW (CLARK and FRITZ 1997 and references herein).

The ${ }^{18} \mathrm{O}$ concentration of the ocean's surface layers ranges between +0.5 and $-0.5 \%$ (EPSTEIN 1956) with deviations given in the tropics and the Polar Regions. Since the former displays more positive values because of strong evaporation effects, the latter produces more negative values as a consequence of the input of isotopically lighter water derived from the melting of snow and ice. KROOPNICK and CRAIG (1972) cite a rather constant $\delta^{18} \mathrm{O}$ value of the global atmospheric oxygen with $+23.5 \%$ (VSMOW). This ${ }^{18} \mathrm{O}$ enrichment in relation to the mean ocean standard water indicates that the atmospheric oxygen is not in equilibrium with the hydrosphere. This so-called "Dole" effect is probably caused by isotope fractionation during photosynthesis/respiration like the preferred removal of the lighter ${ }^{16} \mathrm{O}$ during respiration (BENDER et al. 1994). The atmospheric $\mathrm{CO}_{2}$ is in approximate equilibrium with the ocean water ( $0 \%$ VSMOW) but not with the atmospheric oxygen and yields a global $\delta^{18} \mathrm{O}$ value of $+41 \%$ (VSMOW).

The following transport of the evaporated vapor masses towards the poles is accompanied by gradual rain-outs and thus a depletion of the remaining vapor/moisture in ${ }^{18} \mathrm{O}$ (and ${ }^{2} \mathrm{H}$ ). ROZANSKI et al. (1993) gives an estimation for this latitude effect of $-0.18 \%$ /latitudinal degree for the Northern Hemisphere. The same occurs in regions with an elevated topography where the rain-out is driven by adiabatically cooling of the clouds as they rise over the landscape. This altitude effect for mid-latitudes is ca. -0.15 to $-0.30 \% / 100 \mathrm{~m}$. Landmasses have the effect of forcing rain-out from vapor masses as the clouds move inland from the coast, leaving coastal precipitations isotopically enriched while the colder inner continental regions receive isotopically depleted precipitation (with strong seasonal differences). Increasing continentality shows a progressive ${ }^{18} \mathrm{O}$ removal and thus depletion of about $2.0 \% / 1000 \mathrm{~km}$. This is called the continental effect or distance from coast effect. The most depleted rain-out is measured at the poles with $\delta^{18} \mathrm{O}$ ratios of $-40 \%$ VSMOW $\left(\delta^{2} \mathrm{H} \sim 90 \%\right.$ VSMOW $)$. 
Seasonality of the $\delta^{18} \mathrm{O}$ in meteoric precipitation is controlled either by seasonal changes of the temperature or the rainfall amount. In lower latitudes the $\delta^{18} \mathrm{O}$ ratio of the precipitation is mainly controlled by the amount-effect with more negative $\delta^{18} \mathrm{O}$ values during the rainy season, monsoon, or heavy rains. During heavy rainfalls, the water droplets only partially exchange with the surrounding air, thus preserving the low $\delta^{18} \mathrm{O}$ isotopic composition from within the clouds.

This effect dominates especially at tropical marine stations with a strong seasonally monsoon precipitation. For the mid to high latitudes the $\delta^{18} \mathrm{O}$ of the precipitation are mainly correlated to temperature. Since the temperature is linked with air humidity, it controls the degree of rain-out from vapor masses during its transport to the poles. The dependence of the $\delta^{18} \mathrm{O}$ of the precipitation with the air surface temperature (at the clouds base) occurs because of the rapid equilibration of the raindrops with the ambient air (e.g. GAT 1996, ROZANSKI et al. 1993).

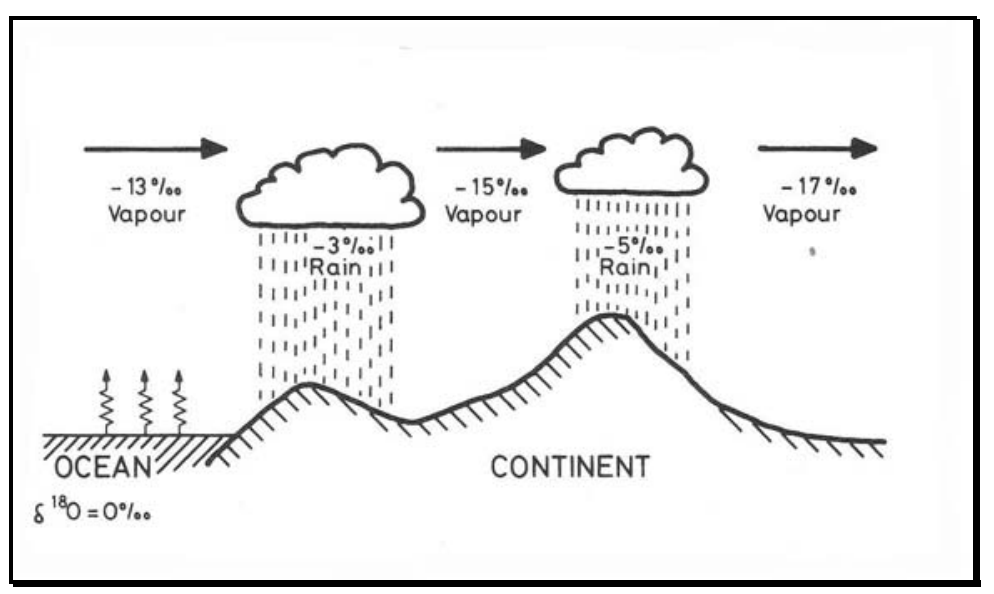

Figure iv - 2: Schematic oxygen isotope fractionation of water in the atmosphere (HOEFS 1997 and references herein).

Long-term changes in the isotopic composition of meteoric precipitation and the surface-air temperature correlate with each other revealing an average of $d \delta^{18} \mathrm{O}_{\text {precip }} / \mathrm{dT}$ ratio of $+0.58 \%{ }^{\circ} /{ }^{\circ} \mathrm{C}$ for non-polar sites (ROZANSKI et al. 1993).

The $\delta^{18} \mathrm{O}$ values of the monthly meteoric precipitation of Germany are mainly controlled by temperature. The GNIP database (IAEA 2001) displays for the period from 1961 to 1999 summertime values between -5 to $-8 \%$ (VSMOW) and for the wintertime -8 to $-14 \%$ (VSMOW). The amount weighted annual $\delta^{18} \mathrm{O}$ in precipitation ranges between -8 to $-11 \%$ (VSMOW). Seasonal changes are also strongly controlled by seasonal changes in the source zones and air-circulation pattern. Major forcing is thereby the North Atlantic Oscillation (NAO), which refers to variations in the atmospheric sea level pressure difference between the Azores High and the Iceland Low and dominates the air temperature and amount of precipitation over large areas of the Northern Hemisphere during the winter (HURREL and VAN LOON 1997). Positive winter values of the NAO index correspond to a strong 
meridional pressure gradient that results in the strong westerly winds, transporting warm, moist maritime vapor masses across Europe, giving rise to warm and wet winters. Vice versa low NAO index values imply weak Westerlies and therefore cold and dry winters in Europe (SLONOSKY et al. 2001).

The incoming meteoric precipitation on the ground is intercepted on the canopy of the vegetation cover and is partly lost by evaporation, leading to an enrichment of the heavy isotopes of the remaining water on the leaves. A further rain shower may flush these enriched residuals to the ground. Infiltration of this water should produce a positive bias in the $\delta^{18} O$ content of the groundwater. However, preferentially the less intense parts of the rain showers are lost by evaporation. Since these usually comprise the isotopically most enriched part of the rain (DANSGAARD 1964), this selection process neutralizes the former enrichment due to the evaporation process (GAT 1996). Since the uptake of soil water through the roots does not seem to fractionate the stable oxygen isotopes, changes in vegetation will not directly influence the $\delta^{18} \mathrm{O}$ of the soil water. Nevertheless, a dense vegetation cover may be the cause of a bias to winter precipitation $\delta^{18} \mathrm{O}$ values in the groundwater due to a reduction in summer recharge as a consequence of a higher degree of evapotranspiration (YONGE et al. 1985). Generally, a less developed plant cover enhances a larger kinetic signal due to evaporation during water runoff prior to infiltration. As an extreme, desert soils display isotopic enrichments of ${ }^{18} \mathrm{O}$ in excess of $10 \%$ relative to the precipitation found (MATHIEU and BARIAC 1996, GAT 1996).

Figure iv - 3: Fusion of the cave temperature effect and the dripwater function.

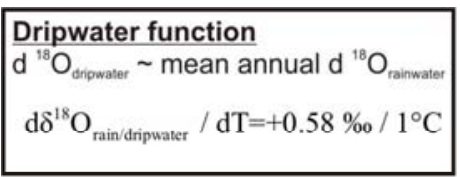

Theoretically, for an in isotopic equilibrium precipitated speleothem, an increase of $1^{\circ} \mathrm{C}$ will lead to an increase of the $\delta^{18} \mathrm{O}_{\text {speleothem }}$ of $+0.36 \%(0.58 \%-0.22 \%)$ : $d \delta^{18} O_{\text {speleothem }} / d T=+0.36 \% /{ }^{\circ} \mathrm{C}$.

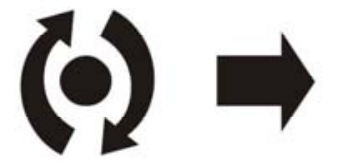

Fusion

$\mathrm{d} \delta^{18} \mathrm{O}$ $/ \mathrm{dT}=+0.36 \% / 1^{\circ} \mathrm{C}$
Cave temperature effect

cave $\mathrm{T}=$ mean annual surface $\mathrm{T}$ dripwater $\mathrm{T}=$ cave $\mathrm{T}$

fractionation calcite - water $=f(T)$ $\mathrm{d} \delta^{18} \mathrm{O}_{\mathrm{c}} / \mathrm{dT}=-0.22 \% \mathrm{o} / 1^{\circ} \mathrm{C}$ 


\section{iv - 2.3.1) Time}

Modeling the above outlined isotopic effects leading to (past) speleothem $\delta^{18} \mathrm{O}_{\mathrm{c}}$ variations, the influence of the mastervariable "time" has to be established. "Time" is used in the sense of a superimposed expression for global and/or regional causes leading to the evolution of the $\delta^{18} O_{\mathrm{c}}$ signal of the monitored speleothem.

For the study on speleothems a rather constant latitude, altitude and continental effect on the stable oxygen isotopic composition of rainwater may be assumed. But nevertheless, the evolution of the $\delta^{18} \mathrm{O}$ composition of the ocean source water through the Last Glacial Maximum (LGM) and Holocene due to a reduction of the ice-volume is superimposed on these temperature-dependant $\delta^{18} O$ changes of the local meteoric precipitation. This "ice-volume effect" is responsible for the Glacial/Interglacial changes observed in marine isotope records. Due to the lower glacial temperatures the relative amount of ${ }^{18} \mathrm{O}$ moving into the vapor at the source zones is comparatively low. Since most of the ${ }^{18} \mathrm{O}$ molecules remain in the ocean water, the resulting $\delta^{18} \mathrm{O}$ signal preserved in icecore profiles displays more negative/lighter values. Vice versa, warmer periods are indicated by heavier (less negative) $\delta^{18} O$ ratios. Deep ocean sediments therefore reveal an inverse signal.

At the LGM the ocean water has been calculated of being 1.2-1.8 \%o heavier than today (SHACKLETON and Opdyke 1973, Fairbanks 1989, Crowley and NORTH 1991). The proceeding deglacial sea level rise occurs in two steps or meltwater pulses (mwp), each of them yielding a rapid $25 \mathrm{~m}$ increase. The mwp's were radiocarbon dated at $12{ }^{14} \mathrm{C}$ ka BP and $9.5{ }^{14} \mathrm{C}$ ka BP. However, the ice-volume effect seems to be negligible for most of the Holocene but has to be taken into account for the (Last) Glacial period (FAIRBANKS 1989).

Given a MAAT of $8.8^{\circ} \mathrm{C}$ and a mean $\delta^{18} \mathrm{O}$ of $-8.64 \%$ VSMOW (24 stations, stacked period 1978-2000; IAEA 2001) German Holocene speleothems are modeled to display a $\delta^{18} O_{C}$ of ca. $-7.3 \%$ VPDB:

(i) At $25^{\circ} \mathrm{C}$ a calcite precipitated in isotopic equilibrium out of a hypothetical water with $0 \%$ VSMOW should display a stable oxygen isotope value of $28.46 \%$ VSMOW $\left(\delta^{18} \mathrm{O}_{\mathrm{C}}-\delta^{18} \mathrm{O}_{\text {precip. }} \approx 1000(\alpha-1)\right.$; $\alpha(0)_{\text {H2O-CaCO3 }}=1.02846\left(\right.$ at $\left.25^{\circ} \mathrm{C}\right)$ or $-2.37 \%$ VPDB $\left(\delta^{18} \mathrm{O}_{\mathrm{VPDB}}=0.97002 * \delta^{18} \mathrm{O}_{\mathrm{VSMOW}}-29.98\right)$.

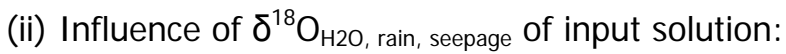

Keeping the temperature constant and lowering the input $\delta^{18} \mathrm{O}$ signal to lighter values, like $-8.64 \%$ VSMOW, which is roughly the mean annual value for Germany, the resulting $\delta^{18} \mathrm{O}_{\mathrm{c}}$ of the speleothem would be $19.82 \%$ VSMOW (-10.74 \%o VPDB).

(iii) Influence of temperature:

The fractionation is temperature dependant and increases with decreasing temperature. As outlined above, the $\delta^{18} \mathrm{O}_{\mathrm{c}}$ diminishes of ca. $-0.22 \%$ per $1^{\circ} \mathrm{C}$ increase $\left(\mathrm{d} \delta^{18} \mathrm{O}_{\mathrm{c}} / \mathrm{dT}=-0.22 \% \mathrm{oo} / 1^{\circ} \mathrm{C}\right)$. Thus, a 
calcite precipitated from a water with $0 \%$ VSMOW at $8.8^{\circ} \mathrm{C}$ (MAAT Germany) will display a $\delta^{18} \mathrm{O}_{\mathrm{C}}$ of $32.02 \%$ VSMOW (1.08\% VPDB).

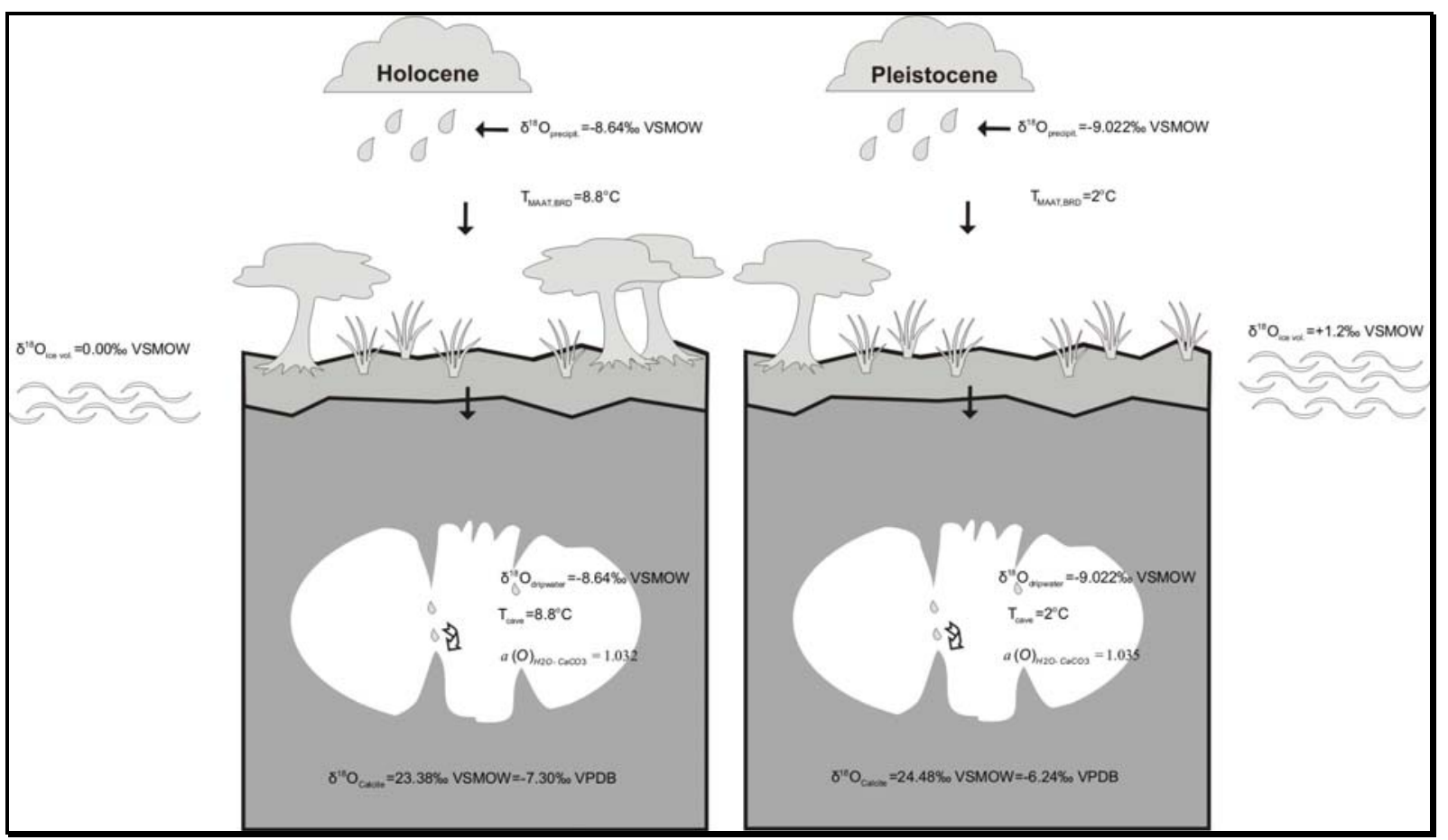

Figure iv - 4: Model for the stable oxygen isotope evolution in German speleothems for the Holocene and the Pleistocene.

(iv) Fusion:

Analogue to the step (ii), the lighter value of $-8.64 \%$ VSMOW for precipitation is substituted for $0 \%$ VSMOW, lowering the resulting $\delta^{18} \mathrm{O}$ value for the speleothem calcite to $23.38 \%$ VSMOW or $7.30 \%$ VPDB.

Theoretically, speleothems precipitated during the Glacial should display $\delta^{18} O_{C}$ values from -5.36 to $6.2 \%$ VPDB, assuming a temperature range of -2 to $2^{\circ} \mathrm{C}$ and taking the mean $\delta^{18} \mathrm{O}_{\text {rain/seepage winter }}$ values of 24 German weather stations (stacked period 1978-2000; IAEA 2001) as input stable oxygen isotope signal (-10.22\% VSMOW). A correction for the ice-volume effect was done with $+1,2 \%$ and the $\mathrm{d} \alpha / \mathrm{dT}$ of $-0.22 /{ }^{\circ} \mathrm{C}$ is assumed being fixed.

As mentioned before, the $\delta^{18} \mathrm{O}$ speleothem-temperature relationship may only be applied for the Holocene since it takes the ice-volume effect not into account. The "delta speleothem function", presented by LAURITZEN and LUNDBERG (1999) and LAURITZEN (1995) involves all variables in a mathematical form but is still only applicable if the speleothem is deposited in isotopic equilibrium and if all involved parameters are known. 


\begin{tabular}{|l|l|l|l|l|}
\hline & $\begin{array}{l}\delta^{18} \mathrm{O} \text { input water } \\
\% \text { vs. VSMOW }\end{array}$ & $\begin{array}{l}\text { Fractionation Factor } \alpha \\
\delta^{18} \mathrm{O}_{\mathrm{C}}-\delta^{18} \mathrm{O}_{\mathrm{H} 2 \mathrm{O}}=\Delta= \\
1000 * \ln \alpha\end{array}$ & $\begin{array}{l}\text { Temperature } \\
\alpha=1.02846\left(25^{\circ} \mathrm{C}\right), \\
\mathrm{d} \alpha / \mathrm{dT}=-0.22 /{ }^{\circ} \mathrm{C}\end{array}$ & $\begin{array}{l}\delta^{18} \mathrm{O} \text { calcite } \\
\% \text { vo }\end{array}$ \\
\hline Holocene & -8.64 & 1.032 & $8.8^{\circ} \mathrm{C}$ & -7.3 \\
\hline Pleistocene (a) & -9.022 & 1.0335 & $2^{\circ} \mathrm{C}$ & -6.24 \\
\hline Pleistocene (b) & -9.022 & 1.0344 & $-2^{\circ} \mathrm{C}$ & -5.36 \\
\hline
\end{tabular}

Table iv - 1: Estimates for the stable oxygen isotope evolution in German speleothems for the Holocene and the Pleistocene.

The interpretation of the $\delta^{18} \mathrm{O}_{\mathrm{C}}$ record is based on the carbonate paleotemperature equation, which relates the $\delta^{18} \mathrm{O}$ value of the carbonate to that of the initial water from which the carbonate precipitated (rainfall/dripwater) and the deposition temperature (surface/cave temperature and thus the fractionation factor $\alpha$ ). The calculation can only be performed by assuming (or direct measuring if possible) one of the factors in the equation like for the Holocene fixing the dripwater composition to the precipitation or the ambient cave temperature to the present-day MAAT at the surface of a site. However, going back in time, e.g. for the Pleistocene, these variables remain unknown. Two approaches to this problem are available. (i) The $\delta^{18} \mathrm{O}$ of the past meteoric precipitation and dripwater feeding the speleothem may be trapped in fluid inclusions within the cave calcite. The stable isotopic $\left(\delta^{18} \mathrm{O}, \delta \mathrm{D}\right)$ content of microscopic fluid inclusions may be measured via "thermal decrepitation" (MATTHews et al. 2000) or "crushing and heating" (Dennis et al. 1997, 2001). Recently GentY et al. (2002) was able to manually extract fossil water out of macroscopic fluid inclusions (several $\mathrm{mm}$ ) from two stalagmites from south-western and southern France and analyzed it directly via injection into a spectrometer. If macroscopic fluid inclusions are abundant, the advantage of this method is that an analytical bias due to kinetic fractionations during heating is avoided.

(ii) Older records can be calibrated with present-day $\delta^{18} \mathrm{O}_{c}$ of stalactite tips and stalagmite surfaces, assuming that they represent the ambient $\mathrm{T}$ (surface and cave temperature) and thus taking this signal as proxy for interglacial, warm conditions at the site. The stable oxygen isotope record of the speleothem may then be interpreted as reflecting warmer or cooler conditions relative to the present environment (LAURITZEN and LUNDBERG 1999).

\section{iv - 2.4) Problems and points of discussion}

Since meteoric precipitation and temperature have opposite effects on $\delta^{18} O_{c}$ of the speleothem calcite, it is necessary to determine which of these is bigger for any given site, in order to interpret shifts in speleothem $\delta^{18} \mathrm{O}_{\mathrm{C}}$. The actual global $\mathrm{d} \delta^{18} \mathrm{O}_{\mathrm{p}} / \mathrm{dT}$ factor equals $+0.58 \% /{ }^{\circ} \mathrm{C}$ but displays in dependence of its location variations from -1.28 to $+0.65 \% /{ }^{\circ} \mathrm{C}$ (ROZANSKI et al. 1993). Therefore it is important for the reconstruction of paleotemperatures to determine if the $d \delta^{18} \mathrm{O}_{\mathrm{p}} / \mathrm{dT}$ factor is smaller or larger than the $d \alpha / d T$ (e.g. $-0.22 \% /{ }^{\circ} \mathrm{C}$ ). The direction of the shift in sign of the $\delta^{18} \mathrm{O}_{\text {speleothem }} / \mathrm{dT}$ will depend on both factors. This is the reason why studies on speleothems and vein calcites display 
positive (Goede et al. 1990; Winograd et al. 1992; Goede 1994; LaURitZen 1995; MCDermott et al. 1999; SteVenson et al. 1999) as well as negative (HENDY and WILSON 1968; EMILIANI 1971; SCHWARCZ et al 1976; THOMPSON et al. 1976; HARMON et al. 1978a; 1978b; TALMA and Vogel 1992) relationships between the $\delta^{18} \mathrm{O}_{c}$ of speleothems and temperature.

If a speleothem has not been deposited continuously throughout the year, seasonal changes in the isotopic values of the input seepage water will alter the resulting isotopic composition of the speleothem.

BAR-MATTHEWs et al. (1996) states that evaporation may take place in the soil zone or within the epikarst which will lead to a relative enrichment of ${ }^{18} \mathrm{O}$ of the seepage-/groundwater and consequently of the cave dripwater and the cave calcite.

The deposition in isotopic equilibrium is central for the use of the stable isotope signal of speleothems as paleotemperature and/or paleoclimate proxy. Evaporation in the cave during calcite precipitation disturbs the equilibrium and preferentially removes the $\mathrm{H}_{2}{ }^{16} \mathrm{O}$ leading to a $\delta^{18} \mathrm{O}_{\mathrm{C}}$ increase (HENDY 1971; GASCOYNE 1992). Nevertheless, a negative Hendy-Test will not necessarily be indicative of kinetic fractionation or evaporative conditions because of the difficulties with physically sampling (e.g. with a drill of $0.5 \mathrm{~mm}$ diameter) along the same coeval growth layer (diameter of less than $<0.1 \mathrm{~mm}$ and thinning out from the central growth axis to the sides). Additionally, a growth layer may only be distinct where a rapid environmental shift occurred. Altogether it seems difficult to avoid accidentally "catching" a calcite that has been precipitated under rather different conditions.

The extraction of fluid inclusion water for $\delta^{18} \mathrm{O}$ and $\delta \mathrm{D}$ analysis performed either by thermal decrepitation (heating under vacuum) or crushing and heating resulted often in low yields and poor reproducibility (SCHWARCZ and YONGE 1983; GENTY et al. 2002) although Rowe et al. (1998) have shown that a combination of crushing with mild heating might give reliable results. Although MATTHEWs et al. (2000) recently improved the decrepitation technique using small samples (100$150 \mathrm{mg}$ ) and heating them up to $900^{\circ} \mathrm{C}$, still a large fractionation occurs and measured $\delta D$ is depleted by $-30 \%$.

AdOLPHE et al. (1991) observed bacteria in speleothem calcite and GRADZINSKY (2000) even suggested a bacterial influence on the $\delta^{18} \mathrm{O}_{\mathrm{c}}$ of cave pisoids in Slovakia in his preliminary results. But nevertheless there is no convincing evidence that bacteria are playing an active role in cave calcite precipitations and that they systematically influence the stable oxygen/carbon isotopic composition of speleothems.

Recrystallization processes lead to an increase of the calcite crystal size and would wipe out the internal speleothem lamination. A homogenization of stable oxygen/carbon isotope values should take 
place. However, recrystallization is often reported in initially aragonite speleothems (CABROL and COUDRAY 1982) but was not often observed in low Mg calcite specimens (KendaLL and BROUGHTON 1978).

\section{iv - 3) Carbon}

The carbon isotopic composition of an in thermal equilibrium deposited low $\mathrm{Mg}$ calcite speleothem is mainly controlled by two factors: (i) The carbon isotopic composition of the carbonate species present in the feeding water (dissolved inorganic carbon, $\mathrm{DIC}$ ) like carbonic acid $\mathrm{H}_{2} \mathrm{CO}_{3}$, bicarbonate $\mathrm{HCO}_{3}{ }^{-}$or carbonate ions $\mathrm{CO}_{3}{ }^{2-}$. (ii) The fractionation between the DIC and the calcium carbonate at the watercalcite interface during precipitation.

The resulting $\delta^{13} \mathrm{C}$ of the DIC is governed by the amount of, and composition of each species abundant, as different species display different isotope effects. The abundance of each species and its $\delta^{13} \mathrm{C}$ may be derived by precise field measurements of temperature and $\mathrm{pH}$ of the associated waters. The $\delta^{13} \mathrm{C}$ of $\mathrm{CO}_{2}$ in equilibrium with a water of known isotopic composition can be calculated via isotopic and chemical mass-balance considerations (IAEA 1983). Compared to the stable oxygen isotope fractionation, the isotope effect of stable carbon isotopes is much less temperature dependent $\left(\sim 0.06 \% /{ }^{\circ} \mathrm{C} ; 0-25^{\circ} \mathrm{C}\right)$. The equilibrium fractionation of the $\mathrm{CO}_{2}-\mathrm{H}_{2} \mathrm{O}-\mathrm{CaCO}_{3}$ system is in the range of 1000 In $\alpha=10.0$ (at $25^{\circ} \mathrm{C}$; see Appendix iv - 2). In this study the data of EMRICH et al. (1970) and DULINSKI and ROZANSKI (1990) is used, because applied experimental conditions reflect those in the cave and the results are based on a compilation of data.

The main source for the different DIC species is the soil- $\mathrm{CO}_{2}$ produced by root respiration and microbial decomposition of organic matter. The pedogenic $\mathrm{CO}_{2}$ with a $\mathrm{pCO}_{2}$ of $\sim 0.1 \mathrm{~atm}$ dissolves in the percolating rainwater $\left(\mathrm{pCO}_{2} \sim 10^{-4} \mathrm{~atm}\right)$ resulting in a weak $\mathrm{H}_{2} \mathrm{CO}_{3}$ acid and leading to carbonate host rock dissolution $\left(\mathrm{pCO}_{2 \text { (cave water) }} \sim 10^{-3} \mathrm{~atm}\right.$ ).

A potential imprint of the parent limestone is usually not detected in the soil carbonates precipitated from these solutions since complete equilibration is believed to take place between soil- $\mathrm{CO}_{2}$ and the dissolved bicarbonate (QUADE et al. 1989). Nevertheless, other authors like GENTY and MASSAULT (1997), GeNTY et al. (1999) or GEYH and FRANKE (1970) estimated an $85 \%$ contribution of soil-CO $\mathrm{CO}_{2}$ in speleothem carbon and a $15 \%$ contamination with dead carbon (carbon containing no more ${ }^{14} \mathrm{C}$, deriving from the limestone and from old organic matter). 


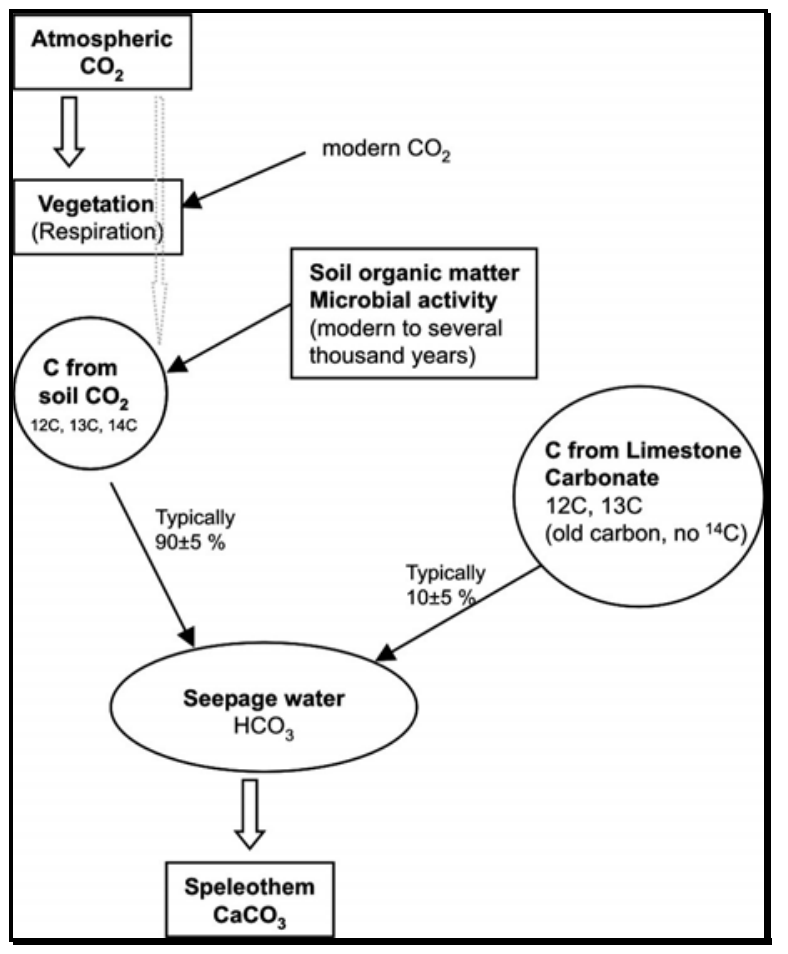

Figure iv - 5: Speleothem carbon sources. The three possible sources are (i) atmospheric $\mathrm{CO}_{2}$, (ii) soil- $\mathrm{CO}_{2}$, and (iii) the host rock carbonate. Data suggest that carbon from the soil- $\mathrm{CO}_{2}$ is the principal source for speleothem carbon but it can be much less at specific sites (according to GENTY et al. 2001).

Assuming the calcite is deposited in isotopic equilibrium and given the fact that the carbon fractionation is only slightly influenced by temperature, the speleothem calcite is believed to mainly reflect the $\delta^{13} \mathrm{C}$ of the associated soil coverage controlled by the above growing vegetation (SMITH and EPSTEIn 1971; Deines 1980; DoRALE et al. 1992). This relationship between speleothem $\delta^{13} C_{C}$, climate, and vegetation may arise due to different modes of photosynthesis-pathways of the climatically adapted vegetation, which show differing degrees of fractionation during the fixation of the initial carbon. The $\underline{\mathrm{C}}_{4}$ or Hatch-Slack photosynthetic pathway (ca. $-13 \%$ VPDB) results in $\delta^{13} \mathrm{C}$ values of the pedogenic $\mathrm{CO}_{2}$ between -16 and $-10 \%$ VPDB and is primarily represented by plants in some degree adapted to arid conditions like desert grasses, certain grains and related crops like corn (maize) or sugarcane. Without a dead carbon proportion and assuming a fractionation factor of $1000 \ln \alpha=10.0$, an associated cave calcite will display a $\delta^{13} C_{C}$ variation of -6 to $+2 \%$ VPDB (CERLING 1984). In temperate regions most plants use the $\underline{C}_{3}$ or Calvin cycle, containing values after fractionation of -32 and $-25 \%$ VPDB (CERLING 1984, O' LEARY 1981). The ascribed soil- $\mathrm{CO}_{2}$ will then have a $\delta^{13} \mathrm{C}$ value of -26 to $-21 \%$ VPDB and the speleothem calcite will display ratios of -14 to $-6 \%$ VPDB (1000Ina $=$ 10.0, no dead carbon contamination; CERLING 1984).

However, taking a dead carbon contamination of $15 \%$ with a $\delta^{13} \mathrm{C}$ value of $0 \%$ into account, a $\mathrm{C}_{3}$ dominated speleothem calcite will display $\delta^{13} C_{c}$ ratios of ca. $-12 \%$ (ca. $-6 \% * 85 \%+0 \%$ o $*$ $15 \%$ ) and $-5 \%$ VPDB and for a $C_{4}$ dominated values of $-5 \%$ to $-1.7 \%$ VPDB). 


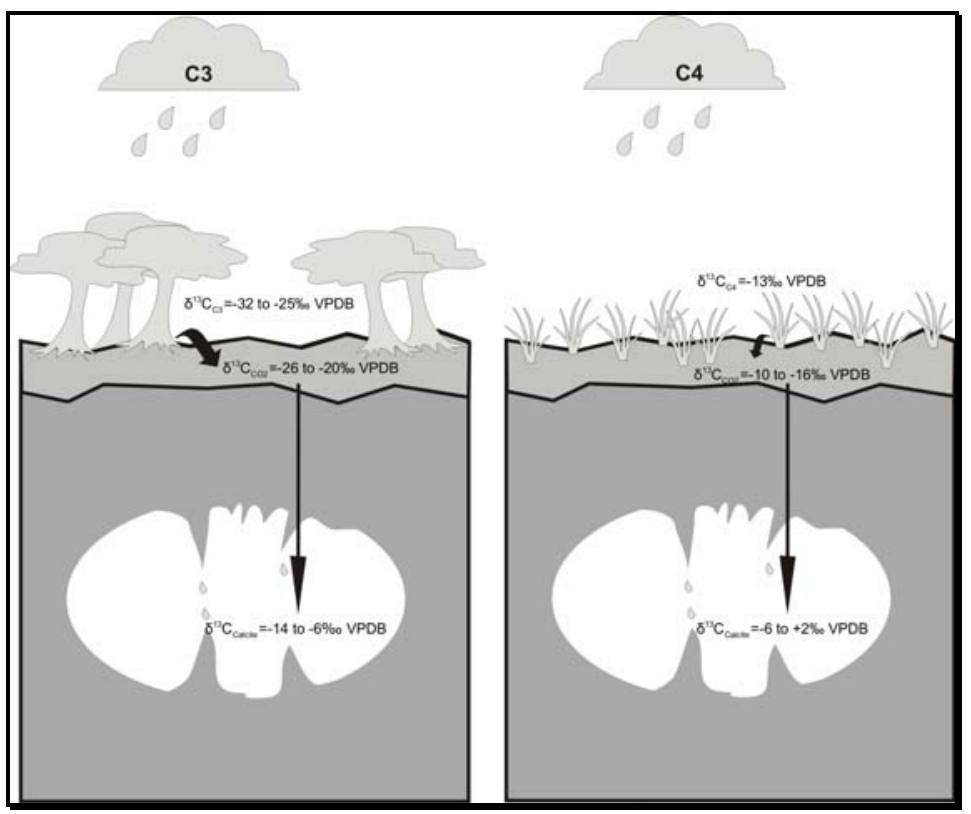

Figure iv - 6 : Stable carbon

isotopes in speleothems. Since a

$C_{3}$ vegetation was present in Germany for most of the Holocene, (HUNTLEY and PRENTICE 1993), we expect a speleothem $\delta^{13} C_{C}$ composition of around -14 to $-6 \%$ VPDB (no dead carbon contamination).

\section{iv - 3.1) Problems and points of discussion}

The mixing of soil gas with the atmosphere due to a decrease of $\mathrm{CO}_{2}$ production from plant respiration/decomposition will increase the $\delta^{13} \mathrm{C}$ of the soil (CERLING 1984) and as a consequence that of the speleothem. In this light HELLSTROM et al. (2000) interpreted a rapid decrease in $\delta^{13} C_{C}$ from $+2 \%$ to $-8 \%$ (between 21 and $14 \mathrm{ka}$ ) of a New Zealand speleothem as a change in the soil $\mathrm{pCO}_{2}$ due to an increase of biological productivity by the development of a vegetational cover above the cave.

As these changes will have their impact on the relative proportions of the different carbon sources involved, the carbon isotopic values of the speleothem will consequently change. In addition to the potential influence of dead carbon contents GENTY and MASSAULT (1997) also modeled the impact of old organic matter ranging between $1 \%$ up to $50 \%$. The input of old carbon in the system increases if vegetation produces slow decomposing organic matter. As seen above, dead carbon from the limestone host rock may increase the $\delta^{13} C_{\text {speleothem,c3 }}$ by approximately $3 \%$ (-18 \%o no dead carbon and $-15 \%$ with dead carbon fraction of $15 \%$ ), while the dead carbon from old organic matter will have the same carbon isotopic ratio as the corresponding plant cover and the soil- $\mathrm{CO}_{2}$.

BAKER et al. (1997a) found highly variable and generally increased $\delta^{13} \mathrm{C}_{c}$ values of recently deposited speleothems form Stump Cross caverns in the range of -10.2 to $-4.4 \%$, where a present $C_{3}$ vegetation coverage should trigger only minor variations. These variations were attributed to calcite precipitation under kinetic fractionation conditions increasing the $\delta^{13} \mathrm{C}$ in the speleothem calcite, to degassing of the groundwater in the unsaturated zone or to unachieved isotopic equilibration at the soil- $\mathrm{CO}_{2}$-water interface due to short residence times of the vadose water. 
Prior calcite precipitation by $\mathrm{CO}_{2}$ degassing in voids or microfissures of the vadose zone above the cave and incongruent solution, which could occur in dolomitic terrains, will increase the $\delta^{13} C_{c}$ of the cave calcite due to a preferred removal of ${ }^{12} \mathrm{CO}_{2}$ (FAIRCHILD et al. 2000.).

The mode of dissolution processes like open, closed, coincident/sequential dissolution might explain $\delta^{13} \mathrm{C}$ variations of speleothems (DraKe 1983; SALOMONS and Mook 1986). Given a $\delta^{13} \mathrm{C}_{\text {soil-CO2 }}$ of $-24 \%$, an average temperature of $10^{\circ} \mathrm{C}$ and a soil $\mathrm{pCO}_{2}$ of 0.02 to $0.0003 \mathrm{~atm}$, HENDY (1971) calculated the resulting $\delta^{13} \mathrm{C}_{\mathrm{C}}$ of a precipitated calcite being $-13.5 \%$ under open-system conditions and between 11.5 and $-10.5 \%$ with prevailing closed-system conditions. Flowpath changes of the seepage water and hence potential variations between open, closed or some intermediate dissolution stages will result in carbon isotopic modifications of the cave calcite.

Kinetic fractionation by the process of evaporation may also occur in the cave during calcite precipitation. The following rapid degassing of $\mathrm{CO}_{2}$ and preferential removal of ${ }^{12} \mathrm{CO}_{2}$ will produce increased $\delta^{13} \mathrm{C}$ values of the speleothem (HENDY 1971). TURNER (1982) found enriched $\delta^{13} \mathrm{C}$ speleothem values of 0.5 to $4 \%$ in his laboratory experiments of $\mathrm{CaCO}_{3}$ precipitation out of supersaturated solutions in dependence of the carbonate precipitation rate. Here, lower precipitation rates produced a higher enrichment of the ${ }^{13} \mathrm{CO}_{2}$.

The influence of potential bacterial or crystallographic controls is as well possible as seasonal bias due to inconsistent driprates on the carbon isotopic composition of the speleothem as well and has already been discussed in the previous stable oxygen isotope section.

\section{iv - 4) State of the art}

Since Hendy and Wilson (1968) and LABEYRIE et al. (1967) demonstrated in the late sixties that isotopic geothermometry may be applied to speleothems through their $\delta^{18} \mathrm{O}_{\mathrm{C}}$ and since CERLING (1984) showed that the $\delta^{13} C_{C}$ of soil carbonates reflect the ratio of $C_{4}$ to $C_{3}$ plants in the vegetation cover, many paleoclimatic studies were performed on speleothems:

In Europe, major studies on speleothems were performed by LABEYRIE et al. (1967), DUPLESSY et al. (1970), Lauritzen (1995), LaURitzen and ONAC (1999b), LAURitZen and LundBerg (1999), McDermott et al. (1999, 2004), PLAGNeS et al. (2002), J ImÉNEZ DE CISNEROS (2003); in North-America by SCHWARCZ et al. (1976), THOMPSON et al. (1976), HARMON et al. (1978a, b, 1979b), GASCOYNE et al. (1980, 1981), Denniston et al. (1999a, b); and, in the Southern Hemisphere by Hendy and WILSON (1968), TALMA et al. (1974), Goede et al. (1986, 1990), TALma and Vogel (1992), Goede (1994), Williams et al. (1999), HOLMGREN et al. (1999). 
The longest $\delta^{18} \mathrm{O}_{c}$ record currently available is a coresample drilled from the Devil's Hole vein calcite (Nevada, U.S.A.). It has been precipitated from the groundwater supersaturated in calcite and covers a time interval from 60 ka to 560 ka BP (LUDWIG et al. 1992). The Devil's Hole core offers a reliable record of the groundwater $\delta^{18} \mathrm{O}$ changes, reflecting changes in $\delta^{18} \mathrm{O}$ of average rainwater, so that lower values indicate colder conditions (WINOGRAD et al. 1992). The record shows until today unique and very similar variations to the marine SPECMAP isotope record as well as to $\delta \mathrm{D}$ in the Vostock icecore, stressing its overregional significance. However, the reservoir effect and the mixing of the water over long periods of time are responsible for the low resolution of the records and for the dating problems (BROeCKer 1992; ShaCKLETON 1993; LUdWIG et al. 1993; EdWARDS and GalluP 1993).

Despite some good correlations between different speleothems (BAR-MATTHEWs et al. 1997; LAURITZEN and ONAC 1999b, MCDERMOTT et al. 2001) and with the marine records (LAURITZEN 1995; 1999b), there is still a lack of convincing paleoclimatic reconstructions. Differing interpretations of $\delta^{18} O_{C}$ shifts like in New Zealand speleothems by WilLiams et al. (1999) and HeLLSTROM et al. (1998) reveal still existing uncertainties especially concerning precise controls on the isotopic composition of these deposits.

Recently, studies with special focus on the uttermost cave environment demonstrated the important variability of stable oxygen and carbon isotope compositions of cave deposits due to several possible kinetic processes in and above the cave (BAKER et al. 1997b; BAR-MATTHEWS et al. 1996).

LABAT et al. (2000a, b; 2002) investigated the discharge of karst springs and found that linear models like stochastic and Fourier models do not reflect the behavior of the springs especially at extreme flow events due to the spatial, dynamical and physical heterogeneity of the karst catchment and its input (meteoric precipitation). BAKER and BRUNSDON (2003) tackled the question whether the same nonlinearity is present at the lower discharge of dripwaters in caves at Stump Cross Caverns, since this would be of crucial importance for the utilization of the different proxies used in speleothems: Nonlinearities in drip-hydrology, owing to e.g. flow switching of different flow routes or water sources, evapotranspiration, etc., could lead to the interpretation of radical climate changes in speleothem proxies (see also section above). Stump Cross Cavern's drip-hydrology provided strong evidence that a non-linear input (meteoric precipitation) and nonlinearities within the karst system lead to non-linear dripping in the cave. In addition to the monitoring of the driprate and the rainfall input Тоотн and FAIRCHILD (2003) also investigated the associated dripwater chemistry at Crag Cave in attempt to determine the extent of hydrological and geochemical response to the recharge at the dripping sites. They found that evolution from the soil matrix and preferential flow solutions seem to exert an important control on dripwater chemistry, since the former is the dominant water source at dry periods and the latter flow via soil macropores during recharge at Crag Cave. Interpretations on the $\mathrm{Ca}^{2+}, \mathrm{SO}_{4}{ }^{2-}, \mathrm{Mg} / \mathrm{Ca}$, and $\mathrm{Sr} / \mathrm{Ca}$ composition of dripwater ties its variation to prior calcite precipitation, piston flow, dilution and the overall rainfall input. 
GENTY and MASSAULT (1999) demonstrated that most of the carbon transfer dynamics are controlled in the soil by soil organic matter (SOM) degradation rates with important consequences for the interpretation of $\delta^{13} C_{C}$ (and ${ }^{14} \mathrm{C}$ ages) of speleothems (GENTY 2001).

Studies in arid to semi-arid regions suggest that changes in humidity and of effective rainfall amount are the dominant factors guiding the speleothem oxygen isotope variations (BAR-MATTHEWS et al., 1996, 1997, 1999; Denniston et al. 1999a; Frumkin et al. 1999). Fleitmann et al. (2003) found a significant correlation between $\delta^{18} \mathrm{O}_{\mathrm{c}}$ of Southern Oman speleothem and its growth layer thickness, thus confirming the reliability of the isotope record being an archive of monsoonal rainfall in the region. Also longer-term dry-wet changes due to geographical shifts of the intertropical convergence zone (ITCZ) have been suggested.

\section{Quintessence}

The most widely used proxies of speleothems which have been found to have paleoclimatic significance is the stable carbon/oxygen isotope composition. The distribution of light and heavy isotopes at the aqueous-solid interface during cave calcite precipitation is only a function of temperature if thermodynamic equilibrium conditions are provided. This is usually given by slow degassing rates and with no evaporation. I sotopic equilibrium conditions are indicated by invariant $\delta^{18} \mathrm{O}_{\mathrm{C}}$ values and a non-correlation with $\delta^{13} \mathrm{C}_{\mathrm{c}}$ if coeval samples along the same growth layer of a speleothem were analyzed ("Hendy-Test"). The $\delta^{18} \mathrm{O}_{c}$ composition of an in isotopic equilibrium deposited speleothem is affected by the different fractionations occurring from the ocean-surface till to the cave system, like cave-temperature, ocean-temperature, rainwater-composition and especially important for pre-Holocene investigations, the ice-volume effect. Thus for any given site, the impact and dynamics of these effects have to be evaluated independently, as the imprint depends on the scale of the climatic change. The ice-volume effect may be important for the relatively large glacialinterglacial cycles as for smaller scale climatic changes, like during the Holocene the rainout or cave temperature effect might gain influence. In contrast to stable oxygen isotopes the temperature much less influences the stable carbon isotope fractionation. Thus, $\delta^{13} C_{c}$ of the speleothem is mainly controlled by the carbon isotopic composition of DIC species in the dripwater and is usually believed to reflect the $\delta^{13} \mathrm{C}$ of the soil and vegetational cover.

Summarizing, caution is needed before interpreting stable oxygen and carbon isotopes timeseries from speleothems with respect to paleoclimatology. In-situ studies stress the point that the cave dynamic has to be completely understood in terms of isotopic abundances and variations before interpreting some obtained timeseries in terms of potential climatic fluctuations. Here a comparison with other parameters in the speleothem, like trace element composition, petrography, organic content, speleothem morphology and growth rate should be helpful for a more realistic interpretation of potential climatic related isotopic shifts (see also studies of HoLmGren et al. 1999; AYALON et al. 1999; TOOTH and FAIRCHILD 2003). 


\section{$\underline{V}$ Regional Geology and Sites}

\section{Introduction}

The investigated speleothems origin from caves situated in the southern German J urassic limestones of the Swabian/Franconian Alb and the northern German small-scale Devonian (reef-) complex of the Harz Mountains. Figure v - 1 displays the situation of the karstic terrains in Germany and the location of the investigated cave systems.

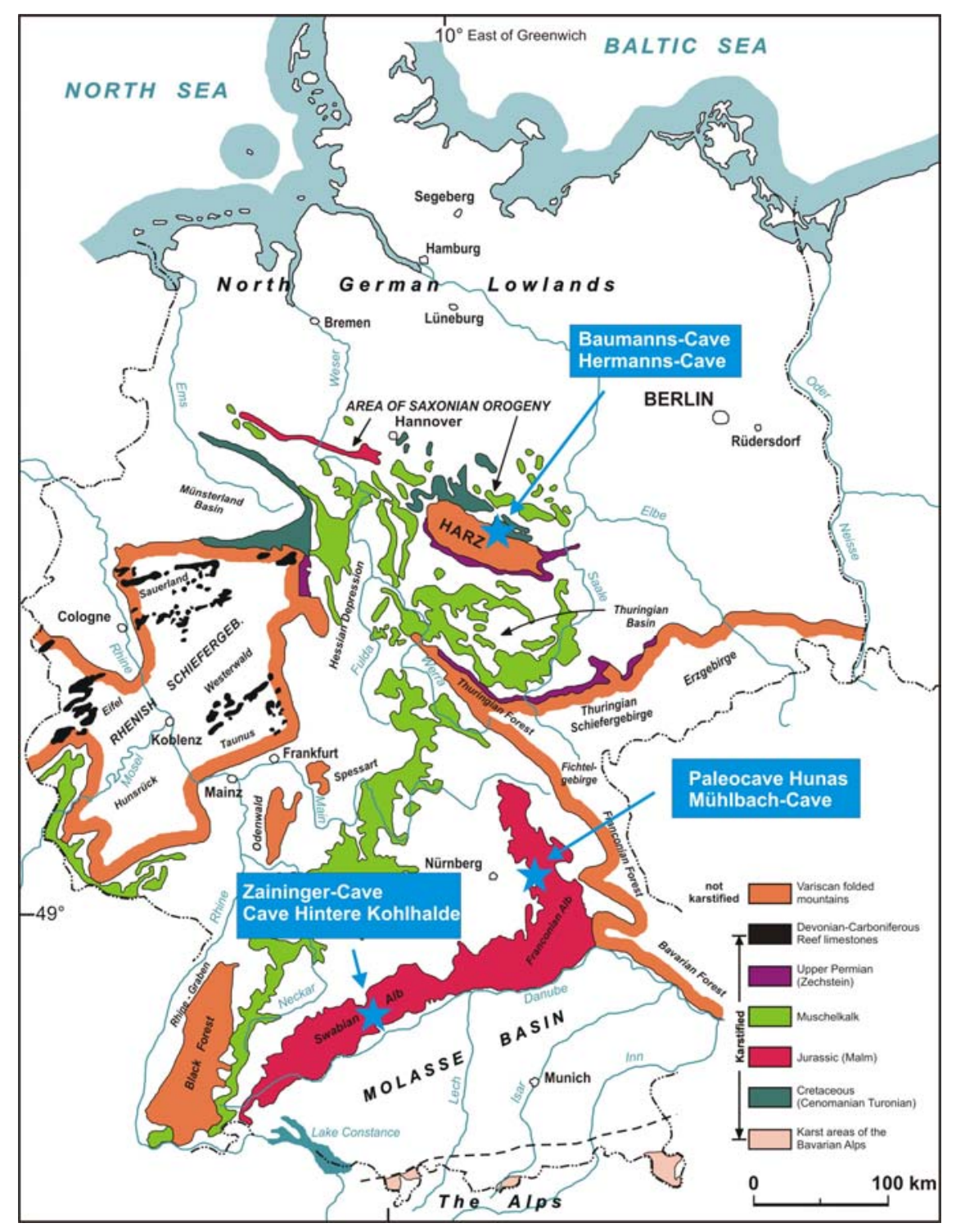

Figure v - 1: Location of the studied sites and the main karst areas of Germany. North is upward. Map compilated and modified from www.showcaves. com and SPEETZEN (1998).

The Cave Hintere Kohlhalde (Hintere Kohlhaldenhöhle) and the Zaininger-Cave (Zaininger Höhle) belong to the Swabian Alb whereas the Paleocave Hunas (Höhlenruine Hunas) and the Mühlbach-Cave 
(Mühlbachquellhöhle) are situated in the adjacent Franconian Alb. The Baumann's- and Hermann'sCave (Baumannshöhle und Hermannshöhle) are located in the Harz Mountains. An overview of the geological setting of each cave system, aspects of speleogenesis and sampling positions within the caves are provided in this section. Geomorphologic parameters describing the cave locations and adjacent environments are summarized in table $v-2$ (page 57).

\section{v - 1) The Cave Hintere Kohlhalde and the Zaininger-Cave of the Swabian Alb}

The Swabian Alb is the largest karst area of Germany. It comprises topographical heights between 400 and $>1000 \mathrm{~m}$ asl and extends over $200 \mathrm{~km}$ from SW to NE yielding a width of $40 \mathrm{~km}$. As part of the southern German cuesta landscape it forms a slightly tilted plateau of Late Jurassic limestones. In the NW, a steep escarpment ("Albtrauf") reaches heights between 700 to $1000 \mathrm{~m}$ asl, and dips SE towards the valley of the Danube River. After GwINNER (1980), the plateau can be divided in two distinctive geomorphologic units: the northern part is characterized by bioherms, which form irregularly shaped hills and gentle slopes and which are referred to as "Kuppenalb". The adjacent southern part of the Swabian Alb is characterized by a comparatively flat landscape of the peneplain ("Flächenalb", see also Appendix v - 1). The peneplain was formed as a result of marine abrasional erosion from the Oligocene to Upper Miocene transgression, which extended over the pre-alpine Molasses basin into this area. In the northern margin of the Miocene sea, cliffs formed along the socalled "cliff-line", dividing the "Kuppenalb" and the "Flächenalb" (GWInNER 1976, 1980). Apart from the inundated peneplain, conditions for the initial set-up of cave developments in the Swabian Alb prevailed since in the Upper J urassic the carbonate plateau emerged from the sea and terrestrial erosion became the major landscaping factor (VILLINGER 1986, GeYER and GWINNER 1991). However, karstification was somewhat restricted and hindered by the relative resistance of the Tithonian Marls (tiZ) and bedded limestones (tiL) and the low elevation above the sea level (low erosional base). After erosion of the Tithonian deposits the massive limestones formed the outcrop but their karstification was again/still prevented due to the relatively high sea water level and hence low erosional base of the transgressing sea. Thus, this period is referred to as period of "shallow karstification" (VILLINGER 1986, GEYER and GWINNER 1991).

During the Pliocene and Early Pleistocene terrestrial erosion increased due to the subsidence of the rift zone of the Upper Rhine Graben which caused an uplift of the adjacent areas. This again promoted a subsequent incision of rivers and therefore lowering of the groundwater level into the massive limestones of the ki2/3. This period of "deep karstification" also enhanced the conditions for speleogenesis due to the steepened hydrological gradient: As karstification advances, the surface runoff and drainage of the upper tributaries increasingly occurred via the subsurface and enhanced dissolution below the epikarst zone. Consequently the valley Tiefental and its side branches, as tributary to the early (Aare-) Danube and later following Blau/Ach river system, dried out completely during the Pliocene and lower Pleistocene (VILLINGER 1980). 
Dry valleys are a characteristic geomorphologic feature of the Alb. They are interpreted as the result of formerly active waterways that have been reactivated during glacial periods. Due to the sealing effect of the vertical drainage pathways by the permafrost zone, the runoff during (summerly) dethawing periods occurred mostly at the surface via the dry valleys (GWINNER 1980, VILLINGER 1973).

\section{v - 1.1) The Cave Hintere Kohlhalde (Swabian Alb)}

The Cave Hintere Kohlhalde (Hintere Kohlhaldenhöhle) is located approximately $2 \mathrm{~km} \mathrm{~S}$ of HeroldstattSontheim at the Blaubeuren Alb (R: 3550769; H: 5366040; 720 m asl; Figure v - 4). Its spatial position is very close to the SW facing valley side slope of the dry valley "Tiefental". This dry valley commences at the "Römerstein-Donnstetten" ( $815 \mathrm{~m}$ asl) and meets the valley "Achtal" (533 m asl) approximately $10 \mathrm{~km} \mathrm{SE}$ of Sontheim. The cave is settled in the uttermost vicinity ( 150 m S) of the Sontheimer Cave (Sontheimer Höhle), which is one of the oldest showcaves on the Swabian Alb. The Cave Hintere Kohlhalde was discovered in 1987 in the course of construction works by chance. Except for one day in the year the cave remains closed to the public for reasons of cave protection. The geology around the Cave Hintere Kohlhalde is exclusively composed of carbonate rocks from the Upper Jurassic. These are mainly algal sponge bioherm limestones of the Middle Kimmeridge (ki2; WJ $\delta$ ) in which the cave is developed (Sheet Blaubeuren 7524; LGBR 1989). Younger glacial alluvial deposits occur in the valley Tiefental. Due to a higher degree of dolomitization and hence slightly increased resistance to erosion, the Upper Kimmeridge Limestones ( $k i 3$ ) set up the topographic heights around the cave entrance. An overview about the abundant stratigraphy and facies of the Upper J urassic is given in Appendix v - 2.

The rather small cave chamber has a ground outline of ca. $32 \mathrm{~m}$ by $8 \mathrm{~m}$ and is $2 \mathrm{~m}$ high close to the entrance and the NNE part (Figure $v-3$ ). Cave roof thickness is 10-15 m. A multitude of the rich speleothem decoration is developed as candle stalagmites and yield diameters of $10-15 \mathrm{~cm}$ with growth heights of 1-2 m. Although the cave was dry during sampling sessions, active speleothem depositions still takes place. This is indicated by numerous straws and fingers at the cave ceiling. Apart from this, most of the stalagmites grow on debris rocks of ceiling breakdowns that cover the cave floor (Figure $v$ - 2).

The vegetation in the vicinity of the Cave Hintere Kohlhalde is dominated by a 80-100 year old beech forest which grows on a ca. $60 \mathrm{~cm}$ marl pararendzina soil (pers. commun. I. Rachor, Inst. of Zoology/Ecology Group, Univ. Göttingen, 2004). 


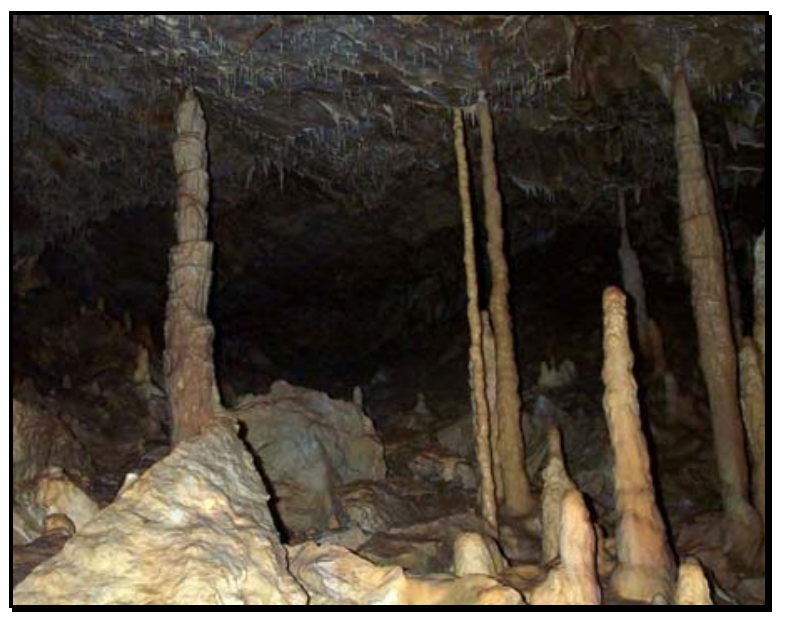

Figure v - 2: Candle stalagmites of the Cave Hintere Kohlhalde.

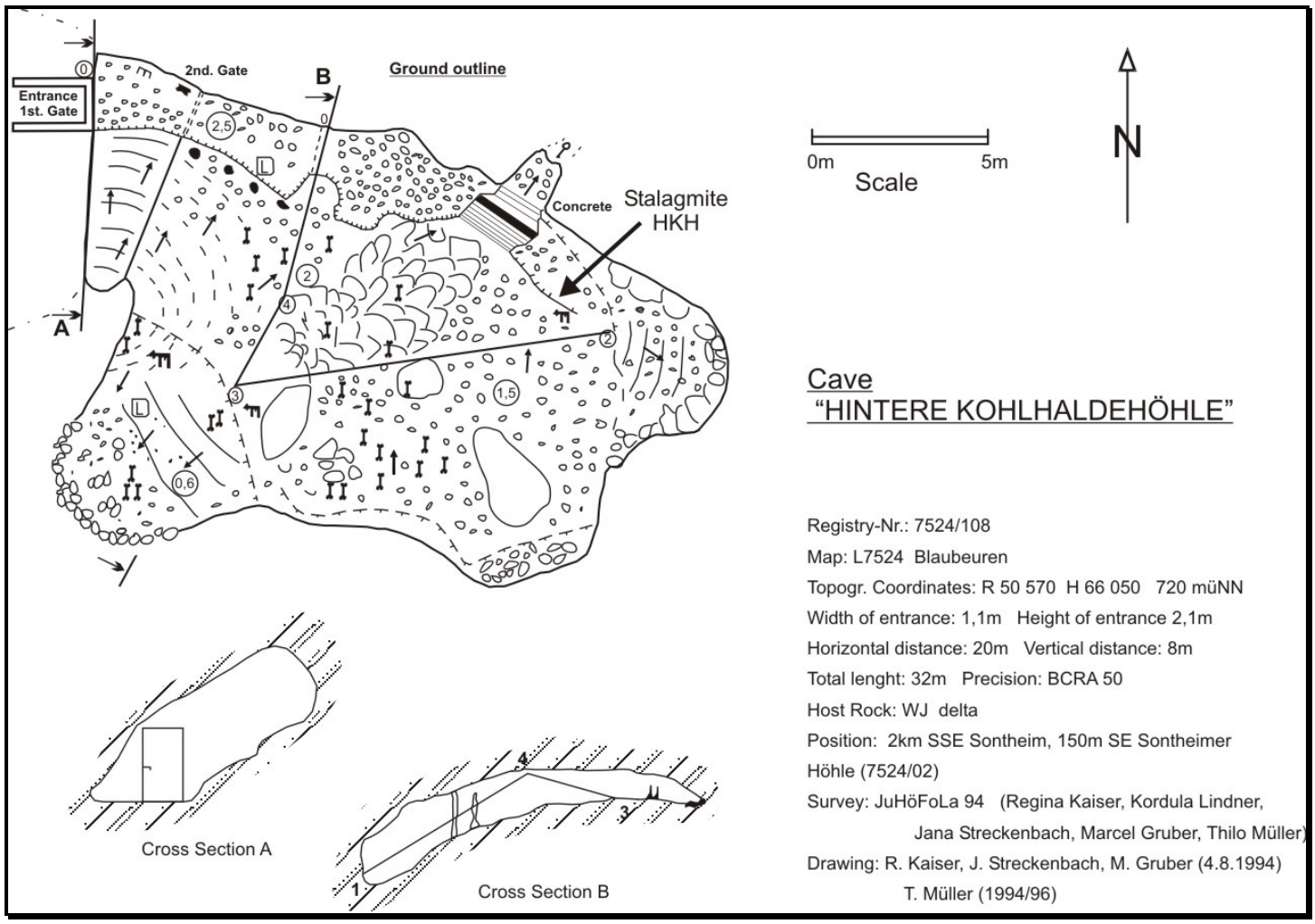

Figure v - 3: Cave map Hintere Kohlhalde with sample position (Map after JuHöFoLa 1994, check box above). Dripwater samples for stable oxygen/carbon isotope analysis were not available during the field campaign.

A subterranean connection to the nearby Sontheimer Cave is neither explored until today, nor is it strictly denied by the local speleologists (pers. commun. Dr. W. Rosendahl, Reiss-Engelhorn-Museum Mannheim/Germany 2003). A paleo-connection of the two caves may be possible considering the close lateral distance of ca. $150 \mathrm{~m}$ and almost the same vertical distribution between 720-680 m asl. Even if not connected in the past, the driving forces for both cave developments in this area were guided by the incision of the valley Tiefental and subsequent lowering of the local erosional base level. 


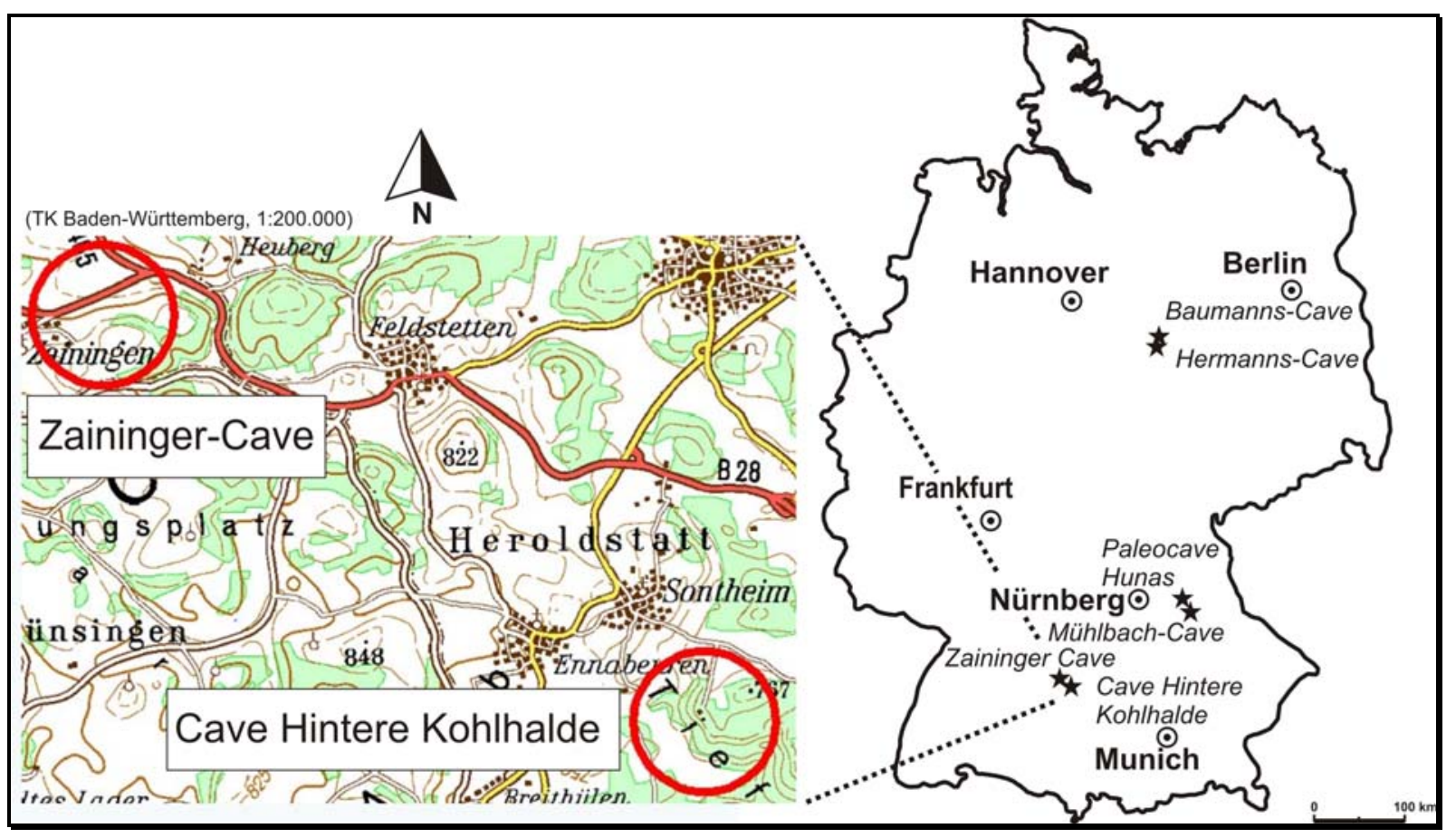

Figure v - 4: Locations of the Cave Hintere Kohlhalde and the Zaininger-Cave (Swabian Alb).

\section{v - 1.2) The Zaininger-Cave (Swabian Alb)}

The Zaininger-Cave (Zaininger Höhle) is located approximately $2 \mathrm{~km} \mathrm{E}$ of the small village Zainingen at the B28 between Bad Urach and Blaubeuren in the area of the hilly "Kuppenalb". The entrance is within a limestone quarry of the company "Rösch" (Figure v - 5/6). The Zaininger-Cave is in $11 \mathrm{~km}$ distance NW to the Cave Hintere Kohlhalde (Figure v - 4). Since the quarry works started in the 1950's, several cave passages were opened, e.g. the "Glass Palace" (Reg. Nr.: 7523/11), or the Zaininger "Steinbruch-Cave" (Reg. Nr.: 7523/08). Until today cave passages of more than $500 \mathrm{~m}$ have been destroyed by mining operations in the area.

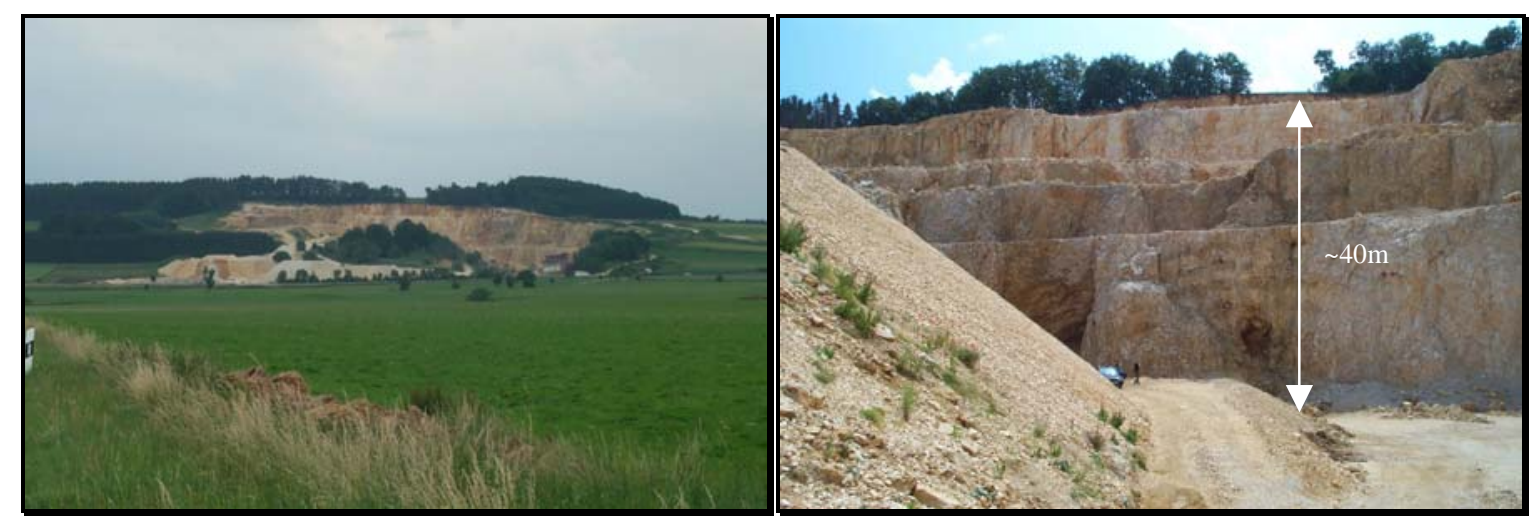

Figure v - 5 and - 6: Limestone quarry of the company "Rösch" near the village of Zainingen. 
The quarry is located $\mathrm{S}$ of the European continental water divide, which runs approximately along the villages of Zainingen-Donnstetten-Westerheim. Tracer tests at the Doline "Hölloch" (village of Zainingen) demonstrated that the Zaininger-Cave is connected to the catchment of the Blautopf at Blaubeuren via the dry valley Tiefental and its side branches (VILLINGER and SAUTER 1999).

The Zaininger-Cave (Reg. Nr.: 7523/12) was discovered in 1998 by R. Eckardt and M. López Correa (LÓPEZ CORREA 2000). The cave (entrance $797 \mathrm{~m}$ asl) covers a horizontal accessible distance of $630 \mathrm{~m}$ and $38 \mathrm{~m}$ difference in elevation. The main passage is running SE to $E$ (Figure $v-8$ ) and thus roughly parallels the dry valley systems in the area of the neighboring Salzwinkel/Au plane. The host rock consists of micritic limestones of the Upper J urassic ( $k i 3$ and tiZ). Since there are no characteristic fossils, a precise stratigraphic classification is lacking (LóPEZ CORREA and FISCHER 2004). Given the altitude of the cave entrance ( $797 \mathrm{~m}$ asl) and the rim of the quarry ( $840 \mathrm{~m}$ asl), the minimum thickness of the overlying host rock is $\sim 40 \mathrm{~m}$. As the vertical distribution drops down to $-38 \mathrm{~m}$ relative to the entrance and given the highest topographical point above the cave at $862 \mathrm{~m}$ asl, the thickness of the overlying rock will add up to at least 80 to $100 \mathrm{~m}$.

Approximately $10-20 \mathrm{~m}$ of the limestone quarry rim is forested by mixed vegetation, whereas the remaining area of the hill "Wanne" is used as agricultural farmland.

The cave passage morphology shows keyhole structures and certain erosional patterns that are typical for the development as a river cave (LóPEZ CORREA 1999). Several remnants of strongly level bound horizontal convex riverbanks were created by a meandering stream in the main passageway. The convex riverbanks are indicative for a low gradient of the former water table (Figure $v-7$ ). Occurring vertical karren are the result of corrosion due to vertical water level fluctuations of the open cave river. However, unambiguous fluviatil marks such as scallops have never been observed (LóPEZ CORREA and FISCHER 2004). Evidence for phreatic conditions are visible as ceiling half-tubes and phreatic tubes along the cave passage.

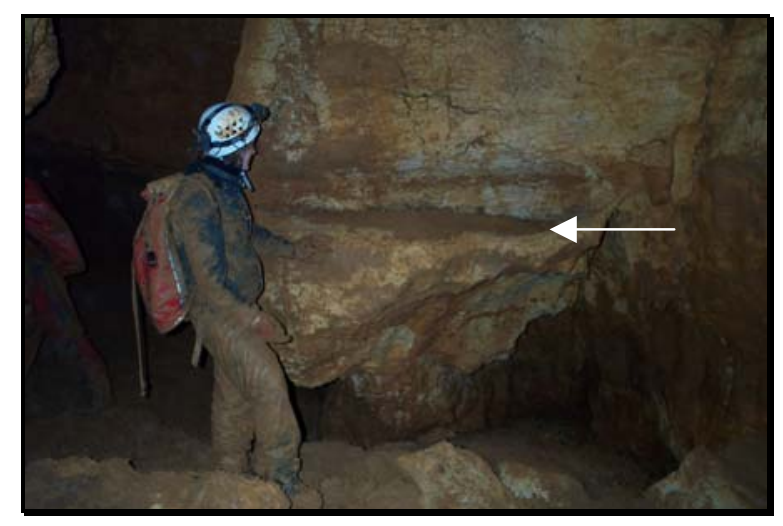

Figure v - 7: Zaininger-Cave: Convex riverbanks in the course of the main cave passage indicate the level (arrow) of the former cave river.

The most impressive speleothems are found in the entrance hall, which covers ca. $20 \mathrm{~m}$ by $30 \mathrm{~m}$. At the lower end of the entrance hall ( $27 \mathrm{~m}$ below the entrance) the main passageway commences $\mathrm{S}$. 
After $150 \mathrm{~m}$ distance from the entrance the passage turns E (area of the "Lehmxylophon", figure v 8), which is accompanied by a decreasing amount of decoration and increasing solution patterns on the cave walls. Macroscopically two speleothem-generations are distinguishable. The youngest (SG-1 generation, terminology after LóPEZ CORREA and FISCHER 2004) stalagmites and stalactites reach vertical heights of up to $1 \mathrm{~m}$ in the area of the entrance chamber and at the very end of the cave passage behind the "Versturzzone". Stalagmites often grow on debris, yielding basal diameters of $<60 \mathrm{~cm}$ and display a yellow to white color. In contrast to this, the older SG-2 generation shows a yellowish-brown color and displays a comparatively slim habitus. In the lower section of the entrance chamber the SG-2 stalagmites are often coated by clay.

Besides the debris from cave roof breakdowns, the most abundant sediment is yellow-brownish, silty clay which show no layering. The cave sediment completely covers the cave floor and builds up bizarre clay pyramids in contact with dripwater. These clay pyramids are mainly found in context with clastic rocks consisting of host limestone and/or speleothem/fossil debris as well as brown ore- and/or dolomite-grains. In dry cave sections the clay displays the typical polygonal shrinkage cracks and the surface is usually coated with dark Fe-Mn varnish.

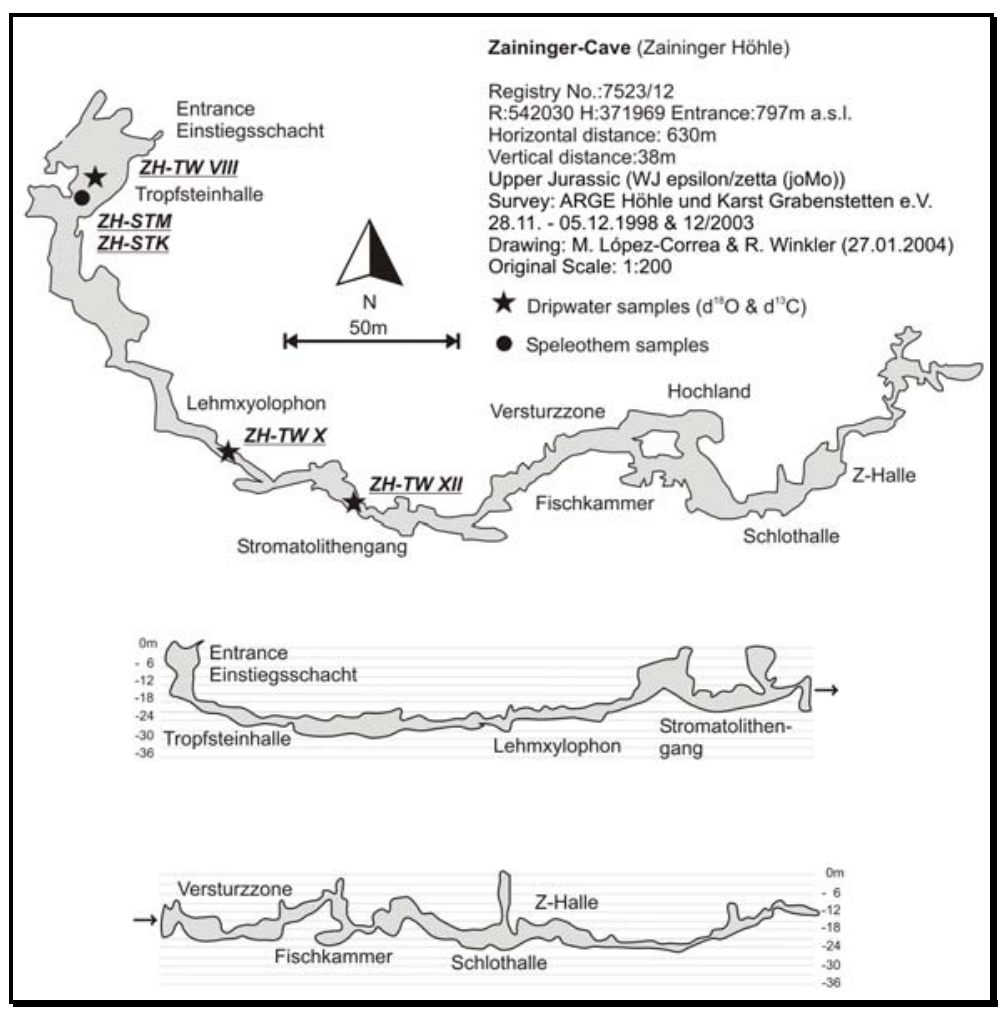

Figure v - 8: Ground outline and cross-section of the Zaininger-Cave with sample positions (modified map after LÓPEZ and FISCHER 2004). 


\section{v - 1.3) Some assumptions on the speleogenesis of the Cave Hintere Kohlhalde and the Zaininger-Cave}

Characteristic features of stagnation phases in the entrenchment of the rivers are comparably static base levels and therefore stable water-levels. Commencing erosion of the base level and hence decreasing height of the water table leave the caves to dry out. Thus, the remaining river terraces and the caves are frequently associated with each other. GLÖKLER (1979) investigated the age of the Sontheimer Cave (and Laichinger Cave) and correlated its corresponding terraces in the valley Tiefental with terraces of the early river Danube. This site is in the same vertical spatial position as the Cave Hintere Kohlhalde (see above). Since the origin of both caves is affected by the incision of the Tiefental, a coeval timing of speleogenesis is assumed. The river terrace level in $700 \mathrm{~m}$ asl were assigned to the main cave level of the Sontheimer Cave although its entrance today is located at $720 \mathrm{~m}$ asl. This slight bias in vertical distance is negligible since the present-day entrance is the result of erosion/peripheral cave breakdown. The associated river terrace level belongs to the oldest Pleistocene (GLÖCKLER 1979). This corresponds to the transition between karstification level III and II (around 1.8 Ma) of ABEL et al. (2002), who investigated the impact of Quaternary climate changes on the development of deep karstification. Surface and subsurface proxies like fluvial terraces, river gradients, caves, and borehole data were correlated. This approach is based on the central assumption that carbonate dissolution preferably occurs at the water table level. After PALMER (1987) more or less horizontal cave passages may then be used to reconstruct the paleo-groundwater level and its relation to the regional fluvial base. As a result the temporal and spatial reconstruction of four single genetic phases or karstification levels (L I - L IV) were provided.

The Tiefental-incision lead only to comparably minor entrenchments or steepening of its upper part and sidebranches on the Salzwinkel/Au-plane in the area of the Zaininger-Cave. Therefore, no river terraces like in the case of the Cave Hintere Kohlhalde were deposited (ABEL 2003). Thus, the transition from phreatic to vadose cave development cannot be directly inferred by correlation with river terraces. A relative minimum age may be estimated in comparing the water table level of the former Zaininger-Cave river (773 $\mathrm{m}$ asl) with the one of other caves in the region. UFRECHT (1987) correlated the upper horizontal level of the cave Laichinger Tiefenhöhle with the valley niveau of the "Kleinen Lauter"-catchment, which has an assigned Pleistocene or even Pliocene age.

As already shown in section ii, the evolution of a conduit as a first step into speleogenesis is determined by multiple variables such as the solution rate, the hydraulic gradient and the initial apertures of the fractures (WHITE 1988, FORD and WILLIAMS 1989). The timing/duration of the typical initiation phase (initial enlargement of a fracture to a critical size) was calculated to take $1 \mathrm{ka}$ to $10 \mathrm{Ma}$, whereas the duration depends on the length and initial width of the fracture (DREYBRODT and GABROVŠEK 2000). The following enlargement of the former proto-conduit (diameter 5-15 mm) to its full size (1-10 m or more) is expected to take 5-20 ka and up to $100 \mathrm{ka}$ (WHITE 1988). Given the right 
conditions e.g. wet terrains with high relief, FORD and WILLIAMS (1989) suggested that conduits can widen to 1-10 $\mathrm{m}$ in diameter in a few thousands years or even in a few hundreds years. BosÁk (2003) concludes, that the minimum age for the cave initiation phase needs a minimum of $10 \mathrm{ka}$ and the latter cave enlargement up to "accessible" diameters takes 10-100 ka under favorable conditions.

Taking into account the theoretical ages summarized by BosÁk (2003) with the field evidence provided by GLÖKLER (1979) and the multiproxy approach of ABEL et al. (2002), a well Pleistocene and maybe even Pliocene age for the beginning speleogenesis of the Cave Hintere Kohlhalde and Zaininger-Cave may be assumed.

\section{v - 2) The Paleocave Hunas and the Mühlbach-Cave of the Franconian Alb}

The Paleocave Hunas (Höhlenruine Hunas) and the Mühlbach-Cave (Mühlbachquellhöhle) are located near Nürnberg on the Franconian Alb. The mountain range is the direct continuation of the Swabian Alb (Figure $v-1$ ). Its topographic outline runs approximately from the Nördlinger Ries $E$ to the city of Regensburg where it turns N-NW (parallel to the Bohemian Forest) to the city of Coburg. J ust like the Swabian Alb, the most striking geological formations were deposited during the Upper Triassic-Upper Jurassic. As result of the two main karstification phases in the area (Lower to Upper Cretaceous and Late Tertiary-Miocene/Pliocene until today) only $200 \mathrm{~m}$ of the whole Malm-limestone sequence escaped erosion in the northern part of the Franconian Alb. Due to the slightly SE dipping beds, the sequence amounts to 500-600 $\mathrm{m}$ in the southern area at the Danube river (GROISS et al. 2000). Therefore, most of today's dry valleys and cave systems of the Franconian Alb developed since the Late Tertiary uplift and lowering of the erosional base level. Most of the Cretaceous karst features have widely been destroyed. Only minor cavities escaped erosion and/or have probably been reactivated for some time. Today remains of the cavities are bound to higher morphologic levels on isolated hills (HERRMANn 1976 and 1980).

\section{v - 2.1) The Paleocave Hunas (Franconian Alb)}

The Paleocave Hunas (Höhlenruine Hunas) is settled 40 to $50 \mathrm{~km} \mathrm{E}$ of the city of Nürnberg. The site is located in a limestone quarry of the company "Sebald Zement" at the B14 ca. $2 \mathrm{~km}$ NW of the village Hartmannshof (R:4467016; H:5485429; Figure v - 11). It was discovered in the year 1956 by the Palaeontologist Prof. Dr. Heller (City of Erlangen). The first and most extensive excavation phase was accomplished until 1964. The cave refills were removed by the excavation teams and composed of a layered mixture between dolomite debris of all sizes and ash (finegrained dolomite sand), loamy cave sediments, and sinter coatings with speleothems of 10 to $40 \mathrm{~cm}$ height (HELLER 1983). The cleared space of the former cavity covered a lateral distance of 15 by $3.5 \mathrm{~m}$ and vertically $12 \mathrm{~m}$.

Facies, paleoclimatological classification of the cave refill and position of the sinterlayer "P1" after Brunnacker (HELLER 1983) are provided in the table $v-1$ and profiles in figure $v-9$ below: 


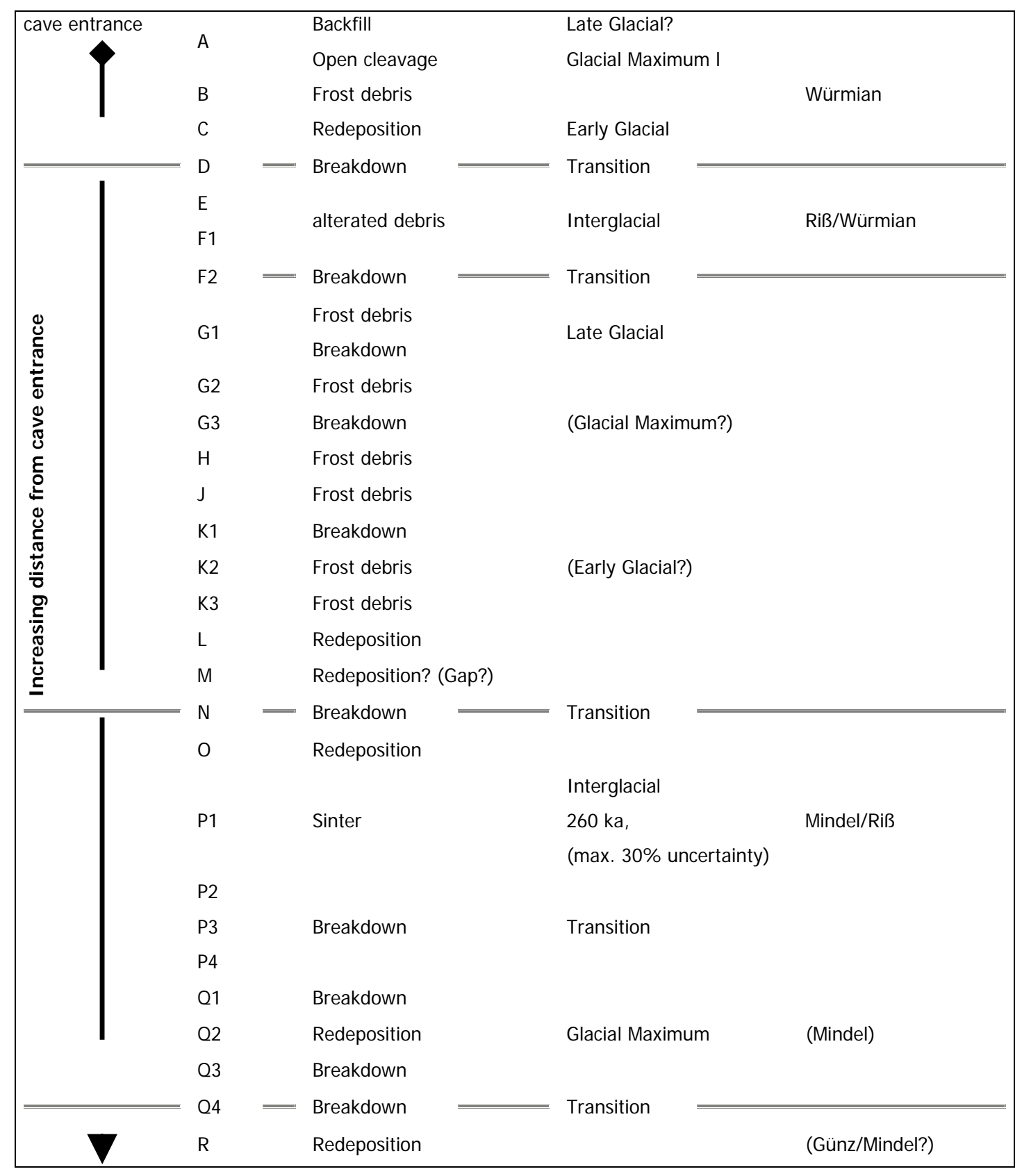



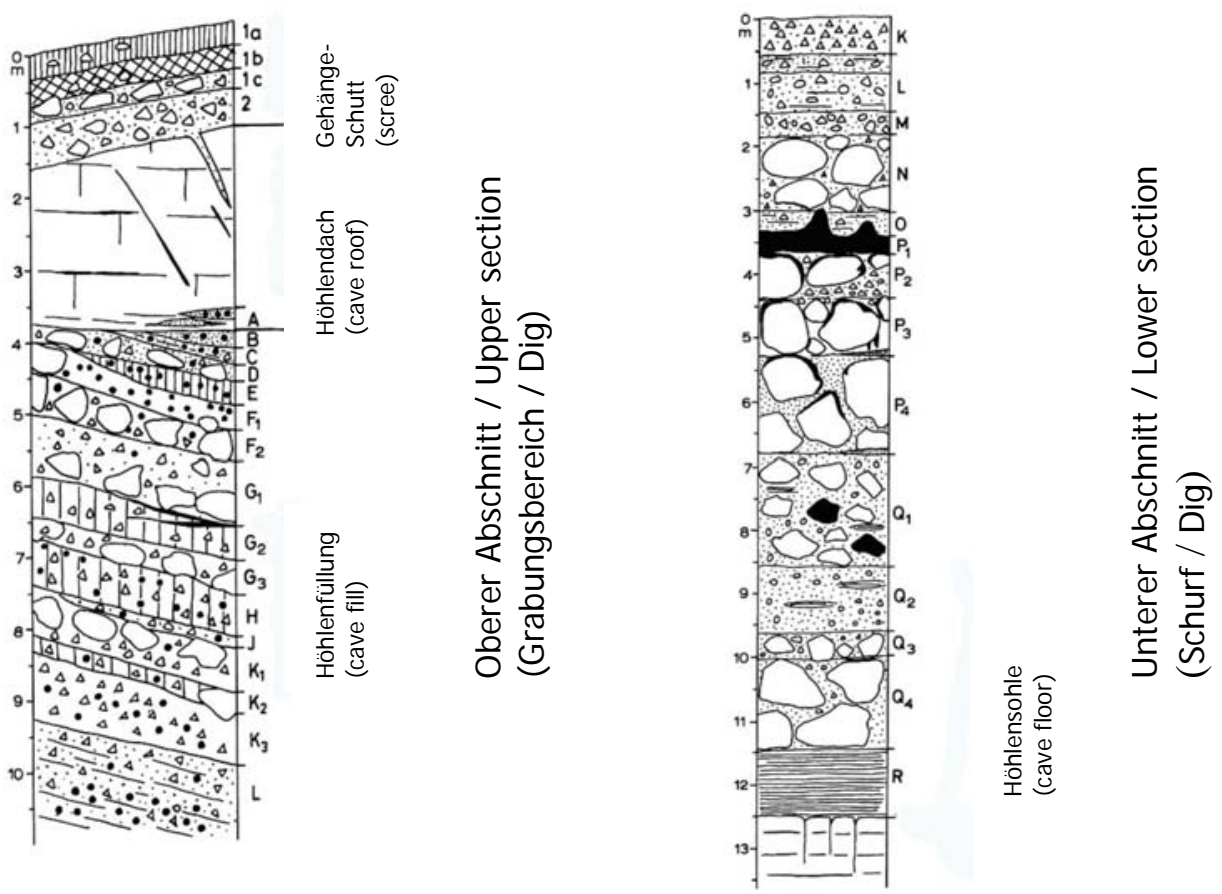

Table v - 1 and Figure v - 9: Cave refill of the Paleocave Hunas. Profile and paleoclimatological interpretation after Brunnacker (modified after HELLER 1983).

The analyzed speleothem was extracted from a layer which was correlated with the "P1 layer" of the lower section (pers. commun. Dr. W. Rosendahl, Reiss-Engelhorn-Museum, Mannheim/Germany, 2003). New excavation activities started 1983 and revealed plenty of fossil findings of more than 130 specimens, artefacts and a molar tooth (GRoIss et al. 2001).

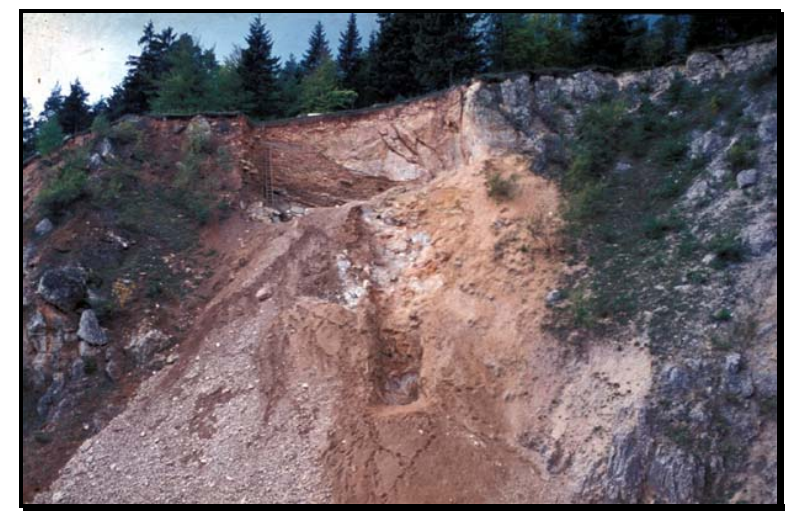

Figure v - 10: Paleocave Hunas and lower 10 m exploration dig, September 1964 (Image taken from: www.pal. unierlangen.de/exp.hoehlen/page/hunas.html)

The regional geology of the site Hunas is characterized by the light colored marls, limestones and the dolomites of the "White J urassic" (=Malm). The profile of the quarry Hartmannshof consists of the Oxfordian Malm- $\alpha$-marls and limestones of the Malm- $\beta$, marls of the Lower Malm- $\gamma$ (Platynatozone, Lower Kimmeridge), and limestones of the Middle Malm- $\gamma$, including loamy karst pockets. The cave 
itself is settled in the Malm- $\delta$, whereas the cave roof consists of 2-3 m of the well-bedded and layered dolomites of the ki3 (Malm- $\varepsilon$ ). The whole profile of the quarry covers a vertical distance of $65 \mathrm{~m}$ with active mining operations on five levels (TREIBS et al. 1977).

The main aquifers of the region are the finegrained Dogger-Sandstones and the complete limestone/dolomite sequence of the Malm. Aquicludes for the former are calcareous shales of the Dogger $\alpha$ (Unteren Aalen-Schichten, Opalinuston) and for the latter the less permeable marls/limestone marls of the Lower Oxfordian and Dogger- $\zeta$ (Ornatenton). The karst aquifer is mainly developed as deep karst. The W-running Högen river at the village Hartmannshof is tributary to the Pegnitz and belongs therefore to the Rhine-Main river system (APEL 1977).

Previous research:

In 1970, Hennig (University Cologne) was provided a sinterfragment from the P1 layer (lower dig) by K. Brunnnacker for U/Th dating. Unfortunately, the sample history was not well documented. So it is not known who took when the sample and a sample split was not provided. In HENNIG (1979) the labeled sample "Hunas Nr. 477" revealed an ${ }^{230} \mathrm{Th} /{ }^{234} \mathrm{U}$ age of $230 \mathrm{ka}$ B.P. What strikes odd is the fact that the same analysis has been mentioned in two successive publications in 1983 but with different ages. HENNIG et al. (1983) cited the age of $221+52 /-32$ ka B.P. whereas BRUNNACKER (1983) referred to $260 \mathrm{ka}+60 /-40$ ka B.P. (Rosendahl et al. 2004). Despite the uncertainties concerning the whereabouts within the dig of Heller and the different age models, the dating of HENNIG (1979) were taken as an important incident for a Middle Pleistocene origin of the cave until today.

In 1986 a new cave with rich speleothem decoration, the Steinberg-Tropfsteinhöhle (Reg. Nr. A 311) was opened during mining operations. The cave is situated ca. $16 \mathrm{~m} \mathrm{~N}$ of the previous dig. Because of the same spatial position in regard to the Paleocave Hunas a formerly connected cave system has been assumed. As a consequence, a correlation of sinter ages to the Hunas site was attempted in order to confirm the published ages. Speleothem analyses via conventional ${ }^{230} \mathrm{Th} /{ }^{234} \mathrm{U}$ spectrometry revealed inconsistent ages of $>131 \mathrm{ka}$ on top (Profile 1), $>225 \mathrm{ka}$ for the middle section (Profile 5) and >26 ka for the speleothem base (Profile 6). This was interpreted by WILLEMS (1989, cited in ROSENDAHL et al. 2004) being due to U-remobilization out of the calcite's lattice.

During the fieldworks 2002 at the Hunas site a new sinterlayer was discovered and found to correlate with the above-mentioned P1-layer. TIMS U/Th results of the extracted stalagmite ("HUSi2", here referred to as HU-STM) are discussed in section vii - 2. 


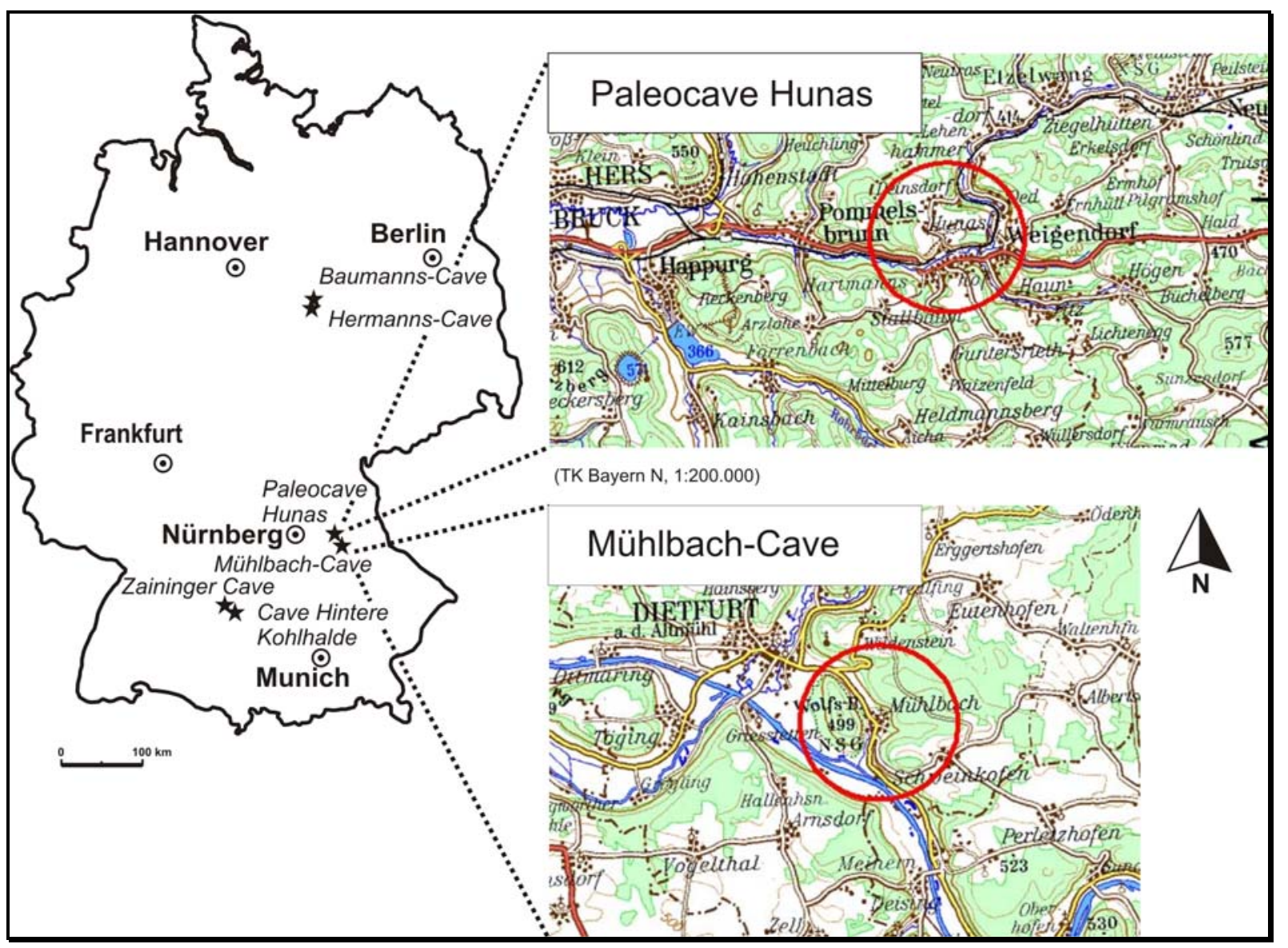

Figure v - 11: Locations of the Paleocave Hunas and the Mühlbach-Cave (Franconian Alb).

\section{v - 2.2) The Mühlbach-Cave (Franconian Alb)}

As depicted in figure v - 11 above, the Mühlbach-Cave (Mühlbachquellhöhle) is located $\sim 62 \mathrm{~km} \mathrm{SE}$ of Nürnberg at the eastern outskirts of the village Mühlbach a.d. Altmühl.

The Mühlbach-Cave has been opened in 2001 after members of the local speleo-club (Karstgruppe Mühlbach/KGM) had spent two years digging and removing debris. Therefore the discovery was the result of previous research in the area that started around 1990. The first point of focus has been the "Warm-Kalt-Höhle" (= "warm-cold cave"), which is known since the 1930's but which has been forgotten over the WWII. In winter-times, a warm airflow streamed out of the cave and condensed to hoar-frost on nearby trees (therefore the name). This led to the assumption that deeper, unknown cave sections still remained to be discovered. Until 1993, the speleologists managed to advance to a cave depth of $70 \mathrm{~m}$. Since it was the aim to discover the cave river and the remaining passages were obstructed, further advances were not attempted at this site. Like other locations in the area, the village Mühlbach was affected by the flooding of 1909. Huge amounts of rainwater collected in a polje on the plain above the village of Mühlbach (around the village of Eutenhofen). Its drainage was blocked by the still frozen ground of the previous winter. Dethawing lead to rapid conduction of the stored water to the subsurface within $27 \mathrm{hrs}$. Given a surface area of $5 \mathrm{~km}^{2}$ and a mean vertical depth of 1-2 m, a stored water volume of 5 to $10 \mathrm{mio}^{3}$ was calculated. Shortly after that, a huge stream 
emerged at the NW-facing slope above the village Mühlbach and ran downhill to the Altmühl river. Since it is evident that the rapid drainage could only have taken place owing to a widespread cave system, the site of the resurfacing water masses was explored. Striking evidence for a nearby cavity opening was thereby a cool airflow, which seemed to emerge off cleavages beneath the forest soil. This reminded of the same phenomenon at the above mentioned "Warm-Kalt-Höhle". The digging started during the summertime 1998, $160 \mathrm{t}$ of debris were removed on a length of $54 \mathrm{~m}$. The final breakthrough succeeded in J anuary 2001. The following explorations lead to the discovery of the largest active river cave of the Franconian Alb. Informations were taken from the KGM's homepage at www. muehlbachquellhöhle.de. Figure v - 12 shows the mapped sections of the active river cave until May 2003. From the entrance (around $400 \mathrm{~m}$ asl) one main passage strikes NE for approximately $1200 \mathrm{~m}$ (Nordgang) and the other to the $\mathrm{E}$ ca. $900 \mathrm{~m}$ (Ostgang).

Most of the cave is developed within the Platynotazone of the Malm- $\gamma$ (Lower Kimmeridge) that is composed of alternating limestones and marls. The subsequent profile on top consists of $20 \mathrm{~m}$ bedded limestones of the Malm- $\gamma$, the $2 \mathrm{~m}$ thickly-bedded Crussoliensis-Zone (again repetitions of limestones and marls), thickly bedded limestones of the Upper Malm- $\gamma$ and Lower Malm- $\delta$ (Middle Kimmeridge). The top of the profile is build up by ca. $80 \mathrm{~m}$ of the highly porous bedded Franconian Dolomite and 5$20 \mathrm{~m}$ bedded limestones of the Malm- $\varepsilon$ (Plattenkalk; GLASER 2003). Considering the geological profile, the resulting host rock thickness amounts to ca. 100-120 m above the cave.

Like at the site Hunas a mixed forest is developed on a $<30 \mathrm{~cm}$ rendzina-terra fusca soil.

Since the erosional base level of the area is lower than the Dogger/Malm transition, the area belongs to the shallow karst. The karst aquifers of the Malm are mostly developed in the limestones and dolomites of the Oxford/Kimmeridge sequences with marls/calcareous marls and the shales of the Ornatenton as aquicludes at its base. Further aquifers are situated in the stratigraphic lower Dogger, Rhetian-Liassic Transition beds, and the Keuper. Quaternary deposits especially in the valley of the Altmühl river consists mainly of fluvial gravel and sands of the Early-Danube and Altmühl which are deposited on the shales of the Dogger- $\alpha$ (Opalinuston as aquiclude; HABBE 1989). 

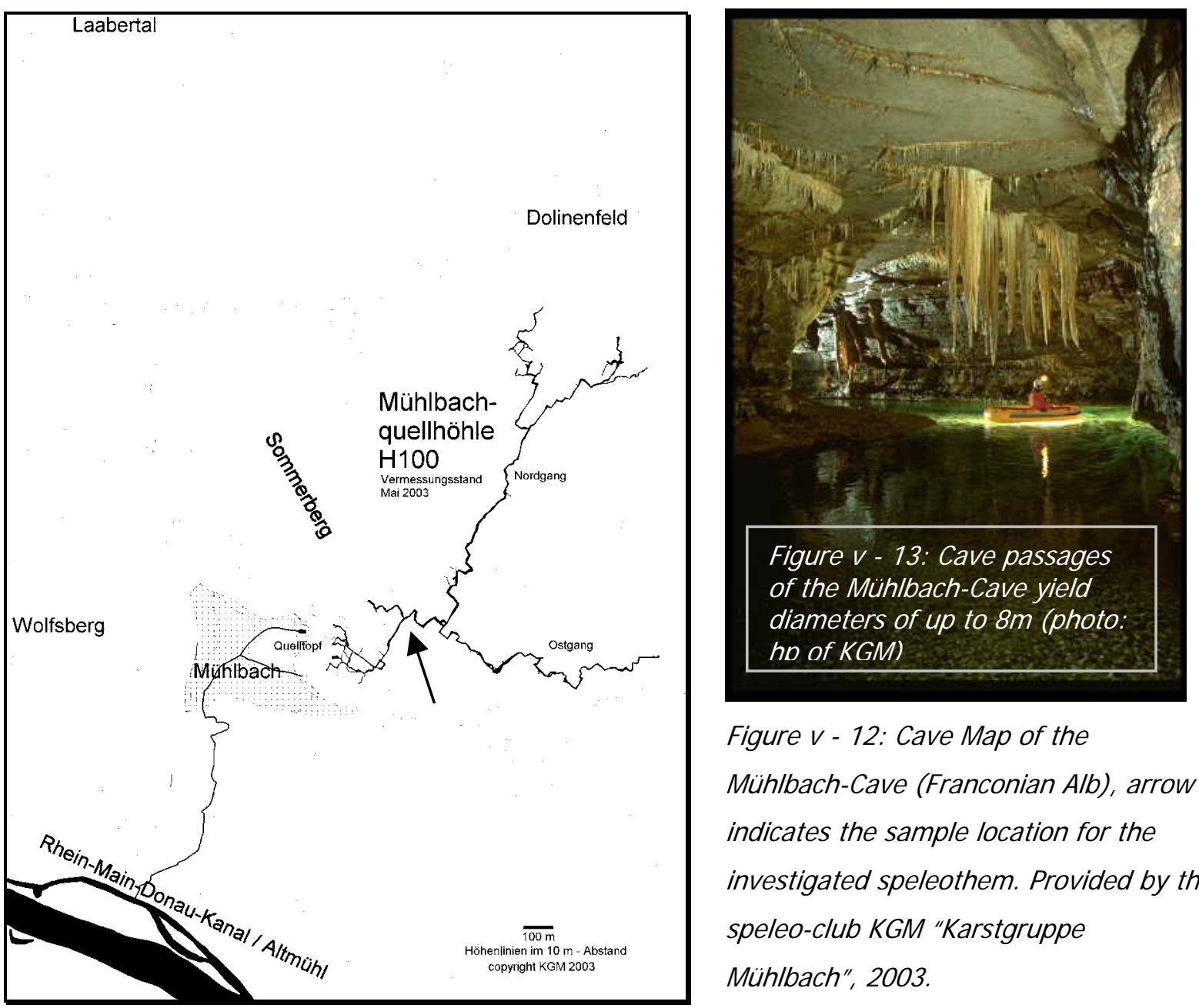

Figure v - 12: Cave Map of the

Mühlbach-Cave (Franconian Alb), arrow indicates the sample location for the investigated speleothem. Provided by the speleo-club KGM "Karstgruppe

Mühlbach", 2003.

\section{v - 3) The Baumann's- and the Hermann's-Cave of the Harz Mountains}

The Harz is the highest mountain range of northern Germany, with a range of $180 \mathrm{~km}$ by $30 \mathrm{~km}$. More or less isolated it rises with steep ascent (especially at the northern and north-western rim) between the cities of Brunswick, Göttingen, Nordhausen, and Quedlinburg. The granite and gneiss massif of the "Brocken" represents its highest elevation with $1142 \mathrm{~m}$ asl. The main axis of the Harz Mountains ranges from NW to SE and divides the catchment areas of the rivers Elbe and Weser.

The Baumann's- and Hermann's-Cave (Baumann's- und Hermann's-Höhle) are located ca. 100 km SE of the city Hannover in the village of Rübeland at the B27 (Figure v - 14). The Hermann's-Cave is ca. $1200 \mathrm{~m}$ long and six cave levels are developed between 378 to ca. $420 \mathrm{~m}$ asl. A sidebranch of the nearby river and local tributary Bode is developed as a cave river in the lowest level (Figure v - 15, lower cross-section). Starting from the same entrance altitude of $378 \mathrm{~m}$ asl, the Baumann's-Cave covers $1980 \mathrm{~m}$ in total length and a maximum vertical distribution to $440 \mathrm{~m}$ asl (Figure $\mathrm{v}-1.14$, upper ground-outline). Both horizontal caves became famous for their rich speleothem decoration and plenty of bone findings, most of them belong to the Pleistocene cave bear. The Devonian limestone host rock in the vicinity of the caves displays cave roof diameters of 10-50 m. Informations concerning abundant facies types are given by AHLBRECHT (1997) or WELLER (1989). The pedosphere in the 
catchment areas of the two caves consists of 0.5-0.9 m Parabraunerde-soils (MINISTERIUM FÜR RAUMORDNUNG, LANDWIRTSCHAFT UND UMWELT/SACHSEN-ANHALT 1996).

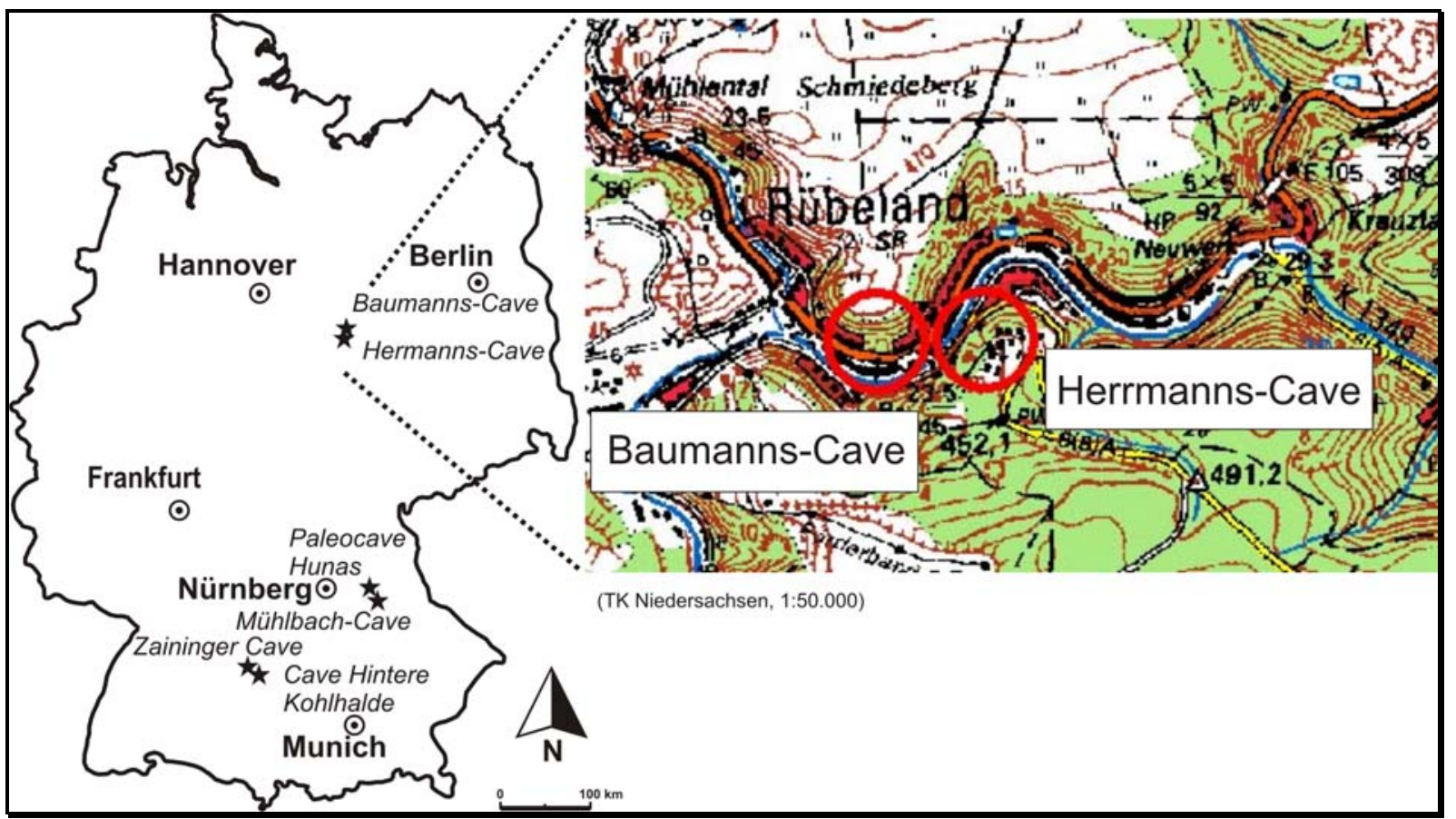

Figure v - 14: Locations of the Baumann's- and Hermann's-Cave (Harz Mountains).

\section{v - 3.1) Speleogenesis of the Baumann's- and Hermann's-Cave}

The investigated cavesystems are settled in Lower Devonian reef limestones. They crop out as $\sim 75 \mathrm{~m}$ high cliffs at the northern and southern valley slope of the Bode river in the village of Rübeland. The course of the Bode's streambed shows the typical spatial patterns of a lowland meandering river, which reflects the paleo-course before the beginning uplift of the Harz Mountains in the Lower Cretaceous (AHLBRECHT 1997, MOHR 1973). The lowering of the erosional base level due to the incision of the river Bode and the increased surface runoff combined with the tropical-subtropical climate promoted the erosion/corrosion of the Devonian limestones and the development of proto-caves. The cross-section of the Hermann's-Cave displays clearly six cave levels (Figure v - 1.14, lower part). This reflects six progressive intervals with increased solution processes during times of slower vertical movements (LÜTTIG 1955; StEINER and STEINER 1969). With cessation of the tectonic movements in the Lower Tertiary the ongoing cave developments were mainly climatically driven during Quaternary times. 

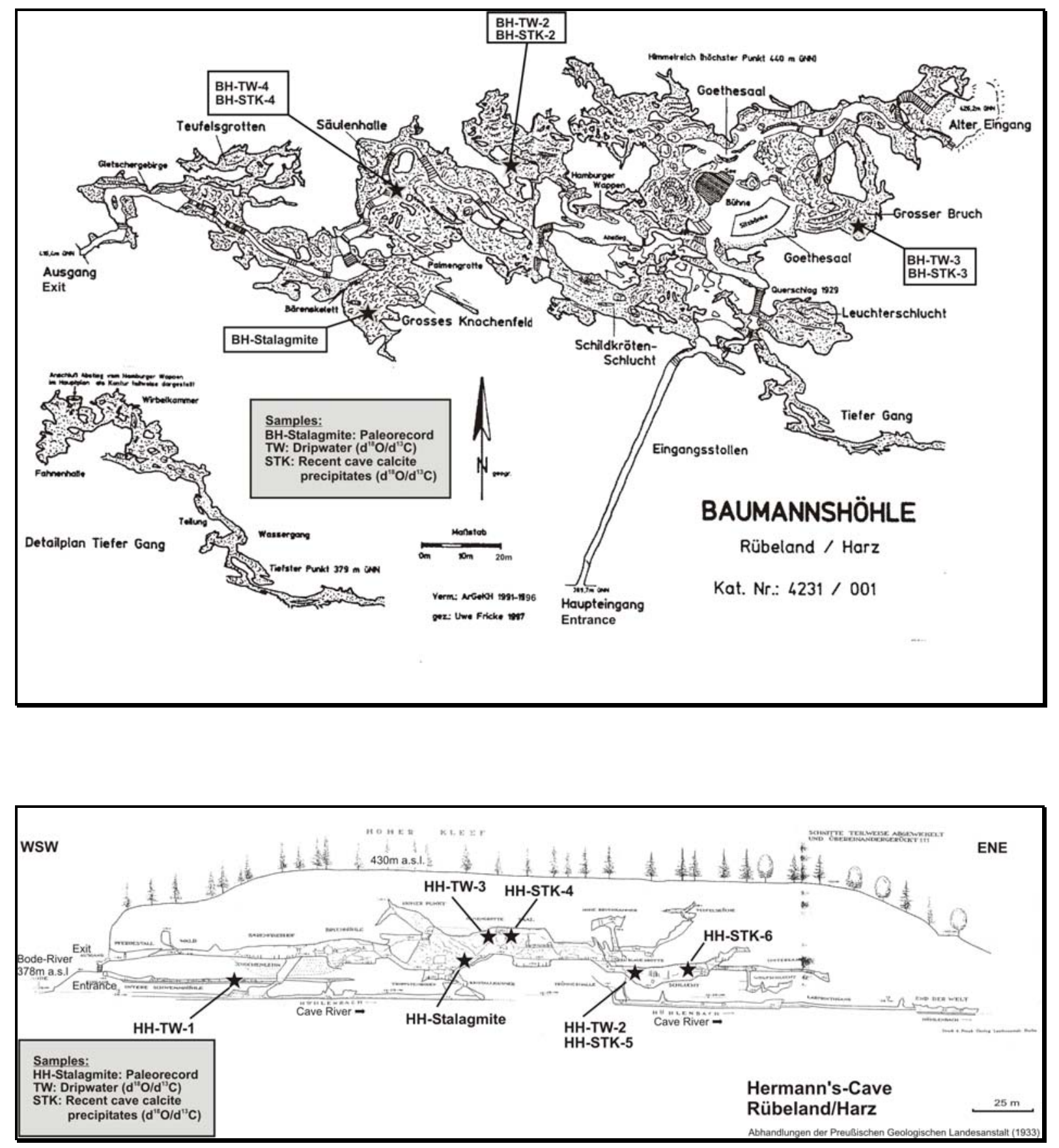

Figure v - 15: Ground outline of the Baumann's-Cave (top) and cross-section of the Hermann's-Cave, Rübeland (Harz). Sample locations for stable oxygen/carbon isotope analyses are indicated. Maps were kindly provided by Prof. S. Kempe (Univ. of Appl. Geosc., Darmstadt).

Owing to the cyclicity of the Pleistocene environmental conditions and the corresponding changes of the fluviatil conditions, older cave sediments (incl. speleothem material) were frequently subjected to endogenous redeposition. This resulted in a somewhat "chaotic disorder" of the cave sediment stratigraphy in the Baumann's-Cave. The primary material of the Young Tertiary and Pleistocene was mixed with younger sediments of the last redeposition phase at the end of the Würmian. Until today, 
only in one place of the Baumann's-Cave an older sediment layer, the "bear horizon could reliably be separated in an intact profile from a younger complex with steppe fauna " (STEINER and STEINER 1969).

\section{Quintessence}

The process of cave developments is basically a competition between a rapidly dissolving host rock producing the caves before the rock is removed by the process of surface erosion (see section ii). This process depends on the through-flow of aggressive solutions along stable flow paths and is thus tied to the extent of the uplift. Therefore, the suggested onsets of the speleogenesis were estimated based on the mean karstification events of each area and the spatial position of the investigated caves. According to the regional karstification levels, the onset of cave developments were in the periods of the Late Tertiary (Pliocene)/Pleistocene for the Paleocave Hunas, the Cave Hintere Kohlhalde and the Zaininger-Cave, and respectively between the Lower to Upper Cretaceous for the Mühlbach-, Baumann's- and Hermann's-Cave. Further research and modeling on the development of each karst area is necessary to provide the necessary frame data to reconstruct the onset of speleogenesis on a higher chronological resolution.

\begin{tabular}{|c|c|c|c|c|c|c|c|c|}
\hline Site & Region & $\begin{array}{l}\text { Geologic } \\
\text { formation }\end{array}$ & $\begin{array}{l}\text { Altitude } \\
\text { entrance } \\
\text { (m asl) }\end{array}$ & $\begin{array}{l}\text { Cave roof } \\
\text { thickness } \\
\text { (m) }\end{array}$ & $\begin{array}{l}\text { Lateral } \\
\text { distribution } \\
\text { (m) }\end{array}$ & \begin{tabular}{|l|} 
Vertical \\
distribution \\
$(\mathrm{m})$
\end{tabular} & Soil cover & Vegetation \\
\hline $\begin{array}{l}\text { Cave Hintere } \\
\text { Kohlhalde }\end{array}$ & Swabian Alb & $\begin{array}{l}\text { Malm ס } \\
\text { (ki2) }\end{array}$ & 720 & $10-15$ & 32 & 8 & Pararendzina & beech \\
\hline Zaininger-Cave & Swabian Alb & $\begin{array}{l}\text { Malm } \varepsilon, \zeta_{1} \\
(\mathrm{ki} 3, \mathrm{tiZ})\end{array}$ & 797 & 80-100 & 630 & 38 & Pararendzina & $\begin{array}{l}\text { mixed forest, } \\
\text { agricult.farml. }\end{array}$ \\
\hline $\begin{array}{l}\text { Paleocave } \\
\text { Hunas }\end{array}$ & $\begin{array}{l}\text { Franconian } \\
\text { Alb }\end{array}$ & $\begin{array}{l}\text { Malm } \delta, \varepsilon \\
(\mathrm{ki} 2,3)\end{array}$ & 520 & $3-5$ & 15 & 12 & $\begin{array}{l}\text { Rendzina-terra } \\
\text { fusca }\end{array}$ & mixed forest \\
\hline $\begin{array}{l}\text { Mühlbach- } \\
\text { Cave }\end{array}$ & $\begin{array}{l}\text { Franconian } \\
\text { Alb }\end{array}$ & $\begin{array}{l}\text { Malm Y } \\
\text { (ki1) }\end{array}$ & 400 & $100-120$ & 900 and 1200 & ? & $\begin{array}{l}\text { Rendzina-terra } \\
\text { fusca }\end{array}$ & mixed forest \\
\hline $\begin{array}{l}\text { Baumann's- } \\
\text { Cave }\end{array}$ & Harz Mountains & Devonian & 378 & $10-50$ & 1980 & 60 & Parabraunerde & $\begin{array}{l}\text { spruce, } \\
\text { agricult. } \\
\text { farml., } \\
\text { settlement }\end{array}$ \\
\hline $\begin{array}{l}\text { Hermann's- } \\
\text { Cave }\end{array}$ & Harz Mountains & Devonian & 378 & $10-50$ & 1200 & 42 & Parabraunerde & $\begin{array}{l}\text { spruce, } \\
\text { settlement }\end{array}$ \\
\hline
\end{tabular}

Table $v$ - 2: Frame data for the investigated cave systems and cave environments. 


\section{Wethods}

\section{Introduction}

In this thesis the potential paleoenvironmental data of speleothems from different sites in Germany were compared. In a first step the present-day conditions of the sites were investigated (section vii 1). Therefore, in addition to the analyses performed on the speleothems itself, the transfer of climatic related information from the input (surface) to the output (the cave system and speleothem), and the impact of environmental changes on this "transfer-function" was examined. This assessment is necessary to extract the climatic signal from the natural background scatter which represents the variability of the Interglacial/Holocene conditions. Thus, the stable oxygen/carbon isotope compositions of the meteoric precipitation, host rocks, soil zones, recent cave calcite precipitates and the dripwater of each site were as well analyzed as the temperature link between the cave atmosphere and the surface. The locations of associated cave systems, regional geology and sampling positions are given in the previous section v.

In a second step the dated older speleothem records were compared against the present-day (Holocene, Interglacial conditions) stable oxygen/carbon isotope data. Finally, a global comparison with well-documented climatic events provided a further control on the climatic interpretation of the speleothem records (section vii - 2).

All data are provided in the Appendix and sorted after appearance in the results section.

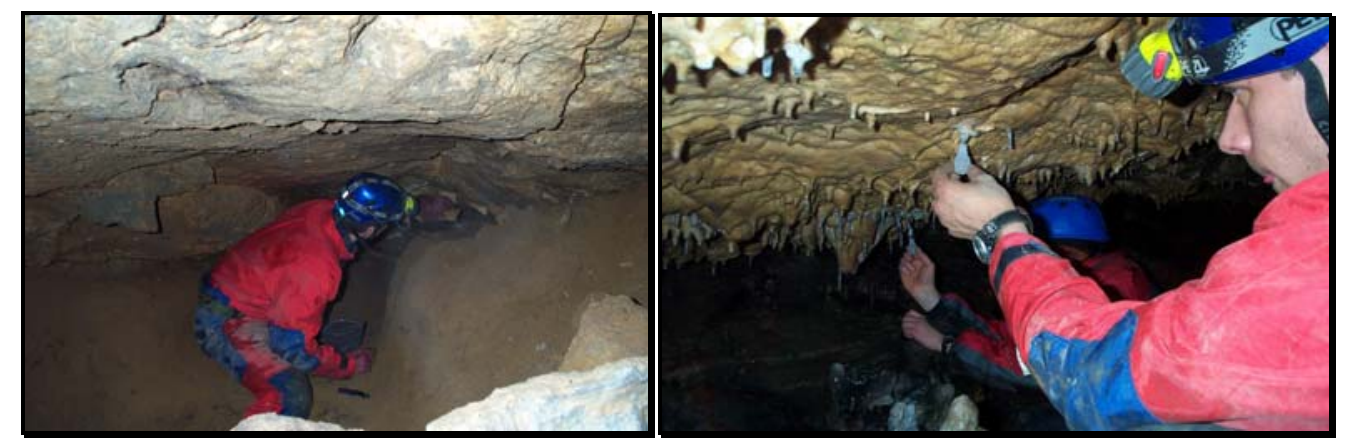

Figure vi - 1, 2: Field sampling of cave sediments in the Hermann's-Cave (left); dripwater for stable isotope analyses were collected (right) in precleaned and conditioned $5 \mathrm{ml} P \mathrm{PE}$ bottles which were sealed for the transport (Baumann's-Cave). Sampling positions are given in the previous section $v$.

\section{vi - 1) Field campaigns and cave parameters}

During the field sessions dripwater was sampled directly in precleaned and conditioned PE bottles. Especially at places with slow dripping rates additional seepage water was collected in leaving bottles with a funnel until the next campaign. 
Surface meteorological data were provided by the German weather forecasting agency ("Deutscher Wetterdienst") and the ISOHIS/GNIP (Isotope Hydrology Section/Global Network of Isotopes in Precipitation of the International Atomic Energy Agency) network. Cave temperature and relative humidity were measured during the field sessions and later compared to surface conditions and/or inferred from the local speleological clubs. Host rock samples of approximately $10 \mathrm{~kg}$ for each site were collected in the caves, each representing the stable isotopic background of the main dominant lithology. If facies shifts were abundant and accessible within the caves, these were sampled and analyzed separately. Where possible, host rock samples were taken from material recently collapsed from cave roof regions in the area of the dripwater locations.

Recent calcite precipitations like the tips of actively dripping stalactites and/or soda straws were allowed to collect in four caves. Cave sediments were sampled in the "Zaininger-Cave" as well as in the investigated caves of the Harz Mountains.

Data of the Paleocave "Hunas" is only provided by a speleothem record, as this cave ruin is completely broken down and/or refilled with fluviatil deposits.

\begin{tabular}{|c|c|c|c|c|}
\hline & & & Sample Type & Caving and fieldwork \\
\hline Cave & Region & $\begin{array}{c}\text { Sampling } \\
\text { Dates }\end{array}$ & $\begin{array}{l}\text { stable } \\
\text { oxyg./(carb.) } \\
\text { isotopes }\end{array}$ & \\
\hline $\begin{array}{l}\text { Herrmannshöhle } \\
(\mathrm{HH})\end{array}$ & Harz Mtns. & $\begin{array}{l}\text { Sep.02 } \\
\text { Oct.02 } \\
\text { Nov.02 } \\
\text { Dec.02 }\end{array}$ & DW, HR, STC-T & $\begin{array}{l}\text { S. Kempe, P. Nordhoff, } \\
\text { D. Walter } \\
\text { P. Nordhoff, H. Lindorfer } \\
\text { P. Nordhoff, H. Lindorfer } \\
\text { P. Nordhoff, H. Stück, } \\
\text { M. Bechthold }\end{array}$ \\
\hline $\begin{array}{l}\text { Baumannshöhle } \\
(\mathrm{BH})\end{array}$ & Harz Mtns. & $\begin{array}{l}\text { Sep.02 } \\
\text { Oct.02 } \\
\text { Nov.02 } \\
\text { Dec.02 }\end{array}$ & DW, HR, STC-T & $\begin{array}{l}\text { S. Kempe, P. Nordhoff, } \\
\text { D. Walter } \\
\text { P. Nordhoff, H. Lindorfer } \\
\text { P. Nordhoff, H. Lindorfer } \\
\text { P. Nordhoff, H. Stück, } \\
\text { M. Bechthold }\end{array}$ \\
\hline $\begin{array}{l}\text { Zaininger Höhle } \\
(\mathrm{ZH})\end{array}$ & Swabian Alb & $\begin{array}{l}\text { Mar.03 } \\
\text { Mar.03 } \\
\text { Jun.03 }\end{array}$ & DW, HR, STC-T & $\begin{array}{l}\text { Chr. Fischer, P. Nordhoff, } \\
\text { Chr. Fischer, P. Nordhoff, } \\
\text { S. Speiser } \\
\text { Chr. Fischer, P. Nordhoff, } \\
\text { H. Stück, D.Christ }\end{array}$ \\
\hline $\begin{array}{l}\text { Mühlbachhöhle } \\
(\mathrm{MH})\end{array}$ & Franconian Alb & May.03 & $\mathrm{HR}$ & $\begin{array}{l}\text { C.Gropp, M. +. R. Queitsch, } \\
\text { D. Gebelein }\end{array}$ \\
\hline $\begin{array}{l}\text { Hintere } \\
\text { Kohlhaldenhöhle } \\
(\mathrm{KH})\end{array}$ & Swabian Alb & Jun.03 & DW, HR, STC-T, & $\begin{array}{l}\text { K. Ruopp, Chr. Fischer, } \\
\text { P. Nordhoff, H. Stück, } \\
\text { D. Christ }\end{array}$ \\
\hline
\end{tabular}

Table $v$ - 1: The field sessions and sample types collected at the different sites.

$D W=$ dripwater; $H R=$ host rock; $S=$ soil, $C S=$ cave sediments, STC-T=stalactite tips/soda straws. 


\section{vi - 2) Sub-sampling}

Stalagmites and stalactites were taken from each cave and cut perpendicular to the growth layers with a diamond saw. The exposed internal laminations were micro-mechanical sub-sampled using a 0.3-0.5 mm drill. The sample amount ranged between 5 and $20 \mathrm{mg}$ carbonate powder for the stable oxygen/carbon isotope analyses.

Sub-samples were taken at a median resolution of 0.5 to $2 \mathrm{~cm}$ along the central growth axis of each speleothem. The check for isotopic equilibrium conditions ("Hendy-Test") was performed at single layers from the apex to the sides.

For 230-Thorium/234-Uranium TIMS (thermal ionization mass spectrometry) analyses approximately $>2 \mathrm{~g}$ were either drilled or sawed off the parent material. These relatively large sample amounts reflect low 238-Uranium values, yielding at some places concentrations of less than $50 \mu \mathrm{g} / \mathrm{kg}$ (see Appendix vii - 2.1.).

\section{vi - 3) Stable isotope analyses}

For oxygen and carbon stable isotope ratio determinations on cave carbonates and host rocks, carbonate powder of $>5 \mathrm{mg}$ were reacted with $100 \%$ phosphoric acid (density $>1.9$ ) at $75^{\circ} \mathrm{C}$ in an online carbonate preparation line (Carbo-Kiel, single sample acid bath) connected to a Finnigan Mat 252 masspectrometer. Results were reported as the per mil difference between sample and the VPDB standard by assigning a $\delta^{13} \mathrm{C}$ value of $+1,95 \%$ and a $\delta^{18} \mathrm{O}$ value of $-2,20 \%$ to NBS19. Reproducibility was checked by replicate analysis of laboratory standards and is better than $\pm 0,004 \%$. Analyses were carried out by Dr. Joachimski at the Institute of Geology and Mineralogy / Erlangen (Germany). $\delta^{18} \mathrm{O}($ and $\delta \mathrm{D}$ ) dripwater composition was measured with a Finnigan Delta-S masspectrometer at the Research Unit Potsdam of the Alfred-Wegener Institute for Polar and Marine Research (AWI). Results are given in VSMOW. $\delta \mathrm{D}$ and $\delta^{18} \mathrm{O}$ are analyzed in a row on $5 \mathrm{ml}$ aliquots which were equilibrated with $\mathrm{H}_{2}$ (2 hrs.) and $\mathrm{CO}_{2}$ (6.5 hrs.; detailed analytical procedure see MEYER et al., 2000). Mean deviation of duplicate analysis is better than the "external" mean deviation of $<0.8 \%$ for $\delta D$ and $<0.1 \%$ for $\delta^{18} \mathrm{O}$. Measurements were performed by Dr. H. Meyer at the AWI I sotope Lab in Potsdam (Germany).

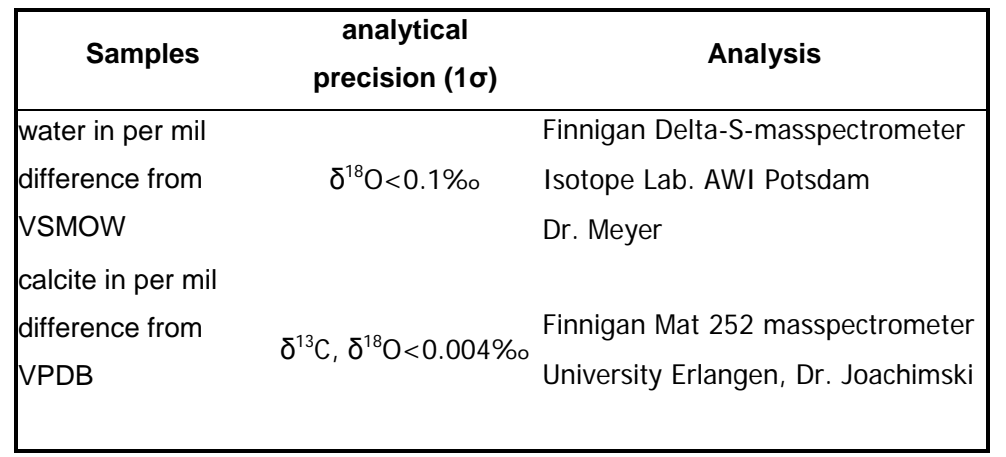

Table v - 2: Instrumental techniques used for stable isotope analyses of calcite and water. 


\section{vi - 4) ${ }^{230} \mathrm{Th} /{ }^{234} \mathrm{U}$ - TI MS dating}

For ${ }^{230} \mathrm{Th} /{ }^{234} \mathrm{U} /$ analyses approximately $2 \mathrm{~g}$ of clean spelean calcite material were completely dissolved in $2 \mathrm{ml}$ concentrated $\mathrm{HNO}_{3}{ }^{3 *}$. After adding $200 \mu \mathrm{l} \mathrm{Fe-solution} \mathrm{(20} \mathrm{ppm} \mathrm{Fe),} \mathrm{an} \mathrm{appropriate} \mathrm{amount} \mathrm{of}$ ${ }^{2}{ }^{229} \mathrm{Th}-{ }^{236} \mathrm{U}$ tracer of known composition was added to each sample solution. The sample solutions were then evaporated to dryness, followed by re-dissolution of the remaining residue with $\mathrm{H}_{2} \mathrm{O}^{4 *}$ and conc. $\mathrm{HNO}_{3}{ }^{3 *} . \mathrm{U}$ and Th were precipitated together with Fe using $\mathrm{NH}_{4} \mathrm{OH}$ (suprapur) at $\mathrm{pH} 10$. The generated precipitate was centrifuged (10 min. at $3800 \mathrm{rds}$./min.), the solution decanted, the precipitate re-suspended with $\mathrm{H}_{2} \mathrm{O}^{4 *}$, and again centrifuged. Then the precipitate was dissolved in $7 \mathrm{~N}$ $\mathrm{HNO}_{3}{ }^{3 *}$ and loaded on pre-cleaned and conditioned polyprep columns (Biorad) using anion exchange resin (Biorad 1x8 AG, 200 - 400 mesh). Th was eluted with $6 \mathrm{~N} \mathrm{HCL}^{3 *}$ (Th) and $\mathrm{U}$ with $\mathrm{H}_{2} \mathrm{O}^{4 *}$ and subsequently evaporated to dryness. $\mathrm{U}$ and Th fractions were redissolved in $0.2 \mathrm{~N} \mathrm{HNO}_{3}{ }^{3 *}$ and loaded on outgassed zone-refined rhenium filaments. The ${ }^{230} \mathrm{Th} /{ }^{234} \mathrm{U}$ analyses were performed by Dr. B. Wiegand at Stanford University (USA), and are kindly provided for this thesis: Both, $U$ and Th were measured on a thermal ionization mass spectrometer (Finnigan MAT262) equipped with a secondary electron multiplier (SEM) using the double filament technique. The currents on the ionization filaments were $5 \mathrm{amps}$, and on the evaporation filament between 1.2 and 2.0 amps. $U$ and Th were both measured in peak-jumping mode. The scanned ratios were ${ }^{235} \mathrm{U} /{ }^{236} \mathrm{U},{ }^{234} \mathrm{U} /{ }^{236} \mathrm{U},{ }^{230} \mathrm{Th} /{ }^{229} \mathrm{Th}$ and ${ }^{232} \mathrm{Th} /{ }^{229 T h}$ (number of scans generally $>100$ per analysis). The standard used for calibration was HU1. ${ }^{234} \mathrm{U} /{ }^{238} \mathrm{U}$ activity ratios were calculated using the measured ${ }^{234} \mathrm{U} /{ }^{236} \mathrm{U}$ and the ${ }^{235} \mathrm{U} /{ }^{236} \mathrm{U}$ atomic ratios. The ${ }^{230} \mathrm{Th} /{ }^{234} \mathrm{U}$ and the ${ }^{230} \mathrm{Th} /{ }^{232} \mathrm{Th}$ activity ratios were calculated using the measured ${ }^{232} \mathrm{Th} /{ }^{229} \mathrm{Th}$ and the ${ }^{230} \mathrm{Th} /{ }^{229} \mathrm{Th}$ ratios. Age calculations were made by iteration and are based on the equation:

${ }^{230} \mathrm{Th} /{ }^{238} \mathrm{U}_{\mathrm{A}}=\left[1-\mathrm{e}^{-\lambda_{230} t}\right]+\left[\delta^{234} \mathrm{U}(\mathrm{T}) / 1000\right] \times\left[\lambda_{230} /\left(\lambda_{230}-\lambda_{234}\right)\right] \times\left[1-\mathrm{e}^{-\left(\lambda_{234}-\lambda_{230}\right) t}\right]$

(KAUfMANN AND BRoECKER 1965, RichardS AND DORALE 2003).

The different notions used to give the age of a sample are:

a B.P. - $>\mathrm{U} / \mathrm{Th}$ age before present.

cal. a B.P -> calibrated U/Th age due to interpolation. 


\section{VI - 1 Results and discussion: Present-day calibration}

\section{Introduction}

If present-day $\delta^{18} \mathrm{O}$ of cave calcites represent the ambient temperature (surface and cave temperature), the stable oxygen isotope paleorecords of speleothems may reflect warmer or cooler conditions relative to the modern (Holocene) environment. Mandatory for this is to understand which modern climatic signals are conducted to which extent to the subsurface and how they are "preserved" in the recent cave calcites. Investigated proxies are the stable isotopic oxygen/carbon abundances of the recent cave calcites, host rock, dripwater, effective meteoric precipitation as well as the feedback of cave parameters to the surface temperature and relative humidity.

In Germany 18 weather stations participate in the IAEA/WMO (International Atomic Energy Agency/World Meteorological Organization) program to monitor the world-wide $\delta^{18} O$ composition of monthly meteoric precipitation. Like in the most projects not focused mainly on e.g. hydrological or hydrogeological aspects, it was not possible to monitor the meteoric precipitation directly at the cave locations. In this case usually the records from the nearest IAEA/WMO stations are referred to. The reference stations are Stuttgart (Cannstatt) and Regensburg for the Swabian/Franconian Alb (Zaininger-Cave, Cave Hintere Kohlhalde and Mühlbach-Cave), and Brunswick for the Baumann's- and Hermann's-Cave in the Harz Mountains (Figure vii - 1.1 and table vii - 1.1, below). The weighted annual mean $\delta^{18} \mathrm{O}$ of the rainwater ranges between ca. -8.00 (Stuttgart/Brunswick) and $-10.00 \%$ VSMOW (Regensburg; ROZANSKI et al. 1993). The monthly mean distribution displays the typical $\delta^{18} \mathrm{O}$ pattern of mid- (and high-) latitude locations with depleted winter and enriched summer precipitation. The mainly temperature (and thus seasonally) controlled stable oxygen isotope ratios show lighter winter signals of ca. -12.3 to $-8.7 \%$ VSMOW (November to February) and heavier summer values in the range of ca. -5.5 to $-8.6 \%$ VSMOW (May to August). Detailed and additional annual IAEA data is provided in Appendix vii - 1.1 and -1.2.

\section{vii - 1.1) Temperature response of the cave atmospheres (results)}

For estimating the cave-temperature effect, reference surface data of the IAEA/WMO and of some regional weather stations were used. The local stations are assumed to enhance the regional resolution of the MAAT (here referred to as "regional MAAT", see table vii - 1.2) since they are situated closer to the caves in question. Long-term timeseries of the surface temperatures taken directly at the cave locations and of the cave atmospheres were not available.

Temperature and precipitation data for the Zaininger-Cave and Cave Hintere Kohlhalde are available from the weather station "Seißen". The station is maintained by the Weather Forecasting Agency of Freiburg i. Br. and is situated $\sim 5 \mathrm{~km}$ SE from the Cave Hintere Kohlhalde. Around the city of 
Blaubeuren the mean annual meteoric precipitation amounts to $730-750 \mathrm{~mm} / \mathrm{a}$ for the period 1930 -

61. It increased NW according to the altitude to $850 \mathrm{~mm} / \mathrm{a}$ in the area of Laichingen (VILLINGER 1978).

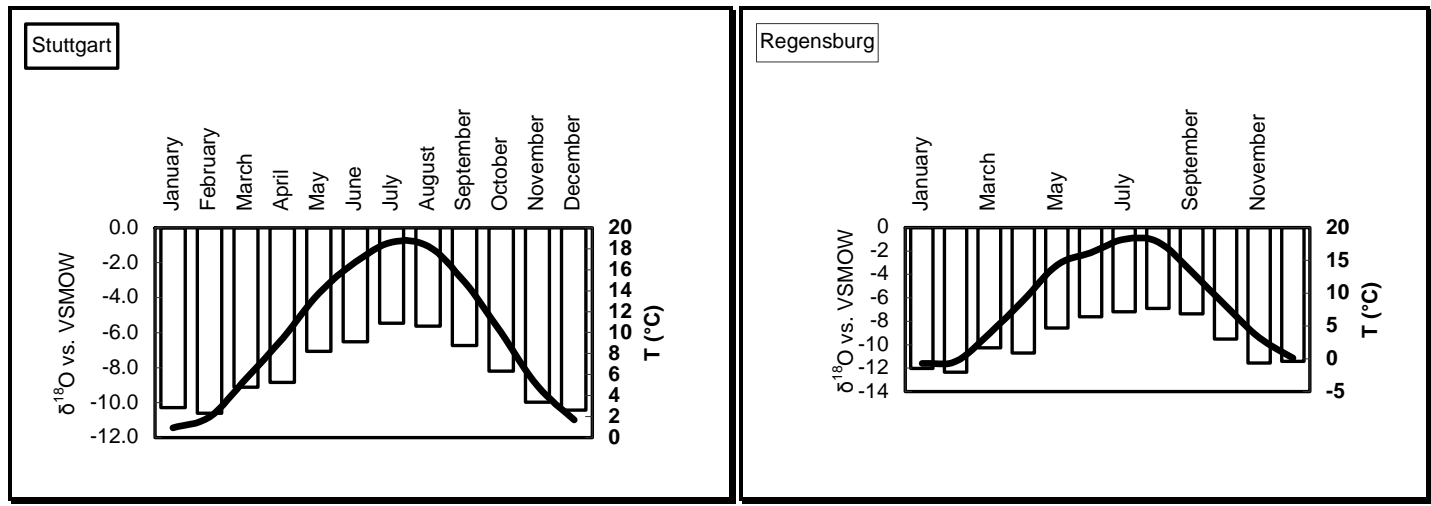

Brunswick

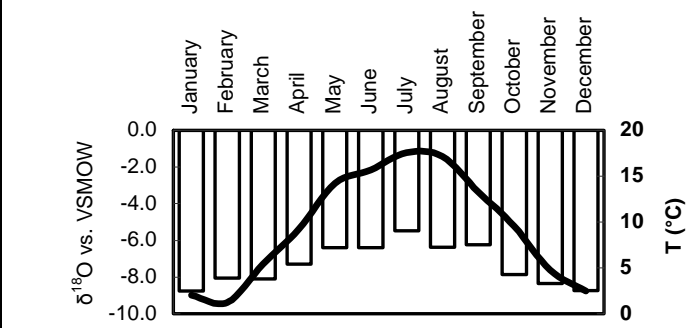

Figure vii - 1.1: Monthly mean $\delta^{18} \mathrm{O}$ rain of

IAEA/WMO stations closest to the investigated sites.
Mean annual averages for the same stations are given in the table vii - 1.1. Sampling periods, additional IAEA data for Germany and for some European sites are summarized in Appendix vii - 1.1 and - 1.2 (Data: ROZANSKI et al. 1993).

Table vii - 1.1:

\begin{tabular}{|l|l|l|l|l|}
\hline $\begin{array}{l}\text { Stations } \\
\text { IAEA/WMO }\end{array}$ & $\begin{array}{l}\text { Altitude } \\
(\mathrm{m} . \text { asl })\end{array}$ & $\begin{array}{l}\text { w.m } \delta^{18} \mathrm{O} \\
(\% 0 \\
\text { vs.VSMOW) }\end{array}$ & $\begin{array}{l}\mathrm{T}\left({ }^{\circ} \mathrm{C}\right) \\
\text { Prec. } \\
(\mathrm{mm} / \mathrm{a})\end{array}$ \\
\hline Brunswick & 88 & -8.1 & 8.3 & 643 \\
\hline Regensburg & 377 & -10.02 & 7.7 & 639 \\
\hline Stuttgart & 315 & -8.01 & 9.3 & 655 \\
\hline
\end{tabular}

The mean annual air temperature (MAAT) is for the same period 6.5 to $7^{\circ} \mathrm{C}$ (SCHIRMER 1978). This coincides well with new dates provided by SAUTER (1992) for the also Danube facing Lauchert-FehlaSchmiecha catchment area. This area is located $\sim 40 \mathrm{~km} \mathrm{SE}$ of the Cave Hintere Kohlhalde, comprises topographic heights from $600-900 \mathrm{~m}$ asl and yields a MAAT of $7.2^{\circ} \mathrm{C}$. Appendix vii -1.3 displays the mean monthly air temperature (and rel. humidity) variation and extreme years for the period 1965-89.

The Paleocave Hunas and the Mühlbach-Cave (Franconian Alb) are situated approximately $50 \mathrm{~km} \mathrm{E}$ of the weather station Nürnberg (318 m asl, station Nürnberg: 10763), which is maintained by the German Weather Forecasting Agency ("Deutscher Wetterdienst, DWD). Climate records for the period 1961-90 show a MAAT of $9.2^{\circ} \mathrm{C}$ and mean annual precipitation of $644 \mathrm{~mm} / \mathrm{a}$ (data online available at: http://www.dwd.de/de/FundE/Klima/KLIS/daten/online/nat/index.htm; Update from J une 2004). 
In northern Germany the Harz Mountains are the region with the highest amount of meteoric precipitation. They are the first "serious" topographic heights (highest elevation: Mount Broken, $1141 \mathrm{~m}$ asl), which are encountered after the SE traveling vapor masses trespassed the northern German lowlands. Therefore, the IAEA/WMO station Brunswick ( $88 \mathrm{~m}$ asl), which is located ca. $60 \mathrm{~km}$ NNW of Rübeland ( $\sim 370-380 \mathrm{~m}$ asl) records lower MAAT's and mean annual precipitations $\left(8.3^{\circ} \mathrm{C}\right.$ and $643 \mathrm{~mm} / \mathrm{a})$ than the local weather station at the village of Rübeland ( $700 \mathrm{~mm} / \mathrm{a}$ and MAAT of $\left.6-7^{\circ} \mathrm{C}\right)$.

\begin{tabular}{|c|c|c|c|c|c|}
\hline Location / Site & $\begin{array}{l}\text { Cave-T } \\
\left({ }^{\circ} \mathrm{C}\right)\end{array}$ & $\begin{array}{c}\text { Regional MAAT } \\
\left({ }^{\circ} \mathrm{C}\right)\end{array}$ & References & \begin{tabular}{|c|} 
Regional mean \\
annual precip. \\
$(\mathrm{mm} / \mathrm{a})$
\end{tabular} & References \\
\hline Zaininger-Cave & $6.0-7.0$ & $6.50-7.20$ & \multirow[b]{2}{*}{$\begin{array}{l}\text { SCHIRMER, } 1978\left(6.5-7.0^{\circ} \mathrm{C}\right) \\
\text { SAUTER, } 1992\left(7.2^{\circ} \mathrm{C}\right)\end{array}$} & $730-850$ & \multirow[b]{2}{*}{ VILLINGER, 1978} \\
\hline $\begin{array}{l}\text { Cave Hintere } \\
\text { Kohlhalde }\end{array}$ & 9.0 & $6.50-7.20$ & & $730-850$ & \\
\hline Mühlbach-Cave & $7.0-8.0$ & 9.2 & $\begin{array}{l}\text { GERMAN } \\
\text { WEATHERFORC.AGENCY } \\
\text { (DWD) Nürnberg }\end{array}$ & 644.0 & $\begin{array}{l}\text { GERMAN } \\
\text { WEATHERFORC.AGENCY } \\
\text { (DWD) Nürnberg }\end{array}$ \\
\hline $\begin{array}{l}\text { Baumann's- } \\
\text { Cave }\end{array}$ & $8.0-9.0$ & $6.1-7.0$ & \multirow{2}{*}{$\begin{array}{l}\text { MINIST. F. } \\
\text { RAUMORDNUNG, } \\
\text { LANDWIRTSCHAFT U. } \\
\text { UMWELT,1996 }\end{array}$} & 700.0 & \multirow{2}{*}{ GLÄSSER, 1991} \\
\hline $\begin{array}{l}\text { Hermann's- } \\
\text { Cave }\end{array}$ & $8.0-9.0$ & $6.1-7.0$ & & 700.0 & \\
\hline
\end{tabular}

Table vii - 1.2: Cave temperatures vs. regional MAAT and mean annual meteoric precipitation. Compilation of regional data see references. Informations about the yearly cave temperatures were provided by the associated speleological clubs (ARGE Grabenstetten, Thüringer Höhlenverein)

The table vii - 1.2 (above) shows that the temperature of the Zaininger-Cave yields $\sim 6.5^{\circ} \mathrm{C}$, which is in good accordance with the mean annual air temperature range at the surface $\left(6.5-7.2^{\circ} \mathrm{C}\right)$ given by SCHIRMER (1978) and SAUTER (1992).

The other cave locations display a slightly temperature bias between 1 and $2^{\circ} \mathrm{C}$ in regard to the regional MAAT.

\section{vii - 1.1.1) Temperature response of the cave atmospheres (discussion)}

Despite the enhanced resolution for the regional MAAT's a small temperature bias is existent. This is probably still on account of the insufficient resolution of the surface reference data. Assuming the established database being representative, other scenarios explaining the temperature bias are provided though difficult to prove:

The Baumann's- and Hermann's-Cave are showcaves which are heavily frequented by tourists. This may potentially exert an impact on the cave temperature. Generally, the main effects of tourists and showcave operations on cave atmospheres are from drying out of cave formations owing to body heat, from lightning (increased evaporation), and from increased $\mathrm{CO}_{2}$ levels: VILLAR et al. (1986) reported released heat rates by single persons of $82-116$ watts $(1 \mathrm{~W}=1 \mathrm{~J} / \mathrm{s})$. At Remouchamps Cave 
(Belgium), a single party of 87 tourists raised cave air temperature by $1.5^{\circ} \mathrm{C}$ during a five minute visit (MerenNe-Schoumaker 1975). Williams (1975) reported that the daily lighting of the Glow-Worm Cave (Waitomo, New Zealand) could be responsible for a $2^{\circ} \mathrm{C}$ rise of the cave temperature.

Although the quantification of the temperature influence due to the showcave operations is out of scope of this thesis, the referred experiences strongly suggest tourist-triggered influences on the cave temperatures (and atmospheres) of the Baumann's- and Hermann's-Cave.

A good example for coupled sub- and surface temperature feedbacks in entrance regions of caves was monitored during the sample session in March 2003 at the Zaininger-Cave. The temperature dropped from $3.5^{\circ} \mathrm{C}$ ( $71 \%$ rel. humidity) at the surface to $1.5-2^{\circ} \mathrm{C}(\sim 97 \%$ rel. humidity) at the entrance hall of the cave ("Tropfsteinhalle", see cave map section v). It adapted to stable cave temperature conditions of 6.5 to $7^{\circ} \mathrm{C},(\sim 99 \%$ rel. humidity) after $150 \mathrm{~m}$ in the area of the "Lehmxylofon", where the main cave passage turns from $\mathrm{S}$ to $\mathrm{E}$. Cold, dense winter air seeped into the cave and got trapped between the entrance chamber and the Lehmxylofon (Data for temperature and rel. humidity measured during this sample session is given in Appendix vii - 1.4). This may have been promoted by the pocket-like cross-section of the passage in this area and by the abundant cave clays potentially sealing the cave bottom. In the winter season 2003 these conditions caused a widespread development of bizarre icicles in the area of the entrance chamber. Most of them were found growing on the bottom between the speleothems (Figure vii - 1.2). This phenomenon have not been observed before in this cave by the local speleologists (person. commun. FISCHER 2003). Therefore, this may be classified as a temporarily irregular occurring and very regional specific setting. During the last years the propagation of the mining operations around the cave entrance may have created further artificial openings and thus favourable conditions for the migration of cold air masses into the cave system.
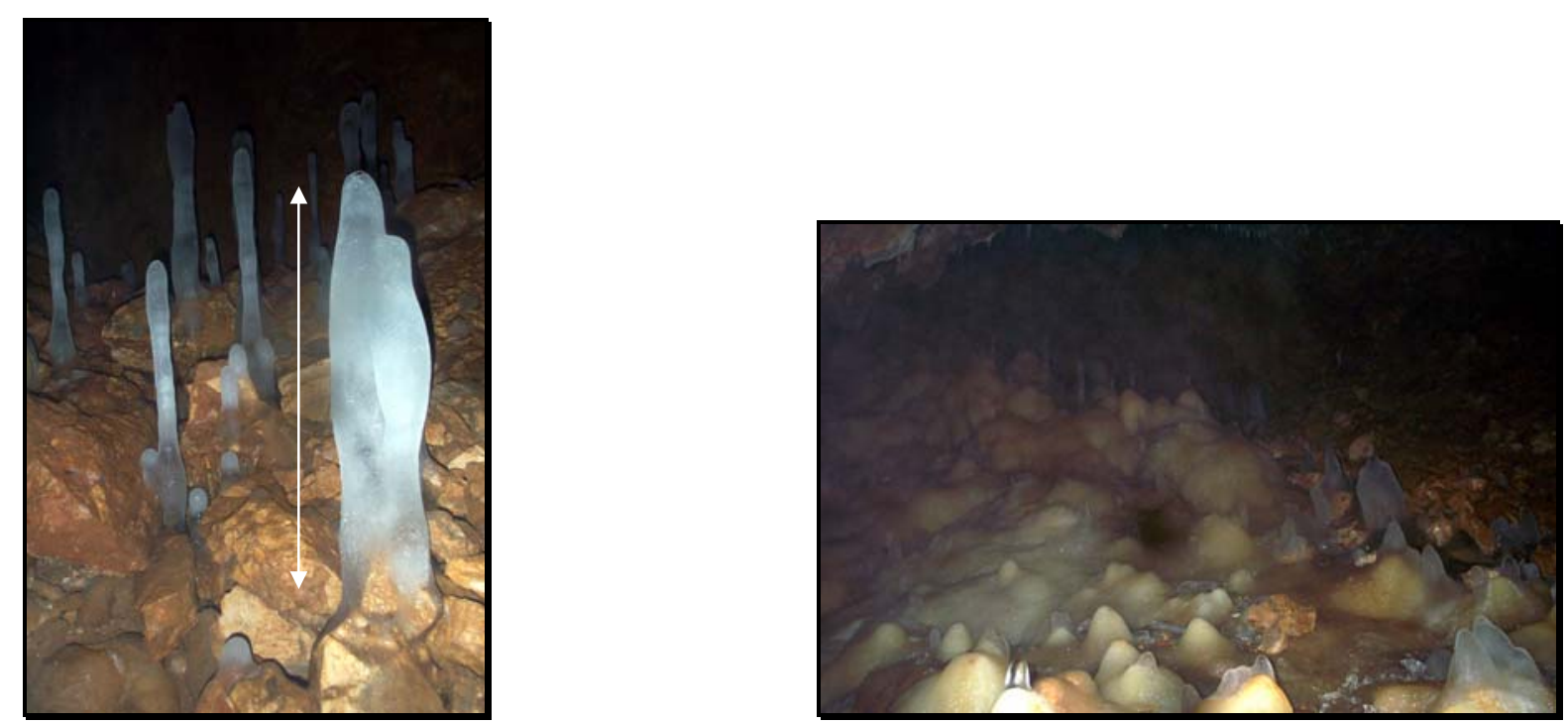

Figure vii - 1.2: Icicles up to $60 \mathrm{~cm}$ length (arrow) developed in the entrance chamber of the Zaininger-Cave during the winter season 2003. 
The higher cave temperature $\left(9^{\circ} \mathrm{C}\right)$ of the Cave Hintere Kohlhalde may have been caused by a higher amount of incident solar radiation in this area. This is favored by the SW exponation of the valley slope and the very close spatial position of the cave to it. An unhindered outflow of dense, colder air at the cave bottom may occur since finegrained cave sediments with sealing potential are not abundant. The relative loss of colder air may lead to a relative increase in cave temperature. This is promoted by the comparatively small size of the cave chamber.

The Mühlbach-Cave shows in contrast to the associated mean annual surface $\left(9.2^{\circ} \mathrm{C}\right.$, station Nürnberg) lower temperatures of $7-8^{\circ} \mathrm{C}$ that might be explained by the cooling effect of the streaming water of the open cave river ( $300 \mathrm{l} / \mathrm{s}$; GLASER 2003).

It is striking that almost all caves exhibiting the temperature bias are to some extend influenced by anthropogenic action (Baumann's- and Hermann's-Cave) or by some very regional settings (Cave Hintere Kohlhalde, Mühlbach-Cave, Zaininger-Cave). Compared to the timeperiod of the Quaternary, most of the inferred causes exert a rather short-term forcing on the cave atmospheres. The temperature bias between surface temperature and subsurface response is $1-2^{\circ} \mathrm{C}$ for the Baumann'sand Hermann's-Cave, the Cave Hintere Kohlhalde and the Mühlbach-Cave. The icicle phenomenon at the Zaininger-Cave showed the limitations of this kind of data-inquisition being one-point measurements during the field campaigns, and/or personal communications without recorded evidences. Due to this, very short-term regional events can occur unnoticed since they do not leave a detectable imprint on the annual scale.

However, the local speleo-clubs reported that the mean annual cave air temperatures are stable and thus decoupled by seasonal influences. Therefore, only long-term MAAT changes will have an impact on the cave temperatures and thus influence the stable oxygen isotope fractionation during calcite precipitation (see "cave-temperature" effect, section iv).

\section{vii - 1.2) Stable oxygen/ carbon isotopic distributions of cave contents (results)}

\section{vii - 1.2.1) Cave dripwater}

The $\delta^{18} \mathrm{O}$ composition of the dripwater collected from the Zaininger-, Hermann's-, and Baumann'sCave are given in Appendix vii - 1.5. No samples were available for the Cave Hintere Kohlhalde and the Mühlbach-Cave. In figure vii - 1.3 the Zaininger-Cave samples display the most depleted $\delta^{18} \mathrm{O}$ values in the range of -10.5 to $-11.69 \%$ VSMOW of all samples. Values of the Hermann's - and Baumann's-Cave are comparably more enriched from -8.77 to $-9.28 \%$ VSMOW but with a considerable lower intra - and intercave mean deviation (Hermann's- vs. Baumann's-Cave). All samples are in accordance with the globally inferred meteoric waterline (GMWL). 


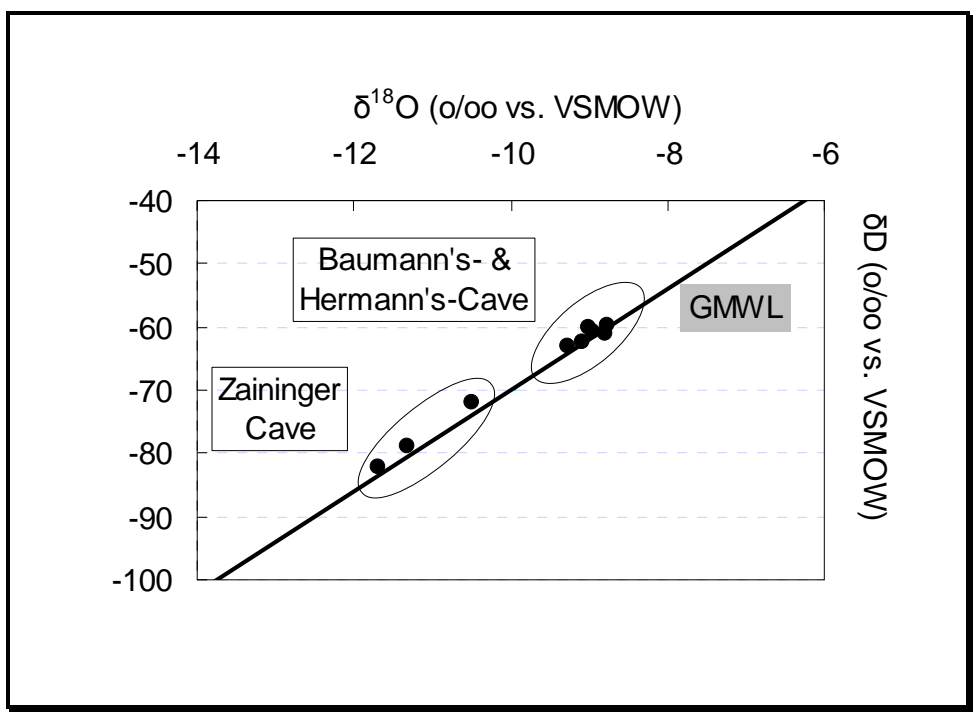

Figure vii - 1.3: Stable isotopic composition of the dripwater samples in regard to the GMWL shows most depleted ratios for the Zaininger-Cave (Data Appendix vii $-1.5)$.

In figure vii - 1.4 (below) the stable oxygen isotope signature of the dripwater is compared with the associated IAEA/WMO precipitation data (data see figure vii - 1.1 above, this section) of Stuttgart, Regensburg and Brunswick. The mean $\delta^{18} \mathrm{O}_{\text {dripwater }}$ of all sites are depleted in ${ }^{18} \mathrm{O}$ in regard to their closest IAEA/WMO station. Since the difference in elevation between the cave entrances and the weather stations ranges between 290 to $472 \mathrm{~m}$, the altitude effect was taken into account. Calculated isotopic fractionation yields ratios of -0.29 to $-0.31 \% / 100 \mathrm{~m}$ for most of the caves. This is in the range of values inferred from studies in different regions of Europe yielding depletions in $\delta^{18} \mathrm{O}$ of -0.15 to -0.30 (RozANSKI et al. 1993) or -0.16 to $-0.40 \%$ (EICHLER 1964, AMBACH et al. 1968) per $100 \mathrm{~m}$ rise of the vapor masses.

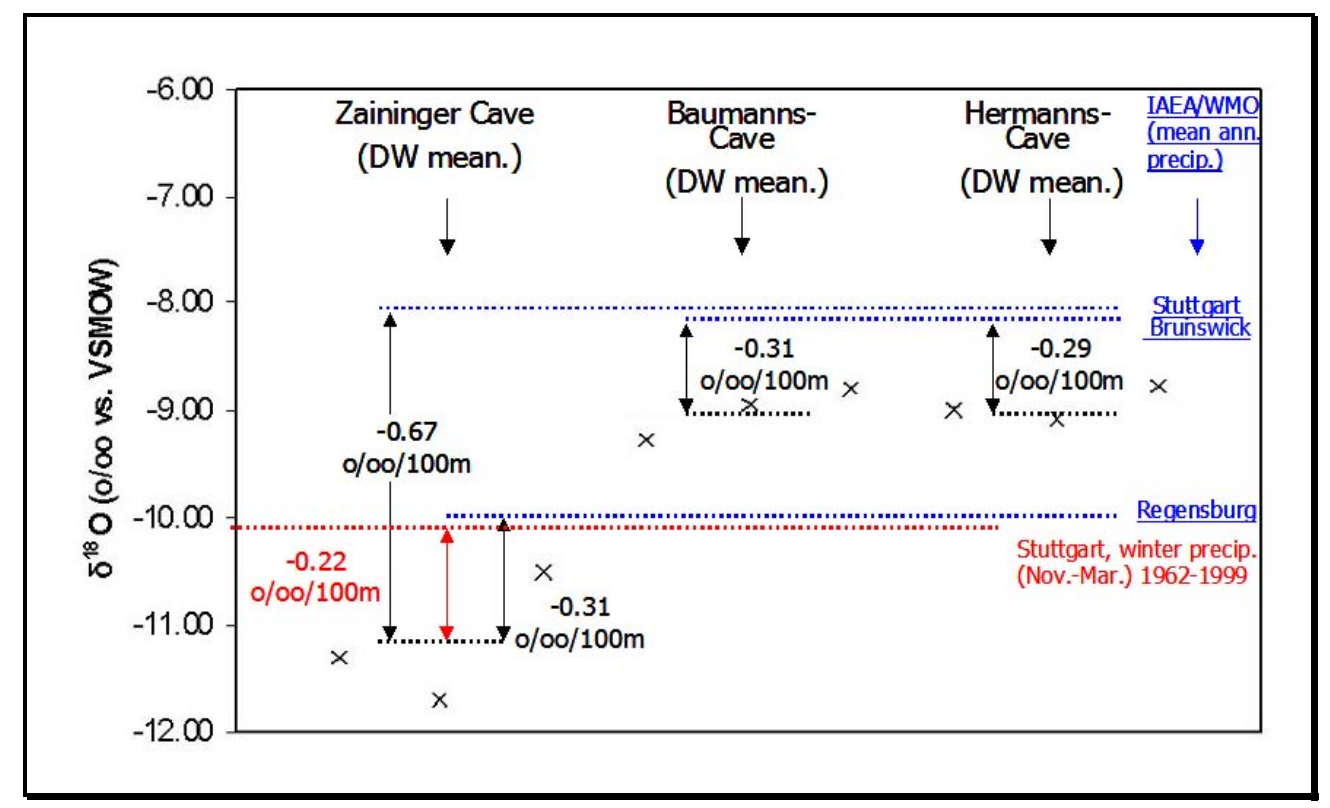

Figure vii - 1.4: $\delta^{18} \mathrm{O}$ of cave dripwater (crosses = single samples, black-dotted lines = arithmetic mean) compared with the mean annual meteoric precipitation (1962-99) of the nearest IAEAIWMO stations (blue). Red: Mean winter precipitation, station Stuttgart (Nov.-Mar., 1962-99). Arrows = calculated altitude effect. 
The estimated altitude effect for the Zaininger-Cave based on the Stuttgart reference data yields the most depleted ratio of $-0.67 \% / 100 \mathrm{~m}$ of this set. Calculated with the $\delta^{18} \mathrm{O}$ precipitation data of Regensburg the altitude effect is $-0.31 \% / 100 \mathrm{~m}$.

\section{vii - 1.2.2) Host rock}

The $\delta^{18} 0$ host rock compositions of the Zaininger-Cave vary between -6.19 and $-2.90 \%$ VPDB with a mean of $-4.92 \%$ VPDB, whereas the sample of the Cave Hintere Kohlhalde yields an intermediate ratio of $-5.70 \%$ VPDB (Table vii -1.3 ). $\delta^{13} \mathrm{C}$ is for both caves between -5.10 and $+1.24 \%$ VPDB with a mean of $-2.99 \%$ VPDB for the Zaininger-Cave. Note the considerable heavier $\delta^{18} \mathrm{O} / \delta^{13} \mathrm{C}$ ratios of the host rock sample 3 of the Zaininger-Cave (ZH-UG-3).

The three samples of the Mühlbach-Cave display the heaviest stable isotopic abundances of this set (excepted ZH-UG-3) with rather constant ratios. $\delta^{18} \mathrm{O}$ ranges between -3.03 and $-2.32 \%$ VPDB (mean: $-2.83 \%$ VPDB). $\delta^{13} \mathrm{C}$ values vary between +2.04 and $+2.45 \%$ VPDB (mean: $+2.22 \%$ o VPDB).

The host rock signature of the Baumann's- and Hermann's-Cave indicate most depleted $\delta^{18} \mathrm{O}$ ratios of all investigated caves (-8.89 and $-6.79 \%$ VPDB). $\delta^{13} \mathrm{C}$ display covariate values of +1.15 and $+1.67 \%$ VPDB.

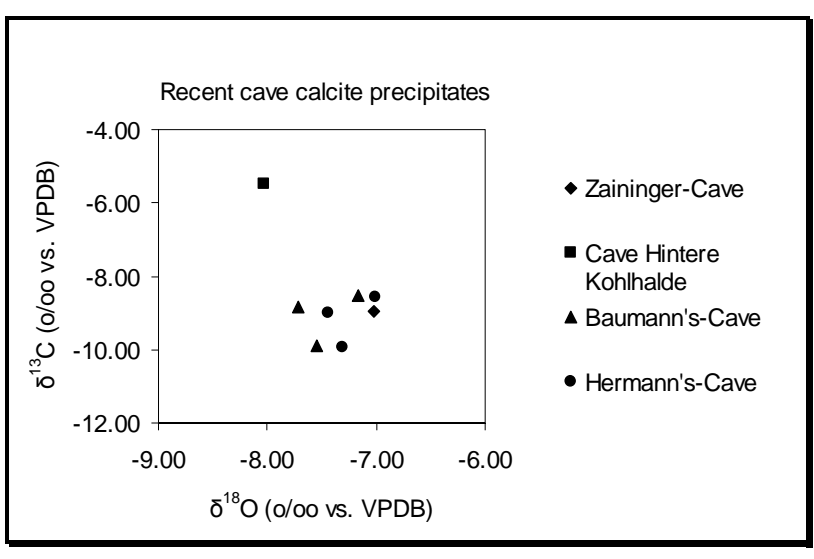

Figure vii - 1.5 / table vii - 1.3: Stable oxygen vs. stable carbon isotopic composition of recent cave calcite precipitates like the tips of soda straws or active growing stalactites (left figure) and the associated host rock (table).

\begin{tabular}{|l|l|l|l|}
\hline $\begin{array}{l}\text { Host rock } \\
\text { composition }\end{array}$ & $\begin{array}{l}\mathbf{\delta}^{\mathbf{1 8}} \mathbf{O} \\
\text { (o/ oo vs. } \\
\text { VPDB) }\end{array}$ & $\begin{array}{l}\mathbf{\delta}^{\mathbf{1 3}} \mathbf{C} \\
\text { (o/ oo vs. } \\
\text { VPDB) }\end{array}$ & \\
\hline Zaininger-Cave & -5.66 & -5.10 & ZH-UG-01 \\
\hline & -6.19 & -5.10 & ZH-UG-02 \\
\hline & -2.90 & 1.24 & ZH-UG-3 \\
\hline Mean & -4.92 & -2.99 & ZH ug mean \\
\hline Kohlhalde & -5.70 & -3.83 & HKH-UG 1 \\
\hline Mühlbach-Cave & -2.32 & 2.45 & MH-UG 1 \\
\hline & -3.15 & 2.04 & MH-UG 2 \\
\hline & -3.03 & 2.22 & MH-UG-3 \\
\hline Mean & -2.83 & 2.24 & MH ug \\
& & & mean \\
\hline Baumann's-Cave & -6.79 & 1.15 & BH-UG-01 \\
\hline Hermann's-Cave & -8.89 & 1.67 & HH-UG-01 \\
\hline
\end{tabular}




\section{vii - 1.2.3) Recent cave calcite depositions}

Recent cave calcite precipitates show quite uniform stable oxygen isotopic values of -8.03 and $7.01 \%$ VPDB and a mean of $-7.41 \%$ VPDB of all investigated sites (data is given in Appendix vii 1.5). Higher variability displays the $\delta^{13} \mathrm{C}$ data, displaying a range of -9.95 up to $-5.48 \%$ VPDB (mean: $-8.64 \%$ VPDB). The most depleted $\delta^{18} \mathrm{O}$ ratios and most enriched $\delta^{13} \mathrm{C}$ values are observed in the sample of the Cave Hintere Kohlhaldenhöhle. The recorded compositions of the Zaininger-Cave sample are $-7.02 \%\left(\delta^{18} \mathrm{O}\right)$ and $-8.94 \%\left(\delta^{13} \mathrm{C}\right)$. The $\delta^{18} \mathrm{O}$ composition of the Baumann's- and Hermann's-Cave samples is consistent with minor variations of $\pm 0.55 \%$ and respectively $\pm 0.43 \%$ o (Figure vii - 1.5, above and table vii - 1.4, below).

\section{vii - 1.2.4) Stable oxygen/ carbon isotopic distributions of cave contents (discussion)}

The investigated cave dripwaters of the Baumann's- and Hermann's-Cave display only minor variations around ca. $-8.98 \%$ VSMOW. The data is well in agreement with altitude corrected reference rainwater data of the IAEA/WMO station Brunswick. The Zaininger-Cave samples show comparably depleted $\delta^{18} \mathrm{O}_{\text {dripwater }}$ values (mean - $11.17 \%$ VSMOW) and an increased altitude effect of $0.67 \%$ / $100 \mathrm{~m}$ modelled with the reference data of Stuttgart. A better estimation of $-0.31 \%$ o $/ 100 \mathrm{~m}$ in regard to the site is provided by the stable oxygen records of the station Regensburg situated $\sim 200 \mathrm{~km}$ to the NW.

Therefore, processes affecting the annual stable oxygen isotope variations of the regional atmospheric/hydrological cycle being relevant for this site may not be represented by the records of the station Stuttgart. On the other hand, the arithmetic winter mean $\delta^{18} \mathrm{O}_{\text {rain }}$ (November-March, 196299 ) in Stuttgart is - $10.1 \%$ VSMOW (see Appendix vii - 1.2). This gives a reasonable altitude effect in regard to the Zaininger-Cave of $-0.22 \% / 100 \mathrm{~m}$. Since it was not possible to i) measure the cave dripwater composition for an appropriate period of time (at least $>1$ year) and/or ii) to investigate the continuity of driprates, the possibility of a conducted seasonal winter-signal cannot be ruled out. Isotope effects concerning the cave itself and associated environment like evaporation within the pedosphere, host rock, mixing with air pockets or with remnant ("older") water within the vadose zone, or kinetic fractionation conditions of the cave atmosphere (see chapter iv) would cause a relative depletion on ${ }^{16} \mathrm{O}$ (enrichment on ${ }^{18} \mathrm{O}$ ). In this case $\delta^{18} \mathrm{O}_{\text {(dripwater) }}$ signals would have shifted into the opposite direction towards heavier values.

Comparing the records of the stations Regensburg and Stuttgart it is obvious that the $\delta^{18} \mathrm{O}_{\text {rain }}$ values of Stuttgart are heavier (-8.01\% VSMOW) than the associated values of Regensburg $(-10.02 \%$ VSMOW). Furthermore, the ratios are by far exceeding the amount that may be ascribed being the net result of the altitude effect alone between the two stations (which would be:

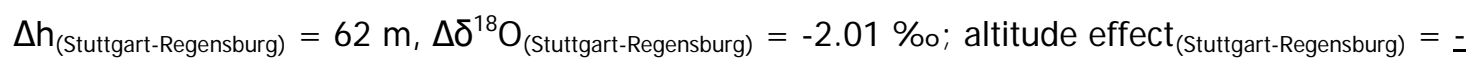
$\underline{3,24 \% / 100 \mathrm{m!}) \text {. }}$

That might be taken as a hint for orographic effects affecting the station Regensburg and the Zaininger-Cave but not the station Stuttgart: 
Depleted stable oxygen isotopic compositions exceeding the "normal" altitude effect caused by the cuesta scarp between the station Stuttgart and the Zaininger-Cave alone may be produced by additional adiabatically cooling. Thus, before the vapor masses hit the cuesta scarp of the Swabian Alb, isotopic depletion of the rainwater would take place. AGSTEN (1977) interpreted the regional mean annual amount pattern of precipitation which may also help to understand the stable oxygen isotope distribution at this site. The eastbound traveling Atlantic maritime vapor masses are believed to be blocked by the Black Forest mountain range in the W. This causes a rise and following adiabatically cooling, thus driving the rainout of approximately $2000 \mathrm{~mm} / \mathrm{a}$ in this area. These kinds of rain-shadow effects may produce lower isotopic values on the lee side of a mountain range and were frequently reported by various authors e.g. FriedmAn and SMITH (1970, Sierra Nevada) or EICHLER (1964, Germany).

Since the relative humidity of the investigated caves is higher than $97 \%$, non-equilibrium fractionation during cave calcite precipitation should be avoided. Given the cave temperatures and stable isotopic dripwater composition, the $\delta^{18} \mathrm{O}$ ratio of recent cave calcite precipitates were calculated and compared to the measured abundances (Table vii - 1.4, next page):

The Zaininger-Cave clearly displays a different isotopic behavior than that of the other caves, mainly the Baumann's- and Hermann's-Cave. Cave calcite precipitations deposited in isotopic equilibrium with the associated dripwater (measured mean $\delta^{18} \mathrm{O}_{\text {dripwater: }}-11.17 \%$ VSMOW) at a temperature of $\sim 6.5^{\circ} \mathrm{C}$ (measured) should result in an oxygen isotope composition of $-9.26 \%$ VPDB (calculated). The analysed sample shows a comparably heavier $\delta^{18} \mathrm{O}_{\text {rec. cave calcite }}$ value of $-7.02 \%$ VPDB. This ${ }^{18} \mathrm{O}$ enrichment in contrast to the dripwater is indicative for non-equilibrium conditions and thus kinetic processes during calcite precipitation must have taken place. This evidence may be supported by the slightly heavier $\delta^{13} C_{c}$ values (-8.94\%o) than expected for a $C_{3}$ vegetation cover (German $\delta^{13} C_{c}$ values for speleothems were estimated between -15 to $-9 \%$ VPDB, incl. $15 \%$ dead carbon fraction; see section iv). The region above the cave is used as agricultural farmland, which may alter the $\delta^{13} C_{\text {speleothem }}$ signature due to crop or other in this sense allochthoneous $C_{4}$ plants. Nevertheless, the geochemical criteria for distinguishing the processes that may be responsible for $\delta^{13} C_{\text {speleothem }}$ variations in temperate regions (with a lack of $\mathrm{C}_{4}$ plants) have not been established until now. Thus, several assumptions on $C_{3}$ intrinsic variations with indicated heavier $\delta^{13} C_{\text {speleothem values ( }>-6 \% \text { ) }}$ have been formulated: Incomplete isotopic equilibration between pedogenic $\mathrm{CO}_{2}$ and the percolating water owing to short residence times may result that the water retains a component of isotopic heavier atmospheric $\mathrm{CO}_{2}$ in solution (BAKER et al. 1997a). Both, the $\delta^{18} \mathrm{O}$ and $\delta^{13} \mathrm{C}$ composition of cave calcite precipitates can be influenced by several kinetic processes. $\delta^{18} \mathrm{O}$ can be altered by evaporation (e.g. Hendy 1971; SCHWARCZ 1986) and by exchange with water vapor (Craig et al. 1963 and STEWART 1975). Rapid $\mathrm{CO}_{2}$ degassing (HENDY 1971; SCHWARCZ 1986; BAKER et al. 1997b), precipitation rate, or exchange with cave atmospheric $\mathrm{CO}_{2}$ if the $\mathrm{pCO}_{2}$ of the water is too low (DULINSKI and ROZANSKI 1990), will change the stable carbon isotopic composition of the speleothem (see also section iv). 


\begin{tabular}{|c|c|c|c|c|c|c|c|}
\hline & Dripwater & $\begin{array}{l}\text { Cave } \\
\text { precip }\end{array}$ & $\begin{array}{l}\text { alcite } \\
\text { tates }\end{array}$ & Cave-T & Calculated & ${ }^{18} \mathrm{O}_{\mathrm{c}}$ & \\
\hline & $\delta^{18} O$ & $\delta^{18} \mathrm{O}$ & $\delta^{13} \mathrm{C}$ & & Fractionation factor $\alpha$ & $\begin{array}{l}\delta^{18} \mathrm{O}_{\mathrm{C}^{-}} \delta \\
\quad \approx 100\end{array}$ & $\begin{array}{l}{ }^{8} \mathrm{O}_{\mathrm{H} 2 \mathrm{O} / \mathrm{DW}} \\
0(\mathrm{a}-1)\end{array}$ \\
\hline & $\begin{array}{l}\text { (0/00 VS. } \\
\text { VSMOW) }\end{array}$ & $\begin{array}{l}\text { (0/00 VS. } \\
\text { VPDB) }\end{array}$ & $\left(\begin{array}{c}\text { (0/00 VS. } \\
\text { VPDB) }\end{array}\right.$ & $\left({ }^{\circ} \mathrm{C}\right)$ & $\begin{array}{c}\alpha=1.02846\left(25^{\circ} \mathrm{C}\right) \\
d \alpha / d T=-0.220 / 00 /{ }^{\circ} \mathrm{C}\end{array}$ & $\begin{array}{c}\text { calc. } \\
\delta^{18} \mathrm{O}_{\mathrm{c}}(0 / 00 \\
\text { vs.VSMOW) }\end{array}$ & $\begin{array}{c}\text { calc. } \\
\delta^{18} \mathrm{O}_{\mathrm{c}}(0 / 00 \\
\text { vs. VPDB) }\end{array}$ \\
\hline \multirow{4}{*}{$\begin{array}{c}\text { Zaininger Cave } \\
\text { (787m asl) }\end{array}$} & -11.17 & \multirow{4}{*}{-7.02} & \multirow{4}{*}{-8.94} & \multirow{4}{*}{6.50} & \multirow{4}{*}{1.03253} & 21.36 & $\underline{-9.26}$ \\
\hline & -11.30 & & & & & 21.23 & -9.39 \\
\hline & -11.69 & & & & & 20.84 & -9.77 \\
\hline & -10.50 & & & & & 22.03 & -8.61 \\
\hline $\begin{array}{c}\text { Cave Hintere } \\
\text { Kohlhalde } \\
\text { (720m asl) }\end{array}$ & n.d. & -8.03 & -5.48 & 9.00 & n.d. & n.d. & n.d. \\
\hline \multirow{4}{*}{$\begin{array}{c}\text { Baumann's- } \\
\text { Cave } \\
\text { (378m asl) }\end{array}$} & -9.01 & -7.48 & -9.07 & \multirow{4}{*}{8.50} & \multirow{4}{*}{1.03209} & $\underline{23.08}$ & $\underline{-7.59}$ \\
\hline & -9.28 & -7.55 & -9.88 & & & 22.81 & -7.85 \\
\hline & -8.95 & -7.72 & -8.82 & & & 23.14 & -7.53 \\
\hline & -8.80 & -7.17 & -8.52 & & & 23.29 & -7.39 \\
\hline \multirow{4}{*}{$\begin{array}{l}\text { Hermann's- } \\
\text { Cave } \\
\text { (378m asl) }\end{array}$} & $\underline{-8.95}$ & -7.17 & -9.26 & \multirow{4}{*}{8.50} & \multirow{4}{*}{1.03209} & 23.14 & -7.53 \\
\hline & -8.99 & -7.44 & -8.99 & & & 23.10 & -7.57 \\
\hline & -9.08 & -7.01 & -8.57 & & & 23.01 & -7.66 \\
\hline & -8.77 & -7.32 & -9.95 & & & 23.32 & -7.36 \\
\hline
\end{tabular}

Table vii - 1.4: Summary of $\delta^{18} \mathrm{O}$ and $\delta^{13} \mathrm{C}$ values for the recent cave calcite precipitates, associated dripwater and calculated recent cave calcite $\delta^{18} \mathrm{O}$ compositions. Arithmetic means for multiple samples are underlined. Fractionation factor $a$ after FRIEDMANN and O'NEIL (1997).

The sample position in the entrance chamber of the Zaininger-Cave ("Tropfsteinhalle", figure vi - 1.7) is in regard of the temperature well in the catchment of the entrance. Considering the ${ }^{18} \mathrm{O}$ enrichment of the recent cave calcites, the occurrence of evaporation seems most likely. Although an increased evaporation will similarly lead to increased $\delta^{13} \mathrm{C}$ values, yet the latter seemed not to have taken place or at least only to an negligible extent considering the value of $-8.94 \%$ VPDB.

Without any dripwater samples and therefore without any directly measured input signals the stable isotopic compositions of the Cave Hintere Kohlhalde sample are difficult to interpret. This site is situated very close to the Zaininger-Cave and is probably affected by the same vapour masses and roughly the same $\delta^{18} \mathrm{O}_{\text {rain }}$ input. Thus, a broad estimate is attempted by comparing the $\delta^{18} \mathrm{O}_{\text {rec.cave calcite }}$ values of this site to the Zaininger-Cave proxies. It may be presumed, that the lack of covariation between enriched (compared to values of the Zaininger-Cave) $\delta^{13} C_{\text {rec.cave calcite }}(-5.48 \%$ VPDB) and 


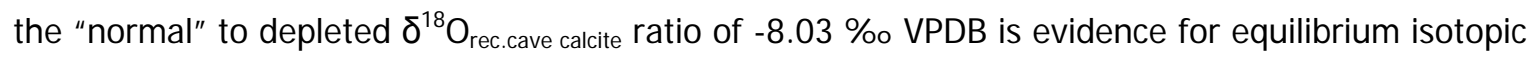
conditions during calcite deposition as well as the reported stable cave temperature. The increased $\delta^{13} C_{\text {rec.cave calcite }}$ value in regard to the expected German value is hard to explain. Parallel to the Zaininger-Cave, the low statistical database (only one sample) bears a high risk of an outlier situation, a theoretical $50 \%$ (!) dead carbon input from the host rock and old organic matter should lead to $\delta^{13} C_{C}$ values of around $-5.5 \%$ VPDB. This would be a novum since until now GENTY and MASSAULT (1997), and GENTY et al. (2001) observed dead carbon contents in speleothems in the maximum range of $10-20 \%$.

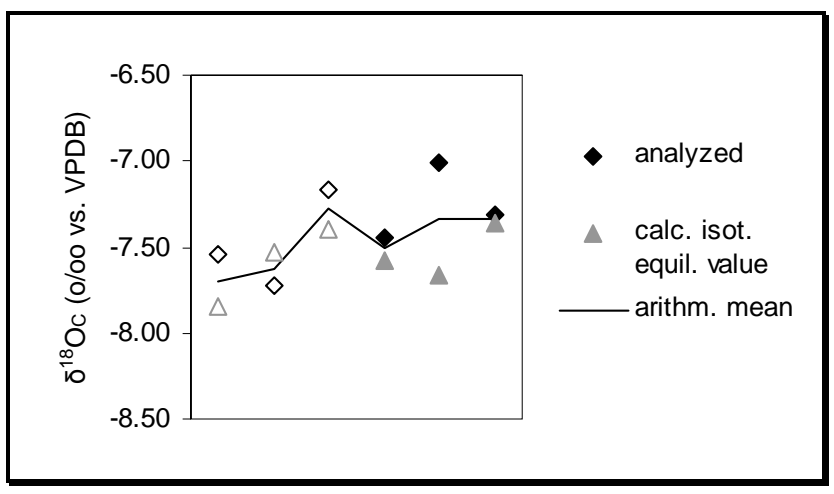

Figure vii - 1.6: Analyzed vs. calculated $\delta^{18} \mathrm{O}$ equilibrium values of recent cave calcite precipitates from the Baumann's(=empty symbols) and Hermann's-Cave (=full symbols).

The low variability and anticorrelation (Figure vii - 1.6) between $\delta^{18} \mathrm{O}$ and $\delta^{13} \mathrm{C}$ of the cave calcite precipitates from the Baumann's- and Hermann's-Cave suggest that calcite precipitation conditions were close to isotopic equilibrium. The occurrence of minor isotopic effects is indicated by the small

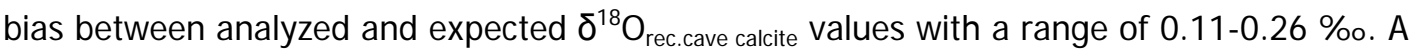
comparison with mean $\delta^{18} \mathrm{O}_{\mathrm{r}}$ values of the dripwater samples of the two caves shows a lower range of 0.02-0.13\%o. The undated recent cave calcite precipitates represent an unknown integral of "time" (per convention usually around 200 a). Thus, their higher variation in regard to the dripwater samples may be a consequence of short-term changes in environmental and climatic conditions of the very youngest Holocene.

The $\delta^{18} \mathrm{O}$ variations of recent calcites found in the Baumann's- and Hermann's-Cave display the same variability observed in other caves. On Vancouver Island (Cascade Cave) GASCOYNE et al. (1980) reported $\delta^{18} \mathrm{O}$ variations of $0.6 \%$ in recent cave calcites. BAR-MATTHEWS et al. (1996) investigated present-day calcite samples of the Soreq Cave (Israel), which, although being in isotopic equilibrium with associated dripwaters still displayed variations of up to $1 \%$. The tips of soda straws of some New Zealand caves showed differences of the same range within the same cave (WILLIAMS et al. 1999). Measurements of three European soda straws displayed typical variations of 1.1-1.5 \%o (MCDermotT et al. 1999). Considerable smaller ranges were observed in Romania (Lithofagus Cave) and in the two Norwegian Caves (Okshola and Stordalsgrotta). Whereas the former displayed variations of $0.11 \%$ (LAURITZEN and ONAC 1999b) the Norwegian caves show $\delta^{18} \mathrm{O}$ ranges of less than $0.1 \%$ (Lauritzen 1995). 


\section{Conclusion}

In this study the stable isotopic compositions of speleothem paleorecords are calibrated to the present-day ratios found in recently deposited cave calcites, which represent the climate optimum of the Holocene. In order to understand how the spelean calcites respond to the conducted climatic signals of the surface (the "transfer-function"), the stable oxygen/carbon isotopic abundances of the meteoric precipitation, dripwater, host rock, and recent cave calcites were as well investigated as the temperature response (and thus relative humidity) and airflow patterns of each cave system. The investigation of the cave atmospheres (relative humidity and temperature) indicate an overall seasonally decoupled response and thus annual stable cave climates (section vii - 1.1). Consequently, only long-term variations of the MAAT will leave an imprint on the cave temperature and the temperature-dependant fractionation factor during calcite precipitation (see also section iv). Nevertheless, a small temperature bias between surface and cave atmosphere of $1-2^{\circ} \mathrm{C}$ for some sites was monitored. This bias is assumed to reflect mainly the low statistical database of the used surface reference data and/or of the cave atmosphere. Other factors possibly creating this bias, like very regional settings (exponation, airflow patterns) and/or anthropogenic influences (showcave business, mining operations) were outlined but could not be certified due to a lack of high resolutional longterm data.

The $\delta^{18} \mathrm{O}$ abundances of most dripwater-samples are in good approximation of the mean annual rainwater ratio which is a sign for prevailing isotopic equilibrium conditions during spelean calcite deposition (section vii - 1.2.1). Variations from within the same cave system are between $\pm 0.4 \%$ (Baumann's-Cave) and $\pm 1.2 \%$ (Zaininger-Cave). Since isotopic equilibrium conditions were inferred temperature wise, the measured $\delta^{18} \mathrm{O}$ of recently deposited cave calcite precipitates were compared to calculated abundances (vii - 1.2.4). They match for the Baumann's- and Hermann's-Cave within a range of 0.04-0.65\% which testified isotopic equilibrium conditions. Thus, the present-day $\delta^{18} \mathrm{O}$ composition of these sites may primarily be controlled by temperature and may be suitable for (paleo) climate reconstructions. However, the isotopic compositions of the recent cave calcite samples of the Zaininger-Cave are controlled by kinetic conditions. This is indicated by the heavier composition of the measured samples in regard to calculated abundances. Considering the local airflow patterns within the cave and sample position, the increase of the ${ }^{18} \mathrm{O}$ input is probably due to evaporation. Since dripwater samples and/or recent calcite precipitates for the Mühlbach-Cave and the Cave Hintere Kohlhalde could not be obtained, present-day isotopic equilibrium conditions can only be assumed. In order to filter out the "natural scatter", such studies should be conducted on a base of several years, usually exceeding the standard PhD. time. Cave calcite examinations should be performed on a statistical base which is difficult due to cave preservation ethics. But even studies relying on a broader database regularly reflect strong variations within one and the same cave system (e.g. LINGE et al. 2001, TOOTH and FAIRCHILD 2003, BAKER et al. 1997, BAKER and BRUNSDOn 2003). 


\section{VI - 2) Results and discussion: Speleothem paleorecords}

\section{Introduction}

The investigation of present-day conditions and transfer-functions showed that most of the sites display a good estimate between the stable isotopic compositions of the meteoric precipitation and cave dripwater, the ambient cave temperature, and the associated present-day spelean calcite (previous section). On the other hand, these investigations also demonstrated that very regional conditions influence the established stable isotopic record despite the rather short monitoring period. For example, clogging of microfractures and apertures above the speleothems may influence the residence time as well as the driprate, or occurring at the cave's bottom may block the natural and steady airflow pattern, which may lead to phenomena observed in the Zaininger-Cave. Also showcave and mining operations of the last decades may have influenced the stable isotopic "natural scatter" of the present-day speleothems. Thus, the interpretation of speleothem timeseries in terms of climate and environment must be performed with caution, since no-one can predict cumulative effects of these settings.

Apart from the very anthropogenic impacts, the detailed knowledge about the isotopic behavior of the cave environment helps to interpret the isotopic composition of a speleothem deposited in terms of climate, at least in comparable periods like the interglacial Holocene. Because it is always critical to extent this principle of uniformitarianism further back in time, e.g. to the Pleistocene, other constraints have to be established to confirm a recorded climatic signal. Thus, the applied multi-proxy approach followed two lines of investigation: The assessment of past isotopic equilibrium conditions of the speleothems, and a comparison to different paleoclimatic archives of the same region recording the same time period.

\section{vii - 2.1) The stalagmites $\mathrm{HKH}-1, \mathrm{ZH}-1$ and the $\mathrm{ZH}-\mathrm{STK}$ stalactite of the Cave Hintere Kohlhalde and the Zaininger-Cave (Swabian Alb)}

\section{vii - 2.1.1) Morphology}

All samples were non-active during field sample sessions and consist of the typical low Mg-calcite (see also section iii). The candle stalagmite HKH-1 (Cave Hintere Kohlhalde) is $125 \mathrm{~cm}$ long and displays a basal diameter of $21 \mathrm{~cm}$. From the Zaininger-Cave two speleothem samples were extracted, the ZH-1 STM stalagmite, $38 \mathrm{~cm}$ in height and $20 \mathrm{~cm}$ at the base and the ZH-STK stalactite $(55 \times 18 \mathrm{~cm}$ ).

Growth laminae are visible almost throughout the whole longitudinal section of the stalagmites, except for the topmost $10 \mathrm{~cm}$ of the ZH-1. The ZH-STK sample displays no layering at all and consists of coarse columnar translucent to transparent crystallites (Figure vii - 2.3). 
HKH-1: Most of the cross-section consists of milky white microcrystalline calcite interrupted by harder compact microcrystalline honey-brown layers. This is reversed in the lower part $(0-11 \mathrm{~cm})$ of the stalagmite, which mainly consists of the browner facies type with compact and narrow layering. The transition at $11 \mathrm{~cm}$ shows clearly the former drop impact point (see white arrow in figure vii - 2.1) overgrown by the white, softer facies type.

Figure vii - 2.1: The HKH-1 stalagmite and its internal longitudinal section. The lower part, with arrow indicating the top, shows a condensed sequence, consisting of the honeybrown compact microcrystalline fabrics. Macroscopically visible pores are tied to the white calcite facies and are layer bound.
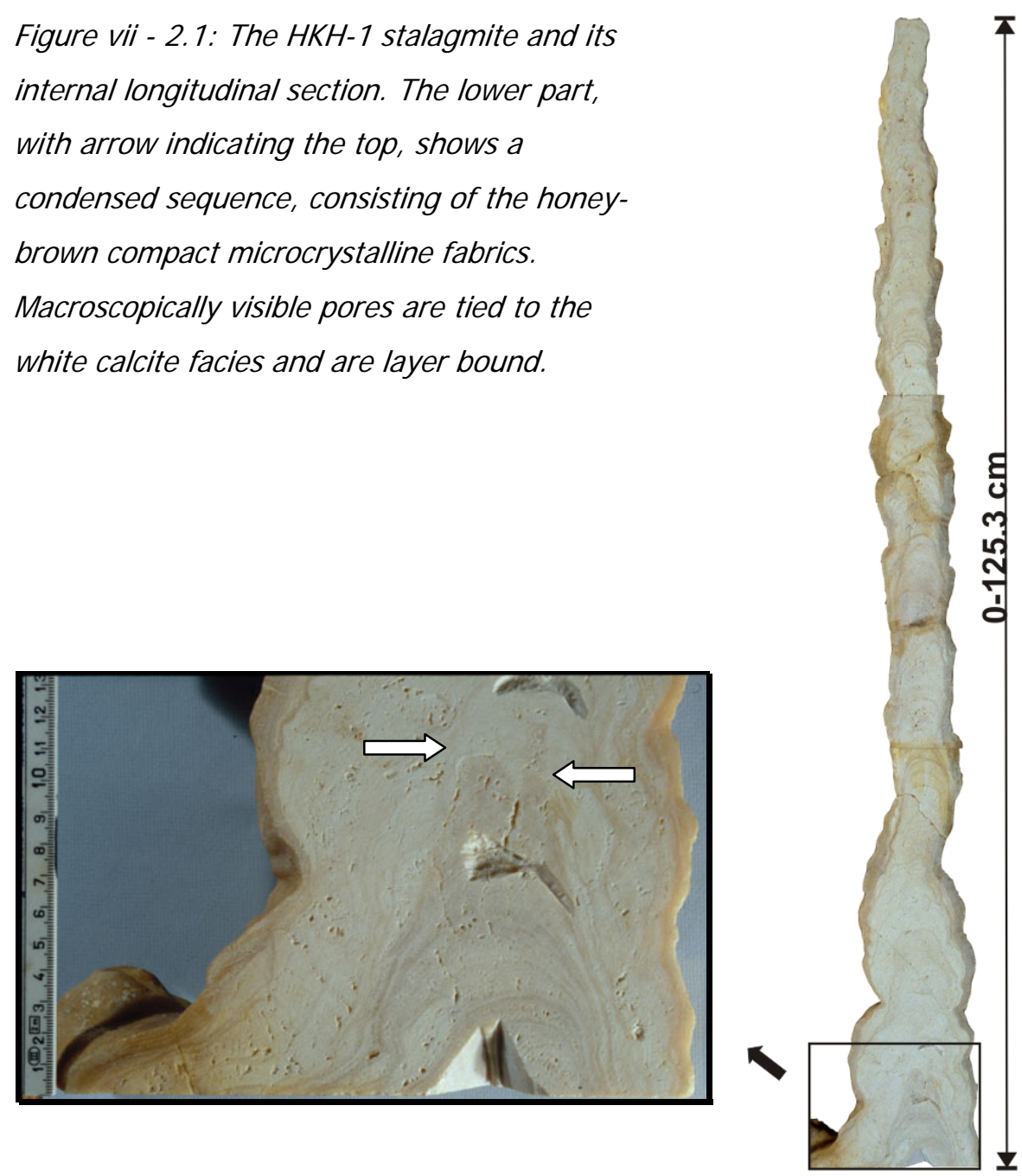

This is believed to be a sign for a rapid change in growth conditions since a higher amount of the feeding solution (thus driprate and available water) is necessary to overgrow the drop impact point. The pores, which can easily be recognized macroscopically, are mainly layer bound to the white and softer facies type thus giving supporting evidence to overall faster calcite deposition conditions.

ZH-1 STM: The macroscopic visible layering yield successions of mainly grey translucent to white microcrystalline calcites interrupted by individual red brown laminae. Laminae diameters are $<1$ to max. $5 \mathrm{~mm}$ (Figure vii - 2.2). 


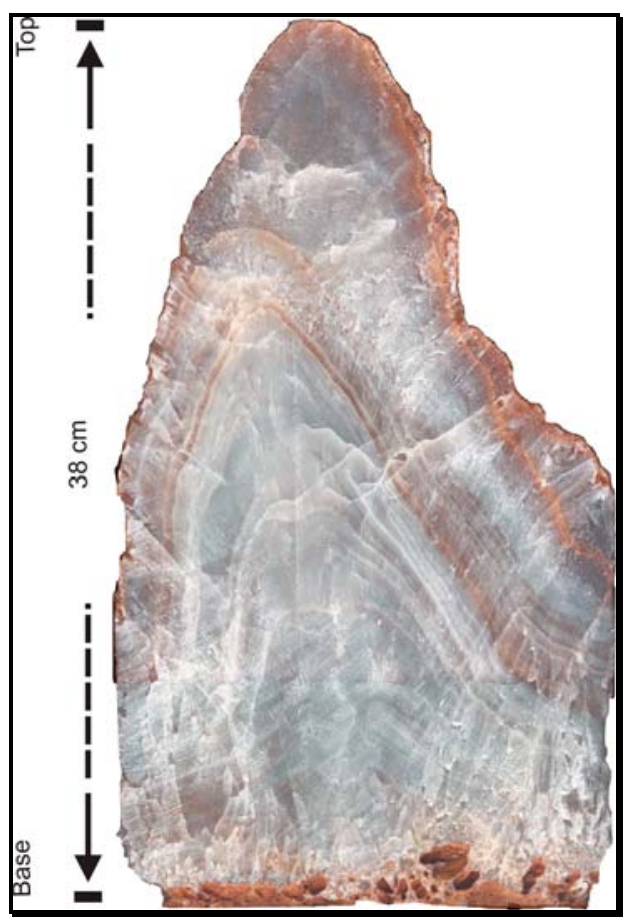

Figure vii - 2.2: ZH-1 stalagmite of the

Zaininger-Cave (cross-section).

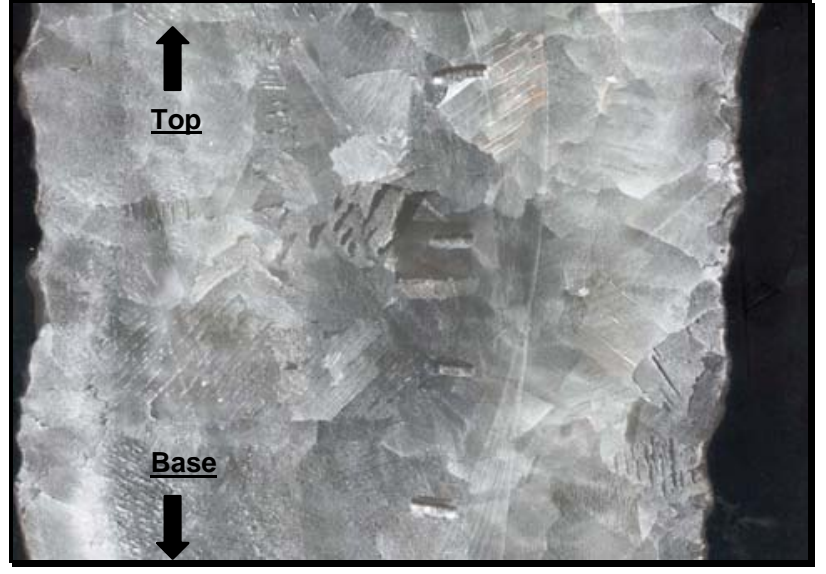

Figure vii - 2.3: The longitudinal cross-section of ZH-STK stalactite (Zaininger-Cave) displays coarse columnar calcite crystallites. Sample holes are 0.3 to $0.5 \mathrm{~mm}$ in height.

\section{vii - 2.1.2) Chronological control and extension rates}

The HKH-1 stalagmite was ${ }^{230} \mathrm{Th} /{ }^{234} \mathrm{U}$-TIMS dated between ca. $44158 \pm 3329$ and $2709 \pm 303$ a B.P. A linear extension rate along the central growth axis was assumed between dated points. Minimum growth rates varied between 2.33 to $3.82 \mathrm{~mm} / \mathrm{ka}$ between $44158 \pm 3329$ and $18979 \pm 1922$ a B.P. The maximum value of $112.44 \mathrm{~mm} / \mathrm{ka}$ between $8632 \pm 846$ to $2709 \pm 303$ a B.P. is followed by an abrupt termination of stalagmite growth. A comparative intermediate extension rate of 46.8 to $49.9 \mathrm{~mm} / \mathrm{ka}$ characterized the growth period between 18979 to 8632 a B.P. (Figure vii - 2.4). The switch around 18979 a B.P. from very slow to faster extension rates correlates with the above mentioned calcite facies change at this point. Depending on the growth rate the resolution ranges between 0.05-2.78 ka, thus one sample represents ca. 429-9 mm/a.

Due to the very low Uranium contents between 0.023 to $0.043 \mathrm{mg} / \mathrm{kg}$ only an age of $71220 \pm$ 13937 a B.P. was derived from the $\mathrm{ZH}-1$ stalagmite, marking the begin of speleothem growth. Extension rates were not calculated. The stalactite of the Zaininger-Cave (ZH-STK) was deposited during between $11624 \pm 6092$ and $2772 \pm 215$ a B.P. yielding a linear growth rate of approximately $60 \mathrm{~mm} / \mathrm{ka}$. The resulting mean resolution for the time of deposition is $450 \mathrm{cal}$. years. Given the drill diameter of 0.3-0.5 mm and allowing for $1 \mathrm{~mm}$ due to physical sampling, one hole represents ca. 17 years. Detailed data see Appendix vii - 2.1. 


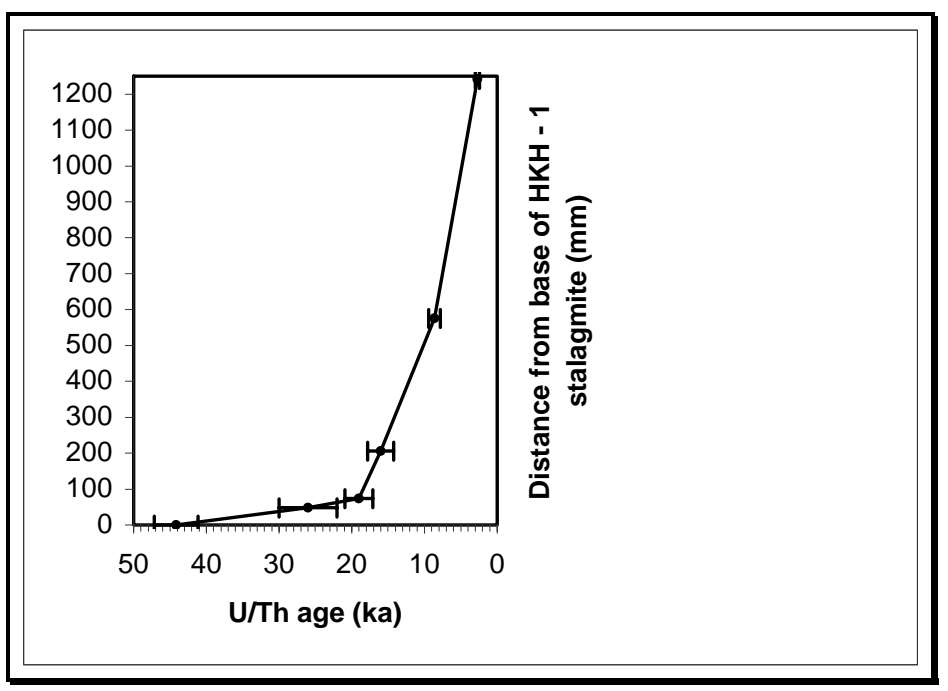

Figure vii - 2.4: The linear assumed extension rates of the HKH-1 stalagmite between dated points display three major growth phases. Extensions rates reveal increasing values since the begin of speleothem deposition (44.16 \pm 3 ka B.P.) towards its termination at around $2.7 \pm 0.3 \mathrm{ka} \mathrm{B.P.} \mathrm{The}$ mean growth rate of $\mathrm{HKH}-1$ stalagmite is $29 \mathrm{~mm} / \mathrm{ka}$ (variations between 2.33 to $112.44 \mathrm{~mm} / \mathrm{ka}$ ), data Appendix vii - 2.1.

\section{vii - 2.1.3) I sotopic equilibrium}

The check for isotopic equilibrium conditions during cave calcite precipitation for the $\mathrm{HKH}-1$ stalagmite of the Cave Hintere Kohlhalde has been performed along five single growth laminae at $80,258,577$, 691, and $989 \mathrm{~mm}$ from the base. The established data is provided in table vii - 2.1 (below) and Appendix vii - 2.3. Within one exception, the overall good correlations of $r^{2}=0.70-0.84$ between the stable isotopic carbon and oxygen ratios of the Hendy-layers may be indicative for non-equilibrium conditions (e.g. kinetic fractionation conditions). In contrast to that, maximum $\delta^{18} 0$ deviations of the tested laminae range from 0.31 to $0.73 \%$ and are within the proposed tolerance of $0.8 \%$ (e.g. Gascoyne 1992) thus providing a strong argument for an established equilibrium environment. The apex difference is the value derived from the two samples closest to the apex or central growth axis (ca. $\pm 5 \mathrm{~mm}$ from the growth axis), the area where the samples for the profile were drilled (see TALMA and Vogel 1992, SPÖTL and MANGINI 2002). These values range from 0.01 to $0.36 \%$ and support just like the non-abundant correlation of the whole timeseries ( $r^{2}=0.19$, Figures vii $-2.7 /-2.8$ below) the evidence for isotopic equilibrium conditions during calcite deposition. Considering this and given the rather small amount of Hendy samples and diminished statistical significance, equilibrium conditions for spelean calcite depositions for the whole sequence are assumed.

Since the stalactite of the Zaininger-Cave (ZH-STK) displays no layering at all, a Hendy-Test is out of question and a comparison to other paleoclimatic archives like speleothems, ice cores, sediment cores etc. might clear the point of equilibrium depositions and a potential global-climatic forcing of the oxygen isotope signal. 


\begin{tabular}{|l|c|c|c|l|l|}
\hline Sample ID & $\begin{array}{l}\text { Vertical distance } \\
\text { from base }(\mathrm{mm})\end{array}$ & $\mathrm{n}$ & $\begin{array}{l}\text { Max. } \\
\left({ }^{2}{ }^{2} \mathrm{O} \text { vs. }{ }^{13} \mathrm{C}\right)\end{array}$ & $\begin{array}{l}\text { Apex } \\
\text { difference } \\
\delta^{18} \mathrm{O}(\mathrm{o} / \mathrm{oo})\end{array}$ & $\begin{array}{l}\text { difference } \\
\delta^{18} \mathrm{O}(\mathrm{o} / \mathrm{oo})\end{array}$ \\
\hline KH I-3.1 & 80 & 6 & 0.71 & 0.53 & 0.15 \\
\hline KH I-10.1 & 250 & 4 & 0.70 & 0.73 & 0.36 \\
\hline KH II-5.1 & 577 & 4 & 0.84 & 0.30 & 0.16 \\
\hline KH II-10.1 & 691 & 4 & 0.83 & 0.24 & 0.01 \\
\hline KH III-7.1 & 989 & 5 & 0.001 & 0.31 & 0.07 \\
\hline
\end{tabular}

Table vii - 2.1: HKH-1 stalagmite: $r^{2}$ values indicate good correlations for $\delta^{18} \mathrm{O} / \delta^{13} \mathrm{C}$ along the single growth layers thus indicating non-equilibrium conditions during precipitation whereas the maximum difference of $\delta^{18} \mathrm{O}$ is well within the proposed tolerance for equilibrium conditions of $0.8 \%$.

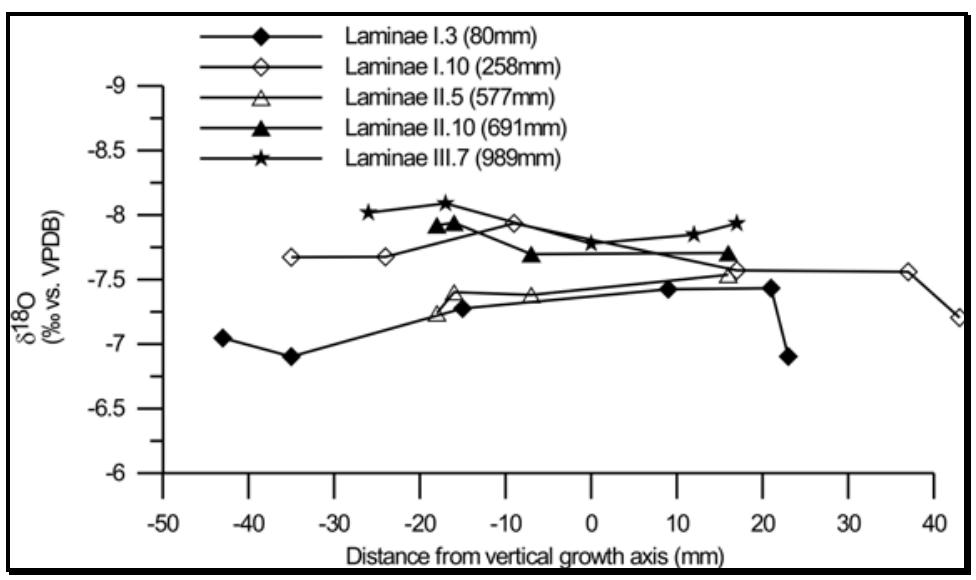

Figure vii - 2.5: HKH-1 stalagmite: $\delta^{18} \mathrm{O}$ variations of five single laminae display maximum differences of $0.73 \%$. X-axis is the distance from the vertical growth $\operatorname{axis}(=0)$

The Hendy-Test was performed at three different heights at the $\mathrm{ZH}-1$ stalagmite and indicates a poor $\delta^{18} \mathrm{O} / \delta^{13} \mathrm{C}$ correlation for the entire time of calcite precipitation (Figure vii - 2.6, data Appendix vii 2.6). The assigned $r^{2}$ are lower than 0.33 which indicates maintained isotopic equilibrium conditions. Maximum differences of the tested single layers are 0.68 and $0.78 \%$ for the upper part of the stalagmite, which coincides with given $r^{2}$ of 0.01 and 0.03 .

The single layer at $75 \mathrm{~mm}$ from the base still yield an insignificant $r^{2}$ of 0.33 but simultaneously displays an exceeding difference of $3.56 \%$ along the tested laminae. Thus, the oxygen/carbon stable isotopic signal of the lower part of the timeseries has to be treated with caution since non-equilibrium conditions may be indicated or at least cannot be ruled out completely.

Since all Hendy-layer variations, including the lowermost, are within calculated variations for recent cave calcites of the Zaininger-Cave ( $\pm 1.2 \%$, section vii -1$)$ and strongly parallel shifts of the $\delta^{18} \mathrm{O}$ and $\delta^{13} \mathrm{C}$ timeseries are not indicated $\left(r^{2}=0.29\right)$, an overall deposition close to the isotopic equilibrium is suggested for the $\mathrm{ZH}-1$ stalagmite. 


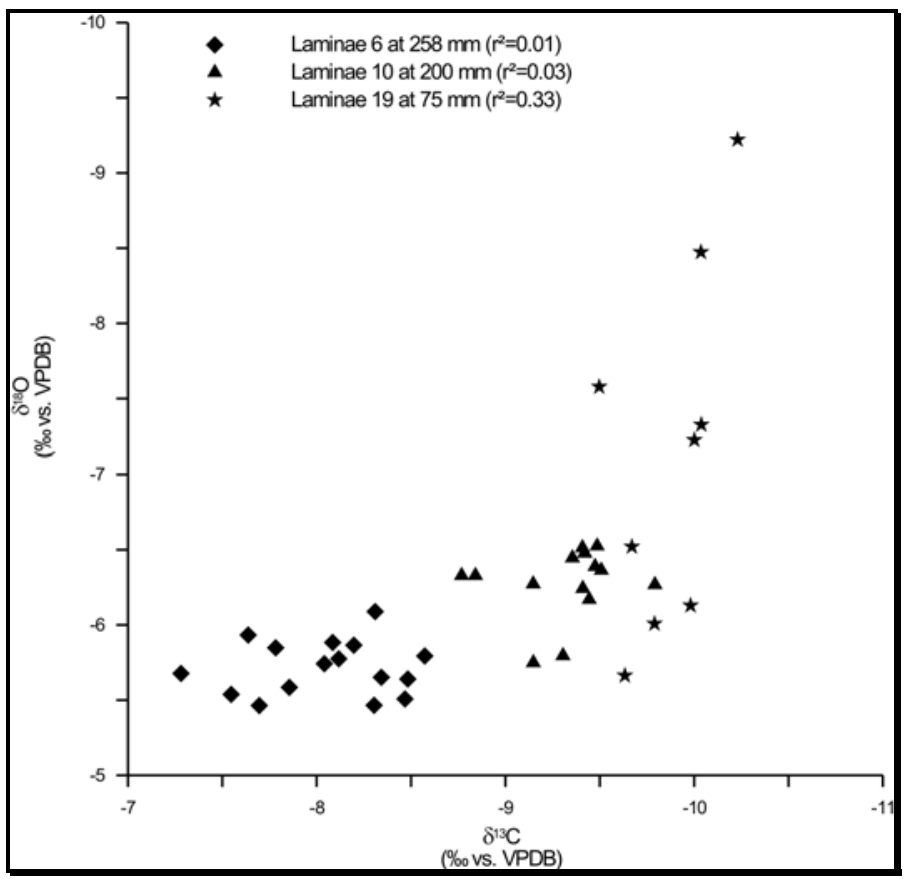

Figure vii - 2.6: $\mathrm{ZH}-1$ stalagmite of the Zaininger-Cave displays no covariation of $\delta^{13} \mathrm{C}$ versus $\delta^{18} \mathrm{O}\left(\mathrm{r}^{2}\right.$ $=0.01$ to 0.33 ).

\section{vii - 2.1.4) I sotopic composition timeseries}

\section{The stalagmite HKH-1 of the Cave Hintere Kohlhalde (Swabian Alb)}

The $\delta^{18} \mathrm{O}$ and $\delta^{13} \mathrm{C}$ timeseries of the $\mathrm{HKH}-1$ stalagmite display mean values of respectively -7.72 and $7.76 \%$ (Table vii -2.2 below, Figures vii - 2.7 above). The variations are in the range of $0.39\left(\delta^{18} \mathrm{O}\right)$ and $0.79 \%\left(\delta^{13} \mathrm{C}\right)$.

The basal $74 \mathrm{~mm}$, representing the very dense layered part of the stalagmite, display no significant trend for $\delta^{18} \mathrm{O}$. Values range from -8.07 to $-7.26 \%$ VPDB and no partial correlation with $\delta^{13} \mathrm{C}(\mathrm{r}=$ $0.35)$ occurs in this speleothem sequence. The $\delta^{13} \mathrm{C}$ profile shows a minor two stepped decreasing trend between $44158 \pm 3329$ a B.P. to $35200 \mathrm{cal}$ a. B.P. and $32630 \mathrm{cal}$. a. B.P. to $18979 \pm 1922 \mathrm{a}$, each followed by an increase of ca. $1 \%$ towards enriched ratios.

The more frequent changes in the timeseries of the remaining unaveraged curve occur due to higher growth rates resulting in a higher resolution of this part of the record. The applied running average (window width $=5$ ) smoothes the profile as it takes out extreme values and thus helps to recognize overall trend patterns. 

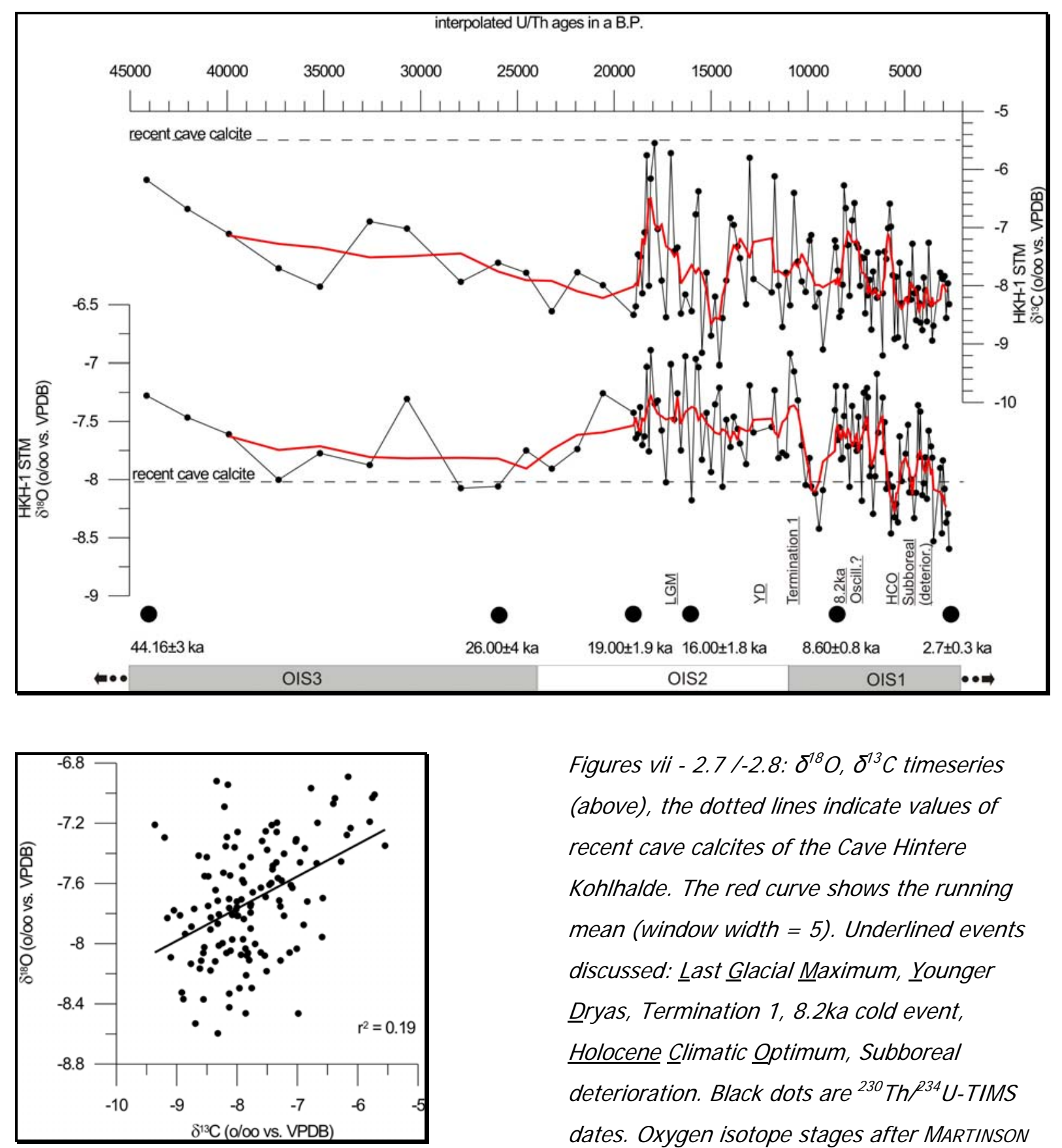

Figures vii - 2.7/-2.8: $\delta^{18} 0, \delta^{13} \mathrm{C}$ timeseries (above), the dotted lines indicate values of recent cave calcites of the Cave Hintere Kohlhalde. The red curve shows the running mean (window width $=5$ ). Underlined events discussed: LLast Glacial Maximum, Younger Dryas, Termination 1, 8.2ka cold event, Holocene Climatic Optimum, Subboreal deterioration. Black dots are ${ }^{230}$ Th/234 U-TIMS dates. Oxygen isotope stages after MARTINSON et al. (1987).

The linear regression analysis of the timeseries is displayed on the left.

Beginning at ca. 18110 cal. a. B.P the highest $\delta^{18} \mathrm{O}$ value of $-6.89 \%$ VPDB of this set follows a weak decreasing pattern until $10910 \mathrm{cal}$. a. B.P. This is followed by a sharp drop towards lighter values of $8.42 \%$ at ca. $9420 \mathrm{cal}$. a. B.P and an immediate increase to almost former enriched $\delta^{18} \mathrm{O}$ values ($7.40 \%$ ) at $8632 \pm 846$ a. B.P. The adjacent time interval shows a comparable steeper trend towards depleted values until termination of speleothem growth around $2709 \pm 303$ a B.P. 
The $\delta^{13} \mathrm{C}$ timeseries of this part displays an overall decreasing trend interrupted by abrupt peaks with increased, enriched ratios at 17910, 13500, 8130, and $5850 \mathrm{cal}$. a. B.P.

Although a covariation of the two proxies is not indicated throughout the profile $\left(r^{2}=0.19\right)$, both display the same long-term trends towards lighter values for the time period $18979 \pm 1922$ to $2709 \pm$ 303 a. B.P.

\begin{tabular}{|l|c|c|}
\hline & $\begin{array}{c}\boldsymbol{\delta}^{13} \mathbf{C} \\
\text { VPDB } \\
\text { [o } / \text { oo] }\end{array}$ & $\begin{array}{c}\boldsymbol{\delta}^{18} \mathbf{O} \\
\text { VPDB } \\
{[\mathbf{o} / \text { oo }]}\end{array}$ \\
\hline Min & -9.36 & -8.60 \\
\hline Max & -5.55 & -6.89 \\
\hline Mean & -7.76 & -7.72 \\
\hline Stand.dev. & 0.79 & 0.39 \\
\hline$r^{2}$ & 0.19 & \\
\hline
\end{tabular}

Table vii - 2.2: Summary of measurements of $\delta^{18} \mathrm{O}$ and $\delta^{13} \mathrm{C}$ timeseries from the $\mathrm{HKH}-1$ stalagmite. See also table Appendix vii - 2.2 for detailed analytical results.

\section{Discussion HKH-1 stalagmite}

Compared to the SPECMAP isotopic chronostratigraphy of MARTINSON et al. (1987) the HKH-1 stable oxygen isotopic timeseries (44158 \pm 3029 and $2709 \pm 303$ a B.P) was deposited during the OIS 3 till the OIS 1 and thus covers the "in and out" of the Last Glacial Maximum to the Holocene. During Glacials the global $\delta^{18} \mathrm{O}$ budget of the source zones is heavier due to the relative removal and storage of preferentially light water on the poles ("ice-volume effect"). The remaining ocean water and consequently the resulting meteoric precipitation, the cave dripwater and the cave calcite are heavier than in the Holocene or warmer isotopic stages.

Considering the $\delta^{18} \mathrm{O}$ mean of the timeseries, three major long-term trends of the $\mathrm{HKH}-1$ stalagmite seem to be roughly tied to the indicated overall global climate shifts. Principally the lighter values of the timeseries coincide with the warmer OIS 3 and OIS 1 and display smaller deviations to the measured $\delta^{18} \mathrm{O}$ of the recent cave calcites whereas heavier values (and a greater bias) are abundant during the OIS 2 (Table vii - 2.3 below).

\begin{tabular}{|c|c|c|c|}
\hline $\begin{array}{c}\text { HKH } \\
\text { timeseries } \\
\delta^{18} \text { O mean } \\
\text { (o } / \text { oo vs. } \\
\text { VPDB) }\end{array}$ & $n$ & $\begin{array}{c}\text { OIS } \\
\text { (MARTINSON et al., } \\
1987)\end{array}$ & $\begin{array}{c}\text { HKH } \\
\delta^{18} \text { O recent } \\
\text { (o / oo vs. VPDB) }\end{array}$ \\
\hline-7.72 & 10 & ois 3 & \multirow{2}{*}{-8.03} \\
\hline-7.51 & 53 & ois 2 & \\
\hline-7.84 & 74 & ois 1 & \\
\hline
\end{tabular}

Table vii - 2.3: $\delta^{18} \mathrm{O}$ mean of the $\mathrm{HKH}-1$ stalagmite tuned to the OIS chronostratigraphy. 
When quantifying the associated $\delta^{18} O$ mean values of the timeseries it is striking that the recorded shifts yield differences of only 0.2 to $0.3 \%$ whilst the ice-volume effect alone is believed to amount globally to differences of 1.2 to $1.8 \%$ of the ocean water (SHACKLETON and OPDYKE 1973, FAIRBANKS 1989, CROWLEY and NORTH 1991). The recorded damped signals may be explained by annihilating effects during deposition of the cave temperature effect versus the dripwater function (section iv) and/or growth rate control:

As already discussed in section iv, the $\delta^{18} \mathrm{O}_{\text {cave calcite }}$ results of the temperature dependant dripwater function (e.g. $d \delta^{18} \mathrm{O}_{\text {rain } / \text { dripwater }} / \mathrm{dT}=0.58 \% \circ / 1^{\circ} \mathrm{C}$ ) and the cave temperature effect (e.g. $d \delta^{18} \mathrm{O}_{\text {cave }}$ calcite/ $\mathrm{dT}=-0.22 \% \circ / 1^{\circ} \mathrm{C}$ ) are factors yielding an opposite sign. Since we know from today-studies that the former is an average representing a global range between -1.28 to $+0.65 \%$ (RoZANSKI et al. 1993), it is theoretically possible that the dripwater function is greater, equal or less than the temperature dependent equilibrium fractionation (cave temperature effect) during cave calcite precipitation. Due to these annihilating effects the $\delta^{18} \mathrm{O}_{\text {speleothem }}$ could decrease, increase or remain invariant and may thus lead to the observed damped signals of the average $\delta^{18} \mathrm{O}_{\text {speleothem }}$ composition. Since the $\delta^{18} \mathrm{O}$ of the $\mathrm{HKH}-1$ stalagmite becomes heavier with decreasing temperature, either the cave temperature effect (e.g. $d \delta^{18} \mathrm{O}_{\text {cave calcite/ }} \mathrm{dT}=-0.22 \% / 1^{\circ} \mathrm{C}$ ) is dominant and/or the dripwater function response (present-day $d \delta^{18} \mathrm{O}_{\text {rain } / \text { dripwater }} / \mathrm{dT}=-1.28$ to $+0.65 \% / 1^{\circ} \mathrm{C}$ ) is negative or weakly positive. Typical growth rates of stalagmites range between 0.01 to $1 \mathrm{~mm} /$ a depending on the vadose recharge and the high $\mathrm{pCO}_{2}$ usually of soil origin and thus the calcium ion concentration of the conducted solution (section iii). Although the inferred linear extension rate of the $\mathrm{HKH}-1$ shows an evolution between 2.3 to $112 \mathrm{~mm} / \mathrm{ka}$ from the onset to cessation of stalagmite growth, the absolute rates are comparably small. The time interval represented by an individual sample depends critically on the linear extension rate of the speleothem. Using a 0.3 to $0.5 \mathrm{~mm}$ micro-drill for subsampling the $\mathrm{HKH}-1$ stalagmite, the inflicted sample holes are less than $1 \mathrm{~mm}$ in diameter which represents time integrals of 428 to $9 \mathrm{a} / \mathrm{mm}$. Thus, the superimposed prerequisite for the detection of short-term variations is the use of relative rapidly deposited speleothems (without exceeding equilibrium conditions and mechanical subsampling assumed). Vice versa, in relative slowly deposited speleothems such as the $\mathrm{HKH}-1$, the lack of recorded (and subsampled) potential short-term variations may favor the observed damped isotope signals.

Before $18879 \pm 1922$ a. B.P. it is difficult to interpret the HKH-1 timeseries since a trend for the investigated stable isotopic proxies is not clearly visible and due to the low resolution. Nevertheless, it seems that conditions (climatic or depositional) until that time were much different from those afterward. This is already indicated by the compact honey brown calcite at the base, which changes to milky white and somewhat softer calcite at this point of time (section above). Growth rates as low as ca. 2-4 mm/ka stand for at least a diminished supply of free circulating water for this period of time. Although a major hiatus seems not to be abundant, the possibility of discontinuous deposition (see section iv) cannot be excluded. Temporarily inconsistent driprates leave not necessarily an imprint on the established timeseries since the spatial and thus stratigraphic resolution depends on the sub- 
sampling techniques and analytical procedures. So even if frequently non-equilibrium conditions were abundant, the probability to "Hendy-check" these relevant layers, which are in sub-mm range during that period, is pretty low.

Between $25909 \pm 4061$ a B.P to 18110 cal. a. B.P. the $\delta^{18} \mathrm{O}$ shifts towards heavier values. Simultaneously, the increase in linear extension rates from $\sim 3 \mathrm{~mm} / \mathrm{ka}$ to $\sim 46 \mathrm{~mm} / \mathrm{ka}$ coincides roughly with the global climatic deterioration from the OIS 3 to the OIS 2.

The HKH-1 does not show any major growth biases (like characteristic detritic layers), which is consequently assumed to indicate more or less continuously deposition conditions. Its relative increase in growth rates at the onset of the glacial OIS 2 in contrast to the interstadial OIS 3 is difficult to explain. Since high $\mathrm{pCO}_{2}$ waters usually of soil-zone origin and vadose recharge are mandatory for the genesis of speleothems, their deposition is unlikely at times and regions overlain by, or being peripheral to ice sheets (e.g. AtKInSON et al. 1986, GASCOYNE 1992 or LAURITZEN 1993; see section iii). Since the Swabian Alb was not directly affected by the advancing alpine ice-masses, it belonged to the periglacial with a continuous or discontinuous permafrost zone during the OIS 2 . The close spatial position of the cave to the dry valley, the minor cave roof thickness (10-15 m), its SW-exponation and therefore increased amount of received radiation from the sun may have promoted the recharge, host rock dissolution and deposition of the stalagmite $\mathrm{HKH}-1$ even with prevailing permafrost conditions. The shift in growth rates between OIS 3 to OIS 2 may be due to a pre-storage of water in the permafrost and small-scale release during dethawing periods. The resulting slow water supply to the cave was obviously favored by the steep hydraulic gradient due to the proximity to the dry valley Tiefental and by short seepage pathways owing to the minor cave roof thickness. Conditions seemed not to exceed isotopic equilibrium conditions since the paleorecord displays no major $\delta^{18} \mathrm{O} / \delta^{13} \mathrm{C}$ sympathetic shifts towards enriched ratios and no incorporated detritic layers were observed for this time.

The most prominent feature of the $\delta^{18} \mathrm{O}$ timeseries is a two-stepped sharp trend encompassing values of -6.92 to $-8.41 \%$ VPDB between 10913 and 9421 cal. a. B.P. If due to a temperature effect the difference to the first warm peak around $10112 \mathrm{cal}$. a B.P. would amount to $6.5-7.4^{\circ} \mathrm{C}\left(\Delta \delta^{18} \mathrm{O}\right.$ plus icevolume effect between 1.2 to $1.8 \%$ divided by $0.36 \% / 1^{\circ} \mathrm{C}$, as explained above). This may be owing to a combination of driprate control and temperature during the change to different cave conditions at the OIS 2-OIS 1 transition.

The Holocene timeseries shows the highest growth rates of around $112 \mathrm{~mm} / \mathrm{ka}$ with an overall corresponding decrease in $\delta^{18} \mathrm{O}$. Higher growth rates are ascribed to higher water availability and to conditions favorable for speleothem deposition (humid, warm, higher soil-activity). The trend towards lower $\delta^{18} \mathrm{O}$ values which were interpreted as a result of a higher effective meteoric precipitation support this hypothesis.

The following Early Holocene till around 6500 cal. a. B.P. displays a heavier running mean (red curve in figure vii - 2.7) and smaller variability between ca. -7.5 to $-7.75 \%$ VPDB which matches in trend 
and value former Late Glacial patterns between 15000 to $13000 \mathrm{cal}$. a. B.P. thus indicating a climatic deterioration towards a colder environment.

Till 5703 cal. a. B.P. the running mean exhibits a comparably higher variability and a steep trend towards lighter ratios. This period could therefore indicate the occurrence of a humid climate optimum with an improved availability of water. From the adjacent Subboreal Period to cessation of speleothem deposition, comparably more enriched values indicate colder climatic conditions.

The stable carbon isotopic timeseries of the $\mathrm{HKH}-1$ stalagmite displays values between -9.36 and $5.55 \%$ VPDB and is predominantly well in the range of expected $C_{3}$ vegetation for temperate regions during the Holocene (-6 to -14 \%o VPDB; e.g. Cerling 1984, Bar-MatThews et al. 1997).

The slightly higher values of $-5.55 \%$ VPDB than predicted with prevalent $\mathrm{C}_{3}$ coverage occur between 18500 to $17000 \mathrm{cal}$. a. B.P. and may be interpreted as a change of the vegetational coverage above the cave towards plants using mainly the Hatch-Slack $\left(\mathrm{C}_{4}\right)$ photosynthetic cycle.

Since the $\mathrm{C}_{4}$ plants are to some extent adapted to dryer conditions this could be a sign of dry, open tundra and polar desert conditions prevailing in Northern Europe in regions which were not occupied by ice sheets during the LGM (Frenzel et al. 1992, FrenZeL 1992).

An unambiguous interpretation for the $\delta^{13} \mathrm{C}$ signature for the $\mathrm{HKH}-1$ remains difficult since the values are still in the range for $\mathrm{C}_{3}$ plants including the elevated LGM compositions when taking a certain amount of dead carbon proportion of the host rock into account (see section iv, $15 \%$ dead carbon contamination would raise the $\mathrm{C}_{3} / \mathrm{C}_{4}$ transition values up to $-5 \%$ ).

Processes which could cause the shift towards heavier values than expected with a dominating $\mathrm{C}_{3}$ coverage may either be interpreted as wetter periods due to shorter residence times with incomplete equilibration as dominating factor. Or, quite the contrary happens when the primary forcings are nonequilibrium conditions like evaporation, rapid degassing, or prior precipitation in the undersaturated zone or in the cave itself. In this case the higher $\delta^{13} \mathrm{C}$ should be associated with drier periods. Since no flanking multiproxy measurements like $\mathrm{Mg} / \mathrm{Ca}, \mathrm{Sr} / \mathrm{Ca}$ and/or stable $\mathrm{Sr}^{87} / \mathrm{Sr}^{86}$ isotopes of the cave calcite were available, information about the potential paleo-residence times can only be taken from the chronological control of the stalagmite and its tuning to well known paleoclimatic events. Comparing the most enriched values with the established chronostratigraphy, which yield a calibrated age of 18500 to $17000 \mathrm{cal}$. a. B.P thus may indicate the occurrence of the Last Glacial Maximum during that time. The decreased availability of water due to the already discussed permafrost conditions and the highest $\delta^{18} \mathrm{O}$ signal may support this estimate. Additionally, the potential imprint of the host rock is expected to gain influence under closed-system conditions (see section iv, HENDY 1971, SALOMONS and MOOK 1998). The isolation of the percolating water from the soil $\mathrm{CO}_{2}$ reservoir may occur during permafrost conditions (dethawing events excepted) due to a decreased amount of circulating water, the snow cover and thus increased residence times.

As is evident, a straightforward interpretation is not possible and ambiguous since other references like VAN ANDEL and TZEDAKIS (1996), HARRISON et al. (1996) or HUIJZER and ISARIN (1996) state that before the onset of the Younger Dryas a closed and continuous forest cover (and thus a clear $\mathrm{C}_{3}$ 
signal) did not prevail in Central/Northern Europe thus contrasting the almost permanent $\mathrm{C}_{3}$ signal from the HKH-1 stalagmite of the Swabian Alb. For example during one of the relative warm interstadials of the OIS 3 between ca. 39000-36000 a. B.P., forest or open woodlands of birch, pine, and other cornifers seem to recolonize the steppe tundra vegetation after the OIS 4 in Germany, the Netherlands and England (VAN ANDEL and TZEDAKIS 1996). Simultaneously fossil bird faunas suggest that the interstadial tree cover was always rather open except for unusually favored sites (TYRBERG 1998). Many of the later interstadials occurring as sudden warm phases against a background of drier and colder conditions in which local tree populations were not present, did not even show this mentioned resurgence of the "patchy" woodland in Northern Europe. Thus pollen cores from Les Echets and Grande Pile dated around 28000 to $25000{ }^{14} \mathrm{C}$ a B.P. in Central France indicate that the tree cover was incomplete with a high proportion of steppic vegetation. The same cool and semi-arid conditions may have prevailed across most of Northern and Central Europe at this time. Supporting evidences are reported by TZEDAKIS (1993) from long cores from the Balkan Mountains, or by a long core from Lago Grande di Monticchio in South-Central Italy. The latter is mainly composed by herbaceous pollen assemblages dominated by Artemisia, Chenopodiacae, and Helianthemum and contains only around $20 \%$ temperate tree pollen (WATTS et al. 1996).

In sum, the stable carbon isotopic abundances of the $\mathrm{HKH}-1$ display almost continuous $\mathrm{C}_{3}$ signals for the entire time of deposition. This is unexpected for the OIS 3 and OIS 2 period considering the pollen records from various European sites and fossil bird assemblages, which indicate for most of the time a discontinuous forest cover, like open woodland and a varying extent of tundra and polar desert conditions. Since the values ranges in between upper $C_{3}$ and lower $C_{4}$ classification, a mixture of $C_{3}$ and $\mathrm{C}_{4}$ vegetational cover may have been recorded for the OIS 2 and 3 periods, which is e.g. known to result from woody savannah conditions (SANAIOTTI et al. 2002). If not, the variations within the given $C_{3}$ signature towards enriched values are assumed to reflect dryer conditions at least during the LGM between 17000 and 18500 cal. a B.P. and probably an increasing imprint of host rock carbon due to increased closed-system conditions. The Holocene $\delta^{13} \mathrm{C}$ timeseries matches the expected $C_{3}$ compositions verifying a closed forest cover within the catchment of the Cave Hintere Kohlhalde. Nevertheless, a stand-alone interpretation based only on the $\delta^{13} \mathrm{C}$ proxy remains ambiguous and needs to be supported by further evidences. 


\section{vii - 2.1.5) I sotopic composition timeseries}

\section{The stalactite ZH-STK of the Zaininger-Cave (Swabian Alb)}

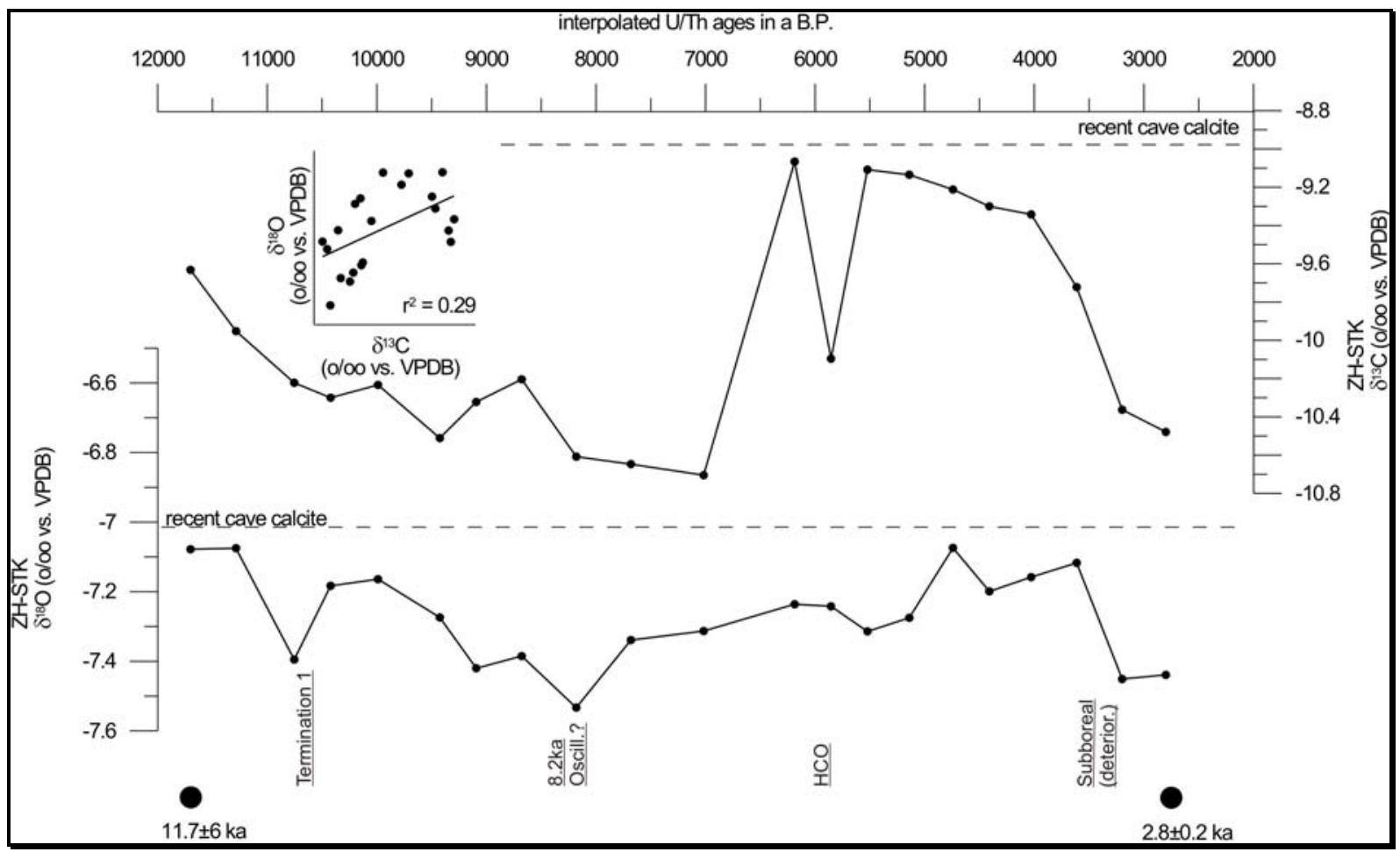

Figure vii - 2.9: $\delta^{18} \mathrm{O}, \delta^{13} \mathrm{C}$ timeseries of the stalactite ZH-STK. Dotted lines are values for recent cave calcites. Underlined events discussed: Last Glacial Maximum, Younger Dryas, Termination 1, 8.2ka cold event, Holocene Climatic Optimum, Subboreal deterioration. Black dots below are ${ }^{230} \mathrm{Th}{ }^{234} \mathrm{U}$-TIMS dates.

The stalactite of the Zaininger-Cave was deposited between $11674 \pm 6092$ and $2772 \pm 215$ a B.P. and displays a linear growth rate of $60 \mathrm{~mm} / \mathrm{ka}$. The mean $\delta^{18} \mathrm{O}$ and $\delta^{13} \mathrm{C}$ of the whole set is respectively 7.27 and $-9.96 \%$ VPDB. The range in variation for $\delta^{18} \mathrm{O}$ is rather small $\left(0.14 \%\right.$ ) whereas $\delta^{13} \mathrm{C}$ displays higher variability of $0.57 \%$. A covariation is not indicated $\left(r^{2}=0.29\right)$ for the time of deposition. A general $\underline{\delta}^{18} \underline{0}$ shift towards lighter values occurs between the start of speleothem deposition and 8180 cal. a B.P. covering values of -7.08 to $-7.53 \%$ VPDB. In the following the $\delta^{18} \mathrm{O}$ increase almost to a maximum value of $-7.12 \%$ VPDB. till ca. 3600 cal. a B.P. Short-term trends accompanied by comparably sudden shifts towards depleted values occur at ca. $10800 \mathrm{cal}$. a B.P. and shortly after 3600 cal. a B.P. Each of this downward peaks amounts to $0.3 \%$ within 400 to 500 years (Figure vii - 2.9).

The $\underline{\delta}^{\underline{13}} \underline{\mathrm{C}}$ timeseries displays a steady long-term shift from $-9.63 \%$ VPDB at the beginning of speleothem growth to more depleted values of $-10.71 \%$ VPDB at $7000 \mathrm{cal}$. a B.P. The adjacent sequence shows an abrupt enrichment in $\delta^{13} \mathrm{C}$ to $-9.1 \%$ VPDB which is, after a sudden downward peak to depleted ratios around 5900 cal. a B.P., followed by gentle decreasing values to $-9.3 \%$ VPDB 
till 4000 cal. a B.P. Until cessation of speleothem deposition the $\delta^{13} \mathrm{C}$ follows again a steep decrease to values as low as $-10.5 \%$ VPDB (Figure vii - 2.9).

\begin{tabular}{|l|c|c|}
\hline & $\begin{array}{c}\mathbf{\delta}^{13} \mathrm{C} \\
\text { VPDB } \\
{[\mathbf{o} / \text { oo }]}\end{array}$ & $\begin{array}{c}\mathbf{\delta}^{18} \mathbf{O} \\
\text { VPDB } \\
{[\mathbf{0} / \text { oo] }}\end{array}$ \\
\hline Min & -10.71 & -7.53 \\
\hline Max & -9.07 & -7.07 \\
\hline Mean & -9.96 & -7.27 \\
\hline Stand.dev. & 0.57 & 0.14 \\
\hline$r^{2}$ & 0.29 & \\
\hline
\end{tabular}

Table vii - 2.4: Summary of measurements of $\delta^{18} \mathrm{O}$ and $\delta^{13} \mathrm{C}$ timeseries from the $\mathrm{ZH}$-STK stalactite. See also table Appendix vii - 2.4 for detailed analytical results.

\section{Discussion Zaininger Cave Stalactite (ZH-STK)}

Since the investigated proxies of the whole timeseries display no covariation and no sympathetic shifts towards heavier values, isotopic equilibrium conditions for the time of stalactite deposition may be assumed.

The timeseries displays lower values in regard to the investigated $\delta^{18} \mathrm{O} / \delta^{13} \mathrm{C}$ of recently deposited cave calcites (respectively - 7.02 and $-8.94 \%$ VPDB; see section vii - 1). This supports the results of the recent cave environment indicating non-equilibrium conditions since both considered proxies shifted towards heavier ratios compared to the timeseries in the paleorecord. Since the ZH-STK ceased growing around $2772 \pm 215$ a B.P. no record is available to enlighten the causes for the transition of the former equilibrium to actual non-equilibrium conditions. Though hypothetical, it is much likely that the ongoing quarry operations lead to rapid widening of proto-tubes, joints, faults etc. even before the cave system itself got partially blasted open. This and the low variability of the $\delta^{18} O$ due to above discussed reasons (discussion $\mathrm{HKH}-1$ ) and thus the absence of recorded major climatic variations like the end of Termination 1 (= transition from stage 2 to 1 ) makes it difficult to estimate the influence of the dripwater function versus the cave temperature effect. However, compared to the $\mathrm{HKH}-1 \delta^{18} \mathrm{O}$ timeseries, the ZH-STK may have recorded the transition of the Last Glacial to the Interglacial between 10750 to 10422 cal. a B.P. which is roughly 200 years later than in the close-by HKH-1 stalagmite (10913 to 9421 cal. a B.P.). The temporal bias is well in the range of absolute dating uncertainties and the established linear chronological control.

Since the dripwater response is positive and obviously large enough to dominate over the cave temperature effect, heavier $\delta^{18} \mathrm{O}$ of the timeseries are associated with increasing temperatures and thus yield an opposite sign compared to the HKH-1 stalagmite.

Owing to the recorded net shift at the transition Younger Dryas/Preboreal to the temperature effect alone, the T-increase would amount to 4.4 to $6.0^{\circ} \mathrm{C}$ depending on the ice-volume effect between 1.2 and $1.8 \%$ as explained in section iv.

The following steady amelioration towards warmer conditions ceased around $8180 \mathrm{cal}$. a B.P. and suggests the occurrence of a distinct but small cold period. The accompanied $\delta^{18} \mathrm{O}$ shift amounts to only $0.13 \%$, which would correspond to a temperature decrease of less than $0.5^{\circ} \mathrm{C}$. 
The adjacent Holocene period displays steady increasing trends towards heavier values due to a general climatic amelioration. The absence of variations if compared to the $\mathrm{HKH}-1$ record may be interpreted as a resolutional bias since it is known from independent sources that the maximum warmth is usually associated with wetter conditions (BELL and WALKER 1992). This should trigger shorter residence times, higher cave dripwater-rates, increased speleothem growth and therefore a rapid signal transfer into the spelean calcite.

The sharp drop in values between 3610 and 3200 cal. a B.P. marks a climatic deterioration towards cooler conditions just before cessation of speleothem growth around $2772 \pm 215$ a B.P. Since both speleothems from the Swabian Alb covering the Holocene ceased growing around the same time, similar deteriorating climatic causes are suggested.

The $\underline{\delta}^{13} \underline{\mathrm{C}}$ timeseries of the ZH-STK display a clear $\mathrm{C}_{3}$ signal for the time of deposition, which is expected for the European Holocene. In similitude to the $\mathrm{HKH}-1$ signal, a stand-alone interpretation within the depicted range is almost impossible. Nevertheless, the long-term shift occurring between ca. 7000 and $6200 \mathrm{cal}$. a B.P. of almost $2 \%$ towards enriched values till around 4000 cal. a B.P. may be interpreted as non-equilibrium conditions. This may be due to shorter residence times, or owing to evaporation effects, rapid degassing, or prior precipitation in the vadose zone/cave (see discussion $\mathrm{HKH}-1$ above). Since the Subboreal is in contrast to the humid warm Middle Holocene characterized by a wetter cold trend, the raised $\delta^{13} \mathrm{C}$ values until ca. $4000 \mathrm{cal}$. a B.P. may be a dry signal since equilibrium conditions of the cave calcite are preserved. The distinct depletion and recovery in $\delta^{13} \mathrm{C}$ around 5900 cal. a B.P. may indicate a higher variability (although not reproducible) of this period. Together with the $\delta^{18} \mathrm{O}$ of the same period, which indicates an overall climatic amelioration, both proxies point towards warmer conditions for this part of the Holocene record. The rapid depletion after ca. 4000 cal. a B.P. may be interpreted as a decreasing host rock influence due to higher effective meteoric precipitation of the Subboreal.

\section{vii - 2.1.6) I sotopic compositions timeseries The stalagmite ZH-1 STM from the Zaininger-Cave (Swabian Alb)}

The $\mathrm{ZH}-1$ stalagmite started growing around $71220 \pm 13940$ a B.P. for an unknown period since further datings did not yield reliable results due to considerable low uranium contents (see section above). Therefore, an age calibration was not performed but nonetheless a discussion of the established data is provided as far as possible. Speleothem growth is assumed to have taken place somewhere around the measured date including its uncertainty. Note that the term "timeseries" is used out of convenience and not senso stricto because only one point in time is given. In contrast to the Holocene stalactite of the same cave (ZH-STK), the stable isotope proxies of the older stalagmite reveal a reversed signature variability-wise. The $\delta^{18} \mathrm{O}$ displays a higher variability of 
$1.11 \%$ whereas the $\delta^{13} \mathrm{C}$ timeseries is with $0.62 \%$ well in the range of the Holocene sample (= $0.57 \%$ ).

From the beginning of speleothem deposition till $156 \mathrm{~mm}$ (distance from base) the $\underline{\delta}^{\underline{18}} \underline{0 \text { timeseries }}$ displays the lightest values of this sequence (between -9.2 to $9.4 \%$ VPDB), interrupted by a sharp peak with a strongly enriched composition of $-6.08 \%$ VPDB. This is followed by a steep decrease in $\delta^{18} \mathrm{O}$ (Figure vii -2.10 , below). This trend is repeated till $258 \mathrm{~mm}$ reaching its maximum composition of $-5.51 \%$ VPDB. This increase in $\delta^{18} \mathrm{O}$ is interrupted with small drawbacks towards lighter values at 185 and $232 \mathrm{~mm}$ from the base. The last sequence of the timeseries is characterized by a general shift towards lighter values whereas a higher variability is displayed till $303 \mathrm{~mm}$ from the base, which gives away to an almost linear downshift trend.

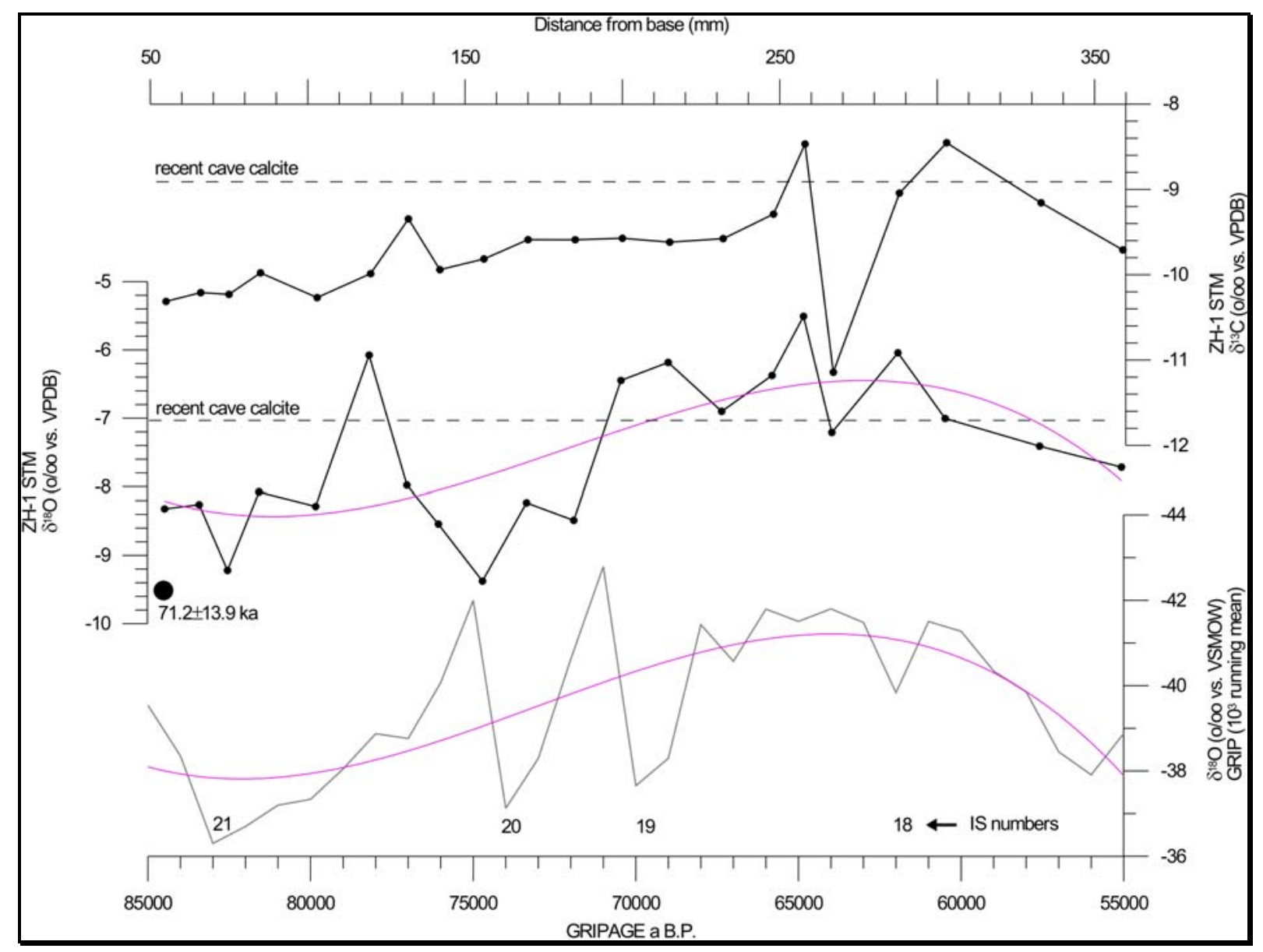

Figure vii - 2.10: $\delta^{18} \mathrm{O}, \delta^{13} \mathrm{C}$ timeseries of the stalagmite $\mathrm{ZH}-1$ STM from the Zaininger Cave. Dotted lines are values for recent cave calcites. Single black dot below: dated absolute age. GRIP data JOHNSEN et al. (1997), available at http://www.ncdc.noaa.gov/paleo/data.html. Pink curve in both plots = polynomial best fit (3rd. order). 


\begin{tabular}{|l|c|c|}
\hline & $\begin{array}{c}\boldsymbol{\delta}^{13} \mathbf{C} \\
\text { VPDB } \\
\text { [o / oo] }\end{array}$ & $\begin{array}{c}\boldsymbol{\delta}^{18} \mathbf{O} \\
\text { VPDB } \\
\text { [o / oo] }\end{array}$ \\
\hline Min & -11.14 & -9.38 \\
\hline Max & -8.45 & -5.51 \\
\hline Mean & -9.68 & -7.51 \\
\hline Stand.dev. & 0.62 & 1.11 \\
\hline $\mathrm{r}^{2}$ & 0.31 & \multicolumn{2}{|l}{} \\
\hline
\end{tabular}

Table vii - 2.5: Summary of measurements of $\delta^{18} \mathrm{O}$ and $\delta^{13} \mathrm{C}$ timeseries from the $\mathrm{ZH}-1$ STM stalagmite. See also table Appendix vii - 2.5 for detailed analytical results.

The $\underline{\delta}^{13} \underline{\mathrm{C}}$ timeseries shows almost no variation between 55 to $248 \mathrm{~mm}$ indicating a net trend from 10.31 to $-9.29 \%$ VPDB towards more enriched values (Figure vii - 2.10, above). The most striking feature of this profile, which resembles much like the one observed in the ZH-STK timeseries, is the following sudden peak of more than $2.5 \%$ to the lowest $\delta^{13} \mathrm{C}$ value $(-11.14 \%$ VPDB) and immediate increase to the former composition.

A covariation of both proxies is not indicated for the time of deposition $\left(r^{2}=0.31\right)$. The only Hendylayer in question at $75 \mathrm{~mm}$ distance from the base revealed an intermediate correlation of $\mathrm{r}^{2}=0.58$. This has been interpreted due to an outlier situation. Since the corresponding part of the timeseries reveals no sympathetic shifts towards enriched values, isotopic equilibrium conditions are assumed to be established here like for the rest of the timeseries.

\section{Discussion ZH-STM}

The onset of speleothem deposition of the ZH-STM was dated around $71220 \pm 13937$ a B.P. Given the date and relatively high uncertainty of \pm 13937 a B.P. it is difficult to tie the $\delta^{18} \mathrm{O}$ to an associated chronostratigraphy. The begin of deposition may correlate either with the onset of OIS 4 reflecting Glacial conditions, or considering the uncertainty, with OIS 5 or even OIS 3, both reflecting warmer conditions. Since a timeseries cannot be constructed due to a lack of age control only some broad remarks can be made:

To tackle the problem of a negative or positive dripwater response, the $\delta^{18} \mathrm{O}$ timeseries was compared to the GRIP icecore between 85000 to 55000 cal. a B.P. (ca. $71000 \pm 14000$ a). To generate a statistical approximation of both timeseries, the GRIP data was filtered as $10^{3}$ mean which gives 31 data points for the GRIP (ZH-1 STM yields $n=21$ ). The shape of the polynomial best-fit curve (3rd. order) displays a sympathetic distribution between the two timeseries when the ZH-1 STM profile is orientated with higher, more enriched values paralleling colder conditions of the reference GRIP timeseries.

In regard to the recent cave calcite and/or modeled Holocene $\delta^{18} \mathrm{O}$ compositions (which reflect an Interglacial signal), the growth axis intervals from 50-110 mm, 125-195 mm and 300-360 mm recorded relatively increased temperatures. 
The mean values for the assigned warmer conditions range around -8.43 to $-8.52 \%$ whereas the coldest signals yields mean compositions of ca. -6.08 to $-6.38 \%$. If due to a temperature effect this trend would correspond to a 3.5 to $4^{\circ} \mathrm{C}\left(\Delta \delta^{18} \mathrm{O}\right.$ divided by $0.36 \% / 1^{\circ} \mathrm{C}$, as explained in section iv above) shift over the entire time of speleothem deposition. The offset towards Holocene $\delta^{18} \mathrm{O}$ (recent cave calcites and modeled values) amounts to ca. $+3{ }^{\circ} \mathrm{C}$ and $-2^{\circ} \mathrm{C}$ for increased or decreased temperature variability respectively. Note that these can only be rough temperature estimates since the ("paleo -") ratio of the dripwater function versus cave temperature effect is not known and was therefore based on Holocene estimates without taking any ice-volume effect into account. The deposition under isotopic equilibrium conditions, the described vigorous shifts in spelean $\delta^{18} \mathrm{O}$ (and thus temperature) strongly suggests being a result of recorded climatic variations. No statement is possible about its extent (local, regional, or global), due to the fact that i) no growth frequency for the speleothem can be modeled and ii) correlations with other archives like GRIP, GISP2, VOSTOCK, SPECMAP etc. bear no direct coincidences.

The $\delta^{13} \mathrm{C}$ timeseries displays a clear $C_{3}$ signal for the whole time of deposition, which makes an intrinsic interpretation rather difficult. $\mathrm{A}_{3}$ vegetational cover may be assumed since at least for the post-Eemian times, especially for the Lower Pleniglacial maximum (OIS 4), and the Last Glacial Maximum (OIS 2) steppe and tundra were the main vegetational types and forest was found only in favored and isolated places (see above, discussion HKH-1 STM). The characteristic patterns of the profile are $\delta^{13} \mathrm{C}$ enrichments, which parallel the $\delta^{18} \mathrm{O}$ enrichments and the increased variability around 250 to $300 \mathrm{~mm}$ distance from the base. Obviously both proxies recorded cold shifts and support the statistical approach to get hold on the direction of $\delta^{18} \mathrm{O}$ shifts. Again, in similitude to the HKH-1 STM it is not possible to make safe assumptions about a cold-wet or cold-dry signal due to the lack of further proxies. 


\section{vii - 2.2) The HU-stalagmite of the Paleocave Hunas and the MH-stalagmite of the Mühlbach-Cave (Franconian Alb)}

\section{vii - 2.2.1) Morphology}

The Hunas stalagmite (HU-STM) is $28 \mathrm{~cm}$ long and $18 \mathrm{~cm}$ at the base. Most of the longitudinal section of the HU-stalagmite consists of dark to honey brown layers, which are interrupted by white isolated layers. Macroscopically most of the laminae can be traced well from the apex down the sides of the stalagmite and a hiatus is not visible (Figure vii - 2.12).

The stalagmite of the Franconian Mühlbach-Cave (MH-stalagmite) is $37 \mathrm{~cm}$ long and displays a basal diameter of $14 \mathrm{~cm}$. The speleothem shows like the Hunas sample non-porous compact microcrystalline low Mg-Calcite. But in contrast to the HU-stalagmite, the cross-section of the MH-stalagmite is set up of translucent gray to light brown alternating layers except the upper $6 \mathrm{~cm}$ which is composed of coarse columnar facies (Figure vii - 2.11).

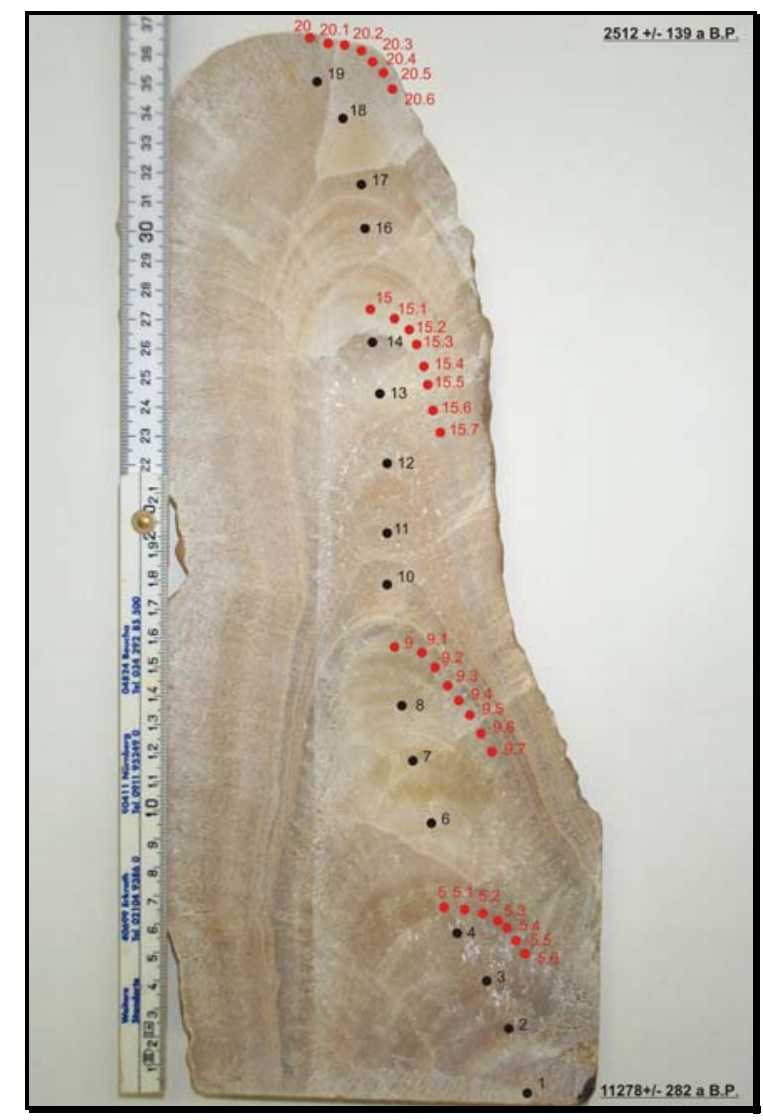

Figure vii - 2.11: Longitudinal cut of the Mühlbach-Cave stalagmite (Franconian Alb). Black dots $=\delta^{18} \mathrm{O} / \delta^{13} \mathrm{C}$ subsamples, red dots $=$ Hendy-samples. 


\section{vii - 2.2.2) Chronological control and extension rates}

The HU-stalagmite has been dated between 79373 and 76872 a. B.P. and displays uncertainties around 9000 a due to the very low Uranium content (between 150 and $200 \mu \mathrm{g} / \mathrm{kg}$, Appendix vii - 2.1). Vertical extension rates range from $78 \mathrm{~mm} / \mathrm{ka}$ between 79373 to 77877 a B.P. and increase to ca. $128 \mathrm{~mm} / \mathrm{ka}$ until cessation of speleothem growth.

The stalagmite of the Mühlbach-Cave (MH-STM) shows a linear extension rate of $41 \mathrm{~mm} / \mathrm{ka}$ between the dated samples and was deposited during Holocene times between ca. $11278 \pm 282$ and $2522 \pm$ 139 a. B.P. The mean resolution of the Hunas-stalagmite amounts to ca. 460 years and one sample represents ca. 8-13 mm/a whereas the Mühlbach-Cave stalagmite displays a 210 year resolution and $24 \mathrm{~mm} / \mathrm{a}$ per sample respectively.

\section{vii - 2.2.3) I sotopic equilibrium}

The $\delta^{18} \mathrm{O}$ and $\delta^{13} \mathrm{C}$ measurements along single growth layers (Hendy-Test) performed at two different heights of the HU-stalagmite suggests isotopic equilibrium conditions (Data Appendix vii - 2.8). The Hendy-Tests in figures vii -2.12 to -14 (below) display intermediate covariations of $r^{2}=0.45$ at $73 \mathrm{~mm}$ (between 79373 and 77877 a B.P.) and $\mathrm{r}^{2}=0.51$ at $188 \mathrm{~mm}$ (between 77877 and 79373 a B.P.). This evidence is supported by only minor deviations of around $0.3 \%$ along the tested single layers (Figure vii - 2.13).
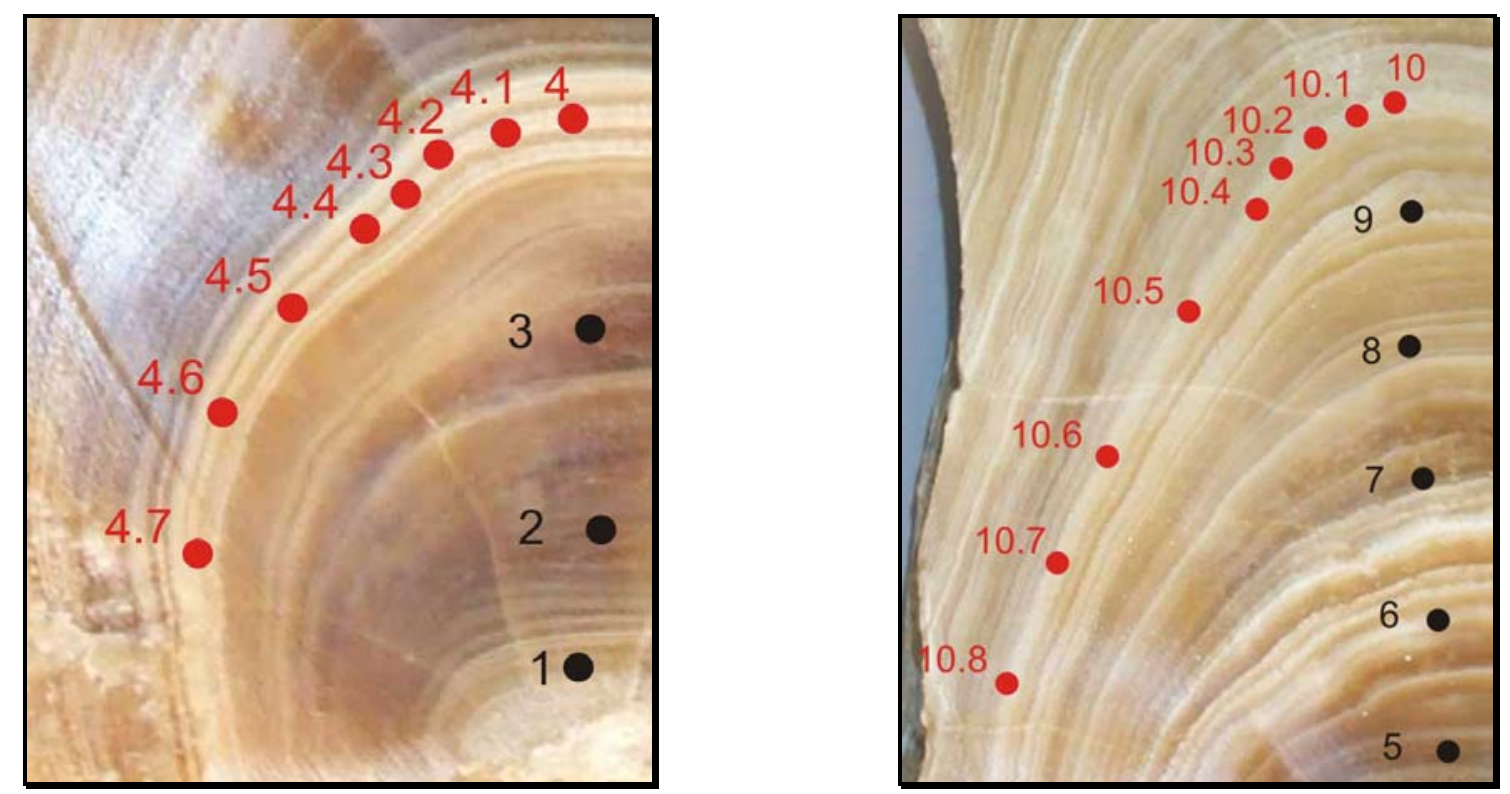

Figure vii - 2.12: Close-up of the internal longitudinal structure of the HU-stalagmite. The red dots show the sample positions of the performed Hendy-test. Section along the vertical growth axis represents 10-92 $\mathrm{mm}$ (left) and $95-210 \mathrm{~mm}$ (right) from the base. 

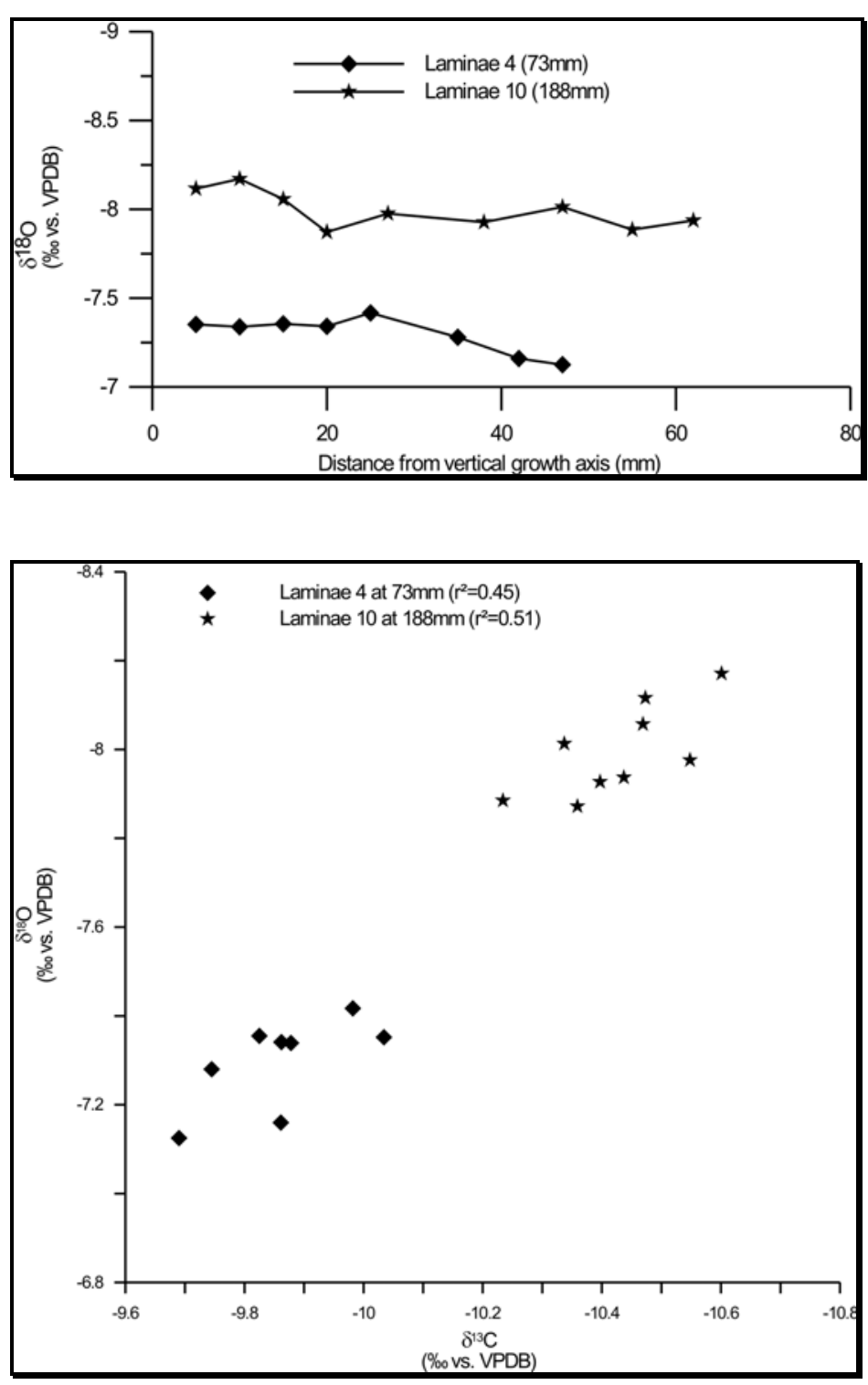

Figure vii - 2.13: $\delta^{18} \mathrm{O}$ variations along the two tested Hendy-layers display only minor variations of \pm $0.3 \%$ for the Hunas stalagmite.

Figure vii - 2.14: Hunas stalagmite: $\delta^{18} \mathrm{O}$ versus $\delta^{13} \mathrm{C}$ of the layers checked for isotopic equilibrium conditions. Both laminae yield an intermediate correlation of around $r^{2}$ $=0.5$ which is indicative for isotopic equilibrium conditions. Considering the spatial position of the samples it is evident that the heaviest values of both laminae are located in the outermost drilling positions. This is indicative for a "stretching" of the isotopic abundances in the regression analysis towards an intermediate linear fit $\left(r^{2}\right)$, probably due to physical sampling uncertainties.

The stalagmite MH-STM from the Mühlbach-Cave was tested for isotopic equilibrium conditions at four different laminae at $69,158,280$ and $370 \mathrm{~mm}$ along the central growth axis. The absence of a coeval development of $\delta^{13} \mathrm{C}$ and $\delta^{18} \mathrm{O}$ suggest suitability for timeseries analysis (Figure vii - 2.16, below). Calculated $r^{2}$ range from 0.36 and 0.01 for the lowest Hendy-layers and develop a trend towards intermediate values of $r^{2}=0.40$ and 0.50 for the upper sequence (Figure vii - 2.15). The maximum differences in $\delta^{18} \mathrm{O}$ of the single layers are between 0.34 and $0.39 \%$ and thus well in the range of the proposed tolerance of $0.8 \%$. 

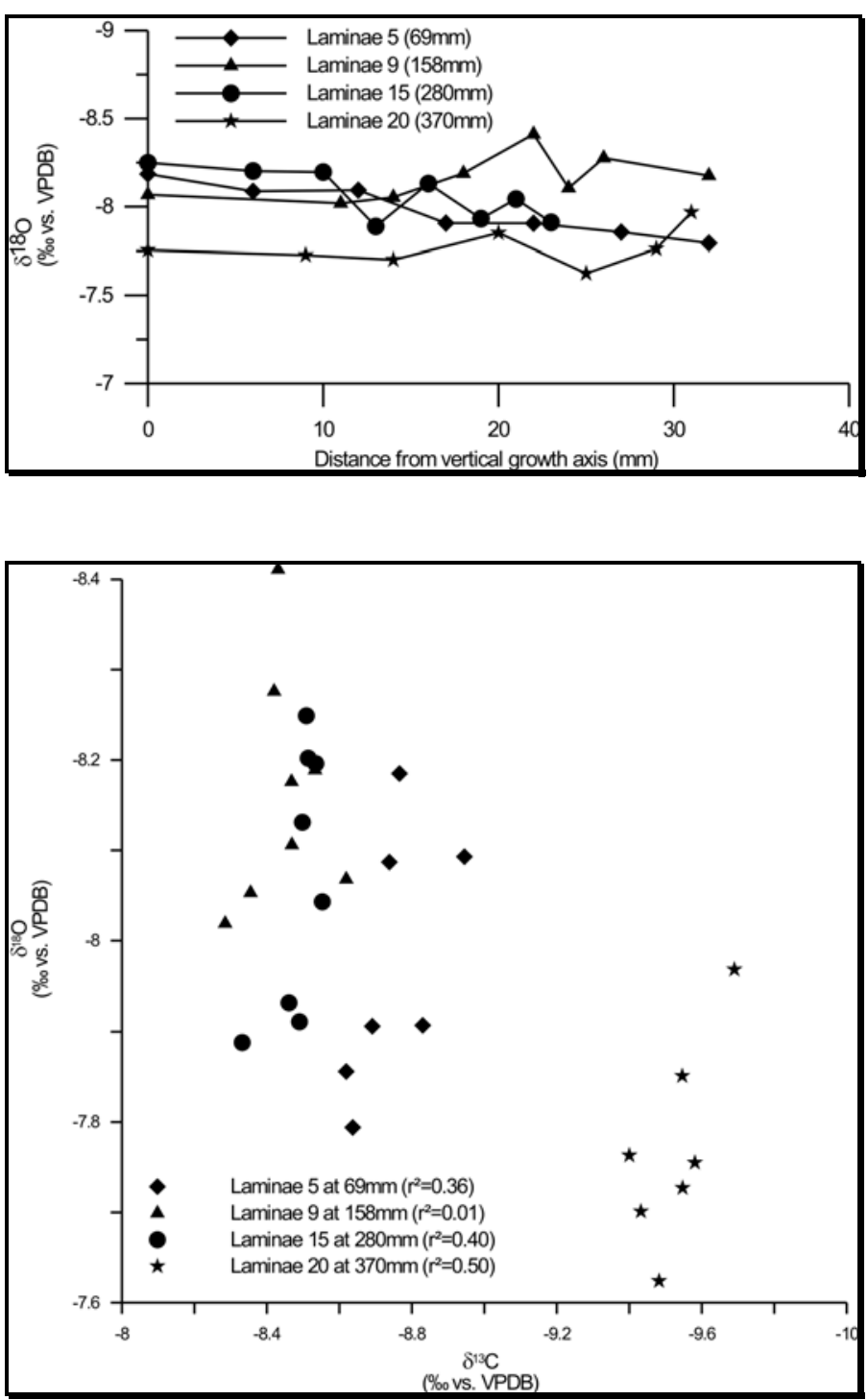

Figure vii - 2.15: $\delta^{18} \mathrm{O}$ variations along the tested Hendy-layers at four different heights along the central growth axis of the $\mathrm{MH}$ stalagmite display only minor variations of 0.3 to $0.4 \%$.

Figure vii - 2.16: Four different single layers of the Mühlbach-Cave stalagmite were controlled for isotope equilibration conditions. The plot $\delta^{18} \mathrm{O}$ versus $\delta^{13} \mathrm{C}$ shows minor to intermediate covariations of $r^{2}=$ 0.36 to 0.50 .

Since both speleothems display only minor single layer deviations in $\delta^{18} \mathrm{O}(0.3$ to $0.4 \% 0)$ and covariations of maximum $r^{2}=0.5$ with $\delta^{13} \mathrm{C}$, the Hendy-Tests therefore suggests that both stalagmites were deposited under isotopic equilibrium conditions.

\section{vii - 2.2.4) I sotopic composition timeseries}

\section{The stalagmite of the Paleocave Hunas (Franconian Alb)}

The stable isotopic timeseries of the Hunas stalagmite display mean values of respectively -7.97 VPDB for $\delta^{18} \mathrm{O}$ and $-9.06 \%$ VPDB for $\delta^{13} \mathrm{C}$ and no covariation $\left(r^{2}=0.02\right)$ over the entire time of deposition. The variations are for $\delta^{18} \mathrm{O}$ in the range of 0.53 and $1.64 \%$ VPDB for $\delta^{13} \mathrm{C}$ (Table vii 2.6).

At the onset of deposition (79373 \pm 8237 a B.P) the $\delta^{18}$ O timeseries shows generally a net trend from more depleted values of $-8.19 \%$ VPDB towards enriched values (-7.29\% VPDB) at the end of 
speleothem growth (76872 \pm 9686 a B.P.). This trend is interrupted by a sudden downshift in value, beginning at $78586 \mathrm{cal}$. a B.P. and reaching minimum isotopic composition of $-8.91 \%$ VPDB after mere 440 years (78148 cal. a B.P). This feature is repeated in principle but displays lower variability and more enriched values between 77712 to 77383 cal. a B.P.

In regard to the $\delta^{18} \mathrm{O}$ timeseries the $\delta^{13} \mathrm{C}$ profile displays an antipathetic distribution. It starts with the highest composition of $-5.64 \%$ VPDB and evolves towards its lowest value of $-10.68 \%$ VPDB around 77045 cal. a B.P. almost at the end of speleothem deposition. A major net drop of $3.36 \%$ towards more depleted values starts at 78857 cal. a B.P.

\begin{tabular}{|c|c|c|}
\hline HU-STM & $\mid \begin{array}{l}\delta^{13} \mathrm{C} \\
\text { VPDB } \\
{[\mathrm{O} / \mathrm{oo}]}\end{array}$ & {$\left[\begin{array}{l}\delta^{18} \mathrm{O} \\
\text { VPDB } \\
{[\mathrm{o} / \mathrm{oo}]}\end{array}\right.$} \\
\hline Min & -10.68 & $3-8.91$ \\
\hline Max & -5.64 & -7.29 \\
\hline Mean & -9.06 & -7.97 \\
\hline stand.dev. & 1.64 & 0.53 \\
\hline $\mathrm{r}^{2}$ & 0.02 & \\
\hline
\end{tabular}

Table vii - 2.6: Summary of measurements of $\delta^{18} \mathrm{O}$ and $\delta^{13} \mathrm{C}$ timeseries from the Hunas-Cave stalagmite. See also table Appendix vii - 2.7 for detailed analytical results.

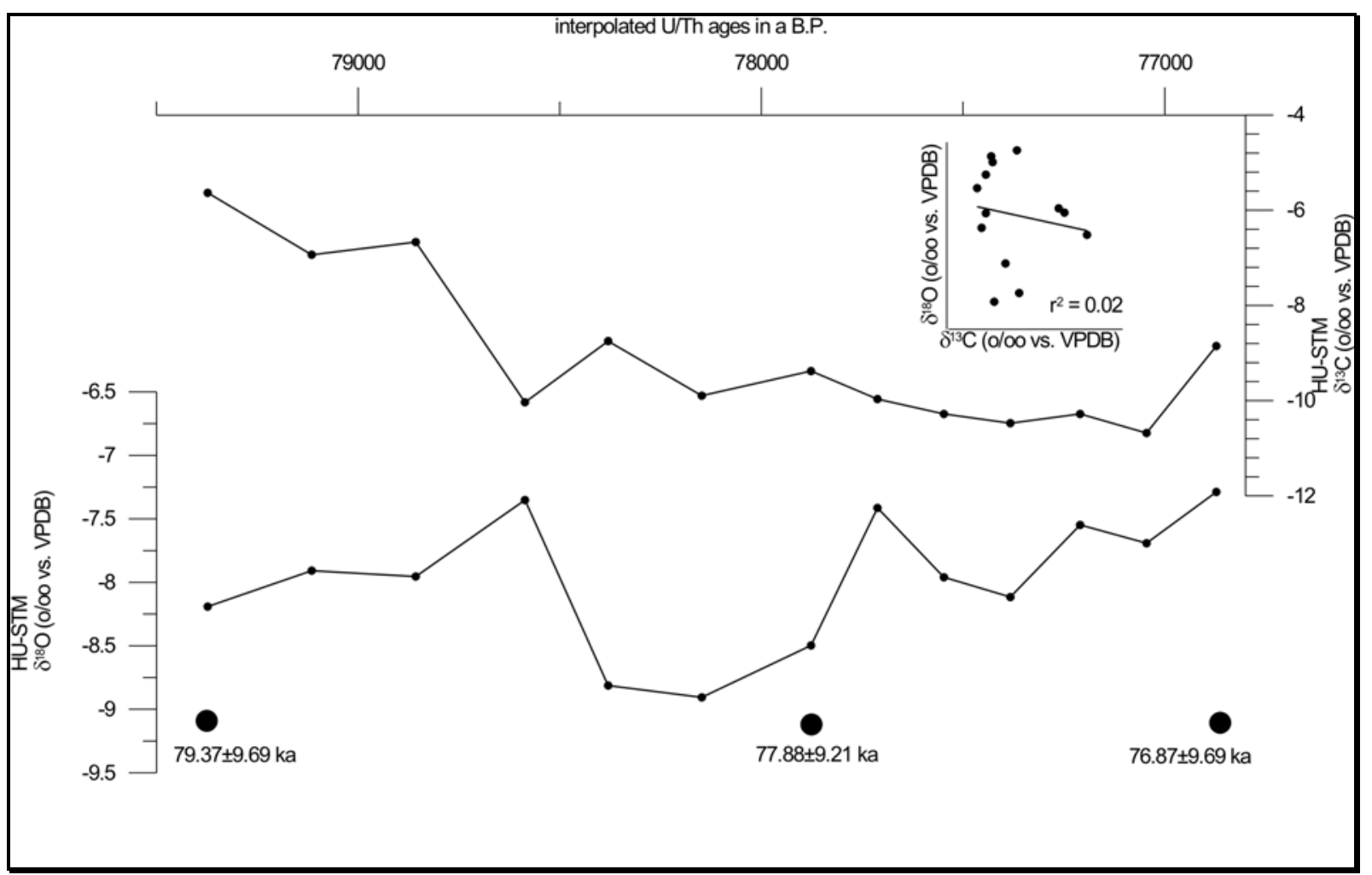

Figure vii - 2.17: $\delta^{18} \mathrm{O}, \delta^{13} \mathrm{C}$ timeseries from the stalagmite of the Paleocave Hunas. 


\section{Discussion Hunas stalagmite:}

The established growth period between $79373 \pm 8237$ and $76872 \pm 9686$ a B.P. of the HU-STM does not match the previous measurements of sinter fragments from the "P1-sinterlayer", which yielded ages of 230 ka B.P (HENNIG et al. 1983) or $221+52 /-32$ ka B.P. (BRUNNACKER 1983).

The chronological bias of the two speleothem samples may arise due to the very low uranium contents and associated dating uncertainties or may reveal the existence of two sinter generations of the Paleocave. The considerable low spelean calcite uranium-contents of ca. $57 \mu \mathrm{g} / \mathrm{kg}$ (HenNIG 1979) lead to uncertainties of around $30 \%$ (HELLER 1983) for the $\alpha$-spectroscopic analysis. In contrast, the HU-STM yielded also low uranium-concentrations of $150-200 \mu \mathrm{g} / \mathrm{kg}$ but was measured with the more precise ${ }^{234} \mathrm{U} /{ }^{230} \mathrm{Th}$ TIMS. The recently established ${ }^{234} \mathrm{U} /{ }^{230} \mathrm{Th}$ TIMS dating from a new extracted flowstone (HU-i) of a correlate to the P1-layer gives an age of $270593 \pm 24379$ a B.P. (data also provided in Appendix vii - 2.1). It is noticeable that besides the same Middle Pleistocene age, the flowstone samples yield in similitude to the sinter fragment dated by HENNIG (1979) also very low uranium concentrations $(0.113-0.057 \mathrm{mg} / \mathrm{kg})$ and thus a relatively high uncertainty of 20 to $30 \mathrm{ka}$. Considering the high uncertainty of all referred datings the first speleothem generation may correlate with the Saalian OIS 7. Since until now no further data for the Hunas flowstone sample exist, the question of growth frequencies, climate signal conservation and thus higher resolutional climatic interpretations are currently not feasible. The assumed second speleothem generation is represented by the HU-STM which was deposited for a short period of time at the onset of OIS 5 (see above). Since the top of this stalagmite yielded the youngest of all dated speleothems, the process of cave degradation and sedimentary backfilling consequently bears an age of $<76872 \pm 9686$ a B.P.

The most characteristic features of the $\underline{\delta}^{18} \underline{0 \text { timeseries }}$ of the HU-STM are generally increasing stable isotopic enrichments till cessation of speleothem growth and a major isotopic depletion of ca. $1.4 \%$ between 78586 and $78380 \mathrm{cal}$. a B.P. An unambiguous interpretation of the short-term variations is difficult in this case since no intrinsic proxies, like fluid inclusions were established. Thus, there is no evidence provided which could specify the paleo-ratio of the former cave temperature effect and the dripwater response. Unfortunately, extrinsic factors like comparison with other archives like GRIP, GISP, or SPECMAP do not yield a straightforward correlation which could enlighten this question. Taking the given dating uncertainties into account the speleothem deposition could have taken place shortly before the onset of OIS 5.1 well into OIS 5.0 or between OIS 5.2 to 5.1. The SPECMAP curve of the former interval shows a clear depletion in values assigned to colder conditions whereas the latter period displays increasing heavier ratios interpreted as a relative warm shift peaking at OIS 5.1. Thus, the net trend towards heavier values of the HU-STM may be interpreted in both directions. Its isotopic depletion of ca. $1.4 \%$ between 78590 and 78380 cal. a B.P. would amount today to roughly $4^{\circ} \mathrm{C}\left(\Delta \delta^{18} \mathrm{O}\right.$ divided by $0.36 \% / 1^{\circ} \mathrm{C}$, as explained in section iv), if due to a temperature effect alone and based on Holocene estimates of the cave temperature effect versus the dripwater response (see also discussion ZH-STM). A major depletion of this extent, which is terminated within ca. 500 to 800 cal. years, may be interpreted as a recorded OIS 5.1 signal since a cooling event of this extent is at 
least globally not recorded for this period of time. Established isotopic equilibrium conditions of the HU-STM support the evidence for recorded climatic signals generally but it is not possible to infer their extent supra-regionally. Therefore, it is critical to tie the interpretation of shifts only to the discussed evidence since also a climatic deterioration of mere regional extent could have been recorded. A further example for the ambiguity of the $\delta^{18} \mathrm{O}$ timeseries is the comparison with the inferred Holocene spelean calcite $\delta^{18} \mathrm{O}$. Modeled values for Germany are in the range of ca. $-7.3 \%$ VPDB (see section iv). Since the evolution of the $\delta^{18} 0$ timeseries is towards this ratio, a warm-trend may be indicated if due to a temperature effect alone. This would support the above-mentioned chronological classification of the assigned growth interval within the older OIS 5.1 but still with a lack in explaining the major downshift as a supra-regional cold-trend .

Considering the $\underline{\delta}^{\underline{13}} \underline{\mathrm{C}}$ timeseries two principal long-term trends can be distinguished. From the onset of deposition to ca. 78857 cal. a B.P. the values range around -5.63 and $-6.67 \%$ VPDB. This is slightly heavier than the suggested transition zones of recorded $\delta^{13} \mathrm{C}$ signals ascribed being due to prevailing $\mathrm{C}_{3}$ or $\mathrm{C}_{4}$ vegetation by secondary carbonates (see section iv).

Thus, a straightforward interpretation in senso stricto may indicate a dominating $\mathrm{C}_{4}$ plant coverage in the catchment area of the Paleocave Hunas for this time. The adjacent sharp drop of $>3 \%$ within the next 250 cal. years lead to values between -10.63 and $-8.75 \%$ VPDB, which indicates a typical $C_{3}$ vegetation above the site. The linear inferred growth intervals increase from $78 \mathrm{~mm} / \mathrm{ka}$ to $128 \mathrm{~mm} / \mathrm{ka}$ for the time of speleothem deposition. Both, the lower growth frequency and thus lower availability of circulating water at the onset of deposition may indicate a recorded $\mathrm{C}_{4}$ signal since this type of vegetation is comparably better adapted to dryer environmental conditions. Consequently, for the youngest part of the $\delta^{13} \mathrm{C}$ timeseries, the increased growth frequency and prevailing $C_{3}$ vegetational coverage may thus indicate a comparably climatic humid amelioration.

Summarizing the $\delta^{13} \mathrm{C}$ signal reflects straightforwardly a vegetation being to some extent adapted to dryer climate conditions, which is supported by a lower growth frequency of the HU-STM between 79373 a.B.P. and ca. 78857 cal. a B.P. Till cessation of speleothem growth around $76872 \mathrm{cal}$. a B.P. a climate amelioration towards humid and warmer conditions may be indicated by prevailing $\mathrm{C}_{3}$ vegetational coverage and increased growth frequency. This is also supported by the interpretation of heavier $\delta^{18} \mathrm{O}$ as being due to a positive temperature response of the spelean calcite. Thus, a net warm trend till the end of deposition is assumed. Considering the assigned age control, a deposition of the HU-STM at the older OIS 5.1 is suggested. As already discussed, this remains ambiguous since no intrinsic proxies shows a clear signal and known external climate forcings and its potential stable isotopic imprints were used to explain the shift in values. Based on the modeled frame conditions a couple of important questions still remain unanswered: If due to a temperature effect alone, the major depletion in $\delta^{18} \mathrm{O}$ between 78586 and $78380 \mathrm{cal}$. a B.P. represents the onset of a relative cold phase which has not been reported from the Franconian Alb so far. Taking the assigned $\delta^{13} \mathrm{C}$ into account during that period of time, a humid cold phase may even be characterized. Nevertheless, 
owing to a lack in correlation with known global climate archives a regionally limited event must be assumed until now.

\section{vii - 2.2.5) I sotopic composition timeseries}

\section{The Mühlbach-Cave stalagmite (Franconian Alb)}

The $\delta^{18} \mathrm{O} / \delta^{13} \mathrm{C}$ profiles of the Mühlbach-Cave stalagmite display mean values of -8.12 and respectively $-8.84 \%$ VPDB for the entire time of deposition. The linear regressions analysis $\left(r^{2}=0.02\right)$ indicates no coeval trends of the two proxies (Table vii - 2.7).

The $\underline{\underline{18}}^{18} \underline{0}$ timeseries displays its lowest value of $-8.41 \%$ VPDB around $10418 \mathrm{cal}$. a B.P. whereas the highest composition of $-7.76 \%$ VPDB is recorded at the close of speleothem growth around $2512 \pm$ 139 a B.P. Given the rather small variation of $0.17 \%$ of the entire set, a long-term trend is only weakly developed. Short-term variations display a characteristic net peak of about $0.5 \%$ towards depleted ratios between 10801 to 10418 cal. a B.P. and a following increase to almost former concentrations of $-7.96 \%$ VPDB around 10035 cal. a B.P. Over the next 2000 years the timeseries shows a stepwise approximation to the lowest value, followed again by an abrupt increase again of roughly $0.5 \%$ at $7568 \mathrm{cal}$. a B.P. The growth phase till $4760 \mathrm{cal}$. a B.P. yields only minor variations in the range of -8.07 to $-8.25 \%$ VPDB. $\delta^{18} \mathrm{O}$ increases towards enriched values until cessation of speleothem deposition.

The ${ }^{\delta} \underline{13}$ C timeseries yields a steady increasing trend without serious variations between -9.12 to $-8.51 \%$ VPDB from the begin of stalagmite growth till around 4670 cal. a B.P. A comparably sharp decreasing shift leads to the lowest recorded $\delta^{13} \mathrm{C}$ composition of $-9.79 \%$ VPDB. The adjacent 790 years display a slightly increase in values.

\begin{tabular}{|c|c|c|}
\hline MH-STM & {$\left[\begin{array}{l}\delta^{13} \mathrm{C} \\
\text { VPDB } \\
{[0 / 00]}\end{array}\right.$} & {$\left[\begin{array}{l}\delta^{18} \mathrm{O} \\
\text { VPDB } \\
{[0 / 00]}\end{array}\right.$} \\
\hline Min & -9.79 & -8.41 \\
\hline Max & -8.34 & -7.76 \\
\hline Mean & -8.84 & -8.12 \\
\hline stand.dev. & 0.41 & 0.17 \\
\hline $\mathrm{r}^{2}$ & 0.07 & \\
\hline
\end{tabular}

Table vii - 2.7: Summary of measurements of $\delta^{18} \mathrm{O}$ and $\delta^{13} \mathrm{C}$ timeseries from the MühlbachCave stalagmite. See also table Appendix vii 2.9 for detailed analytical results.

Although the last five samples (between 4669 cal. a B.P. to $2512 \pm 139$ a B.P.) seem to display sympathetic shifts, the corresponding Hendy-Test at 280 and $370 \mathrm{~mm}$ from the base shows only an intermediate $r^{2}$ of $0.4-0.5$. Thus, a deposition close to isotopic equilibrium conditions can safely be assumed. 


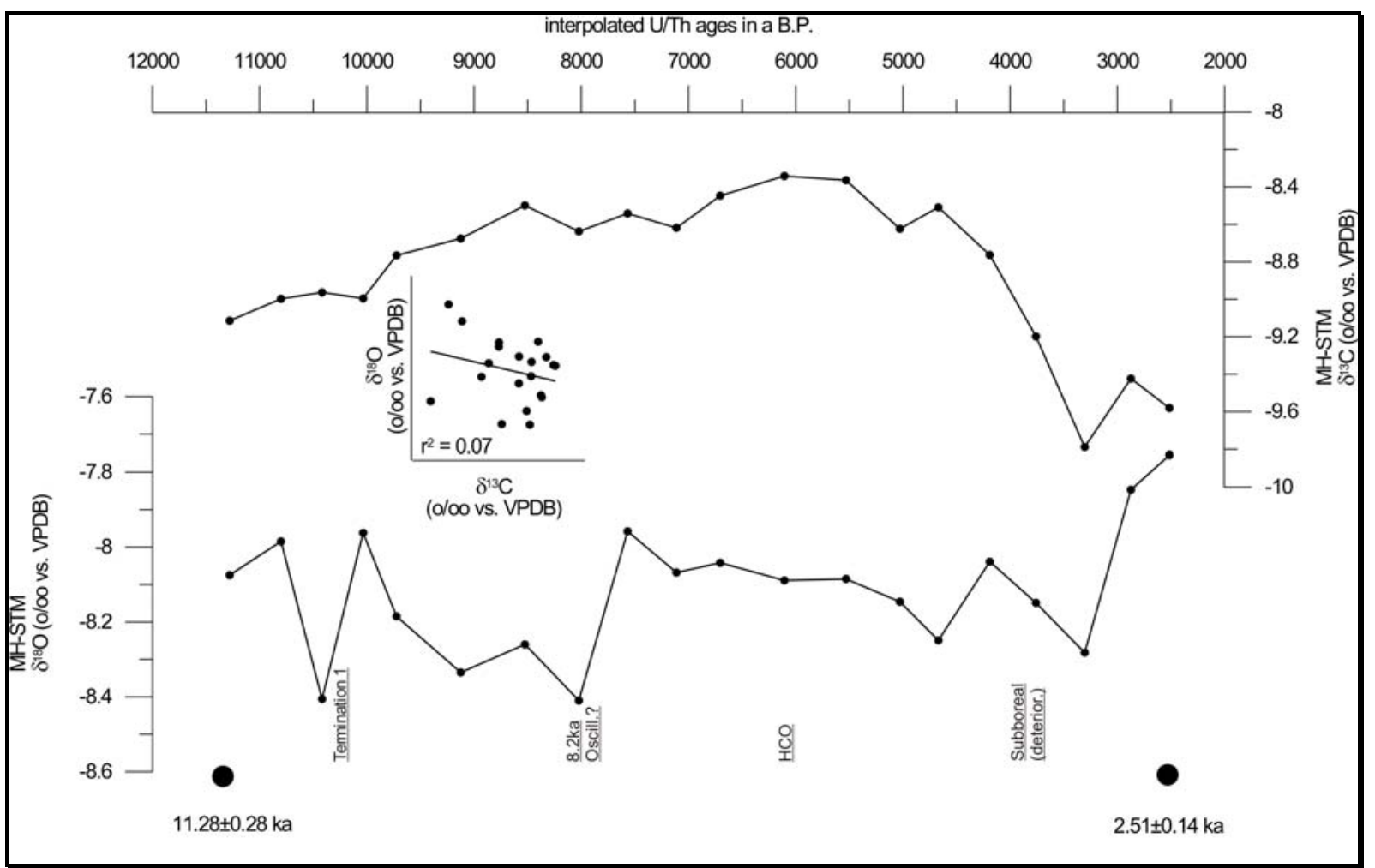

Figure vii - 2.18: $\delta^{18} 0, \delta^{13} \mathrm{C}$ timeseries of the Mühlbach-Cave stalagmite.

Discussion Mühlbach-Cave Stalagmite:

If due to a temperature effect alone, the recorded $\underline{\delta}^{\underline{18}} \underline{\mathrm{O} \text { timeseries }}$ would correspond to a $1.8^{\circ} \mathrm{C}$ increase $\left(0.65 \%\right.$ divided by $0.36 \% / 1^{\circ} \mathrm{C}$ as explained in section iv) over the entire period of stalagmite deposition. However, no long-term information on the cave environment and its isotopic and chemical behavior is available to exclude other environmental influences and to confirm this hypothesis. Since the investigated proxies of the whole timeseries display no covariation, isotopic equilibrium conditions and thus a conducted climatic signal to some extent may be assumed (see section above). Shortly after begin of speleothem deposition a distinct depletion of ca. $0.42 \%$ within roughly $400 \mathrm{cal}$. a B.P. and immediate recovery to former values is recorded. Considering the chronological position and associated dating uncertainties, this event may coincide with the transition of OIS 2-1 to the Preboreal period. The rapid increase of ca. $0.45 \%$ at ca. $10418 \mathrm{cal}$. a B.P. from the Last Glacial to the Early Holocene may be due to a temperature effect of ca. 4.5 to $6.25^{\circ} \mathrm{C}(0.45 \%$ o 1.2 or $1.8 \%$ (= ice-volume effect) divided by $0.36 \%$ ). Note that in similitude to the ZH-STK and $\mathrm{HKH}-1$ STM it may also be due to a combination of temperature and driprate control during the change to different cave conditions during the Late Glacial-Interglacial transition. Stepwise decreasing values for the next 2000 cal. years to a minimum of $-8.41 \%$ VPDB and an adjacent sudden peak to $7.96 \%$ VPDB may indicate a small cold phase around $8000 \mathrm{cal}$. a B.P. Like the ZH-STK, the recorded $\Delta \delta^{18} \mathrm{O}$ of the MH-STM displays a rather small drop in values of $0.15 \%$ but a sudden rise of $0.45 \%$, which corresponds to 0.4 and $1.3^{\circ} \mathrm{C}$ respectively. The subsequent Holocene period till ca. $4670 \mathrm{cal}$. a B.P. displays an increased mean of $-8.08 \%$ VPDB but only minor variations compared e.g. to the 
$\mathrm{HKH}-1$ stalagmite timeseries. Assumably this is due to cumulative effects of the annihilating influences of the dripwater function versus the cave temperature effect, the resolutional bias since the physical sampling distance amounts to $\mathrm{ca}$. 500 years, and of the rather thick host rock coverage of $100-120 \mathrm{~m}$ above the cave. The Middle Holocene warm phase ceases between 4670 and 4191 cal. a B.P. and shows a higher variability but a decreasing net trend towards lower values and thus marks a climate deterioration until ca. $3304 \mathrm{cal}$. a B.P. Although heavier values may indicate a climate amelioration $<3303$ cal. a B.P. at the transition from the Subboreal to the early Subatlanticum, the speleothem growth ceased at $2510 \pm 140$ a B.P.

The $\underline{\delta}^{13} \underline{\mathrm{C}}$ timeseries displays for the entire time of speleothem growth values between -8.84 and $9.79 \%$ VPDB, which is well in the range of the expected $C_{3}$ plant coverage above the cave. Given the steady trend with only minor variations between ca. -9.2 to $-8.4 \%$ VPDB from the onset of deposition on, its most characteristic pattern is the sharp decrease of $-1.28 \%$ to its minimum of $9.79 \%$ VPDB during the Subboreal Period between 4670 and 3304 cal. a B.P. In temperate regions and time periods that lack natural variations between $\mathrm{C}_{3}-\mathrm{C}_{4}$ vegetation, the interpretation of recorded speleothem $\delta^{13} \mathrm{C}$ is difficult because until now the geochemical criteria for distinguishing the processes that might trigger the spelean calcite $\delta^{13} \mathrm{C}$ variations have not been established (see section iv). Closed-system conditions lead generally to a limited extent of limestone dissolution since the percolating water becomes isolated from the pedogenic $\mathrm{CO}_{2}$ and is progressively consumed in the carbonation reaction $\left(\mathrm{H}_{2} \mathrm{O}+\mathrm{CO}_{2}=\mathrm{H}_{2} \mathrm{CO}_{3}\right)$. Thus, the host rock influence on the dissolved inorganic carbon (DIC) increases (HENDY 1971, SALOMONS and Mook 1986, DREYBRODT 1988). This may be the case till around 5000 cal. a B.P. considering the slower vadose recharge suggested by the overall low growth frequency of $41 \mathrm{~mm} / \mathrm{ka}$. Assumed long flowpath patterns in the ca. $120 \mathrm{~m}$ overlying host rock $\left(\delta^{13} \mathrm{C}\right.$ mean $=+2.22 \%$ VPDB $)$ may constrict the soil- $\mathrm{CO}_{2}$ supply and may thus promote more closedsystem conditions. This may become crucial in times of lower effective meteoric precipitation. In addition, evaporation, rapid degassing, or prior calcite precipitation in the vadose zone may also be a potential scenario for this case. Nevertheless, the accompanied non-equilibrium conditions would have been rather small considering the recorded variations despite the resolutional bias and were not recorded with the Hendy-Test.

A decreasing host rock influence due to a switch to more open-system conditions associated with continuous equilibration between the seepage water and an infinite reservoir of pedogenic $\mathrm{CO}_{2}$ or a switch of flowpath patterns may lead to the sharp downshift in values. Higher meteoric precipitations known to accompany the period of Subboreal deterioration may favour this development. 


\begin{tabular}{|c|c|c|c|c|c|c|}
\hline Site & Speleothem-ID & $\begin{array}{l}\text { Age } \\
\text { [ka] }\end{array}$ & OIS & $\begin{array}{l}\text { Linear growth } \\
\text { frequency } \\
\text { Min/Max } \\
{[\mathrm{mm} / \mathrm{ka}]}\end{array}$ & $\begin{array}{l}\text { Resolution } \\
\text { mean [ka] }\end{array}$ & $\begin{array}{l}\delta^{18} \mathrm{O}_{\text {(speleothem) }} \\
\text { temperature } \\
\text { response }\end{array}$ \\
\hline Cave Hintere Kohlhalde & $\begin{array}{l}\mathrm{HKH}-1 \quad \mathrm{STM} \\
\text { Stalagmite }\end{array}$ & $\begin{array}{l}44.16(+/-3) \\
2.7(+/-0.3)\end{array}$ & 3 & $2.3-128.0$ & $0.05-2.78$ & neg. \\
\hline Zaininger-Cave & $\begin{array}{l}\text { ZH-STK } \\
\text { Stalactite }\end{array}$ & $\begin{array}{l}11.7(+/-3) \\
2.8(+/-0.1)\end{array}$ & $\begin{array}{l}(2) \\
1\end{array}$ & 60 & 0.45 & pos. \\
\hline & $\begin{array}{l}\mathrm{ZH}-1 \quad \mathrm{STM} \\
\text { Stalagmite }\end{array}$ & $\begin{array}{l}71.28(+/-13.9) \\
?\end{array}$ & ? & $?$ & ? & neg. \\
\hline Paleocave Hunas & $\begin{array}{l}\text { HU-STM } \\
\text { Stalagmite }\end{array}$ & $\begin{array}{l}79.4(+/-8.2) \\
76.9(+/-9.7)\end{array}$ & $\begin{array}{l}5.2 \\
5.1\end{array}$ & $78-128$ & 0.46 & pos. \\
\hline Mühlbach-Cave & $\begin{array}{l}\text { MH-STM } \\
\text { Stalagmite }\end{array}$ & $\begin{array}{l}11.3(+/-0.3) \\
2.5(+/-0.1)\end{array}$ & $\begin{array}{l}(2) \\
1\end{array}$ & 41 & 0.21 & pos. \\
\hline
\end{tabular}

Table vii - 2.8: Summary of discussed speleothem parameters. The last column refers to the direction of shifts recorded in $\delta^{18} \mathrm{O}_{\text {speleothem }}$ as response on a temperature forcing (see also section iv). Thus a "positive" response implies either heavier or lighter $\delta^{18} 0$ ratios with increasing or respectively decreasing temperatures. Vice versa a "negative" response yields either heavier or lighter values with decreasing or increasing temperatures.

\section{vii-2.2.6) Intercomparison of the established timeseries}

\section{The Late Pleistocene timeseries}

The stalagmite ZH-1 STM from the Zaininger-Cave is not considered here due to a lack in age control (see section above).

The stalagmite ( $\underline{\mathrm{HU}-\mathrm{STM}}$ ) from the Paleocave Hunas (79373 \pm 8237 to $76872 \pm 9690$ a B.P) recorded an increased growth frequency and a net warm trend of the $\delta^{18} O$ timeseries. This indicates improved environmental conditions with a higher amount of effective meteoric precipitation and probably increased temperatures, which are favorable for speleothem deposition. This may be supported by a change from a $\mathrm{C}_{4} \delta^{13} \mathrm{C}$ signal prevailing roughly at the first $250 \mathrm{cal}$. years from the onset of deposition to a $C_{3}$ signal and/or by a change from more closed- to open-system conditions. A palynological paleoprecipitation and -temperature record was developed by GuIOT et al. (1989) at Grande Pile (France). It displays a slightly increasing meteoric precipitation (-250 to $-200 \mathrm{~mm}$, negative sign due to today-calibration) and an insignificantly small increase in temperature around $1^{\circ} \mathrm{C}$ between ca. 80000 to 76000 a. This may support the interpretation of the HU-STM isotopic timeseries evolving 
towards a slight climatic amelioration. However, this is in contrast to the SPECMAP chronology, since BASSINOT et al. (1994) or PISIAS et al. (1984) assigned ca. 79000 a B.P. for the OIS 5.1 (or 5a) peak, which is followed by a decrease in $\delta^{18} O$ and thus implying a cold trend for the time $<79000$ a B.P. Obviously, this trend did not find an echo around that time in the Grande Pile record as well as in the German speleothem from the Paleocave Hunas. Taking the bad age constraints (ca. $\pm 9 \mathrm{ka}$ ) of the HU-STM into account, the deposition and assigned recorded warm trend either took place between ca. 79000 and 76000 a B.P. supported by the relative close by Grande Pile palynological record, or correlated to the SPECMAP data, in the older OIS $5.1>79000 \mathrm{a}$.

The stalagmite of the Cave Hintere Kohlhalde ( $\underline{\mathrm{HKH}-1 \text { STM}})$ grew between $44158 \pm 3329$ and $2709 \pm$ 303 a B.P which is within the OIS 3 into the OIS 1. Since the Holocene section is discussed below, only the older parts of the timeseries are considered here.

The $\delta^{18} \mathrm{O}$ long-term trends are characterized by heavier mean values of $-7.51 \%$ VPDB between ca. 11 to 24 cal. ka B.P. while the oldest part until the onset of deposition displays a mean of $-7.72 \%$ VPDB. Considering the timing and direction of shifts a negative $\delta^{18} 0$ response on potential temperature forcing are diagnosed, assigning the heavier mean to the OIS 2 and the preceding lighter mean to the OIS 3 since the latter estimates the OIS 1 interglacial $\delta^{18}$ O mean pretty closely ($7.81 \% 0$ ).

Low growth rates change to intermediate rates after $25909 \pm 4061$ a B.P. while simultaneously the $\delta^{18} \mathrm{O}$ reveals a climatic deterioration at the onset of the LGM. A general shift in depositional and/or climatic environment is also indicated by a change in spelean calcite fabrics from a very compact honey brown calcite to the milky white and slightly softer calcite after $18979 \pm 1922$ a B.P. Increased availability of circulating water, an active soil-zone and thus higher growth frequency with an overall prevailing cold trend are potentially triggered by discontinuous permafrost conditions in that area. Prestorage of high $\mathrm{pCO}_{2}$ water in the unsaturated zone affected by the discontinuous permafrost and small-scale release during summerly dethawing periods may have favored the supply of seepage water for the HKH-1 speleothem. The special spatial position of the cave seemed to promote the conduction of even low amounts of solution into the underground and is characterized by the close position of the cave to the SW exposed dryvalley "Tiefental" as well as the minor host rock coverage of the cave roof (see vii - 2.1.4).

Highest $\delta^{18} \mathrm{O}$ and $\delta^{13} \mathrm{C}$ values, the latter interpreted as plant coverage to some extent adapted to drier environment and/or as increased host rock influence due to closed-system conditions, were recorded around 18320 to $15650 \mathrm{cal}$. a B.P. This coincides with the occurrence of the cold and arid LGM of the Late Glacial Cold Stage in Europe (19-17 a B.P., FrenZEL 1992; 17 ka B.P. BASSINOT 1994). Till around $13186 \mathrm{cal}$. a B.P. the speleothem $\delta^{18} \mathrm{O}$ displays a climatic warming which is also supported by the $\delta^{13} \mathrm{C}$ signal revealing a clear $\mathrm{C}_{3}$ signal triggered by a potential spread of forest in the area. Following the INTIMATE event-stratigraphy (BJ ÖRCK et al. 1998), this may correlate with the Greenland Interstadial GI-1 (former Boelling-Alleroed) although the onset of the HKH-1 timeseries is roughly 1000 cal years earlier than indicated by the event-stratigraphy (Figure vii - 2.19 below). However, after this 
approximately $2500 \mathrm{cal}$. years lasting climatic amelioration, a drawback into a new and very shortlived cold phase is indicated within less than $200 \mathrm{cal}$. years by again increasingly heavier values, especially for the $\delta^{13} \mathrm{C}$ proxy to almost former LGM values. This may be tied to the Younger Dryas (GS-1, sensu INTIMATE event-stratigraphy for the Last Glacial-Interglacial Transition) with a recorded cold maximum around 13006 and $10913 \mathrm{cal}$. a B.P. Thus, the overall $\delta^{13} \mathrm{C}$ shift from a $C_{3}$ to $C_{4}$ vegetation may indicate retreating tree habitats due to colder and more arid environmental conditions. However, the high variability of the $\delta^{13} \mathrm{C}$ during this time is noticeable. Although a $C_{3}$ intrinsic interpretation remains ambiguous this may be interpreted as short-term switches between open/closed-system conditions due to higher variable effective meteoric precipitations. The transition from Last Glacial to Interglacial conditions was recorded after the latest $\delta^{18} \mathrm{O}$ cold peak around 10913 cal. a B.P. and is considered below.

\section{The Last Glacial-Interglacial Transition}

Comparison of the Cave Hintere Kohlhalde stalagmite ( $\underline{\mathrm{HKH}-1 \mathrm{STM}})$, the Zaininger-Cave stalactite ( $\underline{\mathrm{ZH}}-$

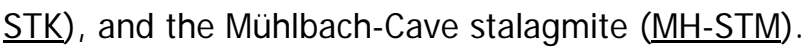

The ZH-STK and MH-STM display a rapid increase in $\delta^{18} \mathrm{O}$ between 10753 to 10420 and respectively 10418 to 10036 cal. a B.P. Owing to a positive temperature response of the $\delta^{18} \mathrm{O}$ timeseries the shift amounts in each record to ca. 4 to $6^{\circ} \mathrm{C}$ (taken the ice-volume effect of 1.2 to $1.8 \%$ o into account) if due to a temperature effect alone. A major decrease in the $\mathrm{HKH}-1$ STM $\delta^{18} \mathrm{O}$ timeseries was recorded between 10913 to $10112 \mathrm{cal}$. a B.P. and was interpreted as a warm shift due to a negative $\delta^{18} \mathrm{O}$ response. The $\delta^{18} \mathrm{O}$ offset would amount to 6.5 to $7.4^{\circ} \mathrm{C}$ which is higher than in the other Holocene records. Theoretically, lower $\delta^{18} \mathrm{O}$ values with increasing temperatures may occur if the dripwater function is negative or weakly positive and/or the cave temperature effect dominates. Although the present-day $\delta^{18} \mathrm{O}$ conduction to the underground yields values being well in the range of $\Delta \delta^{18} \mathrm{O}_{\text {speleothem }}$ / $\Delta \mathrm{T}=+0.36 \% / 1^{\circ} \mathrm{C}$ (section vii - 2.2 ), no long-term information on the cave environment and its isotopic and geochemical behavior is available to exclude other environmental influences for the past. Annihilating effects may shift the ratio between the dripwater function and the cave temperature effect since both yield a different sign.

The mid-point between the last cold and next warm phase of the HKH-1 STM yields 10513 cal. a B.P., $10587 \mathrm{cal}$. a B.P. for the ZH-STK and $10227 \mathrm{cal}$. a B.P. for the MH-STM.

Despite the temporal bias of approximately 300 cal. years, which is well within the cumulative uncertainties given by the dating and linear growth rate approximation, the extent and timing of the recorded spelean calcite $\delta^{18} \mathrm{O}$ responses may suggest the occurrence of the Last Glacial-Interglacial transition (Termination 1).

Nevertheless, the transitions occur roughly 1000 years later than in the GISP2 (TAYLOR et al 1993, $11640 \pm 240$ a B.P.) or GRIP (J OHNSEN et al. 1992, $11550 \pm 90$ a B.P.) records and earlier than indicated by an Irish speleothem from Crag Cave (9300 a B.P., MCDERMOTT et al. 1999). GosLAR et al. 
(1995) investigated laminated lake sediments in Central Europe and dated the Younger DryasPreboreal pollen zones at ca. $11440 \pm 120$ varve years B.P. in Gosciaz Lake, $10986 \pm 86$ varve years B.P. in Soppensee and at $11490 \pm 95$ varve years B.P. in Holzmaar. However, the comparison of different proxy tools is difficult, since their response may of course be controlled by different parameters and intensity. Besides the technical uncertainties like dating problems, the real time-lags of regional responses to climate changes and signal conduction have to be considered.

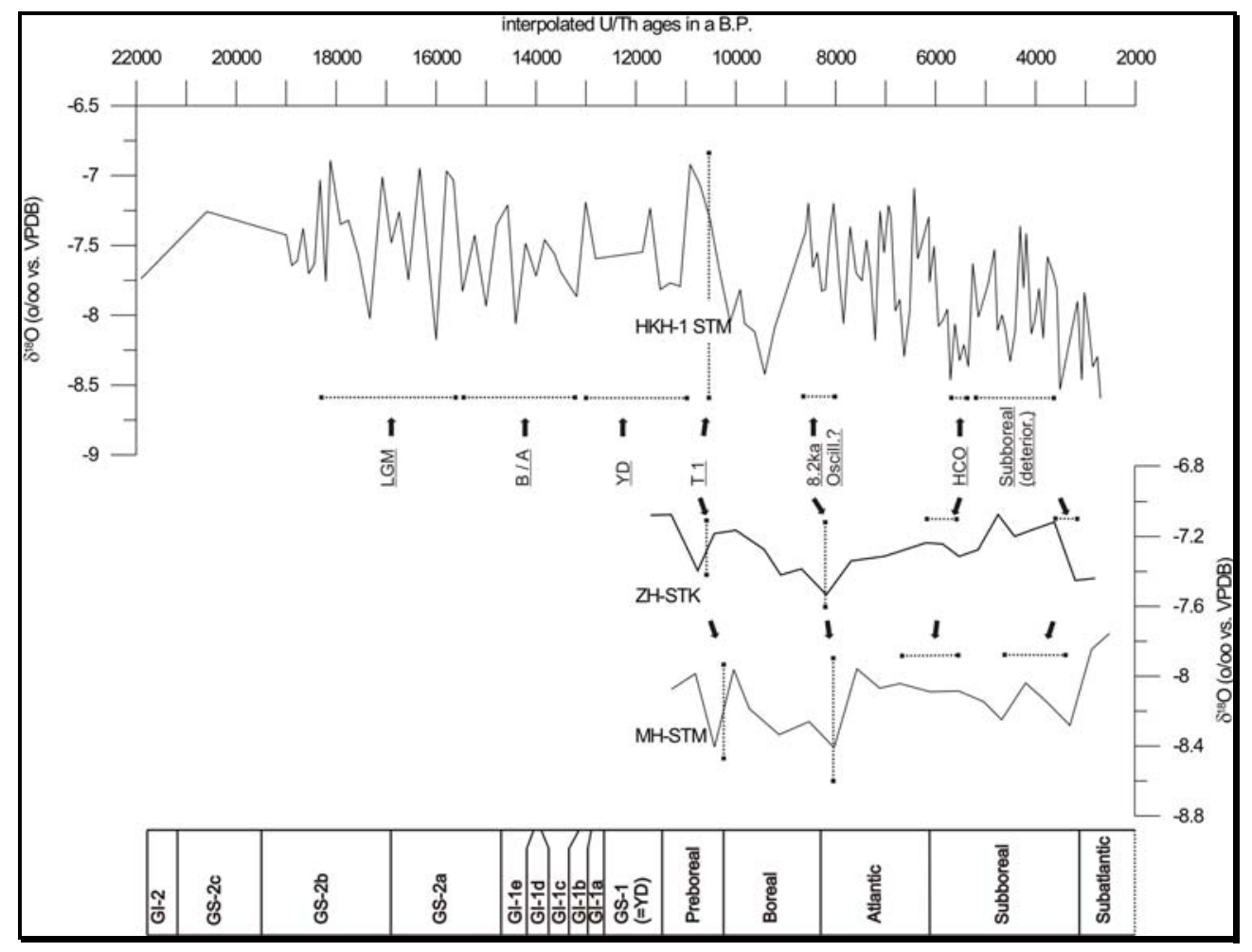

Figure vii - 2.19: HKH-1 STM, ZH-STK and MH-STM $\delta^{18} O$ timeseries between 22 to 2 cal. ka B.P.:

(Inter-) comparison of identified events and correlation to the INTIMATE event-stratigraphy (BJÖRCK et al. 1998) and Holocene chronozones (compiled by Rosendahl et al. 2000). LGM - Last Glacial Maximum; B /A-Boelling/Alleroed; YD-Younger Dryas; T1-Termination 1; 8.2 ka Oscillation; HCOHolocene Climatic Optimum; Subboreal deterioration.

\section{A recorded 8.2 ka cold oscillation?}

The GRIP and GISP2 ice cores reveal almost uniform isotopic patterns throughout the Holocene. However, both display a clear change in $\delta^{18} \mathrm{O}$ between $8000-8400$ a B.P. based on ice layer counting (ALLEY et al. 1997, JoHnSEN et al. 1992) and were interpreted as cold event. This cold phase was recorded in marine records from the North Sea as well as in tree rings in Germany and suggest a temperature drop of ca. $2^{\circ} \mathrm{C}$ in Northern and Central Europe (KLITGAARD-KRISTENSEN et al. 1998). Considering the rather low variations of the ZH-STK and MH-STM for the Early Holocene, the small but distinct anomalies at ca. 8180 cal. a B.P. and respectively 8023 cal. a B.P. are noticeable. The 
accompanied $\delta^{18} \mathrm{O}$ shift of the ZH-STK timeseries amounts only to $0.13 \%$, which would correspond to a temperature decrease of less than $0.5^{\circ} \mathrm{C}$. The $\mathrm{MH}$-STM timeseries displays a calculated temperature drop of $0.7^{\circ} \mathrm{C}(0.25 \%)$ and adjacent rise of ca. $1^{\circ} \mathrm{C}(0.45 \% 0)$. Since the associated temperature drop was calculated being $2^{\circ} \mathrm{C}$, the imprint on the speleothem calcite would be $0.36 \% / 1{ }^{\circ} \mathrm{C} * 2^{\circ} \mathrm{C}=0.72 \%$ if due to the temperature effect alone and would thus exceed the recorded values.

The timing around $8100 \mathrm{cal}$. a B.P., the direction of shifts and only partly recorded damped signals may support the evidence for a recorded $8.2 \mathrm{ka}$ cold oscillation in these speleothems.

Although the given higher resolution of the $\mathrm{HKH}-1$ STM and recorded cold peaks around 8546 and $8041 \mathrm{cal}$. a B.P., this event obviously did not leave any major imprint on its $\delta^{18} \mathrm{O}$ profile since in regard to the rest of the Holocene no distinct cold phase is displayed.

The Holocene Climatic Optimum, the Subboreal deterioration, and cessation of speleothem growth The Holocene Climatic Optimum (HCO) marks in Western Europe a period around $6000{ }^{14} \mathrm{C}$ a B.P. of maximal warmth and associated wetter conditions than the Early Holocene (e.g. BELL and WALKER 1992). A serious break in the prevailing climate came between 5500 and $5000{ }^{14} \mathrm{C}$ a and terminated the rather stable warm climate of the Atlantic period. The Subboreal (roughly 5500 to $2500{ }^{14} \mathrm{C}$ a B.P.) displayed higher climate variability but with a net cooling effect and a distinct deterioration towards colder and wetter environmental conditions between 2800 and $2600{ }^{14} \mathrm{C}$ a B.P. (KULLMANN 1988, VAN GeEL et al. 1996).

The $\delta^{18} \mathrm{O}$ timeseries of the ZH-STK and MH-STM did not show a clear HCO signal given their overall almost non-abundant variability between ca. 7800 to $4800 \mathrm{cal}$. a B.P. This may partly be a response on the stable warm climate conditions of the Atlanticum. On the other side the probability as being due to the resolutional lack is quite high and is contrasted by the relative higher variability of the $\mathrm{HKH}$ -

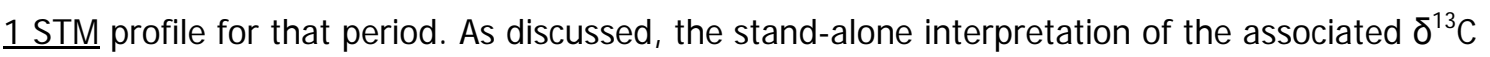
variations within the given $\mathrm{C}_{3}$ signature remains ambiguous. However, it is noticeable that in both speleothems the highest recorded values occur between 6190 to $5520 \mathrm{cal}$. a B.P. (프-STK) and ca. 6700 to 5500 cal. a B.P. (MH-STM). Considering the time period and low growth frequency of both speleothems, this has been discussed as a sign of increased host rock influences owing to more closed-system conditions and/or evaporation, rapid degassing, or early calcite precipitation in the vadose zone or cave itself. Thus, warmer, dryer conditions may be assumed and may support the occurrence of a recorded HCO between roughly 5500 and $6700 \mathrm{cal}$. a B.P. on the Swabian/Franconian Alb. The comparably higher resolution of the HKH-1 STM $\delta^{18} \mathrm{O}$ timeseries shows a slow climatic amelioration cumulating roughly between 5700 to 5300 cal. a B.P. That may indicate the occurrence of the $\mathrm{HCO}$ and thus supports the evidence discussed above. The low variations support a rather stable prevailing climate regime during that time. In the subsequent period all three speleothem timeseries recorded higher stable oxygen isotopic short-term variations and a shift towards colder conditions seems to reflect the known Subboreal net cooling trend. 
In contrast to the ZH-STK timeseries the climate deterioration ceases in the $\delta^{18} \mathrm{O}$ records of the $\underline{\mathrm{HKH}-1}$

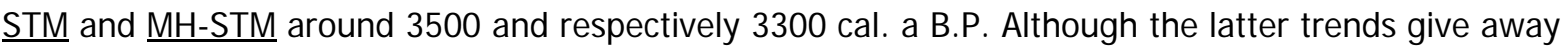
to a slight climatic amelioration in the subsequent period, all three speleothems stopped growing between $2512 \pm 139$ and $2800 \pm 100$ a B.P. VAN GeEL et al. (1996) reported a widespread cool and wet phase, which seems to have affected NW and Central Europe, accompanied by increasing bog growth and lowering of altitudinal tree limits around $2600{ }^{14} \mathrm{C}$ a B.P. Therefore, the almost similar speleothem growth cessation monitored from three different cave systems in Germany suggest an overall climate forcing, which may be tied to the described climatic deterioration at the onset of the Subatlantic.

\section{Conclusion Swabian and Franconian Alb speleothems}

o Five speleothems from caves of the Swabian/Franconian Alb (S Germany) were investigated using $\delta^{18} \mathrm{O}$ and $\delta^{13} \mathrm{C}$. Age control and growth frequency analysis are based on ${ }^{234} \mathrm{U} /{ }^{230} \mathrm{Th}$ disequilibrium method with thermal ionization mass spectrometry (TIMS). The speleothems of the Hermann's- and Baumann's-Cave (Harz Mtns., N-Germany) are subject of the following section (vii - 2.3).

o The fundamental principles on which the speleothem stable isotopic abundances may be interpreted as a climatic proxy are i) established isotopic equilibrium conditions during cave calcite precipitation; ii) a cave air temperature and thus reaction temperature of the calcite precipitation reflecting the mean annual surface temperature which is usually in most natural caves the case despite the uttermost entrance sections; iii) the $\delta^{18} \mathrm{O}$ content of the feeding cave dripwater is constant throughout the year and approximates the $\delta^{18} \mathrm{O}$ of the mean annual meteoric precipitation at the surface. If established, any recorded $\delta^{18} O$ shifts of a given speleothem should reflect long-term changes of the prevailing global climate. In this study the stable isotopic abundances of the speleothem paleorecords were calibrated to present-day cave calcites, which represent the climatic Interglacial optimum of the Holocene. The stable oxygen/carbon isotopic compositions of the meteoric precipitation, dripwater, host rock and recent cave calcites were as well investigated as the temperature response (and thus relative humidity) and airflow patterns of each cave system. Since long-term meteoric precipitation or dripwater sampling were not part of this thesis, existing data from nearby IAEA/WMO stations were evaluated. Dripwater samples were punctually taken during the field campaign as well as only a few of recent cave calcite precipitates due to cave conservation ethics. All in this sense external data (surface temperature and $\delta^{18} \mathrm{O}_{\text {rain }}$ ) was used to model the expected $\delta^{18} \mathrm{O}$ content of the lacking present-day speleothems. Comparison of calculated abundances and measured contents verified the modeled assumptions. The results show clearly that the cave temperature responses; the stable isotopic abundances of the dripwater, and present-day cave calcites reflect mean annual surface air temperatures and respectively established isotopic equilibrium conditions during cave calcite precipitation. However, existing biases have been monitored but most of them may be deduced to anthropogenic influences 
like mining operations (Zaininger-Cave), showcave business (Hermann's- and Baumann'sCave), or to very local factors like the observed icicle phenomenon at the Zaininger-Cave. Although the scenarios leave partially an imprint on present-day spelean calcites, like the indicated non-equilibrium conditions at the Zaininger-Cave, their temporal imprint is restricted very much to the last couple of decennial years and are assumed not to influence the paleorecords at all. Since the $\delta^{18} O$ compositions of present-day calcite precipitates are primarily controlled by temperature, the sites may thus be suitable for paleoclimatic reconstructions from today's perspective.

o Isotopic equilibrium conditions of the paleorecords were verified using the "Hendy-Test", which describes the comparison of $\delta^{18} \mathrm{O}$ versus $\delta^{13} \mathrm{C}$ measurements along a single growth layer of a given speleothem. Depending on the speleothem, between two to five layers were chosen for the isotopic equilibrium check. Since all four stalagmites display rather insignificant changes of $\delta^{18} \mathrm{O}$, which are all in the proposed tolerance zones and no correlation with $\delta^{13} \mathrm{C}$, non-equilibrium isotopic conditions can be ruled out for the Hendy-layers. The stalactite ( $\mathrm{ZH}-$ STK) and in-between the Hendy-layers of all other stalagmites, the assigned $\delta^{18} \mathrm{O} / \delta^{13} \mathrm{C}$ timeseries do not show exceedingly sympathetic shifts toward heavier values, which would indicate isotopic kinetic conditions. This supports the results of the Hendy-Tests and thus all investigated speleothems are suitable for paleoclimatic reconstructions.

o Important changes of the stable isotopic composition occur together with changes in growth rate and in the macroscopic aspect of the investigated speleothems. This confirms that general climatic and environmental parameters control the recorded variations and that they are not owing to very local factors. Criteria for the paleoclimatic interpretations were the linear inferred growth frequency based on ${ }^{234} \mathrm{U} /{ }^{230} \mathrm{Th}$ TIMS datings, the stable oxygen and stable carbon isotopic content of the speleothems. Until now the geochemical criteria, which may distinguish the different processes leading to $\delta^{13} \mathrm{C}$ variations of a speleothem are not well established. However, $\delta^{13} \mathrm{C}$ can straightforwardly be used to verify isotopic equilibrium conditions of the timeseries and as climatic proxy if variations occur which indicate switching between $C_{4}$ and $C_{3}$ plants prevailing in the catchment area above the cave and when independently verified (e.g. pollen data). Intra- $C_{3}$ variations which occur in most temperate region speleothems are difficult to interpret. Elevated values may either be associated with wetter periods and shorter residence times due to incomplete equilibration between the pedogenic $\mathrm{CO}_{2}$ and seepage water. On the contrary, prevailing arid conditions may favor prolonged outgassing of the seepage water in the vadose zone or the cave itself and may result in increased $\delta^{13} \mathrm{C}$ ratios. Since predominantly $C_{3}$ variations were recorded by the speleothems investigated in this study, only assumptions based on the associated $\delta^{18} \mathrm{O}$ timeseries (general warm-cold trend) were stated, combined with external paleoclimatic information. 
o The recorded timescales cover growth periods within the youngest OIS 5 of the Late Pleistocene (Paleocave Hunas Stalagmite), the Late Glacial-Interglacial transition (Cave Hintere Kohlhalde Stalagmite) and the Holocene till the onset of the Subatlantic (Cave Hintere Kohlhalde and Mühlbach-Cave Stalagmites and Zaininger-Cave Stalactite):

The Hunas stalagmite has been dated between $79373 \pm 8237$ and $76872 \pm$ 9686 a. B.P. Due to the age uncertainty, the recorded warm shift of the $\delta^{18} \mathrm{O}$ timeseries and the switch from $C_{4}$ to $C_{3}$ vegetation signaled by the $\delta^{13} C$ at the onset of speleothem growth, an age older than OIS 5.1 warm-peak around $79 \mathrm{ka} \mathrm{B.P}$ is suggested but still needs a tighter age constraint. The HU-STM represents the second speleothem generation of the Paleocave Hunas whereas the first generation is represented by a just recently dated flowstone sample (HU-i) bearing a single age of $270593 \pm 24379$ a B.P., which may belong to the Saalian OIS 7.

The Cave Hintere Kohlhalde stalagmite grew continuously between $44158 \pm 3329$ and $2709 \pm 303$ a B.P. since no major hiatus was detected. Mean $\delta^{18} 0$ shifts correlate with assigned conditions of the OIS 3 to OIS 1 with heaviest values during the OIS 2 . The growth frequency increases during the time of deposition. This is unexpected for the cold OIS 2 and Last Glacial Maximum but it seems to reflect seepage water conduction to the underground during dethawing periods of the discontinuous permafrost on the Swabian Alb. Since also major growth biases are not abundant during that time, a more or less steady low-scale water circulation in the vadose zone is assumed. Dethawing periods should range in minimum between 95 to 330 years considering the linear inferred resolution. Very regional settings like the small cave roof coverage and/or the SW-exponation of the valley slope where the cave is located may support this and suggest an even lower resolution of potential water circulation times. Altered stable oxygen/carbon isotopic compositions can be excluded since nonequilibrium conditions are not indicated by the Hendy-Test and/or by sympathetic shifts of the timeseries towards enriched ratios due to e.g. evaporative conditions. Furthermore, supporting evidence for established equilibrium conditions is provided by the recorded signals, which match the pattern of past global climatic changes. The Last Glacial Maximum, Boelling/Alleroed Interstadial and Younger Dryas cold phase, inferred from the INTIMATE event-stratigraphy suggested by BJ ÖRCK (1998), coincide despite the dating uncertainties and comparably low resolution of the HKH-1 STM. A comparison of the timeseries of the Hintere Kohlhalde stalagmite, the ZainingerCave stalactite (both Swabian Alb) and the Mühlbach-Cave stalagmite (Franconian Alb) reveal some analogy such as the transitions from the Late Glacial to the Early Holocene between 10513 and 10587 cal. a B.P. for the Swabian Alb and 10227 cal. a B.P. for the Franconian Alb; the anomaly around $8.2 \mathrm{ka}$ B.P. recorded in the Zaininger- and Mühlbach-Cave; the bad conditions around 4 cal ka B.P. and further 
climatic deterioration which leads to an almost simultaneous cessation of speleothem growth between 2.5 and $2.8 \mathrm{ka}$ B.P. On the other hand, some other parts are not concordant, like the absence of a clear $8.2 \mathrm{ka}$ signal in the Cave Hintere Kohlhalde or the general low variability of all $\delta^{18} \mathrm{O}$ timeseries considering the absolute ratios. They indicate that other factors, among which are possibly very local factors, are superimposed on the main climatic forcing. Thus, additional studies on speleothems from the same caves/regions are crucial to filter out the additional controls, to verify the recorded variations being due to large-scale climatic events as well as to quantify these climatic variations on a higher resolutional scale. 


\section{vii - 2.3) The stalagmites of the Baumann's- and Hermann's-Cave (Harz Mtns.)}

\section{vii - 2.3.1) Morphology}

The non-active Baumann's-Cave stalagmite BH-2a displays a basal diameter of $18 \mathrm{~cm}$ ( $6.6 \mathrm{~cm}$ on top) and a longitudinal extension of $17 \mathrm{~cm}$. The lamination along the vertical growth axis shows a sequence of dense whitish brown to beige brown layers yielding diameters of 1-5 $\mathrm{mm}$ with undefined transition zones. This is contrasted by thin ca. 0.05 to $1.5 \mathrm{~mm}$ dark brown to black laminae, the most prominent located at 3.7, 6.8 and $9.1 \mathrm{~cm}$ along the central growth axis. Corrosive zones indicated by the occurrence of $<1 \mathrm{~mm}$ diameter micropores occur foremost between 1.8 and $3.5 \mathrm{~cm}$ and at $16 \mathrm{~cm}$ along the central growth axis (Figures vii -2.20 below).

The longitudinal cross-section of the stalagmite extracted from the Herrmann's-Cave (HH-STM) is $25.7 \mathrm{~cm}$ long and displays in contrast to the BH-2a STM almost no continuous lamination (Figures vii 2.20 below). Dense, compact layering is recognizable only at the lowermost $3 \mathrm{~cm}$ of the stalagmite. This overall rather chaotic layering is owing to predominantly white very porous calcite interrupted by, considering the drilling-resistance, harder "layers" less than $10 \mathrm{~mm}$ in diameter. Patchy distributed macropores show randomly acicular to fibrous calcite recrystallysates. The overall basal diameter is $15 \mathrm{~cm}$ and thins out to the top yielding $7.5 \mathrm{~cm}$.

\section{vii - 2.3.2) Chronological control}

As is obvious from the figure above, the established ${ }^{234} \mathrm{U} /{ }^{230} \mathrm{Th}$ TIMS datings (complete data see Appendix vii - 2.1) are for both stalagmites not in the right chronological order. The BH-2a STM displays highest ages of $236340 \pm 16429$ and $232474 \pm 40141$ a B.P. between 7.4 and $13.5 \mathrm{~cm}$ along the central growth axis. Preceding and following ages yield considerable lower ages of $77295 \pm 5280$ and $78020 \pm 6346$ a B.P. Age control at the base of the stalagmite has been calculated $135623 \pm$ 8886 a B.P.

The HH-STM shows at the base of the stalagmite $23130 \pm 711$ and on top $24260 \pm 568$ a B.P. Taking this age control, a linear extension rate would amount roughly to $205 \mathrm{~mm} / \mathrm{ka}$ which is considerable fast. This may be supported by the very porous fabric, which was frequently monitored being associated with either fast flow conditions or evaporation, both leading to a higher growth rate (section iii.). Since the second age in the middle of the speleothem yields $8726 \pm 240$ a B.P., a timeseries cannot be constructed. 

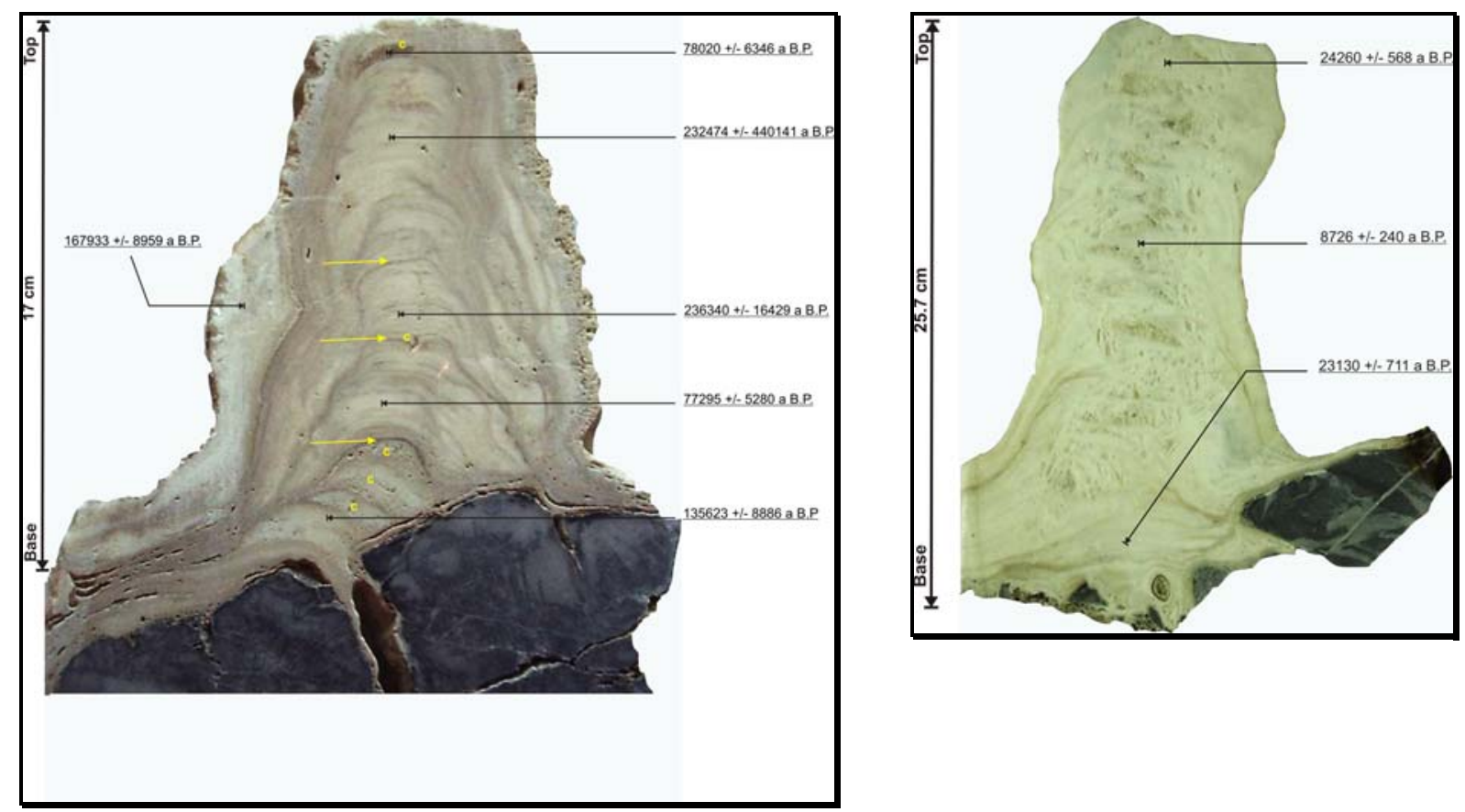

Figures vii - 2.20: The longitudinal section and established ${ }^{234} U{ }^{230} \mathrm{Th}$ TIMS ages of the stalagmites from the Baumann's (left) - and Herrmann's (right)-Cave. Ages are not in chronological order, which is point of discussion below. Yellow arrows (left figure) show dark brown to black detritic layers, yellow " $c$ " sections with the predominantly occurrence of micropores.

\section{vii - 2.3.3) I sotopic equilibrium}

Two single growth layers of the $\mathrm{BH}-2 \mathrm{a}$ stalagmite at 35 and $122 \mathrm{~mm}$ from the base were checked for isotopic equilibrium conditions (Figure vii - 2.21). The lower Hendy-layer displays no $\delta^{13} \mathrm{C} / \delta^{18} \mathrm{O}$ correlation and only minor $\delta^{18} \mathrm{O}$ deviations along the isolated layer, thus indicating preserved isotopic equilibrium conditions.

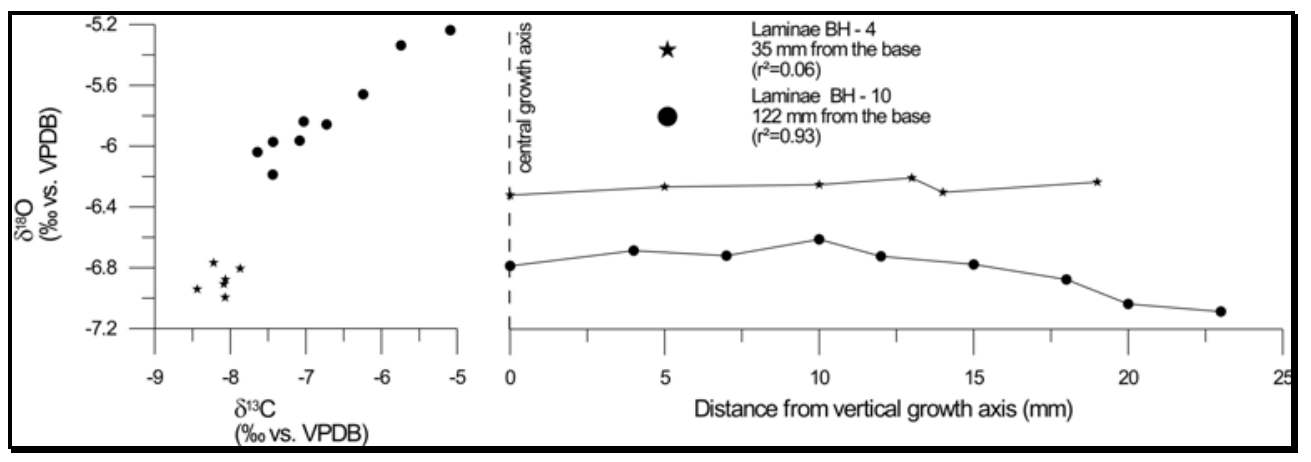

Figures vii - 2.21: Check for isotopic equilibrium of the Baumann's-Cave Stalagmite BH-2a. Only the lowermost Hendy-layer fulfils the criteria for established isotopic equilibrium conditions.

The contrary indicates the upper layer at $122 \mathrm{~m}$ from the base of the stalagmite, yielding a high correlation coefficient of 0.93 and a $\delta^{18} \mathrm{O}$ range between -6.19 to $-5.24 \%$. Although the outermost 
drilling positions may to some extent promote a higher uncertainty of the physical sampling, the overall contribution of the $\delta^{13} \mathrm{C} / \delta^{18} \mathrm{O}$ values in the regression analysis (Figure vii - 2.21) indicates nonequilibrium conditions from the apex down the flanks of the Hendy-layer. This is also supported when taking the natural variations associated with the cave environment into account observed on presentday calcite precipitations, which display a minor range of between -7.17 to $-7.72 \%$.

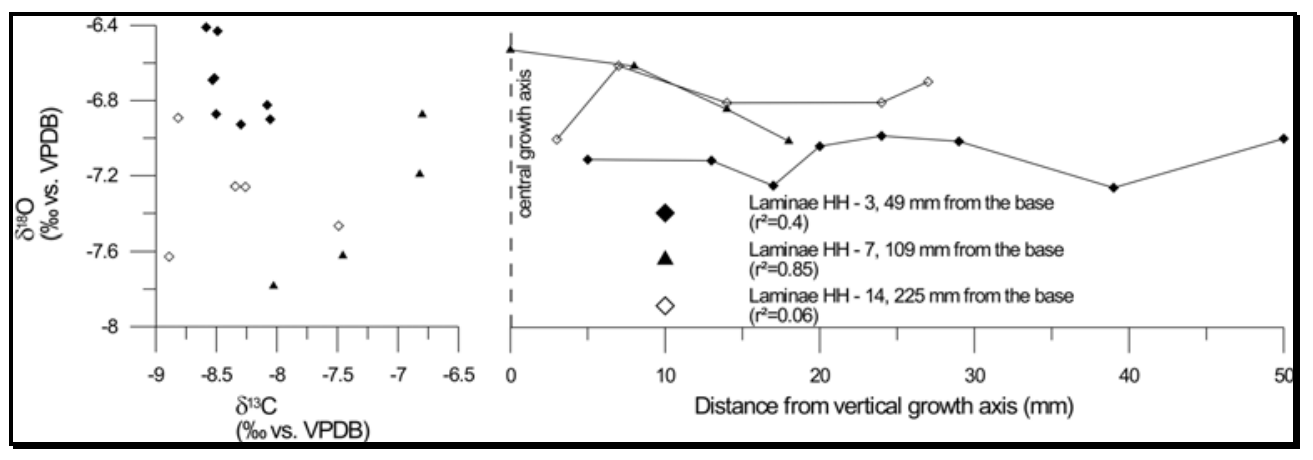

Figures vii - 2.22: Check for isotopic equilibrium of the Hermann's-Cave Stalagmite HH-STM. Most of the stalagmite shows signs for isotopic non-equilibrium conditions during calcite precipitation (layer HH-3 probably excepted).

Considering the regression analysis of the three Hendy-layers from the Herrmann's-Cave stalagmite at 49, 109 and $225 \mathrm{~mm}$ distance from the base, an incoherent picture arises. Whereas the lower- and topmost laminae yield intermediate to low regression coefficients between 0.4 to 0.06 , the layer inbetween displays a considerable high value of $r^{2}=0.85$.

Since laminae HH-3 shows in addition to the intermediate $r^{2}$ a $\delta^{18} \mathrm{O}$ range along the sampled layer between -6.93 to $-6.41 \%$, conditions near the isotopic equilibrium may be postulated for that time. These conditions are not preserved for the rest of the $\mathrm{HH}$-stalagmite since the data range exceeds the tolerance of $0.8 \%$ suggested by GASCOYNE (1992).

In sum, both stalagmites failed the check for isotopic equilibrium conditions for almost the entire time of calcite deposition. Except for the lowest parts of both speleothems, a suitability for paleoclimatic interpretation of $\delta^{18} \mathrm{O} / \delta^{13} \mathrm{C}$ abundances must be negated.

\section{vii - 2.3.4) Discussion}

The established ages of both speleothems are not in chronological order. Therefore, a construction of timeseries is not possible. The recorded spelean uranium content depends generally on the ability of the associated seepage water to dissolve uranium from the host rock and is thus guided by the availability of uranium in the host rock and its stability in the solution until coprecipitation with the spelean calcite. In general, higher uranium concentrations in speleothems are usually owing to the presence of overlying shales or other uranium-rich rocks, or are due to local mineralisations (GASCOYNE 
1982). In contrary, lower uranium abundances are found to be associated with rather bare karst conditions and/or allogenic runoff.

Unlike e.g. $\mathrm{Mg}^{2+}$ or $\mathrm{Ca}^{2+}$, uranium is not appreciable soluble in natural waters as a simple cation e.g. $\mathrm{U}^{\mathrm{IV}+}$ or $\mathrm{U}^{\mathrm{VI}+}$ (these are the main oxidation states). The $\mathrm{U}^{\mathrm{IV}+}$ ion is extremely insoluble $(<0.05 \mu \mathrm{g} / \mathrm{l})$ under normal oxidizing conditions. The $\mathrm{UO}_{2}{ }^{2+}$ (from the $\mathrm{U}^{\mathrm{VI}}$ oxidation state) is more common but still yields a low solubility of ca. $1 \mu \mathrm{g} / \mathrm{l}$ in natural waters. The $\mathrm{UO}_{2}{ }^{2+}$ (uranyl -) species enhances its solubility by complexing with bicarbonate or phosphate ions during host rock dissolution, which may in principle form three anionic species, which account for most of the uranium found in natural waters:

1. $\mathrm{UO}_{2}\left(\mathrm{HPO}_{4}\right)_{2}{ }^{2-}$

2. $\mathrm{UO}_{2}\left(\mathrm{CO}_{3}\right)_{2}^{2-}$

3. $\mathrm{UO}_{2}\left(\mathrm{CO}_{3}\right)_{3}^{4-}$

The stability of the ion-complexes increases from top to base with increasing $\mathrm{pH}$ from 4 to 10 (LANGMUIR 1978). There seems also to be some evidence that the presence of humic and fulvic acids in the solution may promote the leaching of uranium from the host rock since dark brown stalagmites from the Canadian Rocky Mtns. and the North West Territories are enriched in uranium and the coloration seems to be due to the presence of organic materials (GASCOYNE 1978).

With respect to the uranyl-species, ${ }^{230} \mathrm{Th}$ ions are rather insoluble and become transported via adsorption on the surface of clay minerals or insoluble detritus, and/or thorium remains in place as insoluble hydrolysates (HARMON et al. 1975). Since the fractionation occurs owing to the increased mobility of the uranyl-species and the more or less insoluble thorium ions, the feeding waters for the precipitating speleothems can be considered essentially thorium-free. Thus, provided that the initial uranium concentration is sufficient, the direct measurement of ${ }^{234} \mathrm{U} /{ }^{230} \mathrm{Th}$ ratio should indicate the build-up of ${ }^{230} \mathrm{Th}$ as a function of time/radioactive decay. However, constraints arise since the initial activity ratios for ${ }^{234} \mathrm{U} /{ }^{230} \mathrm{Th}$ is typically assumed to be zero, which is only the case when any contamination with detrital thorium can be excluded.

The incorporation of detrital thorium in spelean calcites may occur by cementation of small particles of clay or sand, present in the feeding dripwater, on the surface of a speleothem as it grows. This leads to a relative ubiquitary distribution of sediments throughout the speleothem. However, clastic sediments may also be incorporated by floodings of the cave passage potentially delivering mud depositions on the growing surface. This sediment is subsequently sealed in place when calcite precipitation resumes. Regardless of the mode of deposition, at time zero of the speleothem growth, its ${ }^{230} \mathrm{Th}$ is not zero as it would be the case of a pure spelean calcite. Since this thorium is indistinguishable from the ${ }^{230} \mathrm{Th}$ evolving from the ${ }^{234} \mathrm{U}$ decay, it is also extracted on sample analysis and results in a determined age greater than the actual age. Since the detrital ${ }^{230} \mathrm{Th}$ is always accompanied by ${ }^{232} \mathrm{Th}$, a potential contamination can always be identified during measurement. However, correction for such detrital compositions by subtracting an appropriate amount of ${ }^{230} \mathrm{Th}$ from the total ${ }^{230} \mathrm{Th}$ observed is usually based on the assumption that the initial isotopic composition of the detrital fraction in the sample is uniform, and that the contaminating fraction is proportional to the authigenic ${ }^{232}$ Th content of the sample (e.g. SCHWARCZ and LATHAM 1989, BISCHOFF and FITZPATRICK 
1991, Luo and KU 1991). This always remains ambiguous since the ubiquitary distribution is not always given. E.g. HilLAIRE - MARCEL et al. (1995) reported a very heterogeneous distribution in cases where the contaminating particles are partly composed of reworked carbonate particles that are usually rich in U-series isotopes but poor in ${ }^{232} \mathrm{Th}$.

Thus, several important criteria must be fulfilled for the direct determination of ${ }^{230} \mathrm{Th} /{ }^{234} \mathrm{U}$ ages in speleothem calcite:

o no "detrital" ${ }^{230} \mathrm{Th}$ should be incorporated during calcite precipitation. Typically samples containing $>1 \%$ of acid-insoluble detritus are considered conspicuous.

o afterwards the system must remain closed to radionuclide migration (KAUFMAN et al. 1998, DoRALE et al. 1992, LUDWIG et al. 1992). Usually the rather dense crystalline fabric of the secondary cave calcites favor prevailing closed-system conditions. However, potential indications for post-depositional alteration are deviations in the measured ${ }^{234} \mathrm{U}$ content, the presence of macroscopic pores and/or recrystallizations.

The non-chronological order of the inferred ages and the high porosity with partially observed recrystallizations (see section above) support the occurrence of post-depositional radionuclide migration due to open-system conditions in both speleothems.

\section{Conclusion}

The stalagmites of the Hermann's- and Baumann's-Cave display ages which are not in chronological order due to assumed post-depositional radionuclide migration. Supporting evidence for open-system conditions is provided by the occurrence of macropores, which show acicular to fibrous recrystallizations in case of the Hermann's-Cave stalagmite.

The check for established stable oxygen/carbon isotopic equilibrium conditions yields a negative result for most parts of both speleothems. This may also be explained by the porous fabric, which is known to generate either due to very fast spelean calcite deposition, and/or by precipitation with prevailing non-equilibrium conditions like evaporative cave environments. Only at the oldest parts of the stalagmites isotopic equilibration conditions seemed to prevail. Of inferior influence is the incorporation of detritic thorium and potential contamination of the authigenic ${ }^{234} \mathrm{U} /{ }^{230} \mathrm{Th}$ ratio which may lead to ages being too young. 


\section{$\underline{\text { Vill General Conclusions }}$}

In this study several principal changes of stable oxygen/carbon isotopic compositions and growth frequencies were related to well-known climatic events. However, greatest caution is suggested in the interpretation of speleothem timeseries since only four of seven speleothems investigated in this study were found i) to be suitable for paleoclimatic reconstructions and ii) a straightforward correlation of timeseries representing the same Holocene/Pleistocene times was as well not possible as iii) a direct correlation to other established timeseries which are assumed to reflect past global climatic changes.

Since the associated cave systems are not straightforwardly comparable to each other, considering the size and spatial distribution as well as the status of speleogenesis (from the active river-cave, like the Mühlbach-Cave, to the non-active cave like the Hintere Kohlhalde or to the Paleocave, like Hunas), the present-day signal transfer to the subterranean and climatic forcing had to be investigated. This is a crucial point when investigating potential paleoclimatic signals of speleothems since the main criteria e.g. for the use of the $\delta^{18} \mathrm{O}_{\text {speleothem }}$ proxy are i) continual cave temperature averaging the mean annual surface temperature and being the ambient reaction temperature for the equilibrium oxygen isotope fractionation; and ii) a constant $\delta^{18} \mathrm{O}$ composition of the cave dripwater reflecting the mean annual composition of the meteoric precipitation. If given, both mechanisms are tying recorded spelean calcite shifts only to large-scale climatic changes.

Own data has been combined with external datasets, especially concerning the usually necessary long-term evaluations of the meteoric precipitation, temperature, and $\delta^{18} O$ compositions at the sites. Intra-cave differences in the stable isotopic behavior was testified and clearly demonstrates that it is essential to have a good knowledge of the cave environments in question.

The variations of natural present-day deposits were determined to estimate the uncertainty on reconstructed climatic parameters associated with the cave environment. To determine this "natural scatter" reliably, such studies should be performed on a basis of several years and spelean calcite examinations should be performed on a statistical basis, which is difficult due to cave preservation ethics. However, a begin of sample acquisition is done within this project since some samples could be extracted for the Hermann's- and Baumann's-Cave, the Cave Hintere Kohlhalde and the ZainingerCave and were used to estimate the uncertainty on reconstructed timeseries. To verify the reproducibility and get hold on the natural scatter, further monitoring is absolutely necessary. This study also demonstrates the significance and reproducibility of oxygen isotope values in speleothems which are deposited near to isotopic equilibrium. This was shown by a good estimate between dripwater-abundances and associated present-day precipitates as well as within the timeseries of the paleorecords, which display only minor $\delta^{18} \mathrm{O}$ deviations in the central parts of the stalagmites. 
Some remarks about the Hendy-test

The check for maintained stable isotopic equilibrium conditions performed on single growth layers yielded ambiguous results. Although sympathetic $\delta^{18} \mathrm{O} / \delta^{13} \mathrm{C}$ shifts within some "Hendy-layers" of the $\mathrm{HKH}$-stalagmite indicated prevailing non-equilibrium conditions, the second criteria, the $\delta^{18} \mathrm{O}$ variations indicated the contrary. This, together with an overall antipathetic variation of the $\delta^{18} \mathrm{O} / \delta^{13} \mathrm{C}$ timeseries $\left(r^{2}=0.19\right)$, was interpreted as sign of established equilibrium conditions and was later on confirmed by the possible link to known climatic events.

\section{Reconstruction of paleoclimatic events}

The constructed timeseries from the investigated speleothems suited for paleoclimate studies reveal several similar changes, which could be tied to changes in growth rate and in the macroscopic aspect of speleothem fabric.

The different temperature dependent controls on the speleothem $\delta^{18} 0$ composition, referred to as dripwater function as synonym for meteoric water $\delta^{18} \mathrm{O}$ and as the cave temperature effect meaning the oxygen fractionation factor, cancel each other frequently out owing to their opposite sign. Thus, it is possible that the dripwater function is greater, equal, or less than the temperature dependent equilibrium fractionation during precipitation. This may trigger an increase, decrease, or invariant $\delta^{18} 0$ composition of the spelean cave calcite. In this study the direction in $\delta^{18} \mathrm{O}$ shifts were determined by comparing them with present-day compositions as well as with the growth rate and $\delta^{13} \mathrm{C}$ abundances and foremost by the link to known paleoclimatic events. However, this approach is limited especially in time intervals where temperature changes have been small and first-order climate transitions like terminations are not covered by the paleorecord. Despite the different $d \delta^{18} \mathrm{O} / \mathrm{dT}$ response between the Cave Hintere Kohlhalde stalagmite on the one side and the Mühlbach-Cave stalagmite and Zaininger-Cave stalactite on the other, principal similar changes in the $\delta^{18} 0$ timeseries, supported by changes of the other proxies, were identified between roughly the Last Glacial Maximum and the onset of the Subatlantic. In order to further validate the interpretations, it is necessary to enhance the sampling resolution and chronological control of the speleothems which is essentially true for the older Paleocave Hunas and Zaininger-Cave stalagmites due to an increasing lack of flanking local paleoclimatic geoarchives. Thus, especially for the latter it is crucial to infer the $\delta^{18} \mathrm{O}$ of potential fluid inclusions to get hold on the paleotemperature equation.

\section{Outlook:}

Non-concordant sections of the different timeseries indicate that other factors, among which were probably very local factors, are superimposed on the main controls of the investigated proxies. To determine a speleothem recorded Termination 1 signal it was a good strategy to keep to sample speleothems in areas which were not directly overlain by icesheets like parts of the Swabian and/or Franconian Alb. In contrary, the assumed discontinuous permafrost conditions at least theoretically may have promoted speleothem depositions during that time. In order to characterize the paleodripwater recharge and signal conduction to the underground, being low and steady or event-related 
owing to dethawing periods, the subsample resolution of the HKH - 1 stalagmite should be enhanced. Additional investigations of other chemical parameters like $\mathrm{Sr}$ isotope and $\mathrm{Mg} / \mathrm{a}, \mathrm{Sr} / \mathrm{Ca}$ trace element abundances may clear the question on past water residence times. Further research for caves and active-growing speleothems at sites that are subject to present-day permafrost conditions may help to figure out the key-proxies being related to such a specific environment.

In order to enhance the efficiency of speleothem paleoclimatic investigations an overall strategy is suggested based on the experiences made during this study:

Long-term studies of the associated cave environments of all input parameters must be the fundament for every detailed paleoclimatic speleothem investigations. To get hold on the cave's responses to the surface input, at least two years must be taken into account (longer is better). During that time a close monitoring of the temperature, relative humidity, amount and $\delta^{18} \mathrm{O}$ of meteoric precipitation and corresponding dripwater and its driprate, frequent measurement of $\delta^{18} \mathrm{O}$ from present-day calcite precipitates, e.g. on glass-slabs with the advantage of diminishing impact on the cave system and date control. The measurement of other proxies like trace element abundances and Sr-isotopes should also be performed on a statistical basis.

Caves and speleothem paleorecords should be carefully selected according to the postulated project targets. If, for example the aim is to specify overall growth frequencies from a given region like Germany, only a bulk speleothem sampling and roughly three datings each sample are necessary. Due to cave preservation ethics speleothem cores can be drilled. If, on the other hand a specific past climatic event shall be investigated, like the Termination 1, the further above mentioned approach should be followed closely. Since enough paleoclimatic archives at least in Germany have already been researched to limit down the target area suitable to the postulated aims, the results are manageable and do not anymore rely on accidental sample findings in some unresearched cave systems lacking the affordable frame data.

However, despite the encountered difficulties on the paleoclimate reconstructions on speleothems, this study demonstrates that climatic events may be registered. Following the same development as the investigations on pollen abundances or paleolimnological lake-level variations, further long-term monitoring of caves and construction from speleothems in the same region may filter out the local effects, but with the additional possibility of an absolute chronological control. 


\section{References}

\section{$\underline{A}$}

Abel T., Hinderer M., Sauter M. (2002): Karst genesis of the Swabian Alb, south Germany, since the Pliocene.- Acta Geologica Polonica, Vol. 52, 1, 43-54.

Abel, T. (2003): Untersuchung zur Genese des Malmkarsts der Mittleren Schwäbischen Alb im Quartär und jüngeren Tertiär.- Tübinger Geowiss. Arbeiten, C67, 1-187, Tübingen.

Adolphe J.P., Choppy J., Choppy B., Louière J.F., Paradas J. and Soleihavou F. (1991): Biologie et concrétionnement: un example, les baguettes de gours.- Karstologia, 18, 49-55.

Agricola G. (1546): De ortu et causis subterraneorum.-p. 487. Basel. IN: Im Reich der DunkelheitHöhlen und Höhlenforschung in Deutschland. -W. Rosendahl and E.-B. Krause (1996), Edition Archaea.

Agsten K. (1977): Zur Entwicklung und Vergesellschaftung der Böden in traufnahen Bereichen der westlichen Schwäbischen Alb (Balinger Berge). -Geol. Jb., F5, Hannover, pp. 84.

Ahlbrecht J. (1997): Verkalkte Mikrobenrelikte und kryptische Habitate des Rübeland-Mikrobialiths (Elbingeröder Riffkomplex, Harz, Mittel- bis Oberdevon).- Dipl. Thesis, University Göttingen, unpubl., pp. 185.

Alley R.B., Mayewski P.A., Sowers T., Stuiver M., Taylor K.C., Clark P.U. (1997): Holocene climate instability: a prominent widespread event 8200 yr. ago. -Geology, 25, 6, 483-486.

Ambach W., Dansgaard W., Eisner H., Møller J. (1968): The altitude effect on the isotopic composition of precipitation and glacier ice in the Alps.- Tellus, 20, 595-600.

Apel R. (1977): Hydrogeologische Verhälnisse.- IN: Geologische Karte von Bayern 1:25000, Erläuterungen zum Blatt Nr. 6435 Pommelsbrunn; (Treibs W., Goetze F., Meyer K.F.), Bayerisches Geologisches Landesamt, München, 127p.

Atkinson T.C., Harmon R.S., Smart P.L., Waltham A.C. (1978): Paleoclimatic and geomorphic implications of $230 \mathrm{Th} / 234 \mathrm{U}$ dates on speleothems from Britain.- Nature, 272, 24-28.

Atkinson T.C.,Lawson T.J ., Smart P.L., Harmon R.S.,Hess J.W. (1986): New data on speleothem deposition and paleoclimate in Britain over the last forty thousand years.- J. of Quat. Sci., 1, 67-72.

Ayalon A., Bar-Matthews M., Kaufman A. (1999): Petrography, strontium, barium and uranium concentrations, and strontium and uranium isotope ratios in speleothems as palaeoclimatic proxies: Soreq Cave, Israel.- The Holocene, 9 (6), 715-722.

\section{$\underline{B}$}

Baker A., Smart P.L., Ford D.C. (1993): Northwest European paleoclimate as indicated by growth frequency variations of secondary calcite deposits.- Paleogeography, Paleoclimatology, Paleoecology, 100, 291-301.

Baker A., I to E., Smart P.L., McEwan R.F. (1997a): Elevated and variable values of ${ }^{13} \mathrm{C}$ in speleothems in a British cave system.- Chemical Geology, 136, 263-270.

Baker A., Barnes W. L., Smart P. L. (1997b): Variations in the discharge and organic matter content of stalagmite drip waters in Lower Cave, Bristol.- Hydrological Processes, Vol. 11, 1541-1555.

Baker A. and Brunsdon C. (2003): Non-linearities in drip water hydrology: an example from Stump Cross Caverns, Yorkshire.- J ournal of Hydrology, 277, 151-163. 
Bar-Matthews M., Ayalon A., Matthews A., Sass E., Halicz L. (1996): Carbon and oxygen isotope study of the active water-carbonate system in a karstic Mediterranean cave: implications for paleoclimate research in semiarid regions.- Geochimica et Cosmochimica Acta, 60 (2), 337-347.

Bar-Matthews M., Ayalon A., Kaufman A. (1997): Later Quaternary paleoclimate in the eastern Mediterranean region from stable isotope analysis of speleothems at Soreq cave, Israel.- Quaternary Research, 47, 155-168.

Bar-Matthews M., Ayalon A., Kaufman A., Wasserburg G.J . (1999): The Eastern Mediterranean paleoclimate as a reflection of regional events: Soreq cave Israel.- Earth and Planetary Science Letters, 166, 85-95.

Bassinot F. C., Labeyrie L.D., Vincent E., Quidelleur X., Shackleton N.J., Lancelot Y. (1994): The astronomical theory of climate and the age of the Brunhes-Matuyama magnetic reversal. Earth and Planetary Science Letters, 126, 91-108

Bechtold M. (2003): Die Untersuchung von Tropfwässern aus den Rübeländer Höhlen (Harz) und ihre geochemische Beziehung zum Umgebungsgestein bzw. der Bodenauflage sowie den Sinterabscheidungen.- Bachelor thesis (unpublished), Geoscience Center Göttingen, p. 49.

Bell M., Walker M.J.C. (1992): Later Quaternary environmental change.- Longman Group, UK., 273p.

Bender M., Sowers T., Labeyrie L. (1994): The Dole effect and its variations during the last 130000 years as measured in the Vostok ice core.- Global Biogeochemical Cycles, 8, 363-376.

Bischoff J.L., Fyfe W.S. (1968): Catalysis, inhibition and the calcite-aragonite problems, I: the aragonite-calcite transformation.- American Journal of Science, 266, 65-79.

Bischoff J.L. (1968): Catalysis, inhibition and the calcite-aragonite problem. II The vaterite-aragonite transformation.- American J ournal of Science, 266, 80-90.

Bögli A. (1964a): Mischungskorrosion, ein Beitrag zum Verkarstungsproblem.- Erdkunde, 18/2, 83 92.

Bögli A. (1964b): Die Kalkkorrosion, das zentrale Problem der Verkarstung.- Steir. Beitr. Hydrogeol. 1963/64, 75 - 90.

Bögli A. (1969d): Neue Anschauungen über die Rolle von Schichtfugen und Klüften in der karsthydrographischen Entwicklung.- Geol. Rundsch., 58, 395 - 408.

Bögli A. (1978): Karsthydrographie und physische Speläologie.- Springer Verlag, Berlin/ Heidelberg/New York.

Bosák B. (2003): Karst processes from the beginning to the end: How can they be dated? Speleogenesis and Evolution of Karst Aquifers 1 (3). Available at: http://www.speleogenesis.info

Bischoff J.L., Fitzpatrick J.A. (1991): U-series dating of impure carbonates: An isochrone technique using total-sample dissolution.- Geochim. Cosmomchim. Acta, 55, 543-554.

Björck S., Walker M.J .C., Cwynar L., J ohnson S.J., Knudsen K.L., Lowe J.J., Wolfharth B., INTIMATE Members (1998): An event stratigraphy for the last termination in the North Atlantic based on the Greenland Ice Core record: a proposal by the INTIMATE group.- J ournal of Quaternary Science, 13, 283-292.

Bradley R.S. (1999): Paleoclimatology.- International Geophysics Series, Monograph, 64, Harcourt Academic Press, 610p.

Broeker W.S. (1992): Upset for Milankovitch theory.- Nature, 359, 779-780. 
Brunnacker K. (1983): Die Sedimente der Höhlenruine von Hunas.- Quartär-Bibliothek, 4, 53-89, Bonn.

\section{$\underline{\mathbf{C}}$}

Caballero E., Jimenez de Cisneros C., Reyes E. (1996) : A stable isotope study of cave seepage waters.- Applied Geochemistry, 2, 583-587.

Cabrol P., Coudray J. (1982): Climatic fluctuations influence the genesis and diagenesis of carbonate speleothems in southwestern France.- Natl. Speleol. Soc. Bullet., 44, 112-117.

Cerling Th. E. (1984): The stable isotopic composition of modern soil carbonate and its relationship to climate.- Earth \& Planetary Letters, 71, 229-240.

Clark I.D., Fritz P. (1997): Environmental Isotopes in Hydrogeology.-Lewis Publishers, Boca Raton, New York; available at www. science.uottawa.ca/ eih.

Cohmap members (1988): Climatic changes of the last 18,000 years: oberservations and model simulations.- Science, 241, 1043-1052.

Coplen T.P., Kendall C., Hopple J. (1983): Comparison of stable isotope reference samples.- Nature, 302, 236-238.

Crowley T.J., North G.R. (1991): Paleoclimatology.- Oxford Univ. Press, New York.

Craig H. (1961b): Isotopic variations in meteoric waters.- Science, 133, 1702-1703.

Craig H., Gordon L.I. and Horibe Y. (1963): I sotopic exchange effects in the evaporation of water. Low-temperature experimental results.- J ournal of Geophysical Research, 68 (17), 5079-5087).

Craig H., Gordon L.I. (1965): Deuterium and oxygen-18 variations in the ocean and the marine atmosphere.-In: Stable Isotopes in Oceanographic Studies and Paleotemperatures. Consiglio Nazionale delle Ricerche, Laboratorio di Geologica Nucleare, Pisa, 1-122.

Craig K.D., Horton P.D. and Reams M.W. (1984): Clastic and solutional boundaries as nucleation surfaces for aragonite in speleothems.- NSS Bull., 48, 62-63.

Curl R.L. (1973): Minimum diameter stalagmites.- NSS Bull., 35, 1-9.

\section{$\underline{\mathbf{D}}$}

Dansgaard W. (1964): Stable isotopes in precipitation.- Tellus, 16, 436-468.

Deines P. (1980): The isotopic composition of reduced organic carbon.- IN: Handbook of Environmental Geochemistry (Eds.: P. Fritz and J.C. Fontes), Vol. 1, 329-406. Elsevier, Amsterdam, The Netherlands.

Dennis P.F., Rowe P.J., Atkinson T.C. (1997): The stable isotope composition of paleoprecipitation and paleogroundwater from speleothem fluid inclusions.- International Symposium on Isotope Techniques, Vienna, Austria, 14-18 April 1997; IAEA-SM34944, 1-13.

Dennis P.F., Rowe P.J., Atkinson T.C. (2001): The recovery and isotopic measurement of water from fluid inclusions in speleothems.- Geochimica et Cosmochimica Acta, 65, 871-884.

Denniston R.F., Gonzales L.A., Asmerom Y., Baker R.G., Reagan M.K., Bettis III E.A. (1999a):

Evidence for increased cool season moisture during the middle Holocene.- Geology, 27 (9), 815-818.

Denniston R.F., Gonzales L.A., Baker R.G., Asmerom Y., Reagan M.K., Edwards R.L., Alexander E.C. (1999b): Speleothem evidence for Holocene fluctuations of the prairie-forest ecotone, north-central USA.- The Holocene, 9 (6), 671-676. 
Deutscher Wetterdienst, data online available at http://www.dwd.de

Dorale J.A., Gonzales L.A., Reagan M.K., Pickett D.A., Murrell M.T., Baker R.G. (1992): A high resolution record of Holocene climate change in speleothem calcite from cold water cave, northeast lowa.- Science, 258, 1626-1630.

Drake J.J . (1983): The effect of soil activity on the chemistry of carbonate groundwaters.- Water Resources Research, 16, 223-236.

Dreybrodt W. (1988): Processes in Karst Systems, Physics, Chemistry, and Geology.- Berlin: Springer, 288 pp.

Dreybrodt W., Franke H.W. (1994): J oint controlled solution pockets (Laugungskolke) in ceilings of limestone caves: a model of their genesis, growth rates and diameters.- Zeitschrift für Geomorphologie, Neue Folge 38, 239-245.

Dreybrodt W. (1999): Chemical kinetics, speleothem growth and climate.- Boreas, 28, 347-356.

Dreybrodt W., Gabrovšek F. (2000): Dynamics of the evolution of single karst conduits. -In: A.B. Klimchouk, D.C. Ford, A.N. Palmer, W. Dreybrodt (Eds.), Speleogenesis: Evolution of Karst Aquifers. Huntsville: National Speleological Society, 183-193.

Dulinsky M. and Rozanski K. (1990): Formation of 13C/12C isotope ratios in speleothems: a semidynamic model.- Radiocarbon, 32, 1, 7-16.

Duplessy J.C., Labeyrie J., Lalou C., Nguyen H.V. (1970): Continental climatic variations between 130,000 and 90,000 years BP.- Nature, 226, 631-632.

\section{$\mathbf{E}$}

Edwards R.L., Gallup C.D. (1993): Dating of the Devil's Hole calcite vein.- Science, 259, 1626.

Eichler R. (1964): Deuterium-Isotopenchemie des Grund- und Oberflächenwassers.- Geol. Rd., 55, 144-159.

Ek C., Gilewska S., Kaszowski L. (1969): Some analyses of the $\mathrm{CO}_{2}$ - content of the air in five Polish caves.- Z. Geomorphol., 13/3, 226 - 286.

Eikenberg J ., Vezzu G., Zumsteg I.,Bajo S., Ruethi M.,Wyssling G. (2001): Precise two chronometer dating of Pleistocene travertine: The 230Th/234Th and 226Raex / 226Ra(0) approach.- Quaternary Science Reviews, 20, 1935-1953.

Emiliani C. (1971): The last interglacial paleotemperature and chronology.- Science, 171, 571.-573.

Emrich K., Ehhalt D.H., Vogel J.C. (1970): Carbon isotope fractionation during the precipitation of calcium carbonate.- Earth and Planetary Science Letters, 8, 363-371.

Engelbrecht P. (1997): Touristenidylle und KZ - Grauen - Vergangenheitsbewältigung in Pottenstein.Verlag C. u. C. Rabenstein, Bayreuth.

Epstein S. (1956): Variations in the ${ }^{18} \mathrm{O} /{ }^{16} \mathrm{O}$ ratios of freshwater and ice.- Natnl. Acad. Sc. Nucl. Science Series Report, 19, 20-28.

Epstein P.R., Diaz H.F., Elias S., Grabherr G., Graham N.E., Martens W.J .M., Mosley-Thompson E., Susskind J.(1998): Biological and physical signs of climate change: focus on mosquito-borne diseases.- Bull. Am. Met. Soc., 79, 3, 409-417.

Ernst L. (1964): Zur Frage der Mischungskorrosion.- Die Höhle, 15, 71 - 75. 
Esper J.F. (1774): Ausführliche Nachricht von neuentdeckten Zoolithen unbekannter vierfüsiger Thiere, und denen sie enthaltenden, so wie verschiedenen anderen denkwürdigen Grüften der Oberbürgischen Lande des Markgrafenthums Bayreuth.-Nürnberg. IN: Im Reich der DunkelheitHöhlen und Höhlenforschung in Deutschland. -W. Rosendahl and E.-B. Krause (1996), Edition Archaea.

Ewers R.O. (1972): A model for the development of subsurface drainage routes along bedding planes.- M.D. - Thesis, Univ. Cincinnati, Dept. Geol.

Ewers R.O. (1982): Cavern development in the dimensions of length and breath.- Ph.D. Thesis, Mc. Master Univ., Hamilton, Ontario.

\section{$\mathbf{F}$}

Fairbanks R.G. (1989): A 17,000 year glacio-eustatic sea-level record: influence of glacial melting rates on the Younger Dryas event and deep ocean circulation.- Nature, 342, 637-642.

Fairchild I., Borsato A., Tooth A. F., Frisia S., Hawkesworth C.J ., Huang Y., Dermott F., Spiro B. (2000): Controls on traceelement (Sr-Mg) compositions of carbonate cave waters: I mplications for speleothem climatic records.- Chemical Geology, 166, 255-269.

Fink M.H. (1973): Mehrsprachiges Lexikon der Karst- und Höhlenkunde. Entwurf.- ISU, Int. Speleol. Union.

Fleitmann D., Burns S.J ., Mudelsee M., Neff U., Kramers J., Mangini A., Matter A. (2003): Holocene forcing of the Indian Monsoon recorded in a stalagmite from southern Oman.- Science, 300, 5626, 1737-1739.

Ford D.C. and Williams P.W. (1989): Karst Geomorphology and Hydrology.- London: Unwin Hyman, $601 \mathrm{pp}$.

Franke H.W. (1961): Formgesetze des Höhlensinters.- Rass. Speleol. Italiana, Mem. 5, 185-202.

Franke H.W. (1963): Formprinzipien des Tropfsteins.- Proc. III Internat. Congr. Speleol., 2, 63-71.

Franke H.W. (1965): The theory behind stalagmite shapes.- Studies in Speleo., 1, 89-95.

Franke H.W. (1975): Sub-minimum diameter stalagmites.- NSS Bull., 37, 17-18.

Frappier, A., Sahagian D., González L.A., Carpenter S.J . (2002) : El Nino events recorded by stalagmite carbon isotopes.- Science, 298, 565.

Frenzel B. (1992). Vegetation during the maximum cooling of the last glaciation. In; Frenzel B., Pecsi $B \&$ Velichko A.A.; Atlas of Palaeoclimates \& Palaeoenvironments of the Northern Hemisphere. INQUA/Hungarian Academy of Sciences. Budapest.

Frenzel B., Pecsi B., Velichko A.A. (1992): Atlas of Palaeoclimates \& Palaeoenvironments of the Northern Hemisphere. INQUA/Hungarian Academy of Sciences. Budapest.

Fricke H.C., O'Neil J.R. (1999): The correlation between ${ }^{18} \mathrm{O} /{ }^{16} \mathrm{O}$ ratios of meteoric water and surface temperature: its use in investigating terrestrial climate change over geologic time.- EPSL, 170, 181196.

Friedman I., Smith G. I. (1970): Deuterium content of snow cores from Sierra Nevada area.- Science, $169,467-470$.

Friedman I., O'Neil J.R. (1977): Compilation of stable isotope fractionation factors of geochemical interest. IN: M. Fleischer (ed.) Data of Geochemistry, 6th ed., US Geological Survey Professional Paper, 440kk. 
Frisia S., Borsato A., Fairchild I.J., Mcdermott F. (2000): Calcite fabrics, growth mechanism, and environments of formation in speleothems from the Italian Alps and southwestern I reland.- J. of Sed. Research, Vol. 70, 5, 1183-1196.

Fritz P. (1967): Zur Genese von Dolomit und zuckerkörnigem Kalk im Weißen Jura der Schwäbischen Alb (Württemberg). Mikroskopische Untersuchungen und Isotopenanalysen.- Arb. geol. paläontol. Inst. Techn. Hochsch. Stuttgart, N.F. 50, pp. 104.

Fritz P. (1968): Oxygen and carbon isotopic composition of carbonates from the Jura of Southern Germany.- Canad. J. Earh Sci., 4, 1247-1267, Calgary.

Frumkin A., Carmi I.,Gopher A., Ford D.C., Schwarcz H.P., Tsuk T. (1999): A Holocene millennial-scale climatic cycle from a speleothem in Nahal Qanah Cave, Israel.- The Holocene, 9, 6, 677-682.

\section{$\underline{\mathbf{G}}$}

Gams I. (1981): Contribution to morphometrics of stalagmites.- Proc. 7th. Int. Congr. Speleo., Sheffield, 205-208.

Gascoyne M. (1978): Comment on "Preliminary results on growth rate and paleoclimate studies of a stalagmite from Ogle Cave, New Mexico.- Bull. Nat. Spel. Soc., 40, 123-124.

Gascoyne M., Schwarcz H.P., and Ford D.C. (1980): A paleotemperature record for the Mid-Wisconsin in Vancouver Island.- Naure, 285, 474-476.

Gascoyne M., Ford D.C., Schwarcz H.P. (1981): Late pleistocene chronology and paleoclimate of Vancouver island determined from cave deposits.- Can. Journal of Earth Science, 18, 1643-1652.

Gascoyne M. (1992): Paleoclimate determination from cave calcite deposits.- Quat. Sci. Rew., 11, 609632.

Gat J.R. (1996): Oxygen and hydrogen isotopes in the hydrologic cycle.- Annual Review Earth Planetary Science, 24, 225-262.

Genty D. , Massault M. (1997): Bomb 14C recorded in laminated speleothems: calculation of dead carbon proportion.- Radiocarbon, 39 (1), 33-48.

Genty D., Massault M., Gilmour M., Baker A., Verheyden S., Keppens E. (1999): Calculation of past dead carbon proportion and variability by the comparison of AMS 14C and TIMS U/Th ages on two Holocene stalagmites.- Radiocarbon, 41, 251-270.

Genty D., Baker A., Massault M., Proctor C., Gilmour M., Pons-Branchu E. , Hamelin B. (2001): Dead carbon in stalagmites: Carbonate bedrock paleodissolution vs. ageing of soil organic matter.

Imflications for 13C variations in speleothems.- Geochimica et Cosmochimica Acta, 65, 20, 3443-3457.

Genty D., Plagnes V., Causse C., Cattani O., Stievenard M., Falourd S., Blamart D., Ouahdi R., VanExter S. (2002) : Fossil water in large stalagmite voids as a tool for paleoprecipitation stable isotope composition reconstitution and paleotemperature calculation.- Chemical Geology, 184, 83-95.

Geologische Landesämter der BRD (1971): Geologische Karte von Mitteleuropa.- 2nd. ed., Hannover.

Geyer O.F., Gwinner M.P. (1991): Geologie von Baden Württemberg.- 4th ed., Schweizerbart, Stuttgart, pp. 482.

Geyh M.A., Franke H.W. (1970): Zur Wachstumsgeschwindigkeit von Stalagmiten.- Atompraxis, 16, 1, 46-48.

Gillieson D. (1996): Caves: Processes, Development and Management.- Blackwell, 324 pp.

Glässer R. (1991): Das Klima des Harzes.- Verlag Dr. Kovac, Hamburg, pp. 341. 
Glaser S. (2003): Sinterprobeentnahme in der Mühlbachquellhöhle.- unpublished field report, Stefan Glaser, Albrecht-Dürer-Str. 29, 82152 Krailling

Glatzel K., Jahn R., Müller S., (1967): Südwestdeutsche Waldböden im Farbbild.- Schr.-R. Landesforstv. Bad.-Württ., 23, Stuttgart.

Glöckler K. (1979): Das Alter der Laichinger und der Sontheimer Höhle-eine flußgeschichtliche Betrachtung.- Der Laichinger Höhlenfreund, 14 (2), 73-80.

Goede A., Green D.C., Harmon R.S. (1986): Late pleistocene paleotemperature record from a Tasmanian speleothem.- Australian J ournal of Earth Sciences, 33, 333-342.

Goede A., Veeh H.H., Ayliffe L.K. (1990): Later Quarternary paleotemperature records for two Tamanian speleothems.- Australian J ournal of Earth Sciences, 37, 267-278.

Goede A. (1994): Continuous early last glacial paleoenvironmental record from a Tasmanian speleothem based on stable isotope and minor element variations.- Quaternary Science Reviews, 13, 283-291.

Goldast M.H. (1605): Suevicarum rerum scriptores aliquot. -pp. 289-299. Frankfurt. IN: Im Reich der Dunkelheit- Höhlen und Höhlenforschung in Deutschland. -W. Rosendahl and E.-B. Krause (1996), Edition Archaea.

Gonzalez L.A., Lohmann K.C. (1988): Controls on mineralogy and composition of spelean carbonates: Carlbad Caverns, New Mexico.- IN: N.P. James and P.V. Choquette (ed.): Paleokarst. New York: Springer, pp. 416.

Gordon D., Smart P.L., Ford D.C., Andrews J.N., Atkinson T.C., Rowe P.J ., Christopher N.S.J . (1989): Dating of Last Pleistocene interglacial and interstadial periods in the United Kingdom from speleothem growth frequency.- Quat. Res., 31, 14-26.

Goslar T., Arnold M., Pazdur M. F. (1995): The Younger Dryas cold event-was it synchronous over the North Atlantic region?- Radiocarbon, 37, 63-70.

Gradzinski M. (2000): Bacterial influence on the speleothems oxygen isotope signals: an example based on cave pisoids.- Climate Changes - The Kart Record II, Krakow, 62.

GRIP members (1993): Climate instability during the last interglacial period recorded in the GRIP core.- Nature, 364, 203-207.

Groiss J.Th., Haunschild H., Zeiss A. (2000): Das Ries und sein Vorland.- Sammlung Geologicher Führer, 92, Gebr. Borntraeger Berin-Stuttgart, pp. 271.

Groiss J.Th., Kaulich B., Reisch L. (2001): Hunas, Archiv des Eiszeitalters.- http://www.uf.unierlangen.de/projekte/hunas/hunas.html.

Guiot J., Pons A., Beaulieu J.-L., Reille M. (1989) : A 140,000 year continental climate reconstruction from two European pollen records.- Nature, 338, 309-313.

Gwinner M.P. (1968): Palöogeographie und Landschaftsentwicklung im Weißen (Oberen) Jura der Schwäbischen Alb (Baden-Württemberg).- Geol. Rdsch., 58, 32-41, Stuttgart.

Gwinner M.P. (1976): Origin of the Upper J urassic limestones of the Swabian Alb (southwest Germany).- Contributions to Sedimentology, 5, pp. 75.

Gwinner M.P. (1980): Erläuterungen zu Blatt 7524 Blaubeuren.- Geol. Karte von Baden-Württ. 1:25000, pp. 64, Stuttgart. 
Habbe, K. -A. (1989): Der Karst der Fränkischen Alb - Formen, Prozesse, Datierungsprobleme.- Die Fränkische Alb.- Schr. Z. Inst. fränk. Landeskde. Uni. Erlangen 28: 35-69; Neustadt/A.

Harlacher C. (1995): Der Glaspalast. Eine neue Höhle auf der Schwäbischen Alb.- Der Abseiler, 12, 3536, Nürtingen.

Harmon R.S., Thompson P., Schwarcz H.P., Ford D.C. (1975): Uranium-series dating of speleothems.Bull. Nat. Speleol. Soc., 37, 21-33.

Harmon R.S. Thompson P., Schwarcz H.P., Ford D.C. (1978a): Late Pleistocene paleoclimates of North America as infered from stable isotope studies of speleothems.- Quaternary Research, 9, 54-70.

Harmon R.S., Schwarcz H.P., Ford D.C. (1978b): Stable isotope geochemistry of speleothems and cave waters from the Flint Ridge-Mammoth cave system, Kentucky: implications for terrestrial climate change during the period 230,000 to 100,000 years B.P.- J ournal of Geology, 86, 373-384.

Harmon R.S. (1979b): Paleoclimatic information from isotopic studies of speleothems: a review.- IN: "Quaternary Climate", W.C. Mahaney (Ed.), 299-319.

Harmon R.S., Atkinson T.C., Atkinson J.L. (1983): The mineralogy of the Castleguard Cave, Columbia Icefields, Alberta, Canada.- Arctic and Alpine Research, 15, 503-516.

Harrison S.P., Yu G. \& Tarasov P.E. (1996). Late Quaternary lake-level record from northern Eurasia.Quaternary Research,.45, 138-159.

Hebestreit Ch. (1990): Untersuchungen über fluviatile Geodynamik, Sedimentologie und Subrosion im Rahmen der jung pleistozänen Klima- und Landschaftsgeschichte der Oberen Wutach im Kiesabbau Großwald, Gem. Reiselfingen.- Diplom-thesis, Geolog. Institut, Universität Tübingen, pp. 116.

Heller F. (1983): Die Höhlenruine Hunas bei Hartmannshof (Landkreis Nürnberger Land).Quartärbibliothek, Band 4.

Hellstrom J., McCulloch M. and Stone J. (1998): A detailed 31,000 year record of climate and vegetation change, from the isotopic geochemistry of two New Zealand speleothems.- Quaternary Research, 50, 167-178.

Hellstrom J., McCulloch M. (2000): Multi-proxy constraints on the climatic significance of trace element records from a New Zealand speleothem.- Earth and Planetary Science Letters, 179, 287-297.

Hendy C.H. (1971): The isotopic geochemistry of speleothems-I. The calculation of the effects of different modes of formation on the isotopic composition of speleothems and their applicability as palaeoclimatic indicators.- Geochimica et Cosmochimica Acta, 35, 801-824.

Hendy C.H. and Wilson A.T. (1968): Paleoclimatic data from speleothems.- Nature, 219, 48-50.

Hennig G.J. (1979): Beiträge zur Th-239/U-234 - Altersbestimmung von Höhlensintern sowie ein Vergleich der erzielten Ergebnisse mit den anderer Absolutdatierungsmethoden.- Diss., Inst. f. Kernchemie Universität Köln, pp. 171.

Hennig G.J ., Grün R., Brunnacker K. (1983): Speleothems, Travertines, and Paleoclimates.Quaternary Research, 20, 1-29.

Hennig G.J . and Eisenhauer T. (1997): Methoden zur Altersbestimmung von Tropfsteinen.- In: Kempe S. (ed.): Welt voller Geheimnisse. Höhlen - HB Bildatlas, Sonderausg., 17, 62-69, Hamburg.

Herrmann F.(1976): Jurahöhlen der Oberpfalz.- Regensburg (Pustet), pp 99.

Herrmann F. (1980): Höhlen der Fränkischen und Hersbrucker Schweiz.- Regensburg (Pustet), pp. 167 
Hill C.A., Forti P. (1986): Cave Minerals of the World.- Huntsville, ALA: Nat. Speleo. Soc.

Hillaire-Marcel C., Ghaleb B., Gariepy C., Zazo C., Hoyos M., Goy J.L. (1995): U-series dating by the TIMS technique of land snails from paleosols in the canary islands.- Quaternary Research, 44, 276282.

Hoefs J. (1997): Stable isotopes geochemistry.- 4th. ed. Springer, Berlin, pp. 241.

Holmgren K., Karlén W., Lauritzen S.E., Lee-Thorp J., Partridge T.C., Piketh S., Repinski P., Stevenson C., Svanered O., Tyson P.D. (1999): A 3000-year high-resolution stalagmite-based record of paleoclimate for northeastern South Africa.- The Holocene, 9 (3), 295-309.

Houghton J. (2004): Global Warming.- Cambridge University Press, 351p.

Huber, F. (1967): Die Höhlen des Karstgebietes A Königstein.- Jh. Karst- u. Höhlenkde. 8/2, 1-196.

Huijzer A.S., I sarin R.F.B. (1996). Reconstruction of past climates using multi-proxy evidence: example of the Weichselian pleniglacial in NW and central Europe.- Quaternary Science Reviews, 16, 513-533.

Hurrel J.W., van Loon H. (1997): Decadal variations in climate associated with the North Atlantic Oscillation.- Climate Change, 36, 301-326.

$\underline{I}$

IAEA (1983): Technical report, 228p.

IAEA/WMO (2001): Global Network of I sotopes in Precipitation. The GNIP Database. Accessible at: http://isohis.iaea.org

Intergovernmental Panel on Climate Change, IPCC (2001): Special Report on Emissions Scenarios (SRES). Special Report of the Intergovernmental Panel on Climate Change, Nebojsa Nakicenovic and Rob Swart (Eds.), Cambridge 2000

Intergovernmental Panel on Climate Change, IPCC (2001): Climate Change 2001: The Scientific Basis. Summary for Policimakers and Technical Summary of the Working Group I Report, Cambridge 2001.

Issar A.S. (2003): Climate changes during the Holocene and their impact on hydrological systems.International Hydrological Series, Cambridge University Press, p.127

\section{1}

Jiménez de Cisneros C., Caballero E., Vera J.A., Durán J.J., Juliá R. (2003): A record of Pleistocene climate from a stalactite, Nerja Cave, southern Spain.- Paleogeography, Paleoclimatology, Paleoecology, 189, 1-10.

Johnsen S. J., Clausen H. B., Dansgaard W., Fuhrer K., Gundenstrup N., Hammer C. U., Iversen, P. J ouzel J., Stauiver B., Steffensen J. P. (1992): I rregular glacial interstardials record in a new Greenland ice core.- Nature, 359, 311-313.

Johnsen S.J ., Clausen H.B., Dansgaard W., Gundestrup N.S., Hammer C.U., Andersen U., Andersen K.K., Hvidberg C.S., Dahl-J ensen D.,Steffensen J.P., Shoji H., Sveinbjörnsdóttir A.E., White J.W.C., J ouzel J., Fisher D. (1997): The $\delta^{18} \mathrm{O}$ record along the Greenland Ice Core Pproject deep ice core and the problem of possible Eemian climatic instability.- J ournal of Geophysical Research, 102, 2639726410.

\section{$\underline{\mathbf{K}}$}

Kaufmann A., Broecker W.S. (1965): Comparison of ${ }^{230} \mathrm{Th}$ and ${ }^{14} \mathrm{C}$ ages for carbonate material from Lakes Lahontan and Bonneville.- J. Geophys. Res., 70, 4039-4054. 
Kaufman A., Wasserburg G.J ., Porcelli D., Bar-Matthews M., Ayalon A., Halicz L. (1998): U-Th isotope systematics from the Soreq Cave, Israel, and climatic correlations.- Earth and Planetary Science Letters, 156, 141-155.

Kendall A.C., Broughton P.L. (1978): Origin of fabrics in speleothems composed of columnar calcite crystals.- J ournal of Sedimentary Petrology, 48, 2, 519-538.

Kim S.T., O'Neil J .R. (1997): Equilibrium and non-equilibrium oxygen isotope effects in synthetic carbonates.- Geochimica et Cosmochimica Acta, 61, 16, 3461-3475.

Kirchgäßner A. (2001): Phänoklimatologie von Buchenwäldern im Südwesten der Schwäbischen Alb.Ber. Meteorol. Inst. Univ. Freiburg, 7, pp. 295.

Klitgaard-Kristensen D., Sejrup H.P., Haflidason H., Johnson S., Spurk M. (1998): A regional 8200 cal. year B.P. cooling event in northwestern Europe, induced by final stages of the Laurentide ice-sheet deglaciation? -J ournal of Quaternary Science, 13, 2, 165-169.

Kroopnick P., Craig H. (1972): Atmospheric Oxygen: isotopic composition and solubility fractionation.Science, 175, 54-55.

Kukla G., McManus J.F., Rousseau D.-D., Chuine I. (1997) : How long and how stable was the last interglacial?- Quaternary Science Reviews, 16, 6, 605-612.

Kullmann L (1988): Holocene history of the forest-alpine tundra ecotone in the Scandes Mountains (Cenral Sweden).- New Phytologist, 108, 101-110.

\section{$\underline{\mathbf{L}}$}

Labat D., Ababou R., Mangin A. (2000a) : Rainfall-runoff relations for karstic springs. Part I: convolution and spectral analysis.- Journal of Hydrology, 238, 123-148.

Labat D., Ababou R., Mangin A. (2000b) : Rainfall-runoff relations for karstic springs. Part II: continuous wavelet and discrete orthogonal multi-resolution analyses.- Journal of Hydrology, 238, 149-178.

Labat D., Mangin A., Ababou R. (2002) : Rainfall-runoff relations for karstic springs: multifractal analysis.- J ournal of Hydrology, 256, 176-195.

Labeyrie J., Duplessy J.C., Delibrias G., Letolle R. (1967): Etude des températures des climats anciens par la mesure de l'oxygene-18, du carbone-13 et du carbone-14 dans les concrétions des caverns.IAEA, Radioactive dating and methods of low level counting, 153-160.

Lang H.B. (1964): Dolomit und zuckerkörniger Kalk im Weißen Jura der mittleren Schwäbischen Alb (Württemberg).- N. Jb. Geol. Paläont., Abh., 120, 253-299, Stuttgart.

Langmuir D. (1978): Uranium solution mineral-equilibria at low temperatures with applications to sedimentary ore deposits.- Geochim. Cosmochim. Acta, 42, 547-570.

Latham A.G., Schwarcz H.P., Ford D.C. (1986): The paleomagnetism and U-Th dating of Mexican stalagmite, DAS2.- Earth and Planetary Science Letters, 79, 195- 207.

Lauritzen S.E., Ford D.C., Schwarcz H.P. (1986): Humic substances in speleothem matrix: Paleoclimatic significance.- Proc. 9th Int. Congr. Speleo,. Barcelona, 77-79.

Lauritzen S.E. (1993): Natural environmental change in karst: The Quaternary record.- Catena, Supplement 25, 21-40.

Lauritzen S.E. (1995): High-resolution paleotemperature proxy record for the Last Interglaciation based on Norwegian speleothems.- Quaternary Research, 43, 133-146. 
Lauritzen S.E., Lundberg J. (1999): Speleothems and climate.- The Holocene-sp. issue, 9,9, 643-647.

Lauritzen S.E. and Onac B.P. (1999b): I sotopic stratigraphy of a last interglacial stalagmite from northwestern Romania: Correlation with the deep-sea record and northern-lattitude speleothem.J ournal of Cave and Karst Studies, 61 (1), 22-30.

Laverty M. (1987): Fractals in karst.- Earth Surface Processes and Landforms, 12, 475 - 480.

Landesamt für Geologie, Rohstoffe und Bergbau Baden-Württemberg, LGBR (1989): Geologische Karte von Baden-Württemberg 1,: 25000 Blatt 7524 Blaubeuren.

Li W., Lundberg J., Dickin A.P., Ford D.C., Schwarz H.P., Mac Nutt R., Williams D. (1989): High precision mass-spectrometric uranium series dating of cave deposits and implications for paleoclimate studies.- Nature, 339, 534-536.

Linge H., Lauritzen S.E., Lundberg J., Berstad I.M. (2001): Stabel isotope stratigraphy of Holocene speleothems: examples from a cave system in Rhana, northern Norway.- Paleogeography, Paleoclimatology, Paleoecology, 167, 209-224.

Litt T., Brauer A., Goslar T., Merkt J ., Balaga K., Müller H., Ralska-J asiewiczowa M., Stebich M., Negendank J.F.W. (2001): Correlation and synchronisation of Lateglacial continental sequences in northern central Europe based on annually laminated lacustrine sediments.- Quarternary Science Reviews, 20, 1233-1249.

López Correa (1999): Zaininger Höhle (7523/12)-Eine kleine Entdeckungsgeschichte.- ARGE Höhle und Karst Grabenstetten e.V., Jahresheft, 8-24.

López Correa M. (2000): Die Zaininger Höhle (7523/12)-Eine kleine Entdeckungsgeschichte.Grabenstetter höhlenkundliche Hefte, 3, 8-24, Grabenstetten.

López Correa M., Fischer C. (2004): Die Zaininger Höhle (7523/12) östlich Bad Urach, Schwäbische Alb.- Mitt. Verb. dt. Höhlen- u. Karstforsch., 50 (1), 18-23, München.

Lotter A.F., Eicher U., Siegenthaler U., Birks H.J.B. (1992): Late-glacial climatic oscillations as recorded in Swiss lake sediments.- J ournal of Quarternary Science, 7, 187-204.

Ludwig K.R., Simmons K.R., Szabo B.J ., Winograd I.J ., Landwher J.M., Riggs A.C., Hoffman R.J . (1992): Mass-spectrometric 230Th-234U-238U dating of the Devils Hole calcite vein.- Science, 258, 284-287.

Ludwig K.R., Simmons K.R., Winograd J.M., Szabo B.J ., Landwehr J.M., Riggs A.C. (1993): Last interglacial in Devil's Hole.- Nature, 362, 569.

Lüttig G. (1955): Hat sich der Nordwestharz im Postglazial gehoben?- Geol. Jb., 70, Hannover, 405434.

Luo S., Ku T.L. (1991): U-series isochron dating: A generalized method employing total-sample dissolution.- Geochim. Cosmochim. Acta, 55, 555-564.

\section{$\underline{\mathbf{M}}$}

Martinson D.G., Pisias J.D., Hays J.D., Imbrie J., Moore T.C., Shackleton N.J . (1987): Age dating and the orbital theory of the ice ages: Development of a high-resolution 0-300000 year chronostratigraphy.- Quat. Res. 27, 1-29.

Mathieu R., Bariac T. (1996) : An isotopic study $\left({ }^{2} \mathrm{H}\right.$ and $\left.{ }^{18} \mathrm{O}\right)$ on water movements in clayey soils under a semiarid climate.- Water Resources Research, 32, 779-789.

Matthews A., Ayalon A., Bar-Matthews M. (2000): D/H ratio of fluid inclusions of Soreq cave (Israel) speleothems as a guide to the Eastern Mediterranean Meteoric Line relationships in the last $120 \mathrm{Ky}$.Chemical Geology, 166, 183-191. 
McDermott F., Frisia S., Huang Y., Longinelli A., Spiro B., Heaton T.H.E., Hawkesworth C.J ., Borsato A., Keppens E., Fairchild I.J ., Van der Borg K., Verheyden S. and Selmo E. (1999): Holocene climate variability in Europe: evidence from $\delta^{18} \mathrm{O}$, textural and extension-rate variations in three speleothems.Quaternary Science Reviews, 18, 1021-1038.

McDermott F., Mattey D. P., Hawkesworth C. (2001): Centennial-scale Holocene climate variability revealed by a high-resolution speleothem $\delta^{18} \mathrm{O}$ record from SW Ireland.- Science, 294, 1328-1330.

McDermott F. (2004): Paleo-climate reconstruction from stable isotope variations in speleothems: a review.- Quaternary Science Reviews, 23, 901-918.

Merenne-Schoumaker, B. (1975): Aspects de l'influence des tourists sur les microclimats de la grotte de Remouchamps.- Ann. Spéléo., 30 (2), 273-285.

Meyer H., Schönicke L., Wand U., Hubberten H.-W., Friedrichsen H. (2000): Isotope Studies Of Hydrogen And Oxygen on Ground Ice-Experiences with the equilibration technique.- I sotopes Environmental Health Studies, 36, 133-149.

Mohr K. (1973) : Harz , Westlicher Teil.- Sammlung Geologischer Führer, 58, Gebr. Borntraeger, Berlin-Stuttgart, pp. 200.

Moore G.W. (1952): Speleothem-a new cave term.- Natl. Speleol. Soc. News, 11, 4, 1-3.

Moore G.W., Sullivan G.N. (1964): Speleology.- Zephyrus Press, 2nd. edition, p. 150

Morse J.W., Bender M.L. (1990): Partition coefficients in calcite: Examination of factors influencing the validity of experimental results and their application to natural systems.- Chem. Geol., 82, 265-267.

Miotke F.-D. (1974): Carbon dioxide and the soil atmosphere.- Abh. Karst - Höhlenkd., A/H9.

Ministerium für Raumordnung, Landwirtschaft und Umwelt/Sachsen-Anhalt (1996): Agraratlas des Landes Sachsen-Anhalt, mit Textteil.- Magdeburg.

Müller S. (1963): Bodenentwicklung aus verkarsteten Weißjurakalken in der mittleren Schwäbischen Alb.- Jh. Karst- u. Höhlenk., 4, München, 45-56.

\section{$\underline{\mathbf{N}}$}

Nier A.O. (1950): A redetermination of the relative abundances of the isotopes of carbon, nitrogen, oxygen, argon and potassium.- Phys. Rev., 77, 789-793.

\section{o}

Oeschger H., Beer J., Siegenthaler U., Stauffer B., Dangaard W., Langway C.C. (1984): Late glacial climate history from ice cores. IN: Climate Processes and Climatic Sensitivity: 299-306.

O'Leary M.H. (1981): Carbon isotope fractionation in plants.- Phytochemistry, 20, 553-567.

Onac B.P. (1997): Crystallography of speleothems.- IN: C. Hill and P. Forti (eds.): C.A. Hill and P. Forti (1997): Cave Minerals of the World.- Huntsville, ALA: Nat. Speleo. Soc., 230-236.

O'Neil J.R., Clayton R.N., Mayeda T.K. (1969): Oxygen isotope fractionation in divalent metal carbonates.- J ournal of chemical physics, 51, 12, 5547-5559.

Overpeck J.E. (1996): Varved sediment records of recent seasonal to millennial-scale environmental variability. I N: Climate variations and forcing mechanisms of the last 2000 years.- Eds: Jones P.D., Bradley R.S. J ouzel J., Springer - Verlag, Berlin, 479-498.

\section{$\underline{\mathbf{P}}$}

Palmer A.N. (1987): Cave levels and their interpretation.- The NSS Bulletin, 49, 50-66. 
Perette Y., Delannoy J.J., Bolvin H., Cordonnier M., Destombes J.L., Zhiliskaya E.A., Aboukais A. (1999): Comparative study of a stalagmite sample by stratigraphy, laser induced fluorescence spectrosocopy, EPR spectrometry and reflectance imaging.- Chemical Geology, 162, 3-4, 221-243.

Petit M. (1999): Le changement climatique d'origine humaine. Rappel de quelques résultats généraux.- C.R.Acad.Sci.Paris Earth and Planetary Sciences, 328, 225-227.

Picknett R.G., Bray L.G. and Stenner R.D. (1976): The chemistry of cave waters.- IN: T.D. Ford and C. H.D. Cullingford (ed.): The science of Speleology. London: Academic Press, pp. 593.

Pisias N.G., Martinson D.G., Moore J r. T.C., Shackleton N.J ., Prell W., Hays J., Boden G. (1984): High resolution stratigraphic correlation of benthic oxygen isotopce records spanning the last 300,000 years.- Mar. Geol., 56, 119-136.

Plagnes V., Gausse C., Genty D., Paterne M., Blamart D. (2002) : A discontinuous climatic record from 187 to $74 \mathrm{ka}$ from a speleothem of the Clamouse Cave (south of France).- Earth and Planetary Science Letters, 201, 87-103.

\section{$\underline{Q}$}

Quade J., Cerling T.E., Bowman J.R. (1989): Systematic variations in carbon and oxygen isotopic composition of pedogenic carbonate along elevation transects in the Southern Great Basin, United States.- Geological Society of America Bulletin, 101, 464-475.

Qin X., Tan M., Liu T., Li T., Lu J. (1999): Spectral analysis of a 1000-year stalagmite lamina-thickness record from Shihua cavern, Beijing, China, and its climate signigicance.- The Holocene, 9, 6, 689-694.

Quinif Y. (1990): La datation des spéléothèmes (U/Th) appliquée aux séquences sédimentaires pour une mise en évidence des ruptures paléoclimatiques.- Karstologia Mémoires, 8, 23-32.

$\underline{\mathbf{R}}$

Railsback B. (http://www.gly.uga.edu.railsback/speleoatlas.hml)

Richards D.A., Dorale J.A. (2003): Uranium-series Chronology and Environmental application of Speleothems.- Rev. Mineral. Geochem., 52, 407-450.

Roberts M.S., Smart P.L., Hawkesworth C.J ., Perkins W.T., Pearce N.J .G. (1999): Trace element variations in coeval Holocene speleothems from GB Cave, southwest England.- The Holocene, 9, 707713.

Romanek C.S., Grossman E.L., Morse J.W. (1992): Carbon isotopic fractionation in synthetic aragonite and calcite: effects of temperature and precipitation rate.- Geochimica et Cosmochimica Acta, 56, 419430.

Rosendahl W., Wiegand B., Nordhoff P., Christ D., Kaulich B. (2004): Datierungen an Speläothemen aus der Höhlenruine Hunas / Ldkr. Nürnberger Land - Daten und Interpretationen.- Tagungsband der 46. Tagung der Hugo-Obermaier Gesellschaft, Greifswald, 25-26.

Rowe P.J., Dennis P.F., Atkinson T.C., Lauritzen S.E., Lundberg J. (1998): High resolution deuterium record from fluid inclusions in a later Holocene speleothem from S.W. Britain.- Past Global Changes and their Significance for the Future. 1st. IGBP PAGES, Open Science Meeting, London, p. 112.

Rozanski K., Araguás-Araguás L., Gonfiantini R. (1993): Isotopic patterns in modern global precipitation.- IN: Climate changes in continental isotopic records (Eds.: Swart et al.), Geophysical Monograph, 78, 1-36. 
Salomons W., Mook M.W. (1986) : I sotope geochemistry of carbonates in the weathering zone.- IN: Handbook of Environmental Geochemistry (Eds.: P. Fritz and J.C. Fontes), Vol. 2b, 239-269. Elsevier, Amsterdam, The Netherlands.

Sanaiotti T. M., Martinelli L. A., Victoria R. L., E.Trumbore, P. B. Camarg (2002): Past Vegetation Changes in Amazon Savannas Determined Using Carbon Isotopes of Soil Organic Matter.- Biotropica, $34,1$.

Sauter M. (1992): Quantification and Forecasting of Regional Groundwater Flow and Transport in a Karst Aquifer (Gallusquelle, Malm, SW. Germany).- Tüb. Geowiss. Abh., Reihe C, 13, pp. 150,

Tübingen.

Salomons W., W.G. Mook (1986): I sotope geochemistry of carbonates in the weathering zone.- IN: Fritz P., Fontes C.J : (Eds.): Handbook of Environmental Isotope Geochemistry, Vol. 2, The Terrestrial Environment, Elsevier, Amsterdam, 239-270.

Schmidt-Kaler H. (1983): Geologische Karte von Bayern 1:2500, Erläuterungen zum Blatt Nr. 6935 Beilngrieß.- Bayerisches Geologisches Landesamt, pp. 74, München

Schirmer H. (1978): Maps 20 and 27. -In: Hydrologischer Atlas der Bundesrepublik Deutschland.Deutsche Forschungsgemeinschaft, Boppard.

Schwarcz H.P., Harmon R.S., Thompson P., Ford D.C. (1976): Stable isotope studies of fluid inclusions in speleothems and their paleoclimatic effect.- Geochimica et Cosmochimica Acta, 40, 657-665.

Schwarcz H.P. and Yonge C.J. (1983): Isotopic composition of paleowaters as inferred from speleothem and its fluid inclusions. IN: Paleoclimates and Paleowaters: A Collection of Environmental I sotope Studies.- IAEA, STI/PUB/621, 115-133.

Schwarcz H.P. (1986): Geochronology and isotope geochemistry in speleothems.-In: Handbook of Environmental I sotope Geochemistry. Fritz P. and Fontes S. (eds.), Elsevier, Amsterdam, 271-303.

Schwarcz H.P., Latham A.G.(1989): Dirty calcite. 1-Uranium-series dating of contaminated calcite using leachates alone.- Chemical Geology, 80, 35-43.

Shackleton N.J., Opdyke N.D. (1973): Oxygen isotope and paleomagnetic stratigraphy of equatorial core V-28-238: Oxygen isotope temperatures and ice volumes on a $10^{5}$ year and $10^{6}$ year scale.Quaternary Research 3, 39-55.

Shackleton N.J . (1993): Last Interglacial in Devils Hole - reply.- Nature, 362, 596.

Shaw T.R. (1992): History of Cave Science.- p. 338. Sydney Speleological Society, 2nd. edition.

Shopov Y.Y., Ford D.C., Schwarcz H.P. (1994): Luminescent microbanding in speleothems: High resolution chronology and paleoclimate.- Geology, 22, 407-410.

Siegenthaler U., Oeschger H. (1980): Correlation of 180 in precipitation with temperature and altitude.- Nature, 285, 314-317.

Siegenthaler U., Wenk T. (1984): Rapid atmospheric $\mathrm{CO}_{2}$ variations and ocean circulation.- Nature, $308,624-626$.

Slonosky V.C., J ones P.D., Davies T.D. (2001): Atmospheric circulation and surface temperature in Europe from the 18th century to 1995.- Int. J. Climatol., 21, 63-75.

Smart P.L., Smith B.W., Chandra H., Andrews J.N., Symons M.C.R. (1988): An intercomparison of ESR and Uranium Series ages for Quaternary speleothem calcites.- Quaternary Science Reviews, 7, 411416. 
Smith B.N., Epstein S. (1971): Two categories of ${ }^{13} \mathrm{C} /{ }^{12} \mathrm{C}$ ratios for higher plants.- Plant Physiology, 47, 380-384.

Solomon D.K., Cerling T.E. (1987): The annual $\mathrm{CO}_{2}$ cycle in a montane soil: observations, modeling and implications for weathering.- Water Resour. Res., 23, 2257-2265).

Speer A. (1984): Der Sklavenstaat - Meine Auseinandersetzung mit der SS.- Ullstein-Buch Nr. 33041, Frankfurt - Berlin - Wien.

Speetzen M. (1998): Findlinge in Nordrhein-Westfalen.- Geol. Landesamt NRW, Krefeld.

Spötl C., Mangini A. (2002): Stalagmite from the Austrian Alps reveals Dansgaard-Oeschger events during isotope stage 3: implications for the absolute chronology of Greenland ice cores.- Earth and Planetary Science Letters 203, 507-518.

Steiner U., Steiner W. (1969): Zur Genese der Rübeländer Höhlen.- Geologie, 18, Berlin, 198-203.

Stolberg F. (1926) : Die Höhlen des Harzes.- 2 Bde. Magdeburg. IN: Im Reich der Dunkelheit- Höhlen und Höhlenforschung in Deutschland. -W. Rosendahl and E.-B. Krause (1996), Edition Archaea.

Stolberg F. (1958): Die alten Abbildungen der Baumannshöhle bis 1750.- Harz-Zeitschrift, 10, pp. 6590. Harzburg. IN: Im Reich der Dunkelheit- Höhlen und Höhlenforschung in Deutschland. -W. Rosendahl and E.-B. Krause (1996), Edition Archaea.

Stevenson C., Lee-Thorp J.A., Holmgren K. (1999): A 3000 year isotopic record from a stalagmite in Cold Air Cave, Makapan Valley, Northern Province.- South African J ournal of Science, 95, 46-48.

Stewart M.K. (1975): Stable isotope fractionation due to evaporation and isotopic exchange of falling waterdrops: applications to atmosheric processes and evaporation of lakes.- J ournal of Geophysical Research, 80, 9, 1133-1146.

Svensson U. (1992): Die Lösung und Abscheidungskinetik natürlichen Calcitminerals in wässrigen $\mathrm{CO}_{2}$ - Lösungen nahe dem Gleichgewicht.- Dissertation, Fachber. Geowiss., Univ. Bremen, Selbstverlag.

\section{$\mathbf{T}$}

Talma A.S., Vogel J.C., Partridge T.C. (1974): I sotopic contents of some Transvaal speleothems and their paleoclimatic significance.- South African J ournal of Science, 70, 135-140.

Talma A. S., Vogel J.C. (1992): Late quaternary paleotemperatures derived from a speleothem from Cango caves, Cape province, South Africa.- Quaternary Research, 37, 203-213.

Taylor K.C., Hammer C.U., Alley R.B., Clausen H.B., Dahl-J ensen D., Gow A.J., Gundestrup N.S., Kipfstuhl J., Moore J.C., Waddington E.D. (1993): Electrical conductivity measurements from the GISP2 and GRIP Greenland ice cores.- Nature, 366, 549-552.

Thompson P.T.,Schwarcz H.P., Ford D.C. (1976): Stable isotope geochemistry, geothermometry and geochronology of speleothems from West Virginia.- Geol. Soc. of America Bulletin, 87, 1730-1738.

Tooth A.F., Fairchild I.J. (2003): Soil and karst aquifer hydrological controls on the geochemical evolution of speleothem-forming drip-waters, Crag Cave, soutwest I reland.- J ournal of Hydrology, 273, 51-68.

Treibs W., Goetze F., Meyer K.F. (1977): Geologische Karte von Bayern 1:25000, Erläuterungen zum Blatt Nr. 6435 Pommelsbrunn.- Bayerisches Geologisches Landesamt, München, 127p.

Trimmel H. (1968): Höhlenkunde.- Vieweg Verlag, Braunschweig.

Turner J.V. (1982): Kinetic fractionation of carbon-13 during calcium carbonate precipitation.Geochim. Cosmochim. Acta, 46, 1183-1191. 
Tyrberg T. (1998): Pleistocene Birds of the Paleoarctic, a catalogue.- Publications of the Nuttall Ornithological Club, 28, Cambridge Mass. 1998, 720 pp.

Tzedakis P.C. (1993): Long-term tree populations in northwest Greece through multiple Quaternary climatic cycles.- Nature, 364, 437-440.

\section{$\mathbf{U}$}

Urey H.C. (1947): The thermodynamic properties of isotopic substances.- J ournal of Chemical Society, 562-581.

Ufrecht W. (1987): Weitere Überlegungen zum Karstalter der Laichinger Alb.- Laichinger Höhlenfreund, 22, 2, 83-86.

\section{$\underline{\mathbf{v}}$}

Van Andel T.H., Tzedakis P.C. (1996): Palaeolithic landscapes of Europe and environs: 150,000-25,000 years ago: an overview.- Quaternary Science Reviews,15, 481-500.

Van Geel B., Buurman J., Waterbolk H.T. (1996): Archeological and paleoecological indications of an abrupt climate change in The Netherlands, and evidence for climatological teleconnections around 2650 B.P.- J ournal of Quaternary Science, 11, 6, 451-460.

VdHK - Verband der deutschen Höhlen- und Karstforscher (http://hfc-hersfeld.de/vdhk.html).

Villar E., Fernandez P.L., Gutierrez I., Quindos L.S., Soto J. (1986) : Influence of visitors on carbon dioxide concentrations in Altamira Cave.- Cave Science, 13 (1), 21-23.

Villinger E. (1972): Seichter Karst und Tiefer Karst in der Schwäbischen Alb.- Geol. Jahrb., C2, 153188.

Villinger E. (1973): Ergebnisse der geologischen Rohrgraben-Aufnahme beim Ausbau der BodenseeWasserversorgung im Gebiet zwischen Bodensee und Neckar (SW-Deutschland).- Jh. geol. Landesamt Baden-Württemberg, 15, 187-236.

Villinger E. (1978): Zur Karsthydrologie des Blautopfes und seines Einzugsgebietes (Schwäbische Alb).- Abh. geol. Landesamt Baden-Württ., 8, 59-127, Freiburg i. Br.

Villinger E. (1980): Karstgrundwasser im Weißen Jura.- IN: M.P. Gwinner (1980): Erläuterungen zu Blatt 7524 Blaubeuren.- Geol. Karte von Baden-Württ. 1:25000, pp. 64, Stuttgart.

Villinger E. (1986): Untersuchungen zur Flußgeschichte von Aare-Donau/Alpenrhein und zur Entwicklung des Malm-Karsts in Südwestdeutschland (Oberer Jura, SW-Deutschland).- Jh. geol. Landesamt Baden-Wuerttemberg, 28, 297-362.

Villinger E. (1998): Zur Flußgeschichte von Rhein und Donau in Südwestdeutschland.- J ber. Mitt. oberrhein. geol. Ver., N.F. 80, 361-398.

Villinger , E., Sauter, M. (1999):, Karsthydrogeologie der Schwäbischen Alb.- J ber. Mitt. oberrhein. geol. Ver., N. F., 81, Stuttgart 1999.

von Grafenstein U., Erlenkeuser H., Müller J., Trimborn P., Alefs J . (1996): A 200-year mid-European air temperature record preserved in lake sediments. An extension of the $\delta 180$-air temperature relation into the past.- Geochim. Cosmochim. Acta, 21, 4025-4036.

von Grafenstein U., Erlenkeuser H., Müller J ., J ouzel, J., and J ohnsen S. (1998): The cold event 8200 years ago documented in oxygen isotope records of precipitation in Europe and Greenland.- Climate Dynamics, 14, 2, 73-81. 


\section{$\underline{\mathbf{W}}$}

Walter R. (1995): Geologie von Mitteleuropa.- Schweizerbart, Stuttgart, 186-198.

Watts W.A., Allen J.R.M., Huntley B. (1996): Vegetation history and palaeoclimate of the last glacial period at Lago Grande di Monticchio, Southern Italy.- Quat. Sci Rev., 15, 133-153.

Wegmüller S., Lotter A.F. (1990): Palynostratigraphische Untersuchungen zur spät- und postglazialen Vegetationsgeschichte der Nordwestlichen Kalkalpen.- Botanica Helvetica, 100, 1, 37-73.

Weissensee (1753): Selecta physicooeconomica.- Stuttgart. IN: Im Reich der Dunkelheit- Höhlen und Höhlenforschung in Deutschland. -W. Rosendahl and E.-B. Krause (1996), Edition Archaea.

Weller H. (1989): Fazies, Bau und Karbonate des Elbingeröder Komplexes im Harz.- Diss., University Greifswald (Germany), unpublished, pp. 133.

White W.B. (1976): Cave minerals and speleothems.- IN: T.D. Ford and C. H.D. Cullingford (eds.): The science of Speleology. London: Academic Press, pp. 593.

White W.B. (1981): Reflectance spectra and colour in speleothems.- NSS Bull., 43, 20-26.

White W.B. (1988): Geomorphology and Hydrology of Karst Terrains.- New York: Oxford University Press, pp. 464.

Willems N. (1989): ESR-Datierungen ausgewählter Bodensinterprofile der Steinberg-Tropfsteinhöhle nahe Hunas.- Köln, unpublished Dipl. thesis, Cologne, pp. 97.

Wigley T.M.L., Brown M.C. (1976): The physics of caves. In: Ford, T.D., C.H.D. Cullingford (eds.). The Science of Speleology. Academic Press, London, 329-358.

Williams, P.W. (1975): Report on the conservation of Waitomo Caves.- NZ Speleological Bulletin, 5 (3), 373-396.

Williams P.W. (1983): The role of the subcutaneous zone in karst hydrology.- J. Hydrol., 61, 45 - 67.

Williams P.W., Marshall A., Ford D.C. and Jenkinson (1999): Paleoclimatic interpretation of stable isotope data from Holocene speleothems of the Waitomo district, North Island, New Zealand.- The Holocene, 9 (6), 649-657.

Winograd J.J ., Coplen T.B., Landwehr J.M., Riggs A.C., Ludwig K.R., Szabo B.J., Kolesar P.T., Reves Z.K.M. (1992): Continuous 500.000 year climate record from vein calcite in Devils Hole, Nevada.Science, 258, 227-231.

Wolfharth S. (1996): The chronology of the last termination: a review of radciocarbon-dated, highresolution terrestrial stratigraphies.- Quaternary Science Reviews, 15, 267-284.

Wrede V. (1996): Fremde Welten unter unseren Füßen. Was sind Höhlen?- IN: Im Reich der Dunkelheit- Höhlen und Höhlenforschung in Deutschland. -W. Rosendahl and E.-B. Krause (1996), Edition Archaea, pp. 159.

\section{$\underline{\mathbf{Y}}$}

Yonge C.J., Ford D.C., Gray J., Schwarcz H.P. (1985): Stable isotope studies of cave seepage water.Chemical Geology, 58, 97-105.

\section{$\underline{\mathbf{Z}}$}

Zeller E.J. and Wray J.L. (1956): Factors influencing the precipitation of calcium carbonate.- Bull. Am. Soc. Petrol. Geol., 40, 140-152. 


\section{The PhD study "Stable isotope investigations on speleothems from different cave systems in Germany" was realized thanks to}

my supervisors

Dr. B. Wiegand from the Stanford University (USA) for her inexhaustible commitment on the other side of the Atlantic and

Prof. Dr. B.T. Hansen from the Geoscience Center Goettingen (Germany)

my employers,

the German Research Foundation (DFG) and the University of Goettingen,

Prof. Dr. S. Kempe from the Inst. of Appl. Geosciences (Darmstadt, Germany) and Dr. W. Rosendahl from the Reiss-Engelhorn-Museum (Mannheim, Germany) for the first introduction to the German speleo-club scene and speleothem sampling.

the local speleo-clubs, especially the ARGE Grabenstetten e.V., the Karst-Group Mühlbach (KGM), and the employees/official cave administration of the Baumann's- and Hermann's-Cave, and the dedicated excavation team of the Paleocave Hunas for the accessibility of the sites, the provision of specific cave informations, samples, and logistics as well as for their support during the fieldwork and in caving techniques. Special thanks to S. Glaser for the Cave Mühlbach-samples, C. Fischer for the coordination and outstanding caving experience in the Zaininger-Cave as well as to S. Siegmar for his availability on often very short notice at the Baumann's- and Hermann's-Cave.

M. Bechtold, D. Christ and H. Stück for their contribution as student scientific employees and/or as Bachelor candidates within this project.

all colleagues from the Geoscience Center Goettingen helping with their critical discussion. Special thanks to Dr. K. Simon for his conceptual outlines on stable isotopes.

N. Gerbl, for his immense endurance to straighten out my "english for runaways".

Sensei S. Leijenhorst, S. Burger, A. Großmann, R. Stooß and all Karatekas of the IOGKF Dojo Goettingen for guidance on the path.

the home and members of the Turbojugend Goettingen for just being friends and support in everyday matters. Special thanks to Enne and Harry.

Soyoung and my family.

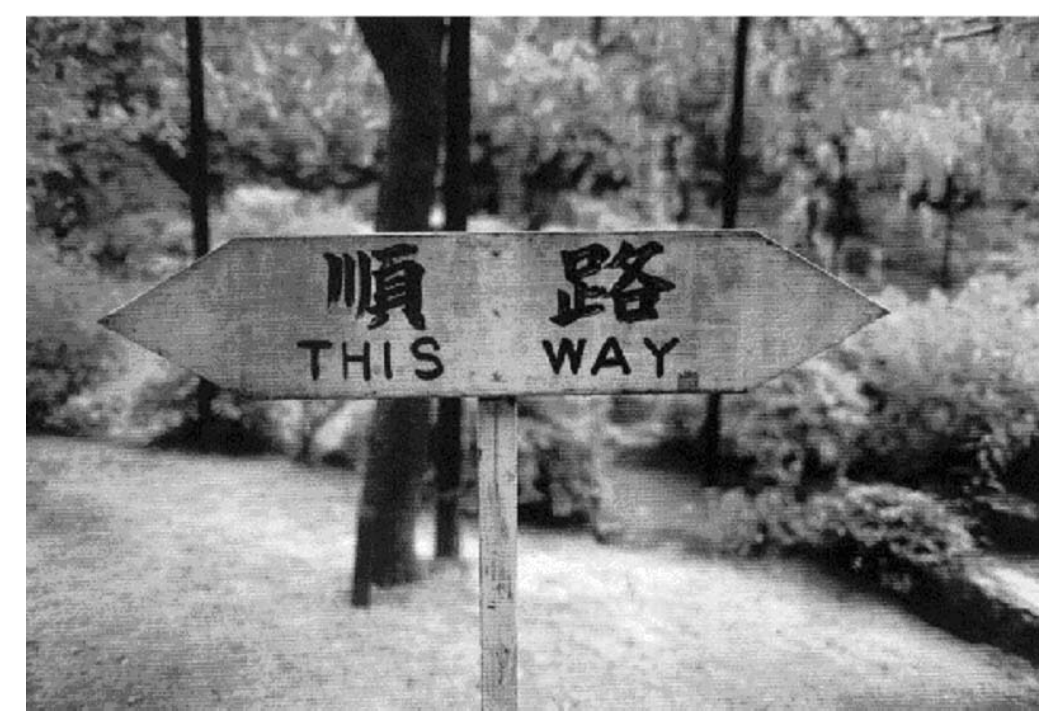




\section{$\underline{\text { Appendix }}$}

Appendix iv - 1:

Appendix iv - 2:

Appendix V - 1:

Appendix $v$ - 2:

Appendix. vii - 1.1:

Appendix vii - 1.2:

Appendix vii - 1.3:

Appendix vii - 1.4:

Appendix vii - 1.5:

Appendix vii - 2.1:

Appendix vii - 2.2:

Appendix vii - 2.3:

Appendix vii - 2.4:

Appendix vii - 2.5:

Appendix vii - 2.6:

Appendix vii - 2.7:

Appendix vii - 2.8:

Appendix vii - 2.9:

Appendix vii - 2.10:

Appendix vii - 2.11:

Appendix vii - 2.12:
Values obtained for the oxygen isotopic fractionation factor.

Values obtained for the carbon isotopic fractionation factor.

Schematic cross section of the Swabian Alb.

Stratigraphy and facies of the Upper Jurassic of the Swabian Alb.

Mean annual $\delta^{18} \mathrm{O}$ of rainwater at some German and selected European sites.

Mean monthly $\delta^{18} \mathrm{O}$ rainwater of stations closest to the investigated sites. Variation of mean annual air temperature and rel, air humidity. Cave climate data of the Zaininger-Cave for the icicle phenomenon. Stable oxygen and carbon isotopic abundances of dripwater, recent cave calcites and adjacent host rocks of the investigated sites.

Results ${ }^{234} \mathrm{U} /{ }^{230} \mathrm{Th}$ TIMS measurements.

Cave Hintere Kohlhalde stalagmite, results $\delta^{18} \mathrm{O}$ and $\delta^{13} \mathrm{C}$ measurements. Cave Hintere Kohlhalde stalagmite, $\delta^{18} \mathrm{O} / \delta^{13} \mathrm{C}$ single layers (Hendy-Test). Zaininger-Cave stalactite, results of $\delta^{18} \mathrm{O}$ and $\delta^{13} \mathrm{C}$ measurements. Zaininger-Cave stalagmite, results $\delta^{18} \mathrm{O}$ and $\delta^{13} \mathrm{C}$ measurements. Zaininger-Cave stalagmite, single layer $\delta^{18} \mathrm{O}$ and $\delta^{13} \mathrm{C}$ (Hendy-Tests). Paleocave Hunas stalagmite, results $\delta^{18} \mathrm{O}$ and $\delta^{13} \mathrm{C}$. Paleocave Hunas stalagmite, single layer $\delta^{18} \mathrm{O}$ and $\delta^{13} \mathrm{C}$ (Hendy-Tests). Mühlbach - Cave stalagmite, results $\delta^{18} \mathrm{O}$ and $\delta^{13} \mathrm{C}$ measurements. Mühlbach - Cave stalagmite, single layer $\delta^{18} \mathrm{O}$ and $\delta^{13} \mathrm{C}$ (Hendy-Tests). Baumann's - and Herrmann's - Cave stalagmites (lower), results $\delta^{18} \mathrm{O}$ and $\delta^{13} \mathrm{C}$ measurements.

Baumann's- and Herrmann's-Cave stalagmites, single layer $\delta^{18} \mathrm{O}$ and $\delta^{13} \mathrm{C}$ (Hendy-Tests). 


\begin{tabular}{|c|c|c|c|c|}
\hline Reference & $\begin{array}{l}\text { temperature } \\
\text { range }\end{array}$ & $1000 * \ln \alpha$ & $\alpha\left(\right.$ at $\left.25^{\circ} \mathrm{C}\right)$ & $\mathrm{da} / \mathrm{dT}\left(\% \circ /{ }^{\circ} \mathrm{C}\right)$ \\
\hline $\begin{array}{l}\text { O'Neil et al. } \\
1969\end{array}$ & $0-500^{\circ} \mathrm{C}$ & $2.78\left(10^{6} \mathrm{~T}\left({ }^{\circ} \mathrm{K}\right)^{-2}\right)-3.39$ & 1.02831 & -0.247 \\
\hline $\begin{array}{l}\text { Tarutani et al. } \\
1969\end{array}$ & $0-25^{\circ} \mathrm{C}$ & 28.1 & 1.02850 & -0.231 \\
\hline $\begin{array}{l}\text { Kim and } \\
\text { O'Neil } 1997\end{array}$ & $10-40^{\circ} \mathrm{C}$ & $18.03\left(10^{3} \mathrm{~T}\left({ }^{\circ} \mathrm{K}\right)^{-1}\right)-32.42$ & 1.02846 & -0.221 \\
\hline
\end{tabular}

Appendix iv - 1: Values obtained for the oxygen isotopic fractionation factor between water and calcite by precipitating calcite from a bicarbonate solution by removal of $\mathrm{CO}_{2}$ with a nitrogen flux.

\begin{tabular}{|c|c|c|c|}
\hline $1000 * \ln \alpha$ & $\mathrm{da} / \mathrm{dT}\left(\% \circ /{ }^{\circ} \mathrm{C}\right)$ & Method & Reference \\
\hline $10.17 \pm 0.18\left(20^{\circ} \mathrm{C}\right)$ & $-0.063 \pm 0.008\left(20^{\circ} \mathrm{C}\right)$ & data compilation & Emrich et al. 1970 \\
\hline $10.14\left(10^{\circ} \mathrm{C}\right)$ & $-0.07\left(5-15^{\circ} \mathrm{C}\right)$ & $\begin{array}{l}\text { calcite precip. from a carbon. } \\
\text { solution in isotopic equilib. with } \\
\mathrm{CO}_{2} \text { by } \mathrm{CO}_{2} \text { removal. }\end{array}$ & Dulinski and Rozanski 1990 \\
\hline $\begin{array}{l}11.98( \pm 0.13) \\
-0.12( \pm 0.01) * \mathrm{~T}\left({ }^{\circ} \mathrm{C}\right)\end{array}$ & $-0.12 \pm 0.1\left(10-40^{\circ} \mathrm{C}\right)$ & $\begin{array}{l}\text { calcite precip. from a } \mathrm{NaHCO}_{3}, \\
\mathrm{CaCl}_{2}, \mathrm{NaCl} \text { solution by removal } \\
\text { of } \mathrm{CO}_{2} \text {. }\end{array}$ & Romanek et al. 1992 \\
\hline
\end{tabular}

Appendix iv - 2: Values obtained for the carbon isotopic fractionation factor between dissolved $\mathrm{CO}_{2}$ and calcite. 


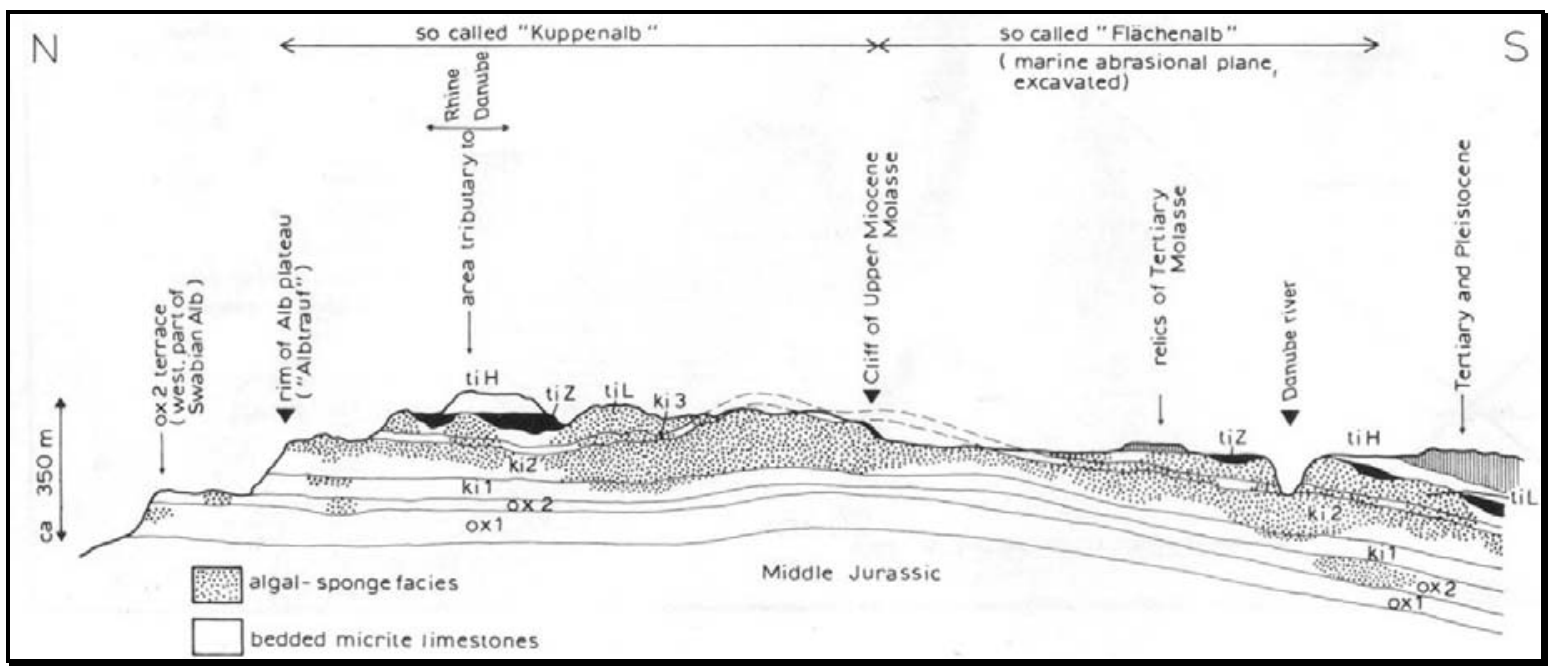

Appendix v - 1: Schematic cross section of the Swabian Alb (GWINNER, 1976).

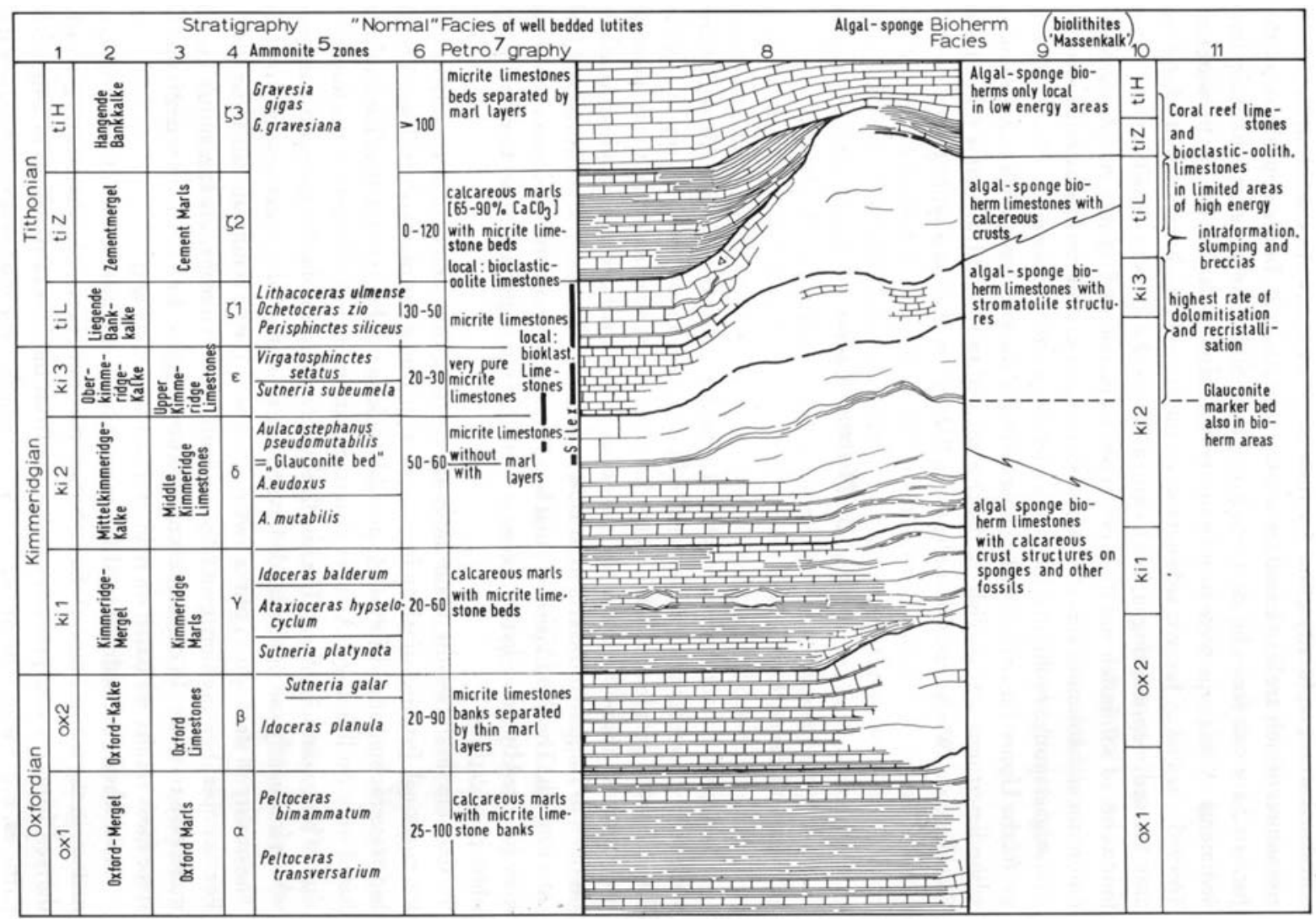

Appendix $v$ - 2:

Stratigraphy and facies of the Upper Jurassic of the Swabian Alb (GWINNER 1976).

columns 1, 2, and 10: stratigraphy now used on geological maps and in this paper.

column 3: English translation used in this paper.

column 6: thickness of bedded sediments ("normal facies").

column 8: schematic profile, also illustrating the distribution of micritic and bioherm sediments.

column 11: remarks. 


\begin{tabular}{|c|c|c|c|c|c|c|c|c|}
\hline Country & Stations IAEA/WMO & Latitude & Longitude & $\begin{array}{r}\text { Altitude } \\
\text { (m.a.s.I.) }\end{array}$ & $\begin{array}{r}\text { w.m } \delta^{18} \mathrm{O} \\
(\% \circ \\
\text { vs.VSMOW) }\end{array}$ & $\mathrm{T}\left({ }^{\circ} \mathrm{C}\right)$ & $\begin{array}{l}\text { Prec. } \\
(\mathrm{mm})\end{array}$ & $\begin{array}{r}\text { ipl.Period } \\
\text { (year) }\end{array}$ \\
\hline Germany & Bad Salzuflen & $52.10 \mathrm{~N}$ & $8.73 \mathrm{E}$ & 100 & -8.22 & 8.8 & 859 & 1978-87 \\
\hline Germany & Berlin & $52.47 \mathrm{~N}$ & $13.40 \mathrm{E}$ & 50 & -8.67 & 8.7 & 584 & 1978-87 \\
\hline Germany & Braunschweig & $52.30 \mathrm{~N}$ & $10.45 \mathrm{E}$ & 88 & -8.1 & 8.3 & 643 & 1978-87 \\
\hline Germany & Cuxhaven & $53.87 \mathrm{~N}$ & $8.72 \mathrm{E}$ & 12 & -7.29 & 8.3 & 829 & 1978-87 \\
\hline Germany & Emmerich & $51.83 \mathrm{~N}$ & $6.60 \mathrm{E}$ & 43 & -7.3 & 9.1 & 744 & 1980-87| - - - \\
\hline Germany & Feldberg/Schw.wald & $47.52 \mathrm{~N}$ & 8.00E & 1493 & -10.59 & 3.1 & 1879 & 1981-85 \\
\hline Germany & Garmisch-Part. & $47.48 \mathrm{~N}$ & $11.07 \mathrm{E}$ & 720 & -10.95 & 6.4 & 1383 & 1978-87 \\
\hline Germany & Hof-Hohensaas & $50.32 \mathrm{~N}$ & $11.88 \mathrm{E}$ & 567 & -9.3 & 6.2 & 738 & 1983-87 \\
\hline Germany & Hohenpeisenberg & $47.8 \mathrm{~N}$ & $11.02 \mathrm{E}$ & 977 & -11.38 & 6.5 & 1053 & 1974-87 \\
\hline Germany & Karlsruhe & $49.02 \mathrm{~N}$ & $8.38 \mathrm{E}$ & 120 & -8.48 & 9.8 & 851 & 1981-87 \\
\hline Germany & Koblenz & $50.35 \mathrm{~N}$ & $7.58 \mathrm{E}$ & 97 & -7.45 & 10.2 & 637 & 1981-87 \\
\hline Germany & Konstanz & $47.68 \mathrm{~N}$ & $9.18 \mathrm{E}$ & 447 & -10.18 & 8.8 & 873 & 1978-87 \\
\hline Germany & Leipzig & $51.35 \mathrm{~N}$ & $12.43 \mathrm{E}$ & 125 & -9.41 & 9 & 552 & 1986-87 \\
\hline Germany & Regensburg & $49.02 \mathrm{~N}$ & 12.07E & 377 & -10.02 & 7.7 & 639 & 1978-87 \\
\hline Germany & Stuttgart & $48.83 \mathrm{~N}$ & $9.2 \mathrm{E}$ & 315 & -8.01 & 9.3 & 655 & 1961-87 \\
\hline Germany & Trier & $49.75 \mathrm{~N}$ & $6.07 \mathrm{E}$ & 273 & -7.75 & 8.7 & 829 & 1978-87 \\
\hline Germany & Wasserkuppe Rhön & $50.5 \mathrm{~N}$ & $9.95 \mathrm{E}$ & 921 & -9.78 & 4.2 & 1127 & 1978-87 \\
\hline Germany & Würzburg & $49.80 \mathrm{~N}$ & $9.90 \mathrm{E}$ & 259 & -8.1 & 8.3 & 612 & 1978-87| \\
\hline \multicolumn{9}{|c|}{ Selected European stations: } \\
\hline \multicolumn{2}{|c|}{ Netherlands Groningen } & $53.21 \mathrm{~N}$ & $6.57 \mathrm{E}$ & $\overline{0}$ & -7.84 & 9.5 & $\overline{758}$ & 1964-87 \\
\hline Belgium & Liège & $50.7 \mathrm{~N}$ & $5.5 \mathrm{E}$ & 190 & \multicolumn{2}{|c|}{-6.8 no data } & 821 & $1966-70$ \\
\hline France & Brest & 52.07 & 23.41E & 142 & -9.4 & 8.5 & 591 & 1980-83 \\
\hline Austria & Vienna (Hohe Warte) & $48.65 \mathrm{~N}$ & 123.43W & 20 & -10.31 & 10.7 & 909 & 1961-87 \\
\hline Poland & Krakow & $50.07 \mathrm{~N}$ & $19.88 \mathrm{E}$ & 205 & -9.35 & 7.7 & 619 & $1975-87$ \\
\hline
\end{tabular}

Appendix. vii - 1.1: Mean annual $\delta^{18} \mathrm{O}$ of rainwater at some German and selected European sites (IAEA data, ROZANSKI et al. 1993).

\begin{tabular}{|c|c|c|c|c|c|c|c|c|c|}
\hline \multirow{3}{*}{ Period } & \multicolumn{3}{|c|}{ Stuttgart (Cannstatt) } & \multicolumn{3}{|c|}{ Regensburg } & \multicolumn{3}{|c|}{ Braunschweig } \\
\hline & $1962-99$ & $1962-99$ & $1962-99$ & $1978-2000$ & $1984-2000$ & $1984-2000$ & $1978-2000$ & $1987-2000$ & $1987-2000$ \\
\hline & $\begin{array}{c}\delta^{18} \mathrm{O}(\% \circ \text { vs. } \\
\text { VSMOW) }\end{array}$ & $\begin{array}{l}\text { Air T } \\
\left({ }^{\circ} \mathrm{C}\right)\end{array}$ & $\begin{array}{c}\text { Precip. } \\
\text { (mm) }\end{array}$ & $\begin{array}{c}\delta^{18} \mathrm{O}(\% \text { vs. } \\
\text { VSMOW) }\end{array}$ & $\begin{array}{l}\text { Air T } \\
\left({ }^{\circ} \mathrm{C}\right) \\
\end{array}$ & $\begin{array}{l}\text { Precip. } \\
\text { (mm) }\end{array}$ & $\begin{array}{c}\delta^{18} \mathrm{O}(\% \circ \mathrm{vs} . \\
\text { VSMOW) }\end{array}$ & $\begin{array}{l}\text { Air T } \\
\left({ }^{\circ} \mathrm{C}\right)\end{array}$ & $\begin{array}{l}\text { Precip. } \\
\text { (mm) }\end{array}$ \\
\hline January & -10.3 & 0.9 & 37 & -12.0 & -0.7 & 37 & -8.8 & 2.0 & 43 \\
\hline February & -10.6 & 2.0 & 34 & -12.3 & -0.4 & 36 & -8.0 & 1.2 & 36 \\
\hline March & -9.1 & 5.6 & 41 & -10.3 & 3.9 & 41 & -8.1 & 5.4 & 54 \\
\hline April & -8.8 & 9.5 & 50 & -10.7 & 8.9 & 37 & -7.3 & 9.2 & 41 \\
\hline May & -7.1 & 13.7 & 79 & -8.6 & 14.3 & 57 & -6.4 & 14.2 & 48 \\
\hline June & -6.5 & 16.7 & 90 & -7.6 & 16.2 & 78 & -6.4 & 15.7 & 67 \\
\hline July & -5.5 & 18.6 & 67 & -7.2 & 18.2 & 85 & -5.5 & 17.6 & 61 \\
\hline August & -5.6 & 18.2 & 72 & -6.9 & 17.8 & 63 & -6.4 & 17.1 & 67 \\
\hline September & -6.7 & 14.8 & 57 & -7.4 & 13.2 & 57 & -6.2 & 13.3 & 48 \\
\hline October & -8.2 & 10.0 & 44 & -9.5 & 8.1 & 52 & -7.9 & 9.5 & 47 \\
\hline November & -10.0 & 4.9 & 46 & -11.5 & 3.2 & 50 & -8.4 & 4.8 & 50 \\
\hline December & -10.4 & 1.7 & 44 & -11.4 & 0.1 & 56 & -8.7 & 2.5 & 58 \\
\hline
\end{tabular}

Appendix vii - 1.2: Mean monthly $\delta^{18} \mathrm{O}$ rainwater of stations closest to the investigated sites (IAEA/WMO 2001). 


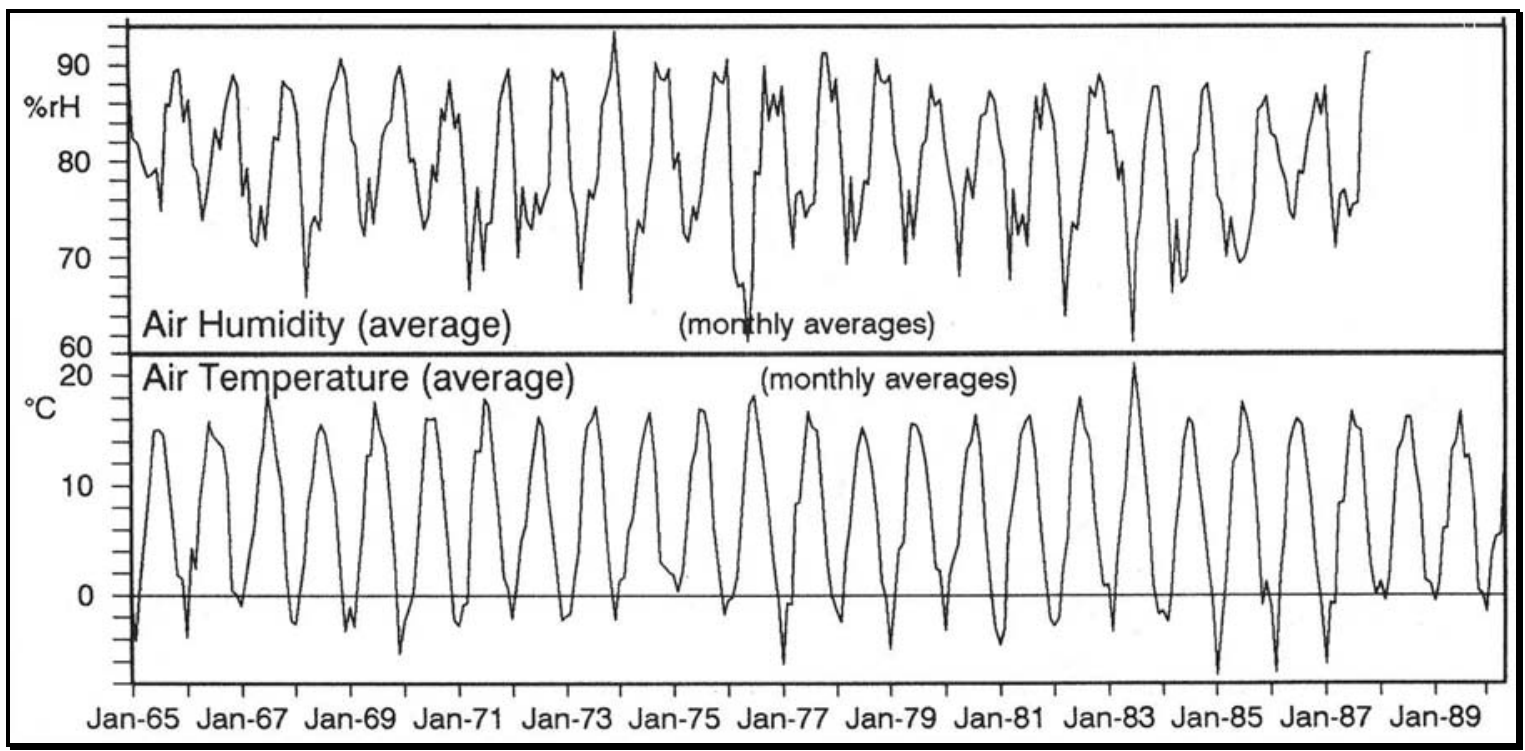

Appendix vii - 1.3: Variation of mean annual air temperature and rel, air humidity (SAUTER 1992).

\begin{tabular}{|c|c|c|c|c|c|c|}
\hline \multirow[t]{2}{*}{ Samstag, 1. März 2003} & \multicolumn{2}{|c|}{ Oberfläche Steinbruch Rösch } & \multicolumn{2}{|c|}{ ZH "Tropfsteinhalle" } & \multicolumn{2}{|c|}{ Lehmxylofon } \\
\hline & $\mathrm{T}\left({ }^{\circ} \mathrm{C}\right)$ & rel. hum. (\%) & $\mathrm{T}\left({ }^{\circ} \mathrm{C}\right)$ & rel. hum. (\%) & $\mathrm{T}\left({ }^{\circ} \mathrm{C}\right)$ & rel. hum. (\%) \\
\hline 13:15 & 4.9 & 69.4 & 1.8 & 92.6 & 8.5 & 93.9 \\
\hline $13: 30$ & 4.4 & 69.4 & 1.8 & 93.5 & 7.5 & 98.5 \\
\hline $13: 45$ & 4.1 & 68.5 & 1.8 & 93 & 6.9 & 99.9 \\
\hline $14: 00$ & 3.9 & 69.9 & 1.8 & 93.9 & 6.7 & 100.8 \\
\hline $14: 15$ & 3.9 & 72.1 & 1.8 & 94.4 & 6.4 & 101.7 \\
\hline $14: 30$ & 3.4 & 71.7 & 1.6 & 94.9 & 6.7 & 102.6 \\
\hline $14: 45$ & 3.6 & 69.4 & 1.6 & 95.8 & 6.7 & 102.6 \\
\hline $15: 00$ & 3.4 & 71.7 & 1.6 & 95.8 & 6.2 & 102.6 \\
\hline $15: 15$ & 3.4 & 70.8 & 1.3 & 95.8 & 6.4 & 103.1 \\
\hline $15: 30$ & 3.4 & 73 & 1.3 & 95.8 & 6.7 & 103.5 \\
\hline $15: 45$ & 3.4 & 70.3 & 1.3 & 96.2 & 6.4 & 103.5 \\
\hline $16: 00$ & 3.4 & 70.8 & 1.3 & 96.7 & 6.7 & 104 \\
\hline $16: 15$ & 3.4 & 71.7 & 1.3 & 97.6 & 6.4 & 104 \\
\hline $16: 30$ & 3.1 & 72.1 & 1.3 & 98.1 & 6.7 & 104.9 \\
\hline $16: 45$ & 3.1 & 72.1 & 1.3 & 98.1 & 6.6 & 105.4 \\
\hline $17: 00$ & 3.4 & 71.7 & 1.1 & 98.1 & 6.7 & 104.3 \\
\hline $17: 15$ & 3.4 & 73.9 & 1.1 & 98.5 & 6.7 & 104.8 \\
\hline $17: 30$ & 3.4 & 71.2 & 1.4 & 98.5 & 6.6 & 105.1 \\
\hline 18:00 & 3.1 & 71.2 & 1.4 & 98.5 & 6.7 & 104.9 \\
\hline
\end{tabular}

Appendix vii - 1.4: Cave climate data of the Zaininger-Cave for the icicle phenomenon observed during the sample session in March 2003. 


\begin{tabular}{|c|c|c|c|c|c|c|c|c|c|c|}
\hline Cave & Sample ID & $\begin{array}{l}\delta^{18} \mathrm{O} \\
\text { (oloo vs. } \\
\text { VSMOW) }\end{array}$ & $\begin{array}{l}\delta^{18} \mathrm{o} \\
1 \mathrm{~s}\end{array}$ & $\begin{array}{l}\delta^{18} \mathrm{O} \\
\text { (o/oo vs. } \\
\text { VPDB) }\end{array}$ & $\begin{array}{l}\delta^{18} \mathrm{O} \\
1 \mathrm{~s}\end{array}$ & $\begin{array}{l}\delta^{13} \mathrm{C} \\
\text { (o/oo vs. } \\
\text { VPDB) }\end{array}$ & $\begin{array}{l}\delta^{13} \mathrm{C} \\
1 \mathrm{~s}\end{array}$ & $\begin{array}{l}\text { oD } \\
\text { (o/oo vs. } \\
\text { vSMOW) }\end{array}$ & $\begin{array}{l}\delta^{18} \mathrm{O} \\
1 \mathrm{~s}\end{array}$ & $\begin{array}{l}\text { Dolomite } \\
\text { acid } \\
\text { fractionation } \\
\text { corrected }\end{array}$ \\
\hline \multicolumn{11}{|l|}{$\begin{array}{l}\text { Zaininger- } \\
\text { Cave }\end{array}$} \\
\hline Dripwater & ZH-VIII-TW & -11.30 & 0.04 & & & & & -78.92 & 0.15 & \\
\hline Dripwater & ZH-X-TW & -11.69 & 0.02 & & & & & -82.09 & 0.12 & \\
\hline Dripwater & ZH-XII-TW & -10.50 & 0.02 & & & & & -72.05 & 0.24 & \\
\hline $\begin{array}{l}\text { Recent cave } \\
\text { calcite } \\
\text { precipitates }\end{array}$ & ZH-STK-rez & & & -7.02 & 0.01 & -8.94 & 0.01 & & & \\
\hline Hostrock & ZH-UG-01 & & & -5.66 & 0.01 & -5.10 & 0.01 & & & \\
\hline Hostrock & ZH-UG-02 & & & -6.19 & 0.03 & -5.10 & 0.01 & & & \\
\hline Hostrock & ZH-UG-3 & & & -2.90 & 0.01 & 1.24 & 0.01 & & & \\
\hline \multicolumn{11}{|l|}{$\begin{array}{l}\text { Cave } \\
\text { Hintere } \\
\text { Kohlhalde }\end{array}$} \\
\hline $\begin{array}{l}\text { Recent cave } \\
\text { calcite } \\
\text { precipitates }\end{array}$ & HKH-STK-rez & & & -8.03 & 0.02 & -5.48 & 0.02 & & & \\
\hline Hostrock & HKH-UG 1 & & & -5.70 & 0.02 & -3.83 & 0.01 & & & \\
\hline \multicolumn{11}{|l|}{$\begin{array}{l}\text { Mühlbach } \\
\text {-Cave }\end{array}$} \\
\hline Hostrock & MH-UG 1 & & & -2.32 & 0.02 & 2.45 & 0.01 & & & -3.95 \\
\hline Hostrock & MH-UG 2 & & & -3.15 & 0.03 & 2.04 & 0.02 & & & \\
\hline Hostrock & MH-UG-3 & & & -3.03 & 0.01 & 2.22 & 0.02 & & & \\
\hline \multicolumn{11}{|l|}{$\begin{array}{l}\text { Baumann's } \\
\text {-Cave }\end{array}$} \\
\hline Dripwater & $\mathrm{BH} 02$ & -9.28 & 0.04 & & & & & -63.12 & 0.19 & \\
\hline Dripwater & $\mathrm{BH} 03$ & -8.95 & 0.03 & & & & & -60.71 & 0.38 & \\
\hline Dripwater & $\mathrm{BH} 04$ & -8.80 & 0.03 & & & & & -61.05 & 0.31 & \\
\hline \multirow{3}{*}{$\begin{array}{l}\text { Recent cave } \mathrm{B} \\
\text { calcite } \\
\text { precipitates }\end{array}$} & BH-STK-02 & & & -7.55 & 0.01 & -9.88 & 0.01 & & & \\
\hline & BH-STK-03 & & & -7.72 & 0.02 & -8.82 & 0.01 & & & \\
\hline & BH-STK-04 & & & -7.17 & 0.01 & -8.52 & 0.01 & & & \\
\hline Hostrock & BH-UG-01 & & & -6.79 & 0.02 & 1.15 & 0.01 & & & \\
\hline \multicolumn{11}{|l|}{$\begin{array}{l}\text { Hermann's } \\
\text {-Cave }\end{array}$} \\
\hline Dripwater & $\mathrm{HH} 01$ & -8.99 & 0.03 & & & & & -60.17 & 0.53 & \\
\hline Dripwater & $\mathrm{HH} 02$ & -9.08 & 0.01 & & & & & -62.35 & 0.46 & \\
\hline Dripwater & $\mathrm{HH} 03$ & -8.77 & 0.04 & & & & & -59.67 & 0.64 & \\
\hline \multirow{3}{*}{$\begin{array}{l}\text { Recent cave } \\
\text { calcite } \\
\text { precipitates }\end{array}$} & HH-STK-04 & & & -7.44 & 0.02 & -8.99 & 0.01 & & & \\
\hline & HH-STK-05 & & & -7.01 & 0.01 & -8.57 & 0.01 & & & \\
\hline & HH-STK-06 & & & -7.32 & 0.02 & -9.95 & 0.02 & & & \\
\hline Hostrock & HH-UG-01 & & & -8.89 & 0.02 & 1.67 & 0.01 & & & \\
\hline
\end{tabular}

Appendix vii - 1.5: Stable oxygen and carbon isotopic abundances of dripwater, recent cave calcites and adjacent host rocks of the investigated sites. 


\begin{tabular}{|c|c|c|c|c|c|c|c|c|c|c|c|c|c|}
\hline $\begin{array}{l}\text { Sample } \\
\text { ID }\end{array}$ & Site & Age & $\begin{array}{c}\text { uncert. } \\
{[+l-]}\end{array}$ & $\begin{array}{c}\mathbf{U} \\
{[\mathrm{mg} / \mathrm{kg}]}\end{array}$ & $2 \sigma$ & $\begin{array}{c}\text { Th } \\
{[\mu \mathrm{g} / \mathrm{kg}]}\end{array}$ & $2 \sigma$ & $\begin{array}{l}\left(\left.{ }^{234} \mathrm{U}\right|^{238} \mathrm{U}\right. \\
\text { act.ratic }\end{array}$ & $2 \sigma$ & $\left(\begin{array}{l}\left({ }^{230} \mathrm{Th} /{ }^{234} \mathrm{U}\right) \\
\text { act.ratio }\end{array}\right.$ & $2 \sigma$ & $\left(\begin{array}{c}\left.{ }^{230} \mathrm{Th} /{ }^{232} \mathrm{Th}\right) \\
\text { act.ratio }\end{array}\right.$ & $2 \sigma$ \\
\hline $\mathrm{BH}-\mathrm{i}$ & & 135623 & 8886 & 0.140 & 0.001 & 19.712 & 0.260 & 1.453 & 0.016 & 0.761 & 0.025 & 23.900 & 0.823 \\
\hline $\mathrm{BH}-\mathrm{ii}$ & & 77295 & 5280 & 0.088 & 0.001 & 3.597 & 0.012 & 1.294 & 0.016 & 0.521 & 0.024 & 49.976 & 2.267 \\
\hline $\mathrm{BH}$-iii & Baumann's & 236340 & 16429 & 0.091 & 0.001 & 5.897 & 0.024 & 1.323 & 0.011 & 0.944 & 0.020 & 58.796 & 1.182 \\
\hline $\mathrm{BH}-\mathrm{iv}$ & Cave & 232474 & 40141 & 0.059 & 0.001 & 3.719 & 0.046 & 1.392 & 0.025 & 0.948 & 0.048 & 63.267 & 3.258 \\
\hline $\mathrm{BH}-\mathrm{v}$ & & 78020 & 6346 & 0.115 & 0.002 & 7.721 & 0.112 & 1.446 & 0.058 & 0.529 & 0.026 & 34.540 & 1.256 \\
\hline BH-vi & & 167933 & 8959 & 0.064 & 0.001 & 2.411 & 0.010 & 1.537 & 0.011 & 0.843 & 0.020 & 104.697 & 2.494 \\
\hline $\mathrm{HH}-\mathrm{i}$ & & 23130 & 711 & 0.251 & 0.005 & 8.471 & 0.001 & 1.209 & 0.024 & 0.193 & 0.002 & 20.909 & 0.066 \\
\hline $\mathrm{HH}-\mathrm{ii}$ & $\begin{array}{l}\text { Hermann's } \\
\text { Cave }\end{array}$ & 8726 & 240 & 0.152 & 0.001 & 0.12 & 0.003 & 1.222 & 0.017 & 0.077 & 0.002 & 365.437 & 12.879 \\
\hline $\mathrm{HH}$-iii & & 24260 & 568 & 0.196 & 0.001 & 0.769 & 0.002 & 1.226 & 0.010 & 0.201 & 0.004 & 190.919 & 3.600 \\
\hline HKH-i & & 44158 & 3329 & 0.083 & 0.002 & 2.140 & 0.006 & 0.980 & 0.044 & 0.333 & 0.016 & 38.315 & 1.150 \\
\hline $\mathrm{HKH}-\mathrm{ii}$ & & 25909 & 4061 & 0.031 & 0.001 & 0.464 & 0.016 & 1.195 & 0.093 & 0.213 & 0.027 & 51.278 & 5.833 \\
\hline HKH-iii & & 18979 & 1922 & 0.103 & 0.001 & 0.527 & 0.027 & 1.019 & 0.027 & 0.160 & 0.015 & 96.917 & 9.874 \\
\hline $\mathrm{HKH}-\mathrm{V}$ & Hin & 16146 & 1802 & 0.062 & 0.001 & 0.723 & 0.007 & 1.690 & 0.011 & 0.139 & 0.015 & 60.804 & 6.364 \\
\hline HKH-vii & & 8632 & 846 & 0.059 & 0.001 & 1.096 & 0.031 & 1.131 & 0.041 & 0.076 & 0.007 & 14.161 & 1.261 \\
\hline HKH-xiii & & 2709 & 303 & 0.071 & 0.001 & 1.279 & 0.006 & 0.914 & 0.014 & 0.025 & 0.003 & 3.803 & 0.414 \\
\hline $\mathrm{ZH}-\mathrm{i}$ & $\begin{array}{l}\text { Zaininger } \\
\text { Cave }\end{array}$ & 71220 & 13937 & 0.043 & 0.001 & 1.513 & 0.008 & 2.917 & 0.093 & 0.511 & 0.076 & 127.058 & 18.446 \\
\hline ZH-vii & STM & $?$ & ? & 0.023 & 0.001 & 0.813 & 0.005 & & & & & & \\
\hline ZH STK-i & $\begin{array}{l}\text { Zaininger } \\
\text { Cave }\end{array}$ & 11674 & 6092 & 0.031 & 0.001 & 0.283 & 0.003 & 0.210 & 0.024 & 0.104 & 0.052 & 70.994 & 35.512 \\
\hline ZH STK-V & iSTK & 2772 & 215 & 0.039 & 0.001 & 0.654 & 0.003 & 0.054 & 0.019 & 0.025 & 0.002 & 9.772 & 0.780 \\
\hline $\mathrm{HU}-\mathrm{i}$ & & 79373 & 8237 & 0.152 & 0.001 & 0.236 & 0.022 & 1.058 & 0.039 & 0.521 & 0.036 & 1072.320 & 117.333 \\
\hline HU-V & & 77877 & 9209 & 0.174 & 0.002 & 0.426 & 0.022 & 1.064 & 0.060 & 0.515 & 0.039 & 679.681 & 49.938 \\
\hline HU-ix & Pale & 76872 & 9686 & 0.208 & 0.001 & 0.738 & 0.026 & 1.089 & 0.033 & 0.511 & 0.044 & 475.512 & 41.894 \\
\hline $\mathrm{HU}-\mathrm{i}(\mathrm{b})$ & Huna & 270593 & 24379 & 0.113 & 0.001 & 0.291 & 0.002 & 1.089 & 0.009 & 0.939 & 0.018 & 1200.234 & 23.052 \\
\hline HU-Si3 & & 116350 & 31389 & 0.057 & 0.002 & 2.563 & 0.016 & 1.006 & 0.045 & 0.658 & 0.092 & 44.472 & 6.037 \\
\hline HU-Si3 & & & $?$ & 0.033 & 0.001 & 6.685 & 0.026 & & & & & & \\
\hline MH-i & Mühlt & 11278 & 282 & 0.522 & 0.002 & 16.532 & 0.088 & 1.843 & 0.013 & 0.099 & 0.002 & 17.537 & 0.404 \\
\hline MH-x & Cave & 2512 & 139 & 0.25 & 0.007 & 11.27 & 0.136 & 8.821 & 0.304 & 0.025 & 0.001 & 14.977 & 0.356 \\
\hline
\end{tabular}

Appendix vii - 2.1: Results ${ }^{234} \mathrm{U} /{ }^{230} \mathrm{Th}$ TIMS measurements, kindly provided by Dr. B. Wiegand, Stanford University (USA). 


\begin{tabular}{|c|c|c|c|c|c|c|c|c|c|c|c|}
\hline $\begin{array}{l}\text { HKH-1 } \\
\text { STM }\end{array}$ & $\begin{array}{c}\text { Distance } \\
\text { from base } \\
\text { [mm] }\end{array}$ & $\begin{array}{l}\delta^{13} \mathrm{C} \\
\text { VPDB } \\
\text { [o/oo] }\end{array}$ & $\begin{array}{c}\text { std.dev. } \\
\text { [o/oo] }\end{array}$ & $\begin{array}{c}\delta^{18} O \\
\text { VPDB } \\
\text { [o/oo] }\end{array}$ & $\begin{array}{c}\text { std.dev. } \\
\text { [o/oo] }\end{array}$ & $\underset{\text { ID }}{\text { Sample }}$ & $\begin{array}{c}\text { Distance } \\
\text { from base } \\
{[\mathrm{mm}]}\end{array}$ & $\begin{array}{c}\delta^{13} \mathrm{C} \\
\text { VPDB } \\
\text { [o/oo] }\end{array}$ & $\begin{array}{c}\text { std.dev. } \\
\text { [o/oo] }\end{array}$ & $\begin{array}{l}\delta^{18} O \\
\text { VPDB } \\
\text { [o/oo] }\end{array}$ & $\begin{array}{c}\text { std.dev. } \\
\text { [o/oo] }\end{array}$ \\
\hline KH 1 & 5.0 & -6.18 & 0.02 & -7.28 & 0.02 & KH 65 & 582.0 & -7.34 & 0.01 & -7.20 & 0.02 \\
\hline KH 2 & 10.0 & -6.68 & 0.01 & -7.47 & 0.03 & KH 66 & 592.0 & -7.74 & 0.04 & -7.66 & 0.07 \\
\hline KH 3 & 15.0 & -7.11 & 0.02 & -7.61 & 0.02 & KH 67 & 602.0 & -8.54 & 0.01 & -7.55 & 0.01 \\
\hline KH 4 & 21.0 & -7.70 & 0.01 & -8.00 & 0.02 & KH 68 & 612.0 & -8.44 & 0.03 & -7.83 & 0.03 \\
\hline KH 5 & 26.0 & -8.02 & 0.01 & -7.77 & 0.01 & KH 69 & 620.5 & -7.99 & 0.02 & -7.82 & 0.02 \\
\hline KH 6 & 32.0 & -6.90 & 0.02 & -7.88 & 0.01 & KH 70 & 629.0 & -6.28 & 0.01 & -7.45 & 0.03 \\
\hline KH 7 & 36.5 & -7.02 & 0.01 & -7.31 & 0.02 & KH 71 & 639.0 & -6.67 & 0.01 & -7.20 & 0.01 \\
\hline KH 8 & 43.0 & -7.93 & 0.00 & -8.07 & 0.02 & KH 72 & 651.5 & -7.30 & 0.03 & -7.71 & 0.04 \\
\hline KH 9 & 47.5 & -7.61 & 0.01 & -8.06 & 0.02 & KH 73 & 661.5 & -8.18 & 0.01 & -8.06 & 0.02 \\
\hline KH 10 & 53.0 & -7.78 & 0.01 & -7.75 & 0.03 & KH 74 & 676.5 & -6.88 & 0.03 & -7.37 & 0.04 \\
\hline KH 11 & 58.0 & -8.44 & 0.01 & -7.91 & 0.02 & KH 75 & 690.0 & -6.58 & 0.02 & -7.70 & 0.04 \\
\hline KH 12 & 63.0 & -7.77 & 0.02 & -7.74 & 0.02 & KH 76 & 703.0 & -7.28 & 0.01 & -7.75 & 0.02 \\
\hline KH 13 & 68.0 & -7.99 & 0.01 & -7.26 & 0.01 & KH 77 & 713.0 & -7.35 & 0.01 & -7.46 & 0.01 \\
\hline KH 14 & 74.0 & -8.50 & 0.04 & -7.43 & 0.06 & KH 78 & 723.0 & -8.00 & 0.01 & -7.72 & 0.01 \\
\hline KH 15 & 79.0 & -8.36 & 0.01 & -7.64 & 0.01 & KH 79 & 733.0 & -7.51 & 0.01 & -8.18 & 0.02 \\
\hline KH 16 & 84.0 & -7.46 & 0.01 & -7.61 & 0.01 & KH 80 & 744.0 & -7.53 & 0.01 & -7.25 & 0.02 \\
\hline KH 17 & 89.0 & -7.50 & 0.00 & -7.38 & 0.00 & KH 81 & 753.0 & -8.48 & 0.02 & -7.55 & 0.04 \\
\hline KH 18 & 94.0 & -8.13 & 0.00 & -7.70 & 0.01 & KH 82 & 763.0 & -7.42 & 0.01 & -7.21 & 0.02 \\
\hline KH 19 & 99.0 & -7.08 & 0.02 & -7.63 & 0.03 & KH 83 & 768.5 & -8.17 & 0.02 & -7.29 & 0.02 \\
\hline KH 20 & 104.0 & -5.76 & 0.01 & -7.03 & 0.02 & KH 84 & 778.5 & -7.90 & 0.01 & -7.97 & 0.03 \\
\hline KH 21 & 109.0 & -8.00 & 0.01 & -7.76 & 0.04 & KH 85 & 788.5 & -8.76 & 0.03 & -7.89 & 0.03 \\
\hline KH 22 & 113.0 & -6.16 & 0.01 & -6.89 & 0.02 & KH 86 & 798.5 & -7.76 & 0.01 & -8.30 & 0.03 \\
\hline KH 23 & 122.0 & -5.55 & 0.01 & -7.35 & 0.01 & KH 87 & 811.0 & -8.08 & 0.02 & -7.97 & 0.02 \\
\hline KH 24 & 129.0 & -7.03 & 0.02 & -7.32 & 0.04 & KH 88 & 821.0 & -8.21 & 0.01 & -7.09 & 0.02 \\
\hline KH 25 & 138.0 & -7.91 & 0.01 & -7.58 & 0.02 & KH 89 & 829.0 & -7.43 & 0.03 & -7.60 & 0.03 \\
\hline KH 26 & 148.0 & -8.54 & 0.01 & -8.02 & 0.02 & KH 90 & 854.5 & -9.20 & 0.02 & -7.29 & 0.03 \\
\hline KH 27 & 159.0 & -5.72 & 0.01 & -7.01 & 0.02 & KH 91 & 856.0 & -8.13 & 0.01 & -7.76 & 0.02 \\
\hline KH 28 & 167.0 & -7.41 & 0.02 & -7.48 & 0.02 & KH 92 & 866.0 & -7.41 & 0.01 & -7.51 & 0.01 \\
\hline KH 29 & 174.0 & -7.34 & 0.01 & -7.26 & 0.01 & KH 93 & 876.0 & -7.54 & 0.02 & -8.08 & 0.04 \\
\hline KH 30 & 182.0 & -8.48 & 0.01 & -7.75 & 0.03 & KH 94 & 886.0 & -7.01 & 0.02 & -8.03 & 0.01 \\
\hline KH 31 & 192.0 & -8.15 & 0.02 & -6.94 & 0.02 & KH 95 & 896.0 & -6.59 & 0.01 & -7.96 & 0.02 \\
\hline KH 32 & 206.5 & -8.44 & 0.02 & -8.18 & 0.02 & KH 96 & 903.0 & -6.99 & 0.02 & -8.46 & 0.02 \\
\hline KH 33 & 217.0 & -6.77 & 0.02 & -6.97 & 0.03 & KH 97 & 913.0 & -7.82 & 0.02 & -8.06 & 0.02 \\
\hline KH 34 & 224.0 & -6.38 & 0.01 & -7.03 & 0.02 & KH 98 & 923.5 & -8.92 & 0.01 & -8.32 & 0.02 \\
\hline KH 35 & 233.0 & -9.16 & 0.01 & -7.83 & 0.03 & KH 99 & 933.5 & -7.85 & 0.01 & -8.21 & 0.01 \\
\hline KH 36 & 245.0 & -7.78 & 0.01 & -7.43 & 0.01 & |KH 100 & 943.5 & -8.89 & 0.02 & -8.37 & 0.03 \\
\hline KH 37 & 256.5 & -8.86 & 0.02 & -7.94 & 0.03 & |KH 101 & 953.5 & -7.61 & 0.01 & -7.63 & 0.02 \\
\hline KH 38 & 267.0 & -8.19 & 0.02 & -7.35 & 0.03 & KH 102 & 966.0 & -8.30 & 0.02 & -8.01 & 0.02 \\
\hline KH 39 & 278.0 & -9.36 & 0.01 & -7.21 & 0.04 & KH 103 & 988.0 & -9.05 & 0.02 & -7.78 & 0.02 \\
\hline KH 40 & 286.0 & -8.56 & 0.02 & -8.06 & 0.02 & KH 104 & 1002.5 & -8.23 & 0.01 & -7.53 & 0.02 \\
\hline KH 41 & 296.0 & -7.91 & 0.02 & -7.49 & 0.01 & KH 105 & 1009.5 & -7.80 & 0.02 & -8.11 & 0.02 \\
\hline KH 42 & 306.5 & -6.84 & 0.02 & -7.72 & 0.04 & KH 106 & 1019.5 & -8.24 & 0.01 & -8.00 & 0.01 \\
\hline KH 43 & 315.0 & -6.96 & 0.01 & -7.46 & 0.01 & KH 107 & 1028.0 & -7.28 & 0.02 & -8.11 & 0.02 \\
\hline KH 44 & 325.0 & -7.32 & 0.03 & -7.56 & 0.02 & KH 108 & 1038.0 & -8.13 & 0.02 & -8.33 & 0.05 \\
\hline KH 45 & 331.0 & -7.53 & 0.01 & -7.69 & 0.04 & KH 109 & 1049.5 & -8.60 & 0.02 & -8.11 & 0.02 \\
\hline KH 46 & 347.0 & -8.32 & 0.01 & -7.87 & 0.02 & KH 110 & 1060.7 & -8.04 & 0.01 & -7.36 & 0.01 \\
\hline KH 47 & 356.0 & -5.80 & 0.02 & -7.19 & 0.02 & |KH 111 & 1068.0 & -8.30 & 0.02 & -7.81 & 0.03 \\
\hline KH 48 & 366.0 & -7.89 & 0.02 & -7.60 & 0.04 & KH 112 & 1074.0 & -8.64 & 0.01 & -7.42 & 0.01 \\
\hline KH 49 & 413.0 & -8.12 & 0.01 & -7.55 & 0.02 & KH 113 & 1086.0 & -8.77 & 0.01 & -8.13 & 0.02 \\
\hline KH 50 & 420.5 & -6.12 & 0.01 & -7.23 & 0.02 & KH 114 & 1094.0 & -7.86 & 0.02 & -8.03 & 0.02 \\
\hline KH 51 & 430.5 & -8.00 & 0.02 & -7.82 & 0.02 & KH 115 & 1103.0 & -8.08 & 0.01 & -7.81 & 0.02 \\
\hline KH 52 & 440.5 & -8.71 & 0.02 & -7.77 & 0.01 & KH 116 & 1112.5 & -8.62 & 0.02 & -8.17 & 0.04 \\
\hline KH 53 & 450.5 & -7.78 & 0.01 & -7.79 & 0.01 & KH 117 & 1122.5 & -7.26 & 0.01 & -7.58 & 0.02 \\
\hline KH 54 & 460.5 & -8.34 & 0.01 & -6.92 & 0.01 & KH 118 & 1136.5 & -8.32 & 0.01 & -7.72 & 0.04 \\
\hline KH 55 & 470.5 & -6.40 & 0.01 & -7.07 & 0.02 & KH 119 & 1143.5 & -8.95 & 0.02 & -7.81 & 0.02 \\
\hline KH 56 & 480.5 & -7.58 & 0.02 & -7.32 & 0.01 & KH 120 & 1150.5 & -8.69 & 0.01 & -8.53 & 0.02 \\
\hline KH 57 & 490.5 & -7.93 & 0.01 & -7.71 & 0.02 & KH 121 & 1190.0 & -7.77 & 0.03 & -7.90 & 0.02 \\
\hline KH 58 & 500.5 & -8.11 & 0.01 & -8.05 & 0.02 & KH 122 & 1200.0 & -7.86 & 0.01 & -8.46 & 0.02 \\
\hline KH 59 & 510.5 & -7.22 & 0.01 & -7.82 & 0.03 & KH 123 & 1205.5 & -7.89 & 0.01 & -7.84 & 0.03 \\
\hline KH 60 & 515.0 & -7.13 & 0.01 & -8.06 & 0.05 & KH 124 & 1215.5 & -7.84 & 0.02 & -8.08 & 0.03 \\
\hline KH 61 & 525.0 & -8.36 & 0.01 & -8.12 & 0.03 & KH 125 & 1225.0 & -8.56 & 0.02 & -8.37 & 0.04 \\
\hline KH 62 & 535.0 & -8.13 & 0.01 & -8.42 & 0.03 & KH 126 & 1235.0 & -7.96 & 0.01 & -8.30 & 0.01 \\
\hline KH 63 & 545.0 & -9.10 & 0.01 & -8.09 & 0.02 & KH 127 & 1242.0 & -8.32 & 0.01 & -8.60 & 0.04 \\
\hline KH 64 & 576.0 & -7.22 & 0.03 & -7.40 & 0.05 & & & & & & \\
\hline
\end{tabular}

Appendix vii - 2.2: Cave Hintere Kohlhalde stalagmite, results $\delta^{18} \mathrm{O}$ and $\delta^{13} \mathrm{C}$ measurements. 


\begin{tabular}{|c|c|c|c|c|c|c|c|}
\hline $\begin{array}{c}80 \mathrm{~mm} \\
\text { from } \\
\text { base }\end{array}$ & $\begin{array}{c}\quad \delta^{13} \mathrm{C} \\
(\mathrm{o} / \mathrm{oo} \text { vs.VPDB) (o/oo }\end{array}$ & $\begin{array}{l}\delta^{18} \mathrm{O} \\
\text { vs.VPDB) }\end{array}$ & $\begin{array}{c}\text { distance from } \\
\text { apex }(\mathrm{mm})\end{array}$ & $\begin{array}{c}691 \mathrm{~mm} \text { from } \\
\text { base }\end{array}$ & & & \\
\hline 131 & -7.38 & -7.05 & -43.00 & 11101 & -6.78 & -7.92 & -18.00 \\
\hline 132 & -6.89 & -6.90 & -35.00 & III 102 & -7.02 & -7.94 & -16.00 \\
\hline 133 & -8.10 & -7.28 & -15.00 & 11103 & -6.58 & -7.70 & -7.00 \\
\hline 134 & -8.50 & -7.43 & 9.00 & II 104 & -6.49 & -7.71 & 16.00 \\
\hline 135 & -7.99 & -7.43 & 21.00 & & & & \\
\hline 136 & -7.66 & -6.90 & 23.00 & & & & \\
\hline $\begin{array}{c}258 \mathrm{~mm} \\
\text { from } \\
\text { base }\end{array}$ & & & & $\begin{array}{l}989 \mathrm{~mm} \text { from } \\
\text { base }\end{array}$ & & & \\
\hline I101 & -9.29 & -7.67 & -35.00 & 11171 & -8.24 & -8.02 & -26.00 \\
\hline I102 & -7.76 & -7.68 & -24.00 & 11172 & -9.18 & -8.09 & -17.00 \\
\hline I103 & -8.86 & -7.94 & -9.00 & 11173 & -9.05 & -7.78 & 0.00 \\
\hline I104 & -7.48 & -7.57 & 17.00 & 11174 & -8.46 & -7.85 & 12.00 \\
\hline I105 & -8.04 & -7.56 & 37.00 & 11175 & -7.34 & -7.93 & 17.00 \\
\hline I106 & -6.31 & -7.21 & 43.00 & & & & \\
\hline $\begin{array}{c}577 \mathrm{~mm} \\
\text { from } \\
\text { base }\end{array}$ & $\begin{array}{c}\quad \delta^{13} \mathrm{C} \\
\text { (o/oo vs.VPDB) (o/oo }\end{array}$ & $\begin{array}{l}\delta^{18} \mathrm{O} \\
\text { vs.VPDB) }\end{array}$ & $\begin{array}{c}\text { distance from } \\
\text { apex }(\mathrm{mm})\end{array}$ & & & & \\
\hline II51 & -6.59 & -7.24 & -18.00 & & & & \\
\hline II52 & -7.22 & -7.40 & -16.00 & & & & \\
\hline 1153 & -6.72 & -7.38 & -7.00 & & & & \\
\hline II54 & -7.79 & -7.54 & 16.00 & & & & \\
\hline
\end{tabular}

Appendix vii - 2.3: Cave Hintere Kohlhalde stalagmite, $\delta^{18} \mathrm{O} / \delta^{13} \mathrm{C}$ single layers (Hendy-Test). 


\begin{tabular}{|c|c|c|c|c|c|}
\hline ZH -STK & \begin{tabular}{|c} 
Distance \\
from base \\
{$[\mathrm{mm}]$}
\end{tabular} & $\begin{array}{c}\delta^{13} \mathrm{C} \\
\text { VPDB } \\
\text { [o/oo] }\end{array}$ & $\begin{array}{c}\text { std. dev. } \\
\text { [o/oo] }\end{array}$ & $\begin{array}{c}\delta^{18} \mathrm{O} \\
\text { VPDB } \\
\text { [o/oo] }\end{array}$ & $\begin{array}{c}\text { std. dev. } \\
\text { [o/oo] }\end{array}$ \\
\hline ZH STK 11 & 8 & -9.63 & 0.01 & -7.08 & 0.01 \\
\hline ZH STK 12 & 33 & -9.95 & 0.01 & -7.08 & 0.01 \\
\hline ZH STK 13 & 65 & -10.22 & 0.01 & -7.40 & 0.02 \\
\hline ZH STK 14 & 85 & -10.30 & 0.01 & -7.18 & 0.02 \\
\hline ZH STK 15 & 111 & -10.23 & 0.01 & -7.16 & 0.01 \\
\hline ZH STK 16 & 145 & -10.51 & 0.01 & -7.27 & 0.02 \\
\hline ZH STK 17 & 165 & -10.32 & 0.01 & -7.42 & 0.02 \\
\hline ZH STK 18 & 190 & -10.20 & 0.01 & -7.39 & 0.02 \\
\hline ZH STK 19 & 220 & -10.61 & 0.01 & -7.53 & 0.02 \\
\hline ZH STK 20 & 250 & -10.65 & 0.01 & -7.34 & 0.01 \\
\hline ZH STK 21 & 290 & -10.71 & 0.01 & -7.31 & 0.02 \\
\hline ZH STK 10 & 340 & -9.07 & 0.01 & -7.24 & 0.02 \\
\hline ZH STK 09 & 360 & -10.10 & 0.01 & -7.24 & 0.01 \\
\hline ZH STK 08 & 380 & -9.11 & 0.01 & -7.31 & 0.01 \\
\hline ZH STK 07 & 403 & -9.14 & 0.01 & -7.28 & 0.01 \\
\hline ZH STK 06 & 427 & -9.21 & 0.01 & -7.07 & 0.01 \\
\hline ZH STK 05 & 447 & -9.30 & 0.01 & -7.20 & 0.01 \\
\hline ZH STK 04 & 470 & -9.34 & 0.01 & -7.16 & 0.01 \\
\hline ZH STK 03 & 495 & -9.72 & 0.01 & -7.12 & 0.01 \\
\hline ZH STK 02 & 520 & -10.36 & 0.01 & -7.45 & 0.01 \\
\hline ZH STK 01 & 544 & -10.48 & 0.01 & -7.44 & 0.01 \\
\hline
\end{tabular}

Appendix vii - 2.4: Zaininger-Cave stalactite, results of $\delta^{18} \mathrm{O}$ and $\delta^{13} \mathrm{C}$ measurements. 


\begin{tabular}{|c|c|c|c|c|c|}
\hline ZH STM & $\begin{array}{c}\text { Distance } \\
\text { from base } \\
{[\mathrm{mm}]}\end{array}$ & $\begin{array}{l}\delta^{13} \mathrm{C} \\
\text { VPDB } \\
{[0 / 00]}\end{array}$ & $\begin{array}{c}\text { std.dev. } \\
\text { [o/oo] }\end{array}$ & $\begin{array}{c}\delta^{18} O \\
\text { VPDB } \\
\text { [o/oo] }\end{array}$ & $\begin{array}{c}\text { std.dev. } \\
\text { [o/oo] }\end{array}$ \\
\hline ZH STM 21 & 55 & -10.31 & 0.01 & -8.32 & 0.02 \\
\hline ZH STM 20 & 66 & -10.21 & 0.01 & -8.26 & 0.01 \\
\hline ZH STM 19 & 75 & -10.23 & 0.01 & -9.22 & 0.02 \\
\hline ZH STM 18 & 85 & -9.98 & 0.01 & -8.08 & 0.02 \\
\hline ZH STM 17 & 103 & -10.27 & 0.01 & -8.29 & 0.01 \\
\hline ZH STM 16 & 120 & -9.99 & 0.01 & -6.08 & 0.02 \\
\hline ZH STM 15 & 132 & -9.35 & 0.01 & -7.98 & 0.01 \\
\hline ZH STM 14 & 142 & -9.94 & 0.01 & -8.54 & 0.02 \\
\hline ZH STM 13 & 156 & -9.82 & 0.01 & -9.38 & 0.02 \\
\hline ZH STM 12 & 170 & -9.59 & 0.01 & -8.23 & 0.01 \\
\hline ZH STM 11 & 185 & -9.59 & 0.01 & -8.49 & 0.01 \\
\hline ZH STM 10 & 200 & -9.57 & 0.01 & -6.45 & 0.02 \\
\hline ZH STM 09 & 215 & -9.62 & 0.01 & -6.18 & 0.01 \\
\hline ZH STM 08 & 232 & -9.58 & 0.01 & -6.90 & 0.01 \\
\hline ZH STM 07 & 248 & -9.29 & 0.01 & -6.37 & 0.01 \\
\hline ZH STM 06 & 258 & -8.47 & 0.01 & -5.51 & 0.01 \\
\hline ZH STM 05 & 267 & -11.14 & 0.01 & -7.21 & 0.01 \\
\hline ZH STM 04 & 288 & -9.04 & 0.01 & -6.04 & 0.01 \\
\hline ZH STM 03 & 303 & -8.45 & 0.01 & -7.00 & 0.01 \\
\hline ZH STM 02 & 333 & -9.16 & 0.01 & -7.41 & 0.01 \\
\hline ZH STM 01 & 359 & -9.71 & 0.01 & -7.72 & 0.01 \\
\hline
\end{tabular}

Appendix vii - 2.5: Zaininger-Cave stalagmite, results $\delta^{18} \mathrm{O}$ and $\delta^{13} \mathrm{C}$ measurements.

\begin{tabular}{|c|c|c|c|c|c|c|c|}
\hline $\begin{array}{c}75 \mathrm{~mm} \text { from } \\
\text { base }\end{array}$ & $\begin{array}{c}\delta^{13} \mathrm{C} \\
\text { (o/oo } \\
\text { vs.VPDB) }\end{array}$ & $\begin{array}{c}\delta^{18} \mathrm{O} \\
\text { (o/oo } \\
\text { vs.VPDB) }\end{array}$ & $\begin{array}{l}\text { distance } \\
\text { from } \\
\text { apex (mm) }\end{array}$ & $\begin{array}{c}258 \mathrm{~mm} \text { from } \\
\text { base }\end{array}$ & $\begin{array}{c}\delta^{13} \mathrm{C} \\
(\mathrm{o} / \mathrm{oo} \\
\text { vs.VP } \\
\text { DB) }\end{array}$ & $\begin{array}{c}\delta^{18} \mathrm{O} \\
\text { (o/oo } \\
\text { vs.VPDB) }\end{array}$ & $\begin{array}{c}\text { distance } \\
\text { from } \\
\text { apex }(\mathrm{mm})\end{array}$ \\
\hline ZH-ST M-19 & -10.23 & -9.22 & 0 & ZH-ST M-06 & -8.47 & -5.51 & 0 \\
\hline ZH-STM-19.1 & -10.04 & -8.47 & -5 & ZH-ST M-6.1 & -8.31 & -6.09 & 5 \\
\hline ZH-STM-19.2 & -10.04 & -7.33 & 5 & ZH-ST M-6.2 & -8.48 & -5.64 & 10 \\
\hline ZH-STM-19.3 & -10.00 & -7.22 & 10 & ZH-ST M-6.3 & -8.57 & -5.79 & 14 \\
\hline ZH-STM-19.4 & -9.50 & -7.58 & 14 & ZH-ST M-6.4 & -8.34 & -5.65 & 19 \\
\hline ZH-STM-19.5 & -9.98 & -6.13 & 17 & ZH-ST M-6.5 & -8.20 & -5.87 & 22 \\
\hline ZH-ST M-19.6 & -9.67 & -6.52 & 25 & ZH-ST M-6.6 & -8.30 & -5.47 & 27 \\
\hline ZH-ST M-19.7 & -9.79 & -6.01 & 36 & ZH-ST M-6.7 & -8.04 & -5.74 & 39 \\
\hline ZH-STM-19.8 & -9.63 & -5.66 & 48 & $\begin{array}{l}\text { ZH-ST11-6.8 } \\
\text { ZH-ST M-6.9 }\end{array}$ & $\begin{array}{l}-8.09 \\
-8.12\end{array}$ & $\begin{array}{l}-5.88 \\
-5.78\end{array}$ & $\begin{array}{l}50 \\
62\end{array}$ \\
\hline $\begin{array}{c}200 \mathrm{~mm} \text { from } \\
\text { base }\end{array}$ & & & & ZH-ST M-6.10 & -7.86 & -5.59 & 76 \\
\hline ZH-STM-10.0 & -9.79 & -6.27 & 0 & ZH-ST M-6.11 & -7.64 & -5.93 & 88 \\
\hline ZH-STM-10.1 & -9.44 & -6.17 & 5 & ZH-STM-6.13 & -7.78 & -5.85 & 108 \\
\hline ZH-ST M-10.2 & -9.41 & -6.24 & 10 & ZH-ST11-6.14 & -7.55 & -5.54 & 118 \\
\hline ZH-ST M-10.3 & -9.31 & -5.80 & 15 & ZH-ST11-6.15 & -7.28 & -5.68 & 133 \\
\hline ZH-STM-10.4 & -9.41 & -6.51 & 20 & ZH-ST M-6.16 & -7.70 & -5.46 & 147 \\
\hline ZH-STM-10.5 & -9.49 & -6.53 & 23 & & & & \\
\hline ZH-STM-10.6 & -9.51 & -6.36 & 27 & & & & \\
\hline ZH-ST M-10.7 & -9.48 & -6.39 & 40 & & & & \\
\hline ZH-STM-10.8 & -9.42 & -6.48 & 52 & & & & \\
\hline ZH-STM-10.9 & -9.36 & -6.45 & 65 & & & & \\
\hline ZH-STM-10.10 & -9.15 & -5.75 & 75 & & & & \\
\hline ZH-ST M-10.11 & -9.15 & -6.27 & 100 & & & & \\
\hline ZH-STM-10.12 & -8.84 & -6.33 & 112 & & & & \\
\hline ZH-ST M-10.13 & -8.77 & -6.33 & 127 & & & & \\
\hline
\end{tabular}

Appendix vii - 2.6: Zaininger-Cave stalagmite, single layer $\delta^{18} \mathrm{O}$ and $\delta^{13} \mathrm{C}$ (Hendy-Tests). 


\begin{tabular}{|c|ccccc|}
\hline HU-STM & $\begin{array}{c}\text { Distance } \\
\text { from base } \\
\text { [mm] }\end{array}$ & $\begin{array}{c}\boldsymbol{\delta}^{13} \mathbf{C} \text { VPDB } \\
\text { [o/oo] }\end{array}$ & $\begin{array}{c}\text { std. dev. } \\
\text { [o/oo] }\end{array}$ & $\begin{array}{c}\mathbf{\delta}^{18} \text { O VPDB } \\
\text { [o/oo] }\end{array}$ & $\begin{array}{c}\text { std. dev. } \\
\text { [o/oo] }\end{array}$ \\
\hline HU-STM-1 & 12 & -5.635 & 0.01 & -8.191 & 0.008 \\
HU-STM-2 & 32 & -6.935 & 0.011 & -7.908 & 0.009 \\
HU-STM-3 & 52 & -6.669 & 0.014 & -7.954 & 0.032 \\
HU-STM-4 & 73 & -10.034 & 0.009 & -7.352 & 0.02 \\
HU-STM-5 & 89 & -8.749 & 0.013 & -8.813 & 0.015 \\
HU-STM-6 & 107 & -9.896 & 0.016 & -8.906 & 0.017 \\
HU-STM-7 & 128 & -9.379 & 0.008 & -8.497 & 0.02 \\
HU-STM-8 & 148 & -9.967 & 0.012 & -7.414 & 0.01 \\
HU-STM-9 & 168 & -10.28 & 0.013 & -7.96 & 0.012 \\
HU-STM-10 & 188 & -10.473 & 0.011 & -8.116 & 0.014 \\
HU-STM-11 & 209 & -10.28 & 0.014 & -7.548 & 0.023 \\
HU-STM-12 & 229 & -10.68 & 0.011 & -7.692 & 0.015 \\
HU-STM-13 & 250 & -8.853 & 0.014 & -7.288 & 0.007 \\
\hline
\end{tabular}

Appendix vii - 2.7: Paleocave Hunas stalagmite, results $\delta^{18} \mathrm{O}$ and $\delta^{13} \mathrm{C}$.

\begin{tabular}{|c|c|c|c|c|c|}
\hline $\begin{array}{l}73 \mathrm{~mm} \text { from } \\
\text { base }\end{array}$ & $\begin{array}{c}\delta^{13} \mathrm{C} \text { VPDB } \\
\text { [o/oo] }\end{array}$ & $\begin{array}{l}\text { std. dev. } \\
\text { [o/oo] }\end{array}$ & $\begin{array}{c}\delta^{18} \mathrm{O} \text { VPDB } \\
\text { [o/oo] }\end{array}$ & $\begin{array}{l}\text { std. dev. } \\
\text { [o/oo] }\end{array}$ & $\begin{array}{c}\text { distance } \\
\text { from apex } \\
{[\mathrm{mm}]}\end{array}$ \\
\hline HU-STM-4 & -10.03 & 0.01 & -7.35 & 0.02 & 5 \\
\hline HU-STM-4.1 & -9.88 & 0.02 & -7.34 & 0.02 & 10 \\
\hline HU-STM-4.2 & -9.83 & 0.01 & -7.36 & 0.02 & 15 \\
\hline HU-STM-4.3 & -9.86 & 0.01 & -7.34 & 0.02 & 20 \\
\hline HU-STM-4.4 & -9.98 & 0.01 & -7.42 & 0.02 & 25 \\
\hline HU-STM-4.5 & -9.75 & 0.01 & -7.28 & 0.02 & 35 \\
\hline HU-STM-4.6 & -9.86 & 0.02 & -7.16 & 0.02 & 42 \\
\hline HU-STM-4.7 & -9.69 & 0.01 & -7.13 & 0.02 & 47 \\
\hline \multicolumn{6}{|l|}{\begin{tabular}{|l|}
$188 \mathrm{~mm}$ from \\
base
\end{tabular}} \\
\hline HU-STM-10.0 & -10.47 & 0.01 & -8.12 & 0.01 & 5 \\
\hline HU-STM-10.1 & -10.60 & 0.01 & -8.17 & 0.01 & 10 \\
\hline HU-STM-10.2 & -10.47 & 0.01 & -8.06 & 0.02 & 15 \\
\hline HU-STM-10.3 & -10.36 & 0.01 & -7.87 & 0.02 & 20 \\
\hline HU-STM-10.4 & -10.55 & 0.01 & -7.98 & 0.01 & 27 \\
\hline HU-STM-10.5 & -10.40 & 0.01 & -7.93 & 0.02 & 38 \\
\hline HU-STM-10.6 & -10.34 & 0.02 & -8.01 & 0.04 & 47 \\
\hline HU-STM-10.7 & -10.23 & 0.01 & -7.89 & 0.01 & 55 \\
\hline HU-STM-10.8 & -10.44 & 0.01 & -7.94 & 0.02 & 62 \\
\hline
\end{tabular}

Appendix vii - 2.8: Paleocave Hunas stalagmite, single layer $\delta^{18} \mathrm{O}$ and $\delta^{13} \mathrm{C}$ (Hendy-Tests). 


\begin{tabular}{|l|ccccc|}
\hline MH-STM & $\begin{array}{c}\text { Distance } \\
\text { from base } \\
\text { [mm] }\end{array}$ & $\begin{array}{c}\mathbf{\delta}^{\mathbf{1 3}} \mathbf{C} \text { VPDB } \\
\text { [o/oo] }\end{array}$ & $\begin{array}{c}\text { std. dev. } \\
\text { [o/oo] }\end{array}$ & $\begin{array}{c}\mathbf{\delta}^{18} \mathbf{O} \text { VPDB } \\
\text { [o/oo] }\end{array}$ & $\begin{array}{c}\text { std. dev. } \\
\text { [o/oo] }\end{array}$ \\
\hline MH-STM-1 & 4 & -9.12 & 0.01 & -8.08 & 0.01 \\
MH-STM-2 & 24 & -9.00 & 0.02 & -7.99 & 0.02 \\
MH-STM-3 & 40 & -8.96 & 0.01 & -8.41 & 0.01 \\
MH-STM-4 & 56 & -9.00 & 0.02 & -7.96 & 0.01 \\
MH-STM-5 & 69 & -8.77 & 0.01 & -8.19 & 0.02 \\
MH-STM-6 & 94 & -8.68 & 0.01 & -8.34 & 0.03 \\
MH-STM-7 & 119 & -8.50 & 0.01 & -8.26 & 0.00 \\
MH-STM-8 & 140 & -8.64 & 0.02 & -8.41 & 0.03 \\
MH-STM-9 & 159 & -8.54 & 0.02 & -7.96 & 0.02 \\
MH-STM-10 & 178 & -8.62 & 0.03 & -8.07 & 0.04 \\
MH-STM-11 & 195 & -8.45 & 0.02 & -8.04 & 0.02 \\
MH-STM-12 & 220 & -8.34 & 0.02 & -8.09 & 0.01 \\
MH-STM-13 & 244 & -8.36 & 0.02 & -8.09 & 0.01 \\
MH-STM-14 & 265 & -8.62 & 0.02 & -8.15 & 0.01 \\
MH-STM-15 & 280 & -8.51 & 0.01 & -8.25 & 0.01 \\
MH-STM-16 & 300 & -8.76 & 0.02 & -8.04 & 0.02 \\
MH-STM-17 & 318 & -9.20 & 0.02 & -8.15 & 0.03 \\
MH-STM-18 & 337 & -9.79 & 0.01 & -8.28 & 0.03 \\
MH-STM-19 & 355 & -9.42 & 0.02 & -7.85 & 0.04 \\
MH-STM-20 & 370 & -9.58 & 0.02 & -7.76 & 0.01 \\
\hline
\end{tabular}

Appendix vii - 2.9: Mühlbach - Cave stalagmite, results $\delta^{18} \mathrm{O}$ and $\delta^{13} \mathrm{C}$ measurements.

\begin{tabular}{|c|c|c|c|c|c|c|c|c|c|c|c|}
\hline $\begin{array}{l}\text { 69mm from } \\
\text { base }\end{array}$ & \begin{tabular}{|l}
$\delta^{13} \mathrm{C}$ \\
VPDB \\
[o/oo]
\end{tabular} & $\begin{array}{l}\text { std. dev. } \\
\text { [o/oo] }\end{array}$ & $\begin{array}{c}\delta^{18} O \\
\text { VPDB } \\
\text { [o/oo] }\end{array}$ & $\begin{array}{l}\text { std. dev. } \\
\text { [o/oo] }\end{array}$ & $\begin{array}{l}\text { distance } \\
\text { from apex } \\
{[\mathrm{mm}]}\end{array}$ & $\begin{array}{l}280 \mathrm{~mm} \text { from } \\
\text { base }\end{array}$ & \begin{tabular}{|c|}
$\delta^{13} \mathrm{C}$ \\
VPDB \\
[o/oo]
\end{tabular} & $\begin{array}{l}\text { std. dev. } \\
\text { [o/oo] }\end{array}$ & $\begin{array}{c}\delta^{18} O \\
\text { VPDB } \\
\text { [o/oo] } \\
\end{array}$ & $\begin{array}{l}\text { std. dev. } \\
\text { [oloo] }\end{array}$ & $\begin{array}{l}\text { distance } \\
\text { from apex } \\
{[\mathrm{mm}]}\end{array}$ \\
\hline $\mathrm{MH}-5.1$ & -8.77 & 0.01 & -8.19 & 0.02 & 0 & MH-STM-15 & -8.51 & 0.01 & -8.25 & 0.01 & 0 \\
\hline MH-5.2 & -8.74 & 0.01 & -8.09 & 0.02 & 6 & MH-STM-15.1 & -8.51 & 0.02 & -8.20 & 0.02 & 6 \\
\hline $\mathrm{MH}-5.3$ & -8.95 & 0.02 & -8.09 & 0.03 & 12 & MH-STM-15.2 & -8.54 & 0.01 & -8.20 & 0.00 & 10 \\
\hline $\mathrm{MH}-5.4$ & -8.83 & 0.01 & -7.91 & 0.01 & 17 & MH-STM-15.3 & -8.33 & 0.01 & -7.89 & 0.01 & 13 \\
\hline MH-5.5 & -8.69 & 0.01 & -7.91 & 0.03 & 22 & MH-STM-15.4 & -8.50 & 0.02 & -8.13 & 0.03 & 16 \\
\hline $\mathrm{MH}-5.6$ & -8.62 & 0.01 & -7.86 & 0.03 & 27 & MH-STM-15.5 & -8.46 & 0.02 & -7.93 & 0.02 & 19 \\
\hline $\mathrm{MH}-5.7$ & -8.64 & 0.01 & -7.79 & 0.01 & 32 & MH-STM-15.6 & -8.55 & 0.01 & -8.04 & 0.01 & 21 \\
\hline \begin{tabular}{|l}
$158 \mathrm{~mm}$ from \\
base
\end{tabular} & & & & & & MH-STM-15.7 & -8.49 & 0.01 & -7.91 & 0.02 & 23 \\
\hline MH-STM-9 & -8.62 & 0.03 & -8.07 & 0.04 & 0 & $\begin{array}{l}370 \mathrm{~mm} \text { from } \\
\text { base }\end{array}$ & & & & & \\
\hline MH-STM-9.1 & -8.29 & 0.02 & -8.02 & 0.03 & 11 & MH-STM-20 & -9.58 & 0.02 & -7.76 & 0.01 & 0 \\
\hline MH-STM-9.2 & -8.36 & 0.02 & -8.05 & 0.02 & 14 & MH-STM-20.1 & -9.55 & 0.03 & -7.73 & 0.02 & 9 \\
\hline MH-STM-9.3 & -8.53 & 0.01 & -8.19 & 0.02 & 18 & MH-STM-20.2 & -9.43 & 0.01 & -7.70 & 0.01 & 14 \\
\hline MH-STM-9.4 & -8.43 & 0.01 & -8.41 & 0.01 & 22 & MH-STM-20.3 & -9.55 & 0.01 & -7.85 & 0.01 & 20 \\
\hline MH-STM-9.5 & -8.47 & 0.01 & -8.11 & 0.01 & 24 & MH-STM-20.4 & -9.48 & 0.02 & -7.62 & 0.02 & 25 \\
\hline MH-STM-9.6 & -8.42 & 0.02 & -8.28 & 0.02 & 26 & MH-STM-20.5 & -9.40 & 0.01 & -7.76 & 0.01 & 29 \\
\hline MH-STM-9.7 & -8.47 & 0.02 & -8.18 & 0.03 & 32 & MH-STM-20.6 & -9.69 & 0.01 & -7.97 & 0.02 & 31 \\
\hline
\end{tabular}

Appendix vii - 2.10: Mühlbach - Cave stalagmite, single layer $\delta^{18} \mathrm{O}$ and $\delta^{13} \mathrm{C}$ (Hendy-Tests). 


\begin{tabular}{|c|c|c|c|c|c|c|c|c|c|c|c|}
\hline $\begin{array}{l}\text { BH 2a- } \\
\text { STM }\end{array}$ & $\begin{array}{c}\text { Distance } \\
\text { from base } \\
{[\mathrm{mm}]}\end{array}$ & $\begin{array}{c}\delta^{13} \mathrm{C} \text { VPDB } \\
\text { [o/oo] }\end{array}$ & $\begin{array}{l}\text { std. dev. } \\
\text { [o/oo] }\end{array}$ & $\begin{array}{c}\delta^{18} \text { O VPDB } \\
\text { [o/oo] }\end{array}$ & $\begin{array}{l}\text { std. dev. } \\
\text { [o/oo] }\end{array}$ & $\begin{array}{l}\text { HH- } \\
\text { STM }\end{array}$ & $\begin{array}{c}\text { Distance } \\
\text { from base } \\
{[\mathrm{mm}]}\end{array}$ & $\begin{array}{c}\delta^{13} \mathrm{C} \text { VPDB } \\
\text { [o/oo] }\end{array}$ & $\begin{array}{l}\text { std. dev. } \\
\text { [o/oo] }\end{array}$ & $\begin{array}{c}\delta^{18} \text { O VPDB } \\
\text { [oloo] }\end{array}$ & $\begin{array}{l}\text { std. dev. } \\
\text { [o/oo] }\end{array}$ \\
\hline $\mathrm{BH}-1$ & 5 & -8.92 & 0.01 & -6.68 & 0.01 & $\mathrm{HH}-1$ & 20 & -6.89 & 0.00 & -7.42 & 0.01 \\
\hline $\mathrm{BH}-2$ & 18 & -6.74 & 0.02 & -6.52 & 0.02 & $\mathrm{HH}-2$ & 38 & -8.33 & 0.01 & -6.93 & 0.00 \\
\hline $\mathrm{BH}-3$ & 25 & -6.85 & 0.01 & -6.45 & 0.01 & $\mathrm{HH}-3$ & 49 & -8.26 & 0.01 & -6.77 & 0.01 \\
\hline $\mathrm{BH}-4$ & 35 & -6.63 & 0.01 & -6.19 & 0.01 & $\mathrm{HH}-4$ & 72 & -7.98 & 0.00 & -7.01 & 0.01 \\
\hline $\mathrm{BH}-5$ & 50 & -8.35 & 0.02 & -6.83 & 0.01 & $\mathrm{HH}-5$ & 85 & -9.65 & 0.01 & -7.47 & 0.03 \\
\hline $\mathrm{BH}-6$ & 60 & -8.41 & 0.01 & -7.17 & 0.02 & HН-6 & 98 & -8.98 & 0.01 & -7.34 & 0.02 \\
\hline $\mathrm{BH}-7$ & 74 & -9.88 & 0.01 & -6.85 & 0.01 & $\mathrm{HH}-7$ & 109 & -8.03 & 0.01 & -7.78 & 0.01 \\
\hline $\mathrm{BH}-8$ & 90 & -8.97 & 0.01 & -7.21 & 0.01 & $\mathrm{HH}-8$ & 122 & -9.36 & 0.01 & -7.45 & 0.01 \\
\hline $\mathrm{BH}-9$ & 105 & -7.45 & 0.01 & -5.81 & 0.02 & $\mathrm{HH}-9$ & 139 & -9.51 & 0.01 & -7.22 & 0.01 \\
\hline $\mathrm{BH}-10$ & 122 & -6.96 & 0.02 & -5.93 & 0.02 & $\mathrm{HH}-10$ & 153 & -9.34 & 0.01 & -7.24 & 0.01 \\
\hline $\mathrm{BH}-11$ & 135 & -8.08 & 0.01 & -6.02 & 0.01 & $\mathrm{HH}-11$ & 165 & -9.21 & 0.01 & -6.63 & 0.01 \\
\hline $\mathrm{BH}-12$ & 150 & -9.09 & 0.01 & -6.35 & 0.02 & $\mathrm{HH}-12$ & 195 & -9.26 & 0.00 & -7.48 & 0.01 \\
\hline $\mathrm{BH}-13$ & 160 & -7.33 & 0.01 & -6.45 & 0.02 & $\mathrm{HH}-13$ & 210 & -8.88 & 0.02 & -7.10 & 0.02 \\
\hline $\mathrm{BH}-14$ & periph.1 & -6.33 & 0.01 & -6.29 & 0.01 & $\mathrm{HH}-14$ & 225 & -8.64 & 0.01 & -7.17 & 0.02 \\
\hline BH-15 & periph.2 & -5.97 & 0.02 & -6.51 & 0.02 & $\mathrm{HH}-15$ & 243 & -8.69 & 0.01 & -6.87 & 0.02 \\
\hline
\end{tabular}

Appendix vii - 2.11: Baumann's- and Herrmann's- Cave stalagmites (lower), results $\delta^{18} \mathrm{O}$ and $\delta^{13} \mathrm{C}$ measurements.

\begin{tabular}{|c|c|c|c|c|c|c|c|c|c|c|c|}
\hline \multicolumn{6}{|c|}{ Baumann's - Cave stalagmite } & \multicolumn{6}{|c|}{ Hermann's - Cave stalagmite } \\
\hline $\begin{array}{l}35 \mathrm{~mm} \text { from } \\
\text { base }\end{array}$ & $\begin{array}{l}\delta^{13} \mathrm{C} \\
\text { VPDB } \\
\text { [o/oo] }\end{array}$ & $\begin{array}{l}\text { std. dev. } \\
\text { [o/oo] }\end{array}$ & $\begin{array}{l}\delta^{18} O \\
\text { VPDB } \\
\text { [o/oo] }\end{array}$ & $\begin{array}{l}\text { std. dev. } \\
\text { [oloo] }\end{array}$ & $\begin{array}{l}\text { distance } \\
\text { from apex } \\
{[\mathrm{mm}]}\end{array}$ & $\begin{array}{l}49 \mathrm{~mm} \text { from } \\
\text { base }\end{array}$ & \begin{tabular}{|l}
$\delta^{13} \mathrm{C}$ \\
VPDB \\
[o/oo]
\end{tabular} & $\begin{array}{l}\text { std. dev. } \\
\text { [o/oo] }\end{array}$ & $\begin{array}{l}\delta^{18} O \\
\text { VPDB } \\
{[0 / 00]}\end{array}$ & $\begin{array}{l}\text { std. dev. } \\
\text { [o/oo] }\end{array}$ & $\begin{array}{l}\text { distance } \\
\text { from apex } \\
{[\mathrm{mm}]}\end{array}$ \\
\hline STM-BH-4.0 & -8.22 & 0.01 & -6.77 & 0.01 & 0 & HH-STM-3.1 & -8.53 & 0.02 & -6.69 & 0.01 & 5 \\
\hline STM-BH-4.1 & -8.07 & 0.03 & -6.88 & 0.03 & 5 & HH-STM-3.2 & -8.52 & 0.01 & -6.68 & 0.01 & 13 \\
\hline STM-BH-4.2 & -8.09 & 0.01 & -6.91 & 0.02 & 10 & HH-STM-3.3 & -8.49 & 0.01 & -6.43 & 0.01 & 17 \\
\hline STM-BH-4.3 & -8.07 & 0.02 & -7.00 & 0.02 & 13 & HH-STM-3.4 & -8.08 & 0.02 & -6.82 & 0.01 & 20 \\
\hline STM-BH-4.4 & -7.87 & 0.01 & -6.81 & 0.02 & 14 & HH-STM-3.5 & -8.30 & 0.01 & -6.93 & 0.02 & 24 \\
\hline STM-BH-4.5 & -8.44 & 0.01 & -6.94 & 0.02 & 19 & HH-STM-3.6 & -8.50 & 0.01 & -6.87 & 0.03 & 29 \\
\hline $\begin{array}{l}122 \mathrm{~mm} \text { from } \\
\text { base }\end{array}$ & & & & & & H-STM-3.7 & 8.58 & 0.01 & -6.41 & 0.01 & 39 \\
\hline STM-BH-10.0 & -7.03 & 0.01 & -5.84 & 0.02 & 0 & HH-STM-3.8 & -8.06 & 0.02 & -6.90 & 0.03 & 50 \\
\hline STM-BH-10.1 & -7.64 & 0.01 & -6.04 & 0.02 & 4 & & & & & & \\
\hline STM-BH-10.2 & -7.43 & 0.01 & -5.97 & 0.01 & 7 & \begin{tabular}{|l|}
$109 \mathrm{~mm}$ from \\
base
\end{tabular} & & & & & \\
\hline STM-BH-10.3 & -7.44 & 0.01 & -6.19 & 0.01 & 10 & HH-STM-7.1 & -7.46 & 0.01 & -7.62 & 0.01 & 8 \\
\hline STM-BH-10.4 & -7.08 & 0.01 & -5.96 & 0.01 & 12 & HH-STM-7.2 & -6.82 & 0.01 & -7.19 & 0.01 & 14 \\
\hline STM-BH-10.5 & -6.73 & 0.01 & -5.86 & 0.01 & 15 & HH-STM-7.3 & -6.80 & 0.03 & -6.88 & 0.03 & 18 \\
\hline STM-BH-10.6 & -6.24 & 0.01 & -5.66 & 0.01 & 18 & $\begin{array}{l}149 \mathrm{~mm} \text { from } \\
\text { base }\end{array}$ & & & & & \\
\hline STM-BH-10.7 & -5.74 & 0.01 & -5.34 & 0.02 & 20 & HH-STM-14.1 & -8.82 & 0.02 & -6.89 & 0.01 & 3 \\
\hline STM-BH-10.8 & -5.09 & 0.01 & -5.24 & 0.02 & 23 & HH-STM-14.2 & -8.89 & 0.00 & -7.63 & 0.01 & 7 \\
\hline & & & & & & HH-STM-14.3 & -8.34 & 0.01 & -7.26 & 0.02 & 14 \\
\hline & & & & & & HH-STM-14.4 & -8.26 & 0.01 & -7.26 & 0.02 & 24 \\
\hline & & & & & & HH-STM-14.5 & -7.49 & 0.02 & -7.47 & 0.02 & 27 \\
\hline
\end{tabular}

Appendix vii - 2.12: Baumann's- and Herrmann's-Cave stalagmites, single layer $\delta^{18} \mathrm{O}$ and $\delta^{13} \mathrm{C}(\mathrm{Hendy}$ Tests). 


\section{Lebenslauf}

Ich, Peter Nordhoff, wurde am 13. August 1971 in Wolfenbüttel (Deutschland) geboren. Von 1976 bis 1980 besuchte ich die Grundschule in Langenhagen/Hannover und anschließend das Albert-Schweitzer Gymnasium in Nienburg/Weser.

Dort erlangte ich 1991 die Allgemeine Hochschulreife und begann im gleichen Jahr das Studium der Geologie/Paläontologie an der Universität Göttingen. Im Wintersemester 1994/95 legte ich meine Vordiplomsprüfung ab. Berufspraktika absolvierte ich 1991 und 1992 bei der BEB Erdgas und Erdöl GmbH (Hannover, Deutschland) und im Anschluß an das Vordiplom bis zum Ende des Jahres 1995 in Vermont und Colorado (U.S.A.) bei dem U.S. National Park Service. Mein Studium schloß ich im Sommersemester $1999 \mathrm{ab}$. Die Diplomarbeit "Geologische und geochemische Untersuchungen zur Sedimentationsgeschichte und zur Frage der Nährstoffrücklösung im Zeller See (Österreich, Blatt 123)" fertigte ich bei Prof. Dr. J. Schneider an. Die Diplomkartierung "Geologische Aufnahmen im Deferegger Gebirge (Ostalpen), Bereich Winkeltal auf Blatt 178 Hopfgarten" wurde von mir bei Prof. Dr. S. Siegesmund in Kooperation mit der Geologischen Bundesanstalt Wien (Österreich) erstellt. Von 1999-2002 arbeitete ich als Projektgeologe in umwelt-, hydro- und ingenieurgeologisch ausgerichteten Planungsbüros in Holzminden und Hannover. Als selbstständiger Geologe kam es in dem mit S. Speiser zusammen initiierten Forschungsprojekt zur Schadensprojektierung des Marktores von Milet (Pergamon Museum, Berlin) durch die Kooperation mit der AG Natursteine (GZG) wieder zu einer Annäherung meines Betätigungsfeldes an das Geowissenschaftliche Zentrum in Göttingen. Seit April 2002 bin ich im Rahmen des von der Deutschen Forschungsgemeinschaft geförderten Projektes "Paläoklima im Pleistozän Zentraleuropas" als wissenschaftlicher Mitarbeiter mit dem Ziel der Promotion beschäftigt. Das von mir bearbeitete Projekt befaßt sich mit der Interpretation und Nutzung von Speläothemen als potentielle paläoklimatische Archive. 